\title{
Mitigation potential from forestrelated activities and incentives for enhanced action in
} developing countries

Miles, Lera ; Sonwa, Denis Jean ; Bakkegaard, Riyong Kim; Bodin, Blaise ; Mant, Rebecca ; Runsten, Lisen ; Sanz Sanchez, Maria ; Todd, Kimberly ; Tubiello, Francesco N. ; Wijaya, Arief

Published in:

The Emissions Gap Report 2015

Publication date:

2015

Document Version

Publisher's PDF, also known as Version of record

Link back to DTU Orbit

Citation (APA):

Miles, L., Sonwa, D. J., Bakkegaard, R. K., Bodin, B., Mant, R., Runsten, L., Sanz Sanchez, M., Todd, K., Tubiello, F. N., \& Wijaya, A. (2015). Mitigation potential from forestrelated activities and incentives for enhanced action in developing countries. In A. Olhoff, J. Christensen, P. Burgon, R. Kim Bakkegaard, C. Larsen, \& M. Schletz (Eds.), The Emissions Gap Report 2015: A UNEP Synthesis Report United Nations Environment Programme.

\section{General rights}

Copyright and moral rights for the publications made accessible in the public portal are retained by the authors and/or other copyright owners and it is a condition of accessing publications that users recognise and abide by the legal requirements associated with these rights.

- Users may download and print one copy of any publication from the public portal for the purpose of private study or research.

- You may not further distribute the material or use it for any profit-making activity or commercial gain

- You may freely distribute the URL identifying the publication in the public portal 


\section{$(4)$ UNEP}

\section{The Emissions Gap Report 2015}

A UNEP Synthesis Report

\section{ADVANCE COPY}

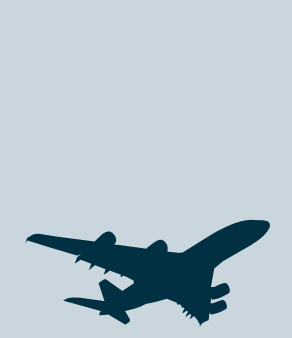

$t^{+1}$ 
Published by the United Nations Environment Programme (UNEP), November 2015

Copyright (C) UNEP 2015

ISBN: 978-92-807-3491-1

Job Number: DEW/1896/NA

This publication may be reproduced in whole or in part and in any form for educational or non-profit services without special permission from the copyright holder, provided acknowledgement of the source is made. UNEP would appreciate receiving a copy of any publication that uses this publication as a source.

No use of this publication may be made for resale or any other commercial purpose whatsoever without prior permission in writing from the United Nations Environment Programme. Applications for such permission, with a statement of the purpose and extent of the reproduction, should be addressed to the Director, DCPI, UNEP, P. O. Box 30552, Nairobi 00100, Kenya.

\section{Disclaimers}

Mention of a commercial company or product in this document does not imply endorsement by UNEP or the authors. The use of information from this document for publicity or advertising is not permitted. Trademark names and symbols are used in an editorial fashion with no intention on infringement of trademark or copyright laws.

The views expressed in this publication are those of the authors and do not necessarily reflect the views of the United Nations Environment Programme. We regret any errors or omissions that may have been unwittingly made.

(C) Images and illustrations as specified.

Citation This document may be cited as: UNEP (2015). The Emissions Gap Report 2015. United Nations Environment Programme (UNEP), Nairobi

A digital copy of this report along with supporting appendices are available at http://www.unep.org/emissionsgapreport2015/

This project is part of the International Climate Initiative. The Federal Ministry for the Environment, Nature Conservation and Nuclear Safely supports this initiative on the basis of a decision adopted by the German Bundestag.
Supported by:

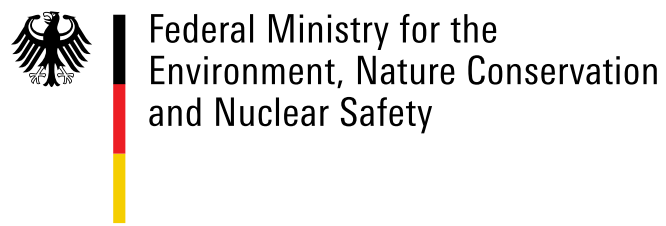

Based on a decision of the Parliament of the Federal Republic of Germany 


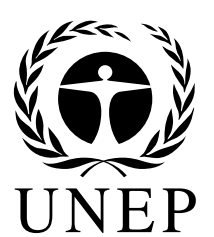

The Emissions Gap Report 2015

A UNEP Synthesis Report

November 2015 


\section{Acknowledgements}

The United Nations Environment Programme (UNEP) would like to thank the members of the steering committee, the lead and contributing authors, reviewers and the secretariat for their contribution to the preparation of this assessment report.

Authors and reviewers have contributed to the report in their individual capacities. Their affiliations are only mentioned for identification purposes.

\section{Project steering committee}

Mónica Araya (Nivela), Pierre Brender (Ministry of Ecology, Sustainable Development and Energy, France), John Christensen (UNEP DTU Partnership), Navroz K. Dubash (Centre for Policy Research, India), Thelma Krug (National Institute for Space Research, Brazil), Simon Maxwell (Climate and Development Knowledge Network), Jacqueline McGlade (United Nations Environment Programme), Bert Metz (European Climate Foundation), Yacob Mulugetta (University College London), Klaus Müschen (Federal Environment Agency of Germany), Katia Simeonova (United Nations Framework Convention on Climate Change), Merlyn van Voore (United Nations Environment Programme)

\section{Chapter 1}

Lead authors: John Christensen (UNEP DTU Partnership), Paul Burgon (independent consultant)

\section{Chapter 2}

\section{Section 2.2}

Lead author: Joeri Rogelj (International Institute for Applied Systems Analysis)

Contributing authors: Kejun Jiang (Energy Research Institute), Jason Lowe (Met Office), Greet Maenhout (Joint Research Centre, European Commission), Steven Smith (Pacific Northwest National Laboratory)

\section{Section 2.3}

Lead authors: Taryn Fransen (World Resources Institute), Michel den Elzen (PBL Netherlands Environmental Assessment Agency), Hanna Fekete (NewClimate Institute), Niklas Höhne (NewClimate Institute)

Contributing authors: Mengpin Ge (World Resources Institute), Heleen van Soest (PBL Netherlands Environmental Assessment Agency)

\section{Chapter 3}

Lead authors: Michel den Elzen (PBL Netherlands Environmental Assessment Agency), Taryn Fransen (World Resources Institute), Niklas Höhne (NewClimate Institute), Harald Winkler (University of Cape Town), Roberto Schaeffer (Universidade Federal do Rio de Janeiro), Fu Sha (National Center for Climate Strategy and International Cooperation), Amit Garg (Indian Institute of Management Ahmedabad)

Contributing authors: Guy Cunliffe (University of Cape Town), Hanna Fekete (NewClimate Institute), Mengpin Ge (World Resources Institute), Giacomo Grassi (Joint Research Centre, European Commission), Mark Roelfsema (PBL Netherlands Environmental Assessment Agency), Joeri Rogelj (International Institute for Applied Systems Analysis), Sebastian Sterl (NewClimate Institute), Eveline Vasquez (Universidade Federal do Rio de Janeiro)

\section{Chapter 4}

Lead author: Anne Olhoff (UNEP DTU Partnership)

Contributing author: John Christensen (UNEP DTU Partnership)

\section{Chapter 5}

Lead authors: Walter Vergara (UNEP DTU Partnership / World Resources Institute), Michiel Schaeffer (Climate Analytics), Kornelis Blok (Ecofys)

Contributing authors: Andrzej Ancygier (Climate Analytics), Skylar Bee (UNEP DTU Partnership), Philip Drost (United Nations Environment Programme), Lara Esser (Ecofys), Mark Roelfsema (PBL Netherlands Environmental Assessment Agency)

\section{Chapter 6}

Lead authors: Lera Miles (UNEP World Conservation Monitoring Centre), Denis Jean Sonwa (Center for International Forestry Research)

Contributing authors: Riyong Kim Bakkegaard (UNEP DTU Partnership), Blaise Bodin (UNEP World Conservation Monitoring Centre), Rebecca Mant (UNEP World Conservation Monitoring Centre), Lisen Runsten (UNEP World Conservation Monitoring Centre), Maria Sanz Sanchez (Food and Agriculture Organization of the United Nations), Kimberly Todd (United Nations Development Programme), 
Francesco Tubiello (Food and Agriculture Organization of the United Nations), Arief Wijaya (Centre for International Forestry Research / Thuenen Institute Hamburg)

\section{Reviewers}

Maria Belenky (Climate Advisers), Duncan Brack (Chatham House), Pieter Boot (PBL Netherlands Environmental Assessment Agency), Michael Bucki (European Commission), Katherine Calvin (Pacific Northwest National Laboratory), Tim Christophersen (United Nations Environment Programme), Leon Clarke (Pacific Northwest National Laboratory), Michel Colombier (Sustainable Development and International Relations - IDDRI), Laura Cozzi (International Energy Agency), Joe Cranston Turner (London School of Economics and Political Science), Rob Dellink (Organisation for Economic Cooperation and Development), Harald Diaz-Bone (independent consultant), Steffen Dockweiler (Danish Energy Agency), Thomas Enters (United Nations Environment Programme), Thomas Hale (University of Oxford), Richard Houghton (Woods Hole Research Center), Inkar Kadyrzhanova (United Nations Framework Convention on Climate Change), Johan Kieft (United Nations Office for REDD+ Coordination in Indonesia - UNORCID), Ariane Labat (European Commission), Axel Michaelowa (Perspectives), Perry Miles (European Commission), Peter Minang (World Agroforestry Centre - ICRAF), Helen Mountford (New Climate Economy), Dirk Nemitz (United Nations Framework Convention on Climate Change), Ian Ponce (United Nations Framework Convention on Climate Change), Mark Roelfsema (PBL Netherlands Environmental Assessment Agency), James Rydge (New Climate Economy), Katja Schumacher (Institute for Applied Ecology, Germany), Rajendra Shende (Technology, Education, Research and Rehabilitation for the Environment - TERRE Policy Centre), Anne Siemons (Institute for Applied Ecology, Germany), VU University Amsterdam), Erin Sills (North Carolina State University), Thomas Spencer (Sustainable Development and International Relations - IDDRI), Jaime Webbe (United Nations Environment Programme), Oscar Widerberg (Institute for Environmental Studies (IVM)), Michael Wolosin (Climate Advisers), Zhao Xiusheng (Tshingua University)

\section{Editorial team}

Anne Olhoff (UNEP DTU Partnership), John Christensen (UNEP DTU Partnership), Paul Burgon (independent consultant), Riyong Kim Bakkegaard (UNEP DTU Partnership)

Editorial Support: Cecilie Larsen (UNEP DTU Partnership), Marco Schletz (UNEP DTU Partnership)

\section{Project coordination}

Anne Olhoff (UNEP DTU Partnership), John Christensen (UNEP DTU Partnership), Cecilie Larsen (UNEP DTU Partnership), Paul Burgon (independent consultant), Riyong Kim Bakkegaard (UNEP DTU Partnership), Volodymyr Demkine (United Nations Environment Programme)

\section{Media support}

Shereen Zorba (United Nations Environment Programme), Fanina Kodre (United Nations Environment Programme), Michael Logan (United Nations Environment Programme), Kelvin Memia (United Nations Environment Programme), Tamiza Khalid (United Nations Environment Programme), Waiganjo Njoroge (United Nations Environment Programme), Mette Annelie Rasmussen (UNEP DTU Partnership)

\section{Assessment webpage on UNEP Live}

Simone Targettiferri (United Nations Environment Programme)

\section{INDC assessment and gap calculations}

Michel den Elzen (PBL Netherlands Environmental Assessment Agency), Hanna Fekete (NewClimate Institute), Niklas Höhne (NewClimate Institute)

\section{External modelling data contributors}

Alterra / Wageningen University and Research (Chapter 6) Centre for Policy Research, India (Chapter 3) (Navroz K. Dubash) Climate Action Tracker (Chapter 3)

Climate Advisers (Chapter 3)

Climate Interactive (Chapter 3) (Lori Siegel)

Danish Energy Agency (Chapter 3) (Steffen Dockweiler)

Energy Research Institute, China (Chapter 3) (Chenmin He and Kejun Jiang)

Fondazione Eni Enrico Mattei (Chapter 3)

International Energy Agency (Chapter 3)

International Institute for Applied Systems Analysis (Chapter 3) London School of Economics and Political Science (Chapter 3) (Joe Cranston Turner, Rodney Boyd and Bob Ward)

National Center for Climate Strategy and International Cooperation (Chapter 3)

National Institute for Environmental Studies, Japan (Chapter 3) (Tatsuya Hanaoka)

PBL Netherlands Environmental Assessment Agency

(Chapter 3)

Potsdam Institute for Climate Impact Research (Chapter 3)

The Energy Resources Institute (Chapter 3) (Manish Shrivastava) United States Environmental Protection Agency (Chapter 3) University of Melbourne (Chapter 3) (Malte Meinshausen) World Resources Institute (Chapter 3)

\section{Thanks also to}

Jørgen Fenhann (UNEP DTU Partnership), Christina Power (United Nations Environment Programme), Gemma Shepherd (United Nations Environment Programme), Lene Thorsted (UNEP DTU Partnership), Fabian Twerdy (Federal Environment Agency of Germany), United Nations Reducing Emissions from Deforestation and forest Degradation Programme (UN-REDD)

\section{Design, layout and printing}

Audrey Ringler (United Nations Environment Programme), Jennifer Odallo, UNON Publishing Services (ISO 14001:2004 certified), Caren Weeks (independent consultant) 


\section{Contents}

Acknowledgements

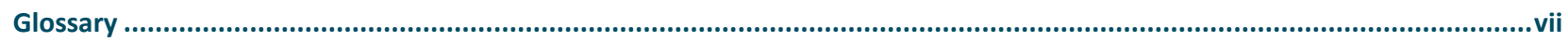

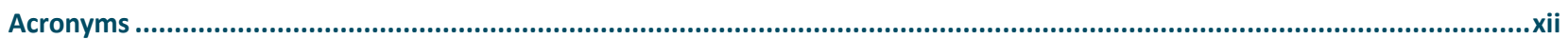

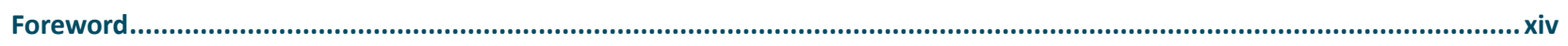

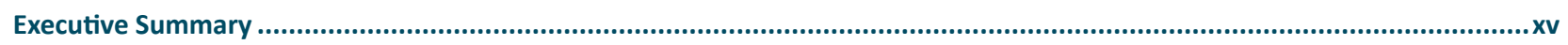

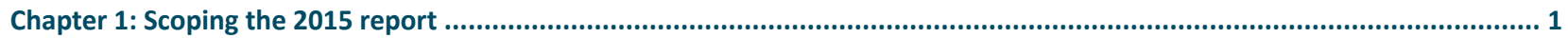

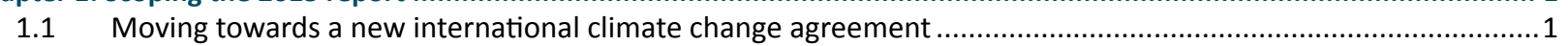

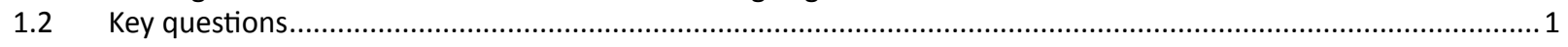

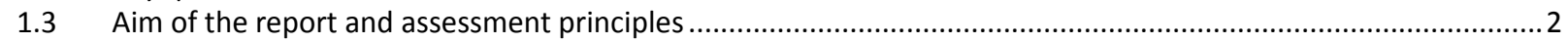

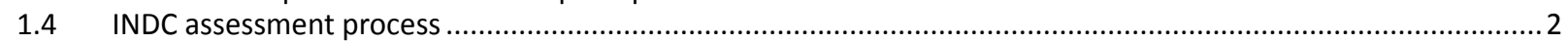

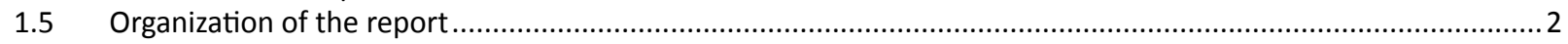

PART I THE EMISSIONS GAP

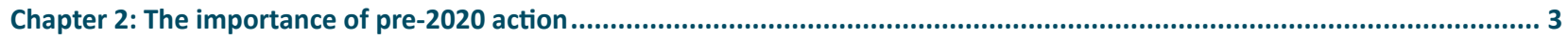

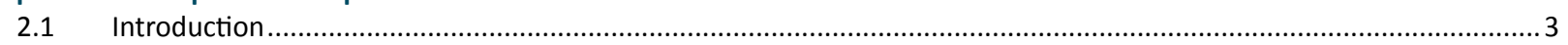

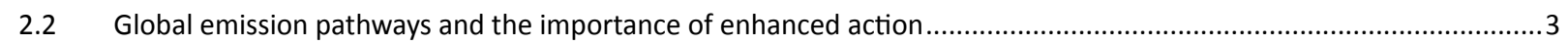

2.3 Progress towards the 2020 pledges: a closer look at major economies ..............................................................

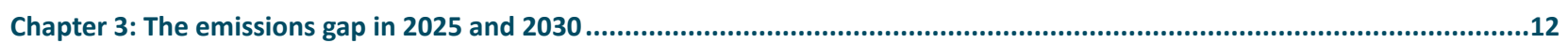

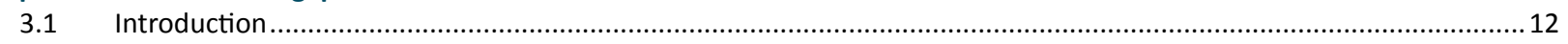

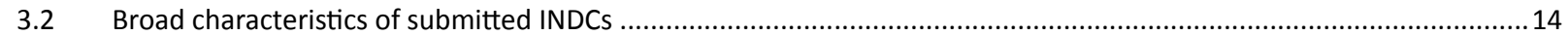

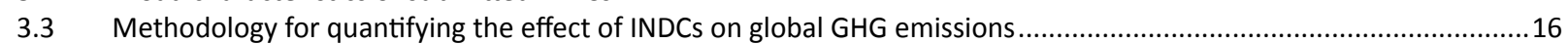

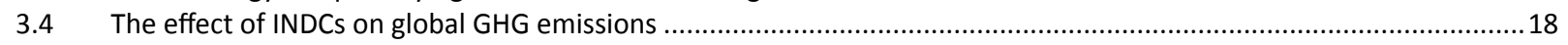

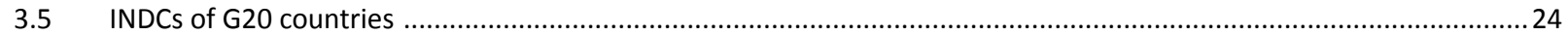

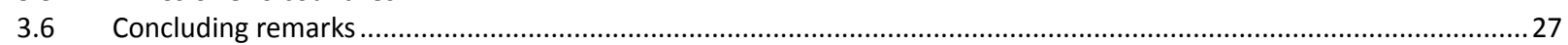

PART II BRIDGING THE GAP

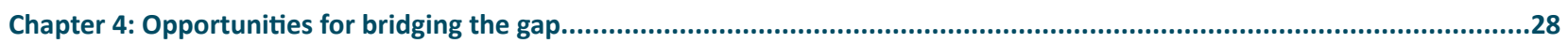

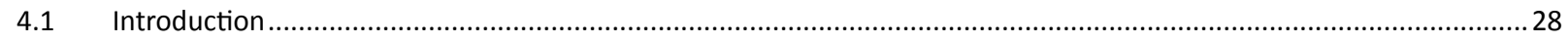

4.2 Ensuring coherence, synergy and complementarity between climate change,

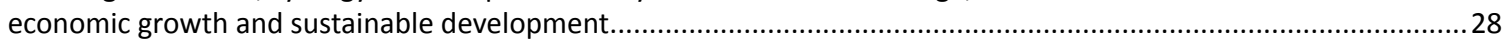

4.3 A robust, effective and transparent follow-up and review framework under the Paris

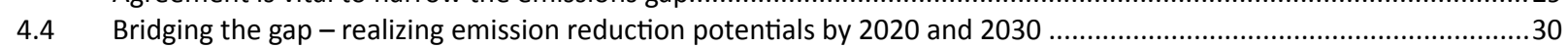

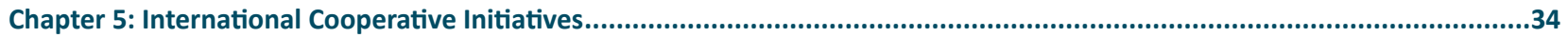

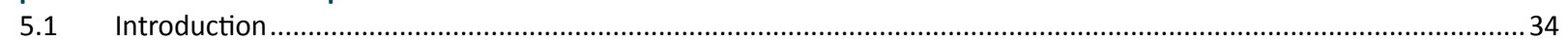

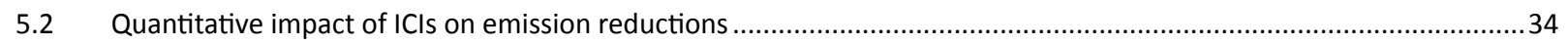

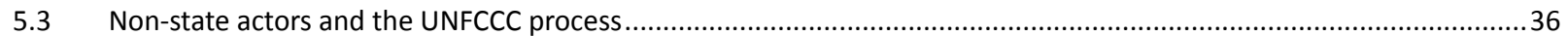

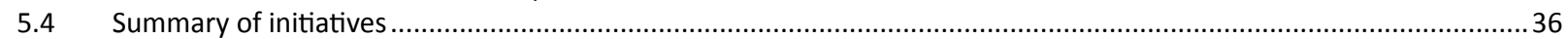

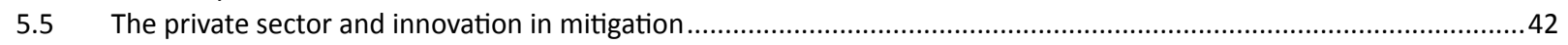

Chapter 6: Mitigation potential from forest-related activities and incentives for enhanced action in developing countries ........44

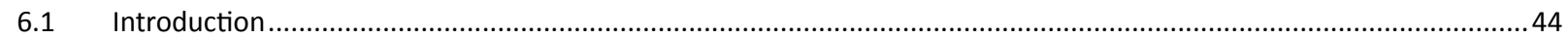

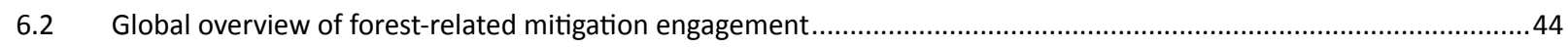

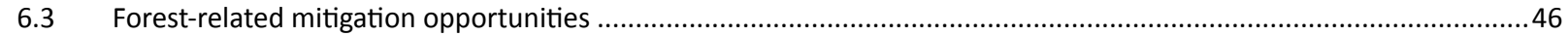

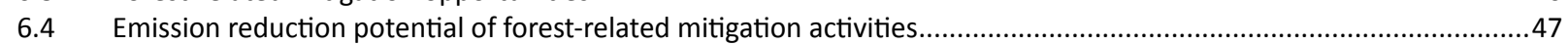

6.5 REDD+ as a key instrument to realize forest-related emission reductions in developing countries ...............................49

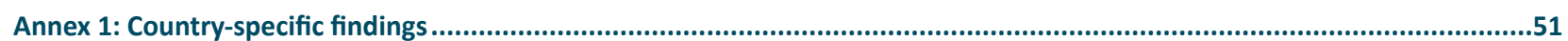

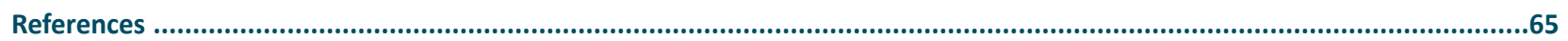




\section{Glossary}

This glossary is compiled according to the Lead Authors of the report drawing on glossaries and other resources available on the websites of the following organizations, networks and projects: Center for International Forestry Research, Food and Agriculture Organization of the United Nations, Intergovernmental Panel on Climate Change, Non-State Actor Zone for Climate Action, United Nations Environment Programme, United Nations Framework Convention on Climate Change and World Resources Institute.

Adaptation: The process of adjustment to actual or expected climate and its effects. In human systems, adaptation seeks to moderate or avoid harm or exploit beneficial opportunities. In some natural systems, human intervention may facilitate adjustment to expected climate and its effects.

Additionality: A criterion sometimes applied to projects aimed at reducing GHG emissions. It stipulates that the emission reductions accomplished by the project must not have happened anyway had the project not taken place.

Afforestation: Planting of new forests on lands that historically have not contained forests.

Agriculture, forestry and other land use: AFOLU plays a central role for food security and sustainable development. The main mitigation options within AFOLU involve one or more of three strategies: prevention of emissions to the atmosphere by conserving existing carbon pools in soils or vegetation or by reducing emissions of methane and nitrous oxide; sequestration-increasing the size of existing carbon pools and thereby extracting carbon dioxide $\left(\mathrm{CO}_{2}\right)$ from the atmosphere; and substitution-substituting biological products for fossil fuels or energy-intensive products, thereby reducing $\mathrm{CO}_{2}$ emissions. Demand-side measures (for example, reducing losses and wastes of food, changes in human diet, or changes in wood consumption) may also play a role. FOLU (Forestry and Other Land Use)-also referred to as LULUCF (Land Use, Land-Use Change, and Forestry) - is the subset of AFOLU emissions and removals of GHGs resulting from direct human-induced land use, land-use change, and forestry activities excluding agricultural emissions.
Annex I Parties: The industrialized countries listed in Annex I to the Convention, which committed to returning their GHG emissions to 1990 levels by the year 2000 as per Article 4.2(a) and (b). They have also accepted emission targets for the period 2008-12 as per Article 3 and Annex B of the Kyoto Protocol. They include the 24 original OECD members, the European Union, and 14 countries with economies in transition (Croatia, Liechtenstein, Monaco and Slovenia joined Annex I at COP 3, and the Czech Republic and Slovakia replaced Czechoslovakia). See also Non-Annex I Parties.

Annex II Parties: The countries listed in Annex II to the Convention which have a special obligation to provide financial resources and facilitate technology transfer to developing countries. Annex II Parties include the $\mathbf{2 4}$ original OECD members plus the European Union.

Baseline/reference: The state against which change is measured. In the context of transformation pathways, the term 'baseline scenarios' refers to scenarios that are based on the assumption that no mitigation policies or measures will be implemented beyond those that are already in force and/or are legislated or planned to be adopted. Baseline scenarios are not intended to be predictions of the future, but rather counterfactual constructions that can serve to highlight the level of emissions that would occur without further policy effort. Typically, baseline scenarios are then compared to mitigation scenarios that are constructed to meet different goals for GHG emissions, atmospheric concentrations or temperature change. The term 'baseline scenario' is used interchangeably with 'reference scenario' and 'no policy scenario'. In much of the literature the term is also synonymous with the term 'business-as-usual (BAU) scenario', although the term 'BAU' has fallen out of favour because the idea of 'business-as-usual' in century-long socioeconomic projections is hard to fathom.

Biomass: The total mass of living organisms in a given area or volume, including products, by-products, and waste of biological origin (plants or animal matter) and excluding material embedded in geological formations and transformed to fossil fuels or peat. 
Biomass plus carbon capture and storage (BioCCS or BECCS): Use of energy produced from biomass where the combustion gases are then captured and stored underground or used, for example, in industrial processes. It excludes gases generated through, for example, a fermentation process (as opposed to combustion).

Black carbon: The substance formed through the incomplete combustion of fossil fuels, biofuels, and biomass, which is emitted in both anthropogenic and naturally occurring soot. It consists of pure carbon in several linked forms. Black carbon warms the Earth by absorbing heat in the atmosphere and by reducing albedo - the ability to reflect sunlight - when deposited on snow and ice.

Bottom-up model: In the context of this assessment, a model that represents a system by looking at its detailed underlying parts. Compared to so-called top-down models, which focus on economic interlinkages, bottom-up models of energy use and emissions can provide greater resolution with regards to sectors or mitigation technologies.

Business-as-usual: A scenario that describes future GHG emission levels in the absence of additional mitigation efforts and policies (with respect to an agreed set). In the 2014 EGR (page 5, para 2), BAU scenarios were based on an extrapolation of current economic, social and technological trends. They only took into account climate policies implemented up to around 2005-10 (that is, more recent country pledges and policies were not considered) and therefore served as a reference point for what would happen to emissions if planned climate mitigation policies were not implemented. See Baseline/reference.

Bunker fuels: A term used to refer to fuels consumed for international marine and air transport.

Cancun pledge: During 2010, many countries submitted their existing plans for controlling GHG emissions to the Climate Change Secretariat and these proposals were formally acknowledged under the UNFCCC. Developed countries presented their plans in the shape of economy-wide targets to reduce emissions, mainly up to 2020 , while developing countries proposed ways to limit their growth of emissions in the shape of plans of action.

Carbon credits: An entitlement allocated by a government to a legal entity (company or other type of emitter) to emit a specified amount of a substance. These entitlements, which may be transferrable and tradable, can be used to reduce emissions of GHGs (by giving them a monetary value) or can be used for accounting of emissions.

Carbon dioxide emission budget: For a given temperature rise limit, for example a $1.5^{\circ} \mathrm{C}$ or $2^{\circ} \mathrm{C}$ long-term limit, the corresponding carbon budget reflects the total amount of carbon emissions that can be emitted to stay within that limit. Stated differently, a carbon budget is the area under a GHG emission trajectory that satisfies assumptions about limits on cumulative emissions estimated to avoid a certain level of global mean surface temperature rise.
Carbon dioxide equivalent: $A$ way to place emissions of various radiative forcing agents on a common footing by accounting for their effect on climate. It describes, for a given mixture and amount of GHGs, the amount of carbon dioxide that would have the same global warming ability, when measured over a specified time period. For the purpose of this report, GHG emissions (unless otherwise specified) are the sum of the basket of GHG listed in Annex A to the Kyoto Protocol, expressed as carbon dioxide equivalents assuming a 100 -year global warming potential.

Carbon intensity: The amount of emissions of carbon dioxide released per unit of another variable such as gross domestic product (GDP), output energy use or transport.

Carbon market: A popular (but misleading) term for a trading system through which countries may buy or sell units of GHG emissions in an effort to meet their national limits on emissions, either under the Kyoto Protocol or under other agreements, such as that among member states of the European Union. The term comes from the fact that $\mathrm{CO}_{2}$ is the predominant GHG, and other gases are measured in units called ' $\mathrm{CO}_{2}$ equivalents'.

\section{Carbon offset: See Offset.}

Carbon price: The price for avoided or released $\mathrm{CO}_{2}$ or $\mathrm{CO}_{2}$-equivalent emissions. This may refer to the rate of a carbon tax or the price of emission permits. In many models that are used to assess the economic costs of mitigation, carbon prices are used as a proxy to represent the level of effort in mitigation policies.

Carbon sequestration: The process of removing carbon from the atmosphere and depositing it in a reservoir.

Carbon sink: A pool (reservoir) that removes carbon from the active part of the carbon cycle.

Carbon stock: The quantity of carbon contained in a carbon pool.

Carbon tax: A levy on the carbon content of fossil fuels. Because virtually all of the carbon in fossil fuels is ultimately emitted as carbon dioxide, a carbon tax is equivalent to an emission tax on $\mathrm{CO}_{2}$ emissions.

Co-benefits: The positive effects that a policy or measure aimed at one objective might have on other objectives, without yet evaluating the net effect on overall social welfare. Co-benefits are often subject to uncertainty and depend on, among others, local circumstances and implementation practices. Co-benefits are often referred to as ancillary benefits.

Conditional INDCs: INDCS proposed by some countries that are contingent on a range of possible conditions, such as the ability of national legislatures to enact the necessary laws, ambitious action from other countries, realization of finance and technical support, or other factors. 
Conference of the Parties (COP): The supreme body of the Convention. It currently meets once a year to review the Convention's progress.

Current policy trajectory: This trajectory is based on estimates of 2020 emissions considering projected economic trends and current policy approaches including policies at least through 2012. Estimates may be based on either official data or independent analysis.

Decarbonization: The process by which countries or other entities aim to achieve a low-carbon economy, or by which individuals aim to reduce their carbon consumption.

Deforestation: The direct human-induced conversion of forested land to non-forested land (Marrakesh Accords). The conversion of forest to another land use or the long-term reduction of the tree canopy cover below the minimum 10 per cent threshold.

Degradation (forest): Changes within the forest that negatively affect the structure or function of the forest stand or site, and thereby lower its capacity to supply products and services.

Delayed-action scenarios: See Later-action scenarios.

Double counting: In the context of this assessment, double counting refers to a situation in which the same emission reductions are counted towards meeting two countries' pledges.

Emissions gap: The difference between the GHG emission levels consistent with having a likely chance ( $>66$ per cent) of limiting the mean global temperature rise to below $2^{\circ} \mathrm{C}$ or $1.5^{\circ} \mathrm{C}$ in 2100 above pre-industrial levels and the $\mathrm{GHG}$ emission levels consistent with the global effect of the INDCs, assuming full implementation from 2020.

Emission pathway: The trajectory of annual GHG emissions over time.

Forest: Land spanning more than 0.5 ha with trees higher than $5 \mathrm{~m}$ and a canopy cover of more than 10 per cent, or trees able to reach these thresholds in situ. It does not include land that is predominantly under agricultural or urban land use.

Forest landscape restoration: A process which aims to regain ecological integrity and enhance human wellbeing in deforested or degraded forest landscapes to meet present and future needs and accommodate multiple uses over time.

Global warming potential: An index representing the combined effect of the differing times GHGs remain in the atmosphere and their relative effectiveness in absorbing outgoing infrared radiation.

Greenhouse gases (GHGs): The atmospheric gases responsible for causing global warming and climatic change. The major $\mathrm{GHGs}$ are carbon dioxide $\left(\mathrm{CO}_{2}\right)$, methane $\left(\mathrm{CH}_{4}\right)$ and nitrous oxide $\left(\mathrm{N}_{2} \mathrm{O}\right)$. Less prevalent, but very powerful, GHGs are hydrofluorocarbons (HFCs), perfluorocarbons (PFCs) and sulphur hexafluoride $\left(\mathrm{SF}_{6}\right)$.
Grid parity: This occurs when an alternative energy source can generate power at a levelized cost of electricity (LCOE) that is less than or equal to the price of purchasing power from the electricity grid.

Gross domestic product (GDP): The sum of gross value added, at purchasers' prices, by all resident and non-resident producers in the economy, plus any taxes and minus any subsidies not included in the value of products in a country or geographic region for a given period, normally one year. GDP is calculated without deducting for depreciation of fabricated assets or depletion and degradation of natural resources.

'Hot air': Refers to the concern that some governments will be able to meet their targets for GHG emissions under any formal agreement with minimal effort and could then flood the market with emission credits, reducing the incentive for other countries to cut their own domestic emissions.

Integrated assessment models: Models that seek to combine knowledge from multiple disciplines in the form of equations and/or algorithms in order to explore complex environmental problems. As such, they describe the full chain of climate change, from production of GHGs to atmospheric responses. This necessarily includes relevant links and feedbacks between socio-economic and biophysical processes.

Intended nationally determined contribution (INDC): Submissions by Parties which identify actions each national government intends to take under the future UNFCCC climate agreement, due to be negotiated in Paris in December 2015. INDCs are, in effect, the basis of post-2020 global emission reduction commitments that will be included in the future climate agreement.

International cooperative initiatives (ICls): Initiatives outside the United Nations Framework Convention on Climate Change aimed at reducing emissions of climate forcers by, for example, promoting actions that are less GHG intensive, compared to prevailing alternatives. Cooperative initiatives also involve national and sub-national partners (they are often referred to as, simply, 'cooperative initiatives').

Kyoto Protocol: An international agreement, standing on its own, and requiring separate ratification by governments, but linked to the UNFCCC. The Kyoto Protocol, among other things, sets binding targets for the reduction of GHG emissions by industrialized countries.

Land use, land-use change and forestry (LULUCF): A GHG inventory sector that covers emissions and removals of GHGs resulting from direct human-induced land use, land-use change and forestry activities.

Later-action scenarios: Climate change mitigation scenarios in which emission levels in the near term, typically up to 2020 or 2030, are higher than those in the corresponding least-cost scenarios.

Leakage: That portion of cuts in GHG emissions by developed countries - countries trying to meet mandatory limits under 
the Kyoto Protocol - that may reappear in other countries not bound by such limits. For example, multinational corporations may shift factories from developed to developing countries to escape restrictions on emissions.

Least-cost scenarios: Climate change mitigation scenarios assuming that emission reductions start immediately after the model base year, and are distributed optimally over time, sectors and regions, such that aggregate costs of reaching the climate target are minimized.

Likely chance: A likelihood greater than 66 per cent chance. Used in this assessment to convey the probabilities of meeting temperature limits.

Lock-in: Lock-in occurs when a market is stuck with a standard even though participants would be better off with an alternative.

Medium chance: A likelihood of 50-66 per cent chance. Used in this report to convey the probabilities of meeting temperature limits.

Mitigation: In the context of climate change, a human intervention to reduce the sources, or enhance the sinks of GHGs. Examples include using fossil fuels more efficiently for industrial processes or electricity generation, switching to solar energy or wind power, improving the insulation of buildings and expanding forests and other 'sinks' to remove greater amounts of $\mathrm{CO}_{2}$ from the atmosphere.

Monitoring, reporting and verification: A process/concept that potentially supports greater transparency in the climate change regime.

Montreal Protocol: The Montreal Protocol on Substances that Deplete the Ozone Layer is an international treaty that was designed to reduce the production and consumption of ozone-depleting substances in order to reduce their abundance in the atmosphere, and thereby protect the Earth's ozone layer.

Mosaic restoration: This integrates trees into mixed-use landscapes, such as agricultural lands and settlements, where trees can support people through improved water quality, increased soil fertility, and other ecosystem services. This type of restoration is more likely in deforested or degraded forest landscapes with moderate population density (10-100 people/ $\left.\mathrm{km}^{2}\right)$.

Net negative emissions: A situation of net negative emissions is achieved when, as a result of human activities, more GHGs are sequestered or stored than are released into the atmosphere.

\section{No-policy scenario: See Baseline/reference.}

Non-Annex I Parties: The countries that have ratified or acceded to the UNFCCC that are not included in Annex I of the Convention.

Non-state actor: In the context of climate action, 'non-state actor' includes companies, cities, subnational regions and investors. More broadly, non-state actors have been defined as entities that participate or act in international relations. They are organizations with sufficient power to influence and cause a change even though they do not belong to any state institution.

Offset (in climate policy): $\mathrm{A}$ unit of $\mathrm{CO}_{2}$-equivalent emissions that is reduced, avoided, or sequestered to compensate for emissions occurring elsewhere.

Party: A state (or regional economic integration organization such as the EU) that agrees to be bound by a treaty and for which the treaty has entered into force.

Pledge case: This case identifies the maximum level of GHG emissions that each country or Party could emit in 2020 and still meet its pledge - without considering the use of offsets.

Readiness: REDD+ country actions - including capacity building, policy design, consultation and consensus building, and testing and evaluation of a REDD+ national strategy - that are taken prior to the comprehensive implementation of REDD+.

REDD+: Reducing emissions from deforestation and forest degradation in developing countries; and the role of conservation, sustainable management of forests and enhancement of forest carbon stocks in developing countries.

Reference scenario: See Baseline/reference.

Reforestation: Planting of forests on lands that have previously contained forests but that have been converted to some other use.

Rehabilitation (forest): Restoration of the capacity of degraded forest land to deliver forest products and services. Forest rehabilitation re-establishes the original productivity of the forest and some, but not necessarily all, of the plant and animal species thought to be originally present at a site.

Restoration forest: Restoration of a degraded forest to its original state - that is, to re-establish the presumed structure, productivity and species diversity of the forest originally present at a site.

Results-based payments: Payments for fully measured, reported and verified emission reductions (or removals), also conditional upon the country having a national strategy/action plan for REDD+, a national forest monitoring system, national forest reference emission level and/or forest reference level, a safeguard information system and a summary of information on how safeguards have been addressed and respected.

Scenario: A description of how the future may unfold based on 'if-then' propositions. Scenarios typically include an initial socio-economic situation and a description of the key driving forces and future changes in emissions, temperature or other climate change-related variables.

Sink: Any process, activity or mechanism which removes a GHG, an aerosol or a precursor of a GHG from the 
atmosphere. Forests and other vegetation are considered sinks because they remove $\mathrm{CO}_{2}$ through photosynthesis.

Source: Any process, activity or mechanism that releases a GHG, an aerosol or a precursor of a GHG or aerosol into the atmosphere.

Sustainable development: Development that meets the needs of the present without compromising the ability of future generations to meet their own needs.

Technology transfer: A broad set of processes covering the flows of know-how, experience and equipment for mitigating and adapting to climate change among different stakeholders.

Temperature overshoot: An emission pathway that temporarily exceeds target temperature limits $\left(2^{\circ} \mathrm{C}\right.$ or $\left.1.5^{\circ} \mathrm{C}\right)$ before falling below the limits again by 2100 with a given percentage chance.

Tipping point: A level of change in system properties beyond which a system reorganizes, often abruptly, and does not return to the initial state even if the drivers of the change are abated. For the climate system, it refers to a critical threshold when global or regional climate changes from one stable state to another stable state. The tipping point event may be irreversible.

Top-down model: A model that applies macroeconomic theory, econometric and/or optimization techniques to aggregate economic variables. Using historical data on consumption, prices, incomes, and factor costs, topdown models assess demand and emissions for goods and services from main sectors, such as energy conversion, transportation, buildings, agriculture and industry.
Transient climate response: Measure of the temperature rise that occurs at the time of a doubling of carbon dioxide concentration in the atmosphere.

Transient climate response to cumulative carbon emissions: Measure of temperature rise per unit of cumulative carbon emissions.

Uncertainty: A cognitive state of incomplete knowledge that can result from a lack of information or from disagreement about what is known or even knowable. It may have many types of sources, from imprecision in the data to ambiguously defined concepts or terminology, or uncertain projections of human behaviour. Uncertainty can therefore be represented by quantitative measures (for example a probability density function) or by qualitative statements (for example reflecting the judgement of a team of experts).

Unconditional INDCs: INDCs proposed by countries without conditions attached.

Wide-scale restoration: Aims to restore closed forests to the landscape. This type of restoration is more likely in deforested or degraded landscapes with low population density $\left(<10\right.$ people $\left./ \mathrm{km}^{2}\right)$ that are also areas where closed forests formerly dominated the landscape.

2020 pledge: See Cancun pledge.

$20^{\text {th }}-\mathbf{8 0}^{\text {th }}$ percentile range: Results that fall within the $20-80$ per cent range of the frequency distribution of results in this assessment. 


\section{Acronyms}

\begin{tabular}{|c|c|c|c|}
\hline AFOLU & agriculture, forestry and other land use & ERU & emission reduction unit \\
\hline AR5 & fifth Assessment Report of the & EU-ETS & European Union Emissions Trading System \\
\hline BAU & $\begin{array}{l}\text { Intergovernmental Panel on Climate Change } \\
\text { business as usual }\end{array}$ & FAO & $\begin{array}{l}\text { Food and Agriculture Organization of the } \\
\text { United Nations }\end{array}$ \\
\hline BC & black carbon & FCPF & Forest Carbon Partnership Facility \\
\hline BECCS & $\begin{array}{l}\text { biomass plus carbon capture and storage (or } \\
\text { BioCCS) }\end{array}$ & $\begin{array}{l}\text { FF\&I } \\
\text { FIA }\end{array}$ & $\begin{array}{l}\text { fossil fuels and industry } \\
\text { Federation Internationale de l'Automobile }\end{array}$ \\
\hline BELC & Business Environmental Leadership Council & FLR & forest landscape restoration \\
\hline BRT & Bus Rapid Transit & FS-UNEP & Frankfurt School - UNEP Collaborating \\
\hline CAIT & Climate Analysis Indicators Tool & & Centre for Climate and Sustainable Energy \\
\hline CAT & Climate Action Tracker & & Finance \\
\hline CBD & Convention on Biological Diversity & GDP & gross domestic product \\
\hline CCR & carbonn Climate Registry & GEA & Global Energy Assessment \\
\hline CCS & carbon capture and storage & GFEI & Global Fuel Economy Initiative \\
\hline CDKN & $\begin{array}{l}\text { Climate and Development Knowledge } \\
\text { Network }\end{array}$ & $\begin{array}{l}\text { GHG } \\
\text { GLOBIOM }\end{array}$ & $\begin{array}{l}\text { greenhouse gas } \\
\text { global biosphere management model }\end{array}$ \\
\hline CDM & Clean Development Mechanism & GPC & Global Protocol for Community-scale GHG \\
\hline CDP & Carbon Disclosure Project (now 'CDP’) & & Emissions \\
\hline CER & certified emission reduction & Gt & gigatonne \\
\hline CFC & chlorofluorocarbon & GWP & global warming potential \\
\hline $\mathrm{CH}_{4}$ & methane & G4M & global forest model \\
\hline CISL & $\begin{array}{l}\text { Cambridge Institute for Sustainability } \\
\text { Leadership }\end{array}$ & $\begin{array}{l}\text { HFC } \\
\text { IAM }\end{array}$ & $\begin{array}{l}\text { hydrofluorocarbon } \\
\text { integrated assessment model }\end{array}$ \\
\hline $\mathrm{CO}_{2}$ & carbon dioxide & ICAO & International Civil Aviation Organization \\
\hline $\mathrm{CO}_{2} \mathrm{e}$ & carbon dioxide equivalent & $\mathbf{I C I}$ & international cooperative initiative \\
\hline CoM & Covenant of Mayors & ICLEI & International Council for Local \\
\hline COP & Conference of the Parties to the UNFCCC & & Environmental Initiatives \\
\hline CRF & common reporting format (of the UNFCCC) & ICRAF & World Agroforestry Centre (formerly \\
\hline C-ROADS & $\begin{array}{l}\text { Climate Rapid Overview and Decision } \\
\text { Support }\end{array}$ & & $\begin{array}{l}\text { International Centre for Research in } \\
\text { Agroforestry) }\end{array}$ \\
\hline CSI & Cement Sustainability Initiative & IDDRI & Institut du Developpement Durables et des \\
\hline CSP & concentrating solar power & & Relations Internationales \\
\hline DEA & Danish Energy Agency & IEA & International Energy Agency \\
\hline EDGAR & $\begin{array}{l}\text { Emissions Database for Global Atmospheric } \\
\text { Research }\end{array}$ & IIASA & $\begin{array}{l}\text { International Institute for Applied Systems } \\
\text { Analysis }\end{array}$ \\
\hline EEA & European Environment Agency & IIMA & Indian Institute of Management, \\
\hline EHCC & Earth Hour City Challenge & & Ahmedabad \\
\hline ERI & Energy Research Institute & IMO & International Maritime Organization \\
\hline ER-PIN & $\begin{array}{l}\text { Emission Reductions Program Idea Note } \\
\text { (in FCPF) }\end{array}$ & INDC & $\begin{array}{l}\text { Intended Nationally Determined } \\
\text { Contribution }\end{array}$ \\
\hline
\end{tabular}




\begin{tabular}{|c|c|c|c|}
\hline INPE & National Institute for Space Research & PRIMAP & Potsdam Real-time Integrated Model for \\
\hline IPCC & Intergovernmental Panel on Climate Change & & probabilistic Assessment of emission Paths \\
\hline IPPU & $\begin{array}{l}\text { industrial processes and product use (IPCC } \\
\text { sector) }\end{array}$ & $\begin{array}{l}\text { PV } \\
\text { REALU }\end{array}$ & $\begin{array}{l}\text { photovoltaic } \\
\text { reducing emissions from all land uses }\end{array}$ \\
\hline $\begin{array}{l}\text { IRENA } \\
\text { IUCN }\end{array}$ & $\begin{array}{l}\text { International Renewable Energy Agency } \\
\text { International Union for Conservation of } \\
\text { Nature }\end{array}$ & REDD+ & $\begin{array}{l}\text { Reduced Emissions from Deforestation } \\
\text { and forest Degradation Plus in developing } \\
\text { countries (includes sustainable management }\end{array}$ \\
\hline JRC & $\begin{array}{l}\text { Joint Research Centre (European } \\
\text { Commission) }\end{array}$ & SBT & $\begin{array}{l}\text { and enhancement of forest carbon stocks) } \\
\text { science-based targets }\end{array}$ \\
\hline LIMITS & $\begin{array}{l}\text { Low climate IMpact scenarios and the } \\
\text { Implications of required Tight emission } \\
\text { control Strategies }\end{array}$ & $\begin{array}{l}\text { SDG } \\
\text { SE4ALL } \\
\text { SEAP }\end{array}$ & $\begin{array}{l}\text { Sustainable Development Goal } \\
\text { Sustainable Energy for All } \\
\text { Sustainable Energy Action Plan }\end{array}$ \\
\hline LSE & $\begin{array}{l}\text { London School of Economics and Political } \\
\text { Science }\end{array}$ & $\begin{array}{l}\text { SF }_{6} \\
\text { SIDS }\end{array}$ & $\begin{array}{l}\text { sulphur hexafluoride } \\
\text { small island developing states }\end{array}$ \\
\hline LULUCF & land use, land-use change and forestry & SLCF & short-lived climate forcers \\
\hline MCPA & $\begin{array}{l}\text { Mayors' Climate Protection Agreement } \\
\text { (USA) }\end{array}$ & $\begin{array}{l}\text { SOC } \\
\text { TCR }\end{array}$ & $\begin{array}{l}\text { soil organic carbon } \\
\text { transient climate response }\end{array}$ \\
\hline MRV & monitoring, reporting and verification & UCL & University College London \\
\hline $\mathrm{MtCO}_{2} \mathrm{e}$ & million metric tons of $\mathrm{CO}_{2}$ equivalent & UCLG & United Cities and Local Governments \\
\hline NAMA & Nationally Appropriate Mitigation Action & ULCOS & ultra-low $\mathrm{CO}_{2}$ steelmaking \\
\hline NAP & National Adaptation Plan & UNCCD & United Nations Convention to Combat \\
\hline NAZCA & Non-State Actor Zone for Climate Action & & Desertification \\
\hline NCSC & $\begin{array}{l}\text { National Center for Climate Strategy and } \\
\text { International Cooperation }\end{array}$ & $\begin{array}{l}\text { UNEP } \\
\text { UNEP-DTU }\end{array}$ & $\begin{array}{l}\text { United Nations Environment Programme } \\
\text { UNEP-Technical University of Denmark }\end{array}$ \\
\hline $\begin{array}{l}\mathrm{NF}_{3} \\
\mathrm{NGO}\end{array}$ & $\begin{array}{l}\text { nitrogen trifluoride } \\
\text { non-governmental organization }\end{array}$ & UNEP-WCMC & $\begin{array}{l}\text { UNEP-World Conservation Monitoring } \\
\text { Centre }\end{array}$ \\
\hline $\begin{array}{l}\text { NIES } \\
\text { NYDF }\end{array}$ & $\begin{array}{l}\text { National Institute for Environmental Studies } \\
\text { New York Declaration on Forests }\end{array}$ & UNFCCC & $\begin{array}{l}\text { United Nations Framework Convention on } \\
\text { Climate Change }\end{array}$ \\
\hline $\mathrm{N}_{2} \mathrm{O}$ & nitrous oxide & UNGA & United Nations General Assembly \\
\hline $\begin{array}{l}\text { OC } \\
\text { ODS }\end{array}$ & $\begin{array}{l}\text { organic carbon } \\
\text { ozone-depleting substances }\end{array}$ & UNORCID & $\begin{array}{l}\text { United Nations Office for REDD+ } \\
\text { Coordination in Indonesia }\end{array}$ \\
\hline OECD & $\begin{array}{l}\text { Organisation for Economic Cooperation and } \\
\text { Development }\end{array}$ & WBCSD & $\begin{array}{l}\text { World Business Council for Sustainable } \\
\text { Development }\end{array}$ \\
\hline OPIC & Overseas Private Investment Corporation & WHRC & Woods Hole Research Center \\
\hline PAM & policies and measures & WMCCC & World Mayors Council on Climate Change \\
\hline PFC & perfluorocarbon & WRI & World Resources Institute \\
\hline PIK & Potsdam Institute for Climate Change & WWF & World Wildlife Fund \\
\hline
\end{tabular}




\section{Foreword}

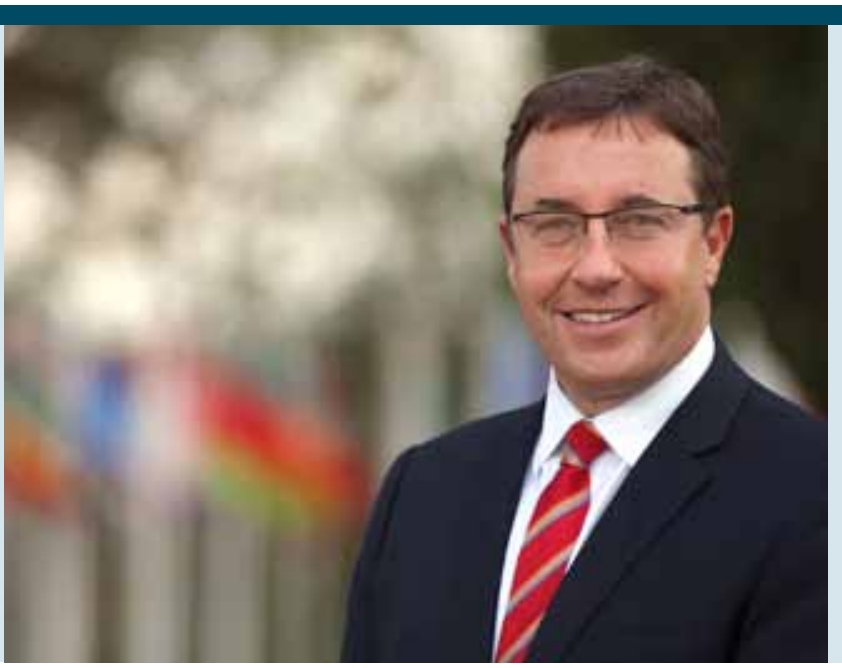

Following the historic signing of the 2030 Agenda for Sustainable Development, this sixth edition of the UNEP Emissions Gap Report comes as world leaders start gathering in Paris to establish a new agreement on climate change.

The report offers an independent assessment of the mitigation contributions from the Intended Nationally Determined Contributions (INDC) committed to by 1 October 2015 , by the 146 countries that account for around 90 per cent of global emissions. It compares the 2030 emission levels that would result from these commitments with what science tells us would keep average temperature increases on track to stay below $2^{\circ} \mathrm{C}$ by the end of the century; it provides data for an aspirational target of keeping that increase below $1.5^{\circ} \mathrm{C}$; and it evaluates the INDCs in relation to progress on the 2020 pledges made in Cancun.

The INDCs demonstrate a significant increase in ambition and their successful delivery could reduce emissions by around 25 per cent compared to the level expected from current policies and pledges. However, this would still put long-term temperatures on track for an increase and lead to serious climate impact, so more action is required.

Therefore, the Emissions Gap Report also explores how available financial, technical and capacity building solutions can be scaled up, or even accelerated, to close the gap between the expected and required levels of emissions. This includes detailed assessments that look beyond the INDCs to identify the further gains being identified by the International Cooperative Initiatives and by Reducing Emissions from Deforestation and Forest Degradation (REDD+).
With many new emission reduction initiatives also generating substantial economic, social and environmental benefits, the INDC preparation process in most countries encouraged greater exploration of the links between development and climate. This is an important first step in a possible transition towards more low carbon economies.

The Emissions Gap Report makes it very clear that while reaching a meaningful global agreement in Paris is essential, it is not the end of the climate change story: it is a stepping stone on a much longer journey that requires us to stay alert to the science and remain dynamic in our response. The world has already tripled the expected performance on scaling up clean energy and been able to start reversing damage to the ozone layer.

I firmly believe that if we act on the findings of this report, there is nothing to stop us closing the emissions gap and creating a more inclusive and sustainable future for both the developed and the developing world.

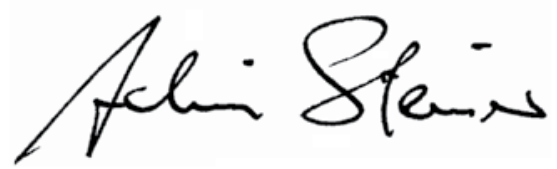

\section{Achim Steiner}

UN Under-Secretary-General, UNEP Executive Director 


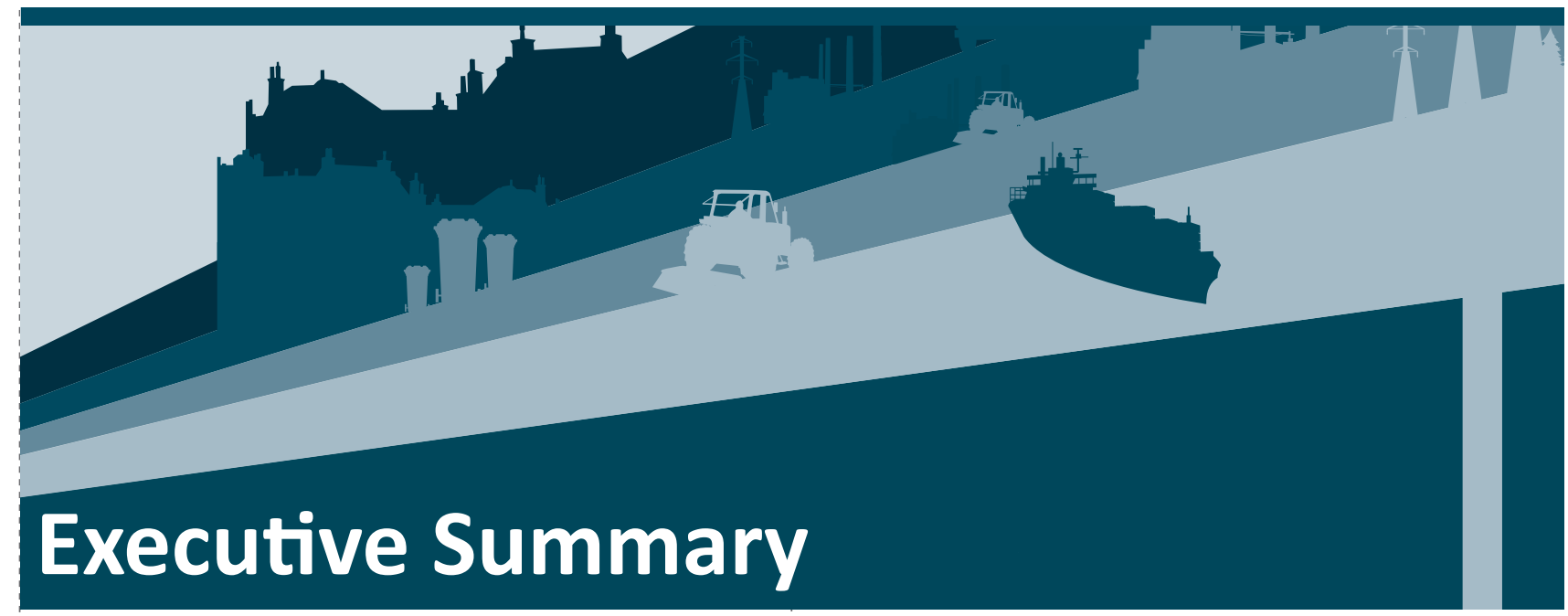

The year $\mathbf{2 0 1 5}$ has the potential to become a turning point in global efforts to transform the prevailing social and economic development paradigm into a more sustainable one.

The global community reached agreement in September 2015 on a set of 17 sustainable development goals to be achieved by 2030 , including climate change. Countries will meet again at the United Nations Framework Convention on Climate Change (UNFCCC) $21^{\text {st }}$ Conference of the Parties (COP 21) in Paris with the aim of establishing a new global agreement on climate change, hereafter the 'Paris Agreement', with the ambition of limiting changes in global temperatures to below $2^{\circ} \mathrm{C}$ or $1.5^{\circ} \mathrm{C}$ warming in 2100 compared to pre-industrial levels. The Paris Agreement will also aim to establish a framework to provide technological and financial support for developing countries to accelerate the transition towards low carbon and climate resilient development paths.

The architecture of a new climate agreement has many facets with an array of issues under negotiation that have become significantly more complex since the Framework Convention on Climate Change entered into force in 1994. The core structure of the Paris Agreement will comprise the "Intended Nationally Determined Contributions" (INDCs) as well as the process by which implementation of the agreement will proceed over time to advance the objectives of the UNFCCC. In addition, a number of key decisions will be required covering issues like adaptation, finance, technology, and capacity building.

\section{What is covered in the 2015 Emissions Gap Report?}

This sixth UNEP Emissions Gap Report provides a scientific assessment of the mitigation contributions from the submitted INDCs. As in the previous reports, it then compares the resulting emission levels in $\mathbf{2 0 3 0}$ with what science tells us is required to be on track towards the agreed target of a global average temperature increase below $2^{\circ} \mathrm{C}$ by 2100 . The Report also provides data for the aspirational target of keeping the temperature increase below $1.5^{\circ} \mathrm{C}$. In addition, the Report presents selected areas where enhanced action can be taken, accelerated and scaled up to close the emissions gap.

The 2015 Emissions Gap Report addresses the following key questions:

- What are the latest estimates of 2025 and 2030 total global emissions levels consistent with the goal of holding the global average temperature rise below $2^{\circ} \mathrm{C}$ or $1.5^{\circ} \mathrm{C}$ above pre-industrial levels by 2100 ?

- What is the progress on implementation of the Cancun pledges for the period to 2020?

- Will the combined INDC commitments for 2030 (if fully implemented) be sufficient to stay within the range consistent with the $2^{\circ} \mathrm{C}$ temperature goal?

- What are possible contributions in selected key areas, where action can be accelerated to enhance the ambition of national pledges both in the period before and after the expected entry into force in 2020 of the Paris Agreement? This year the detailed assessment is on possible mitigation contributions from International Cooperative Initiatives (ICls) and enhanced forest-related mitigation activities with a focus on Reducing Emissions from Deforestation and Forest Degradation (REDD+).

By 1 October 2015, a total of 119 INDCs had been submitted to the UNFCCC. Fifteen INDCs included only mitigation, while most included both adaptation and mitigation components. The report only presents qualitative information about the adaptation component of the INDCs submitted.

The report has been prepared by an international team of leading scientists assessing all available information, including that reviewed by the IPCC in its fifth assessment report, as well as more recent scientific studies. The assessment production process has been transparent and participatory. The assessment methodology and preliminary findings were made available to governments and stakeholders concerned 
during relevant international fora as well as on the UNEP Live website. The governments of the countries with specific mention in the report have been invited to comment on the assessment findings.

\section{What are current emissions and what emission levels in 2030 are consistent with the $2^{\circ} \mathrm{C}$ and the $1.5^{\circ} \mathrm{C}$ targets?}

Over the past decades global GHG emissions have been increasing steadily, with small variations around a longerterm trend.

The most recent global emission estimates ${ }^{1}$ are available for the year 2014. In that year, total global Kyoto-GHG emissions ${ }^{2}$ amounted to about $52.7 \mathrm{GtCO}_{2}$ e (range: 47.9-57.5). Global carbon-dioxide $\left(\mathrm{CO}_{2}\right)$ emissions from fossil-fuel and industry were estimated at $35.5 \mathrm{GtCO}_{2}$ for 2014 (range: 32.5-38.5).

Staying below $2^{\circ} \mathrm{C}$ temperature rise implies that $\mathrm{CO}_{2}$ emissions are reduced to net zero by 2060-2075.

The IPCC in its fifth assessment report concluded that to limit global warming to below $2^{\circ} \mathrm{C}$, the remaining cumulative $\mathrm{CO}_{2}$ emissions - the so-called carbon budget - are in the order of $1000 \mathrm{GtCO}_{2}$. This remaining budget can be utilized in different ways, but given the most recent assessment of current trends, net global carbon emissions will eventually need to be reduced to zero between 2060 and $2075^{3}$. For a detailed discussion of the carbon budget, see the 2014 Emissions Gap Report.

Figure ES1: Historical greenhouse (GHG) emissions and projections until 2050

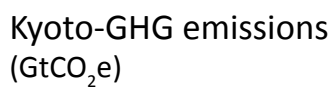

Kyoto-GHG emissions

$\left(\mathrm{GtCO}_{2} \mathrm{e}\right)$

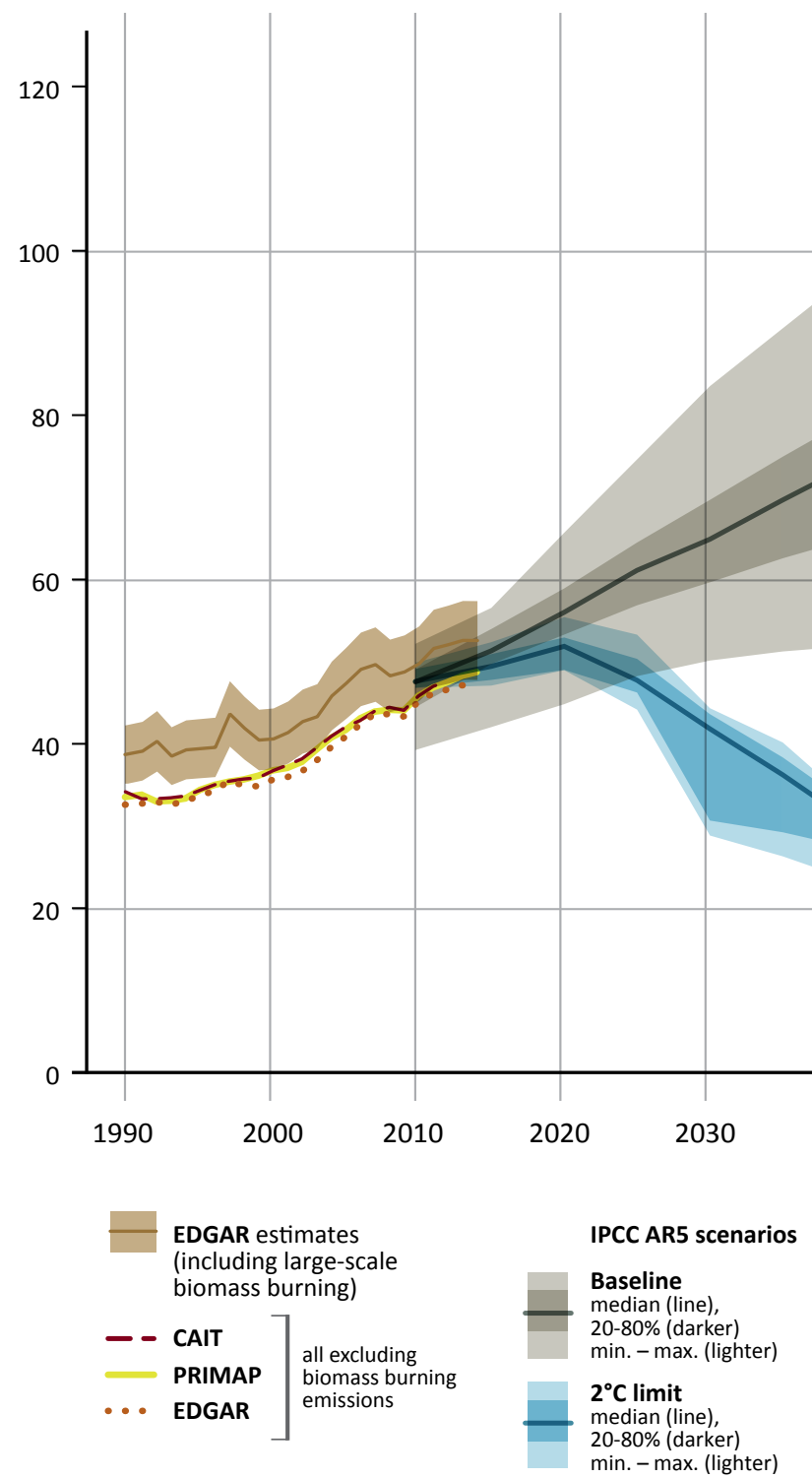

Estimated global warming by 2100

$\left({ }^{\circ} \mathrm{C}\right.$ rel. $\left.1850-1900\right)$

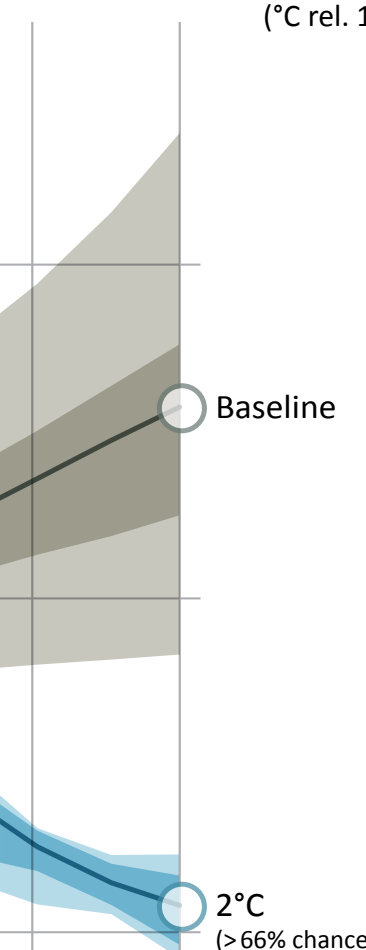

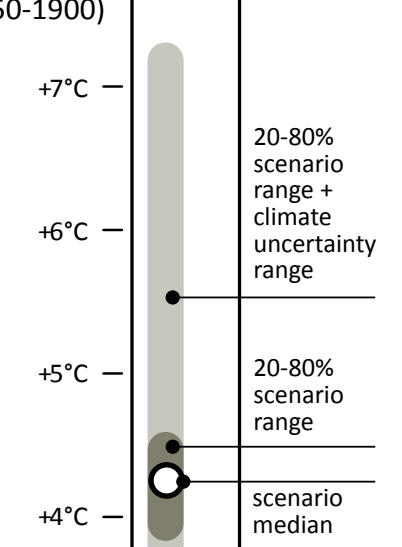

Data for 2014 are available from EDGAR and PRIMAP, see Chapter 2

The six greenhouse gases covered by the UNFCCC/Kyoto Protocol - carbon dioxide, methane, nitrous oxide, hydrofluorocarbons, perfluorocarbons and sulphur hexafluoride. Here aggregated with 100-year Global Warming Potentials (GWPs) of the IPCC Second Assessment Report.

Based on the final released IPCC AR5 scenarios database data. 
The 2015 Report presents an updated set of possible pathways to stay within this budget, and also includes an updated assessment of the pathways and requirements to stay within the more ambitious $1.5^{\circ} \mathrm{C}$ temperature goal.

The median emission level in $\mathbf{2 0 3 0}$ in scenarios that have a >66 per cent chance of keeping temperature increase to below $2^{\circ} \mathrm{C}$ by the end of the century is $42 \mathrm{GtCO}_{2} \mathrm{e}$ (range: $31-44)$. The similar level for a $1.5^{\circ} \mathrm{C}$ pathway is $39 \mathrm{GtCO}_{2} \mathrm{e}^{4}$. The trajectories for the two target levels are similar in many aspects, but earlier and much stronger action is necessary for the $1.5^{\circ} \mathrm{C}$ target to be kept.

As reflected in last year's report, the focus for the gap assessment has shifted from 2020 to 2030, reflecting that the underlying scenarios assume emission levels that are consistent with the Cancun pledges until 2020. Least-cost enhanced emission reduction pathways are only assumed from 2020. Earlier analysis assumed the world would move onto a least-cost pathway by 2010 . Current trends indicate that this will not be the case, and accordingly the new set of scenarios from the IPCC, which are referenced in this report, include only those that assume least-cost pathways starting from 2020.

\section{What are the implications of the scenarios that are consistent with the temperature goals?}

The scenarios used in this Report as reference for meeting the $2^{\circ} \mathrm{C}$ and $1.5^{\circ} \mathrm{C}$ goals are all characterized by modest emissions reductions compared to current policies until $2020^{5}$ that are in line with the ambition of Cancun pledges. This implies a need for deep and stringent emission reductions over later decades. Enhanced action before 2020 that would bring emission levels below the projected 2020 Cancun pledge level would ease the challenge and reduce overall cost of transitioning to least-cost pathways after 2020. It should be noted that in order to move to such pathways after 2020 , the necessary policies and investment will need to be prepared well in advance.

The assessment of the pathways and target levels point at three key issues that have also been raised in previous gap reports:

- All scenarios analyzing $2^{\circ} \mathrm{C}$ pathways that follow the Cancun pledges until 2020 and with a least-cost starting point in 2020, require strong reductions after 2020. They also rely on so-called 'negative emission technologies' such as bioenergy combined with carbon capture and storage

- For scenarios analyzing the $1.5^{\circ} \mathrm{C}$ target, the reduction rates will need to be steeper

- The feasibility of large scale deployment of negative emission technologies is still a contentious issue.

4 As there are fewer than 10 scenarios available for the $1.5^{\circ} \mathrm{C}$ pathways, the $20^{\text {th }}$ to $80^{\text {th }}$ percentile range is not provided. However, the minimum and maximum values are $37 \mathrm{GtCO}_{2}$ e and $40 \mathrm{GtCO}_{2}$ e respectively.

5 Global emissions in 2020 under various pledge cases are estimated to be about 52-54 GtCO e. The least-cost 2020 scenarios used here have global emissions close to this range (49-56 $\left.\mathrm{GtCO}_{2} \mathrm{e}\right)$.

Enhanced early action (such as moving below the 2020 pledges) is associated with the following economic and technological advantages:

- $\quad$ Softening the requirement for very steep emission reductions over the medium term

- Facilitating mitigation in the medium to long term by reducing lock-in of carbon and energy intensive infrastructure in the energy system and society as a whole

- Encouraging near-term learning and development of technologies that will be essential in the long term

- Providing early policy signals which are needed for action later in the coming decades

- $\quad$ Reducing the overall costs and economic challenges in terms of, for example, upscaling of energy investments, during the transitional period

- Reducing the dependence on unproven technologies and increase the options society can choose from in terms of means to achieve stringent emission reductions in the long term.

Delaying stringent mitigation efforts until 2030 (in other words, not following a least-cost reduction trajectory after 2020) would with high confidence make the transition to longer-term emissions levels in line with the $2^{\circ} \mathrm{C}$ goal significantly more difficult. A significant number of models are not able to produce $2^{\circ} \mathrm{C}$ scenarios consistent with global emission levels in 2030 above $55 \mathrm{GtCO}_{2} \mathrm{e}$, while other scenarios which delay enhanced mitigation action until after 2030 would imply massive cost increases coupled with a need for unprecedented political action.

\section{Are $\mathbf{G} 20$ countries making progress on the implementation of 2020 pledges?}

Among the $\mathbf{G} 20$ there are thirteen countries with pledges for $\mathbf{2 0 2 0}$ (counting the EU members France, Germany, Italy and UK as one) and three countries without pledges. Six of these are assessed as being on track to meet pledges or extremely close, four are not, and three cannot be assessed, because there is insufficient evidence.

Pledges are self-determined. A country being on track does not necessarily mean that it undertakes more stringent action on mitigation than a country that is not on track - it depends on the ambition of the pledge.

The report presents an assessment of progress by $\mathrm{G} 20$ countries on the national pledges presented in the context of the Cancun agreement, and referred to here as the Cancun pledges.

The assessment compares projected 2020 emissions under three cases:

- $\quad$ Pledge case - projecting the maximum amount of emissions for 2020 compatible with the pledge

- Current policy trajectory - official national estimate

- Current policy trajectory - independent analysis.

Despite progress towards implementing policies in line with pledges, it is evident that work remains to be done to bring all G20 countries into pledge attainment. 


\section{What is the emissions gap in 2025 and} 2030 assuming full implementation of the INDCs?

The emissions gap between what the full implementation of the unconditional INDCs contribute and the least-cost emission level for a pathway to stay below $2^{\circ} \mathrm{C}$, is estimated to be $14 \mathrm{GtCO}_{2} \mathrm{e}$ (range: 12-17) in 2030 and $7 \mathrm{GtCO}_{2} \mathrm{e}$ (range: 5-10) in 2025. When conditional INDCs are included as fully implemented, the emissions gap in $\mathbf{2 0 3 0}$ is estimated to be $12 \mathrm{GtCO}_{2} \mathrm{e}$ (range: 10-15) and $5 \mathrm{GtCO}_{2} \mathrm{e}$ (range: 4-8) in 2025.

If countries that have not yet submitted an INDC were to reduce their emissions at the same percentage below current policy trajectories as those that have already submitted, the projected global emissions would be further reduced, and the gap narrowed, by a further $0.5 \mathrm{GtCO}_{2} \mathrm{e}$ in 2025 and $1 \mathrm{GtCO}_{2} \mathrm{e}$ in 2030.

Full implementation of unconditional INDC results in emission level estimates in $\mathbf{2 0 3 0}$ that are most consistent with scenarios that limit global average temperature increase to below $3.5^{\circ} \mathrm{C}$ until 2100 with a greater than 66 per cent chance. INDC estimates do, however, come with uncertainty ranges. When taking this into account the $3.5^{\circ} \mathrm{C}$ value could decrease to $3^{\circ} \mathrm{C}$ or increase towards $4^{\circ} \mathrm{C}$ for the low and high unconditional INDC estimates, respectively. When including the full implementation of conditional INDCs, the emissions level estimates become most consistent with long-term scenarios that limit global average temperature increase to $<3-3.5^{\circ} \mathrm{C}$ by the end of the century with a greater than 66 per cent chance.

These numbers essentially tell two stories. Firstly the INDCs do present a real increase in the ambition level compared to a projection of current policies; all global modelling groups that have been assessed reached this conclusion. Secondly the submitted contributions are far from enough and the emissions gap in both 2025 and 2030 will be very significant.

The Report presents an assessment of the 119 INDCs submitted by 1 October 2015, covering 146 countries and 85-88 per cent of global GHG emissions in 2012. A final update of the assessment including later submissions will be presented on the UNEP Live website before the start of COP 21.

In the absence of agreed formats for reporting on mitigation contributions, including on the units in which those might be expressed, Parties have chosen a wide variety of forms and contributions: for example, targets used include:

- Economy-wide absolute reduction from historical base year emissions

- Emissions reduction relative to a baseline projection for the emissions associated with energy consumption

- Trajectory target for specific sectors or gases

- $\quad$ Specifying a peaking year

- Emissions intensity of GDP

- A fixed level target.

This has increased the analytical challenge of ensuring consistency when comparing and aggregating different mitigation contributions. The assessment builds on a combination of global and country-specific modelling studies from independent research teams, and official countryspecific data sources.

The global emission levels in 2030 consistent with having a likely chance ( $>66$ per cent) of staying below the $2^{\circ} \mathrm{C}$ goal in 2100 , following a least-cost pathway from 2020 with only modest improvement of the GHG intensity until then, is $42 \mathrm{GtCO}_{2} \mathrm{e}$ (range: 31-44). In 2025 this level is $48 \mathrm{GtCO}_{2} \mathrm{e}$ (range: 46-50).

In comparison, global GHG emissions, based on assessment of the INDCs submitted by 1 October 2015, are for the unconditional INDCs projected to be at $54 \mathrm{GtCO}_{2} \mathrm{e}$ (range: 53-58) in 2025, and $56 \mathrm{GtCO}_{2} \mathrm{e}$ (range: 54-59) in 2030. If conditional INDCs are included, the global emissions projection is $53 \mathrm{GtCO}_{2} \mathrm{e}$ (range: 52-56) in 2025 and $54 \mathrm{GtCO}_{2}$ e (range: $52-57$ ) in 2030. The emission levels resulting from submitted INDCs are 4 to $6 \mathrm{GtCO}_{2} \mathrm{e}$ lower than the current policy trajectory in 2030 of $60 \mathrm{GtCO}_{2} \mathrm{e}$ (range: 58-62). They are 9 to $11 \mathrm{GtCO}_{2} \mathrm{e}$ lower than the baseline of $65 \mathrm{GtCO}_{2} \mathrm{e}$ (range: $60-70$ ), which is based on IPCC AR5 scenarios and assumes no additional climate policies are put in place after 2010.

\section{Can the INDC process become a foundation for enhancing ambition?}

It is clear from the assessment of the mitigation contributions from the INDCs that much more needs to be done. This round of INDCs should therefore be considered as the first step in building foundations for a successful global climate agreement. The social and political effects of the INDCs and the processes undertaken at national level transcend the aggregate effect they are estimated to have on total global GHG emission levels in 2025 and 2030. The preparation of the INDCs has in many countries incentivized exploration of linkages between development and climate, as well as development of new national climate polices, and can be seen as an important step in a transition towards low carbon economies.

The Paris Agreement can support these national transitions and provide the framework for mobilization of the enhanced mitigation effort that is required to align national efforts with the global mitigation ambition indicated by the $2^{\circ} \mathrm{C}$ pathways. Establishing a robust, effective and transparent follow-up and review framework as part of the Paris Agreement will be critical in this context.

The INDCs and options for enhanced mitigation action must be seen in the broader context of economic growth and sustainable development. The Sustainable Development Goals (SDGs) recently adopted in New York by Heads of State of all member states of the United Nations explicitly recognise the interdependence between the achievement of climate, development and sustainability goals and recommends prioritizing coherence, co-benefits, and complementarity between the SDGs and a climate change agreement under the UNFCCC.

The SDG Goal 13 "Take urgent action to combat climate change and its impacts" specifically acknowledges that the 
Figure ES2: The emissions gap

Annual Global Total Greenhouse Gas Emissions $\left(\mathrm{GtCO}_{2} \mathrm{e}\right)$

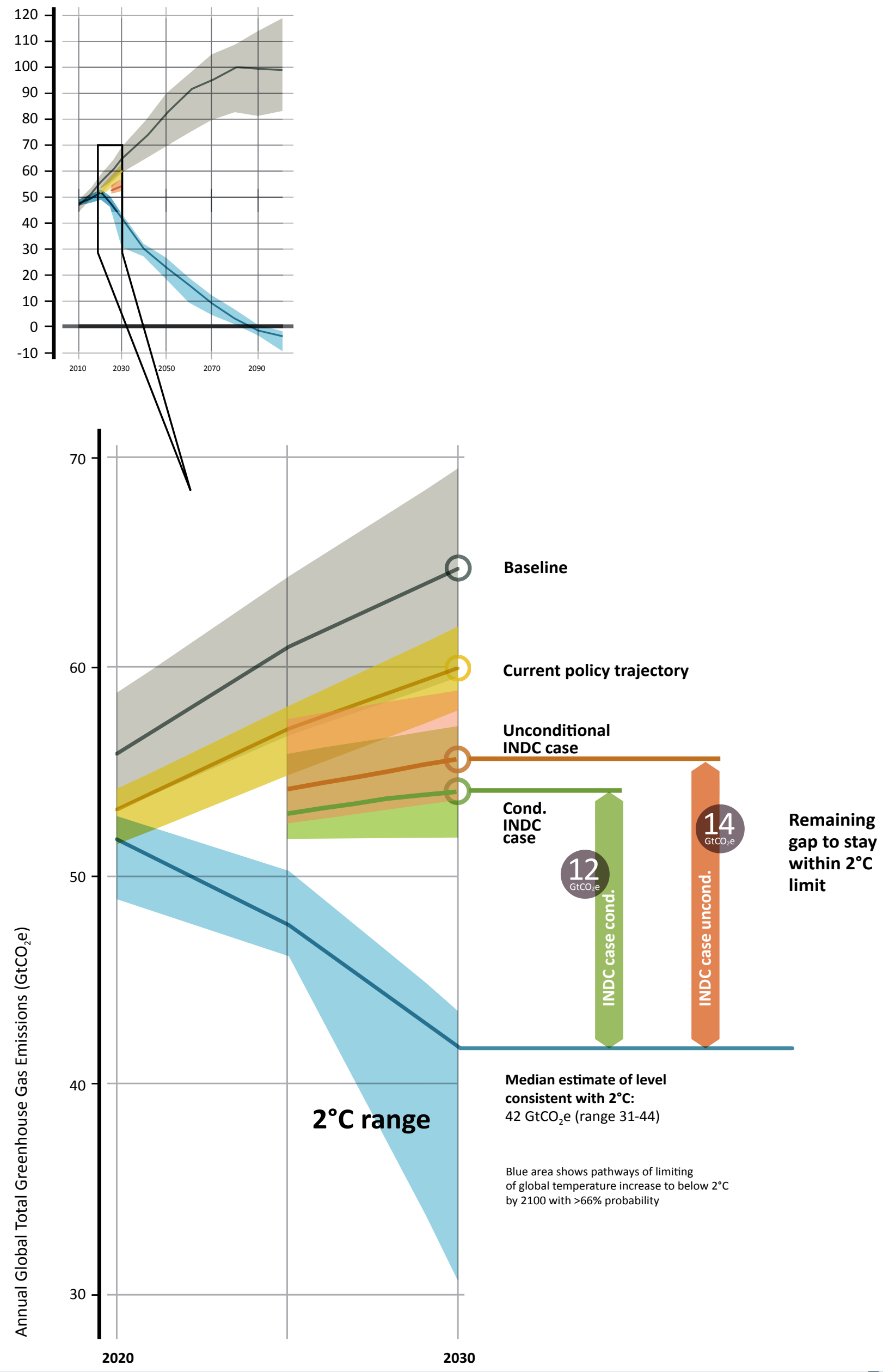


United Nations Framework Convention on Climate Change is the primary international, intergovernmental forum for negotiating the global response to climate change, and the targets associated with the goal are clearly aligned with the ambitions in the INDCs.

\section{What are some of the options for closing the gap?}

A number of recent global studies conclude that there is a significant potential to reduce global emissions in $\mathbf{2 0 3 0}$ - beyond the reductions resulting from implementation of the INDCs. If this potential is fully exploited, it could bring global emissions to a level very close to bridge the emissions gap in 2030. Furthermore, the studies suggest that this can be done by relying on proven technologies and policies.

A number of recent studies and reports, including by the IPCC and leading international research institutions, identifies a significant emissions reduction potential by 2030. Acknowledging that the methodologies, assumptions, scope and coverage of measures considered vary across the assessed studies, they all show that tapping into unused emission reduction potential could narrow the emissions gap in 2030 considerably. Taken together, they indicate that global greenhouse gas emissions could be further reduced by between 5 to $12 \mathrm{GtCO}_{2} \mathrm{e} / \mathrm{yr}$ (range: 3-13) relative to the emissions level resulting from implementation of the unconditional INDCs, and between 5 to $10 \mathrm{GtCO}_{2} \mathrm{e} / \mathrm{yr}$ (range: 1-11) relative to the emissions level associated with implementation of the conditional INDCs. These reductions could contribute to the reductions needed to bridge the emissions gap in 2030, which as previously stated is estimated at $14 \mathrm{GtCO}_{2}$ e (range: $12-17$ ) for the unconditional INDC case and at $12 \mathrm{GtCO}_{2} \mathrm{e}$ (range: 10-15), if both unconditional and conditional INDCs are implemented.

There is considerable uncertainty associated with the possibilities for achieving the emission reduction opportunities put forward in some of these studies. At the same time, the studies assessed do not cover all relevant measures, thematic areas and sectors. In other words the total technical and economic emission reduction potential in 2030 could be larger than indicated in the studies assessed. In comparison the Fourth Assessment Report of the IPCC indicated a total emission reduction potential in 2030 of $23 \mathrm{GtCO}_{2}$ e (range: 16-31). No update of the total emission reduction potential in 2030 was provided in the Fifth Assessment Report of the IPCC, but sectoral updates in this report indicate emission reduction potentials in 2030 of the same order of magnitude.

The assessed recent studies emphasize the key importance of enhanced energy efficiency with a particular emphasis on industry, buildings and transport, and expanded use of renewable energy technologies for power production combined with increased efficiency of fossil fuel-based power production will all be critical for achievement of the desired large-scale emission reductions. Other key sectors for enhanced mitigation action emphasized in the studies include forestry, agriculture and waste.

These are all sectors that have been assessed in earlier UNEP Emissions Gap Reports and where significant opportunities for bridging the gap have been highlighted through possibilities for replication, acceleration and scaling up proven good practices and policies.

\section{How can International Cooperative Initiatives contribute to implementation of INDCs and enhance ambitions?}

The impact of actions by International Cooperative Initiatives can potentially be significant. Preliminary assessments indicate a contribution in the range of 2.5 to $4 \mathrm{GtCO}_{2} \mathrm{e}$ in 2020, if fully implemented. Part of this contribution falls within the Cancun pledges while the additional contribution may be in the range of 0.75 to $2 \mathrm{GtCO}_{2} \mathrm{e}$ in 2020.

Significant attention has been put on mitigation actions by ICls including actors other than Parties to the UNFCCC.

ICls include a wide variety of activities, which makes consistent and thorough assessment difficult. Nevertheless, an effort has been made to assess all available information and organize it under a simple catalogue of actions categorized by type of constituent engaged. This catalogue serves to focus on those ICls that have the most impact potential and by disentangling the various initiatives the overlap and double-counting risks with the national pledges can be minimized.

The report examines initiatives in three broad categories:

- Cities and regions

- Companies

- Sectors

A few examples below illustrate the wide span of ICls:

- $\quad$ C40 Cities Climate Leadership Group - is a network of the world's megacities committed to taking action that reduces global GHG emissions. It has 75 affiliated cities (as of July 2015) and a total of 80 total participants

- The Compact of Mayors - is an agreement by three city networks to undertake a transparent and supportive approach to reduce city-level emissions, and to reduce vulnerability from, and enhance resilience to, climate change, in a consistent and complementary manner to national level climate protection efforts. It builds on ongoing city-level efforts

- Cement Sustainability Initiative (CSI) - is an alliance of 25 leading companies in the global cement industry created under the auspices of the World Business Council for Sustainable Development (WBCSD). Participants commit to developing a climate change mitigation strategy, setting reduction targets for $\mathrm{CO}_{2}$ and reporting annually on their progress. 
A number of new studies have examined the major initiatives and this report presents an assessment of these studies and their estimates of the emission reduction potential for each category of initiative. The studies list a number of challenges related to the analyzed ICls including elements of overlap between initiatives and comparability of transparent monitoring, reporting and verification (MRV) of results. It is therefore difficult to assess whether all the international initiatives actually deliver on promises, as most initiatives propose only voluntary commitments and hence make it difficult for accountability and compliance to be enforced and sometimes lack robust Monitoring, Reporting and Verification (MRV).

Many initiatives can, however, play important roles to advance climate action, as they:

- Encourage or facilitate emission reductions at the city and regional level, via knowledge sharing, capacity building and technical support for project planning and implementation

- Identify partnerships and support local communities to become climate resilient

- Represent common city-level interests to influence policymakers at other levels

- Help implement climate plans and low-carbon and climate-resilient economic development projects

- Achieve transparency and accountability by encouraging best practice in GHG emission reporting

- Help overcome financial barriers and attract investors and accelerate additional capital flows into cities for low carbon projects.
The studies compare the emissions reduction potential for the different categories of initiatives compared to a current trajectory baseline (noting that studies are not necessarily using same baseline approaches). Even if uncertainties are quite large, it is interesting that results are quite comparable at the aggregate level, even if the assessment of the different groups of initiatives varies significantly.

The assessment notes that the impact of non-state climate commitments can be significant, most likely in the range between 2.5 and $4 \mathrm{GtCO}_{2} \mathrm{e}$ in 2020 (taking into account that not all initiatives are included in all assessments). These numbers include an estimate of overlaps between the various initiatives, in terms of actual actions, sectors, greenhouse gases and regions.

It is harder to estimate the overlap between these nonstate initiatives and government emission reduction pledges for 2020. The recent studies examined in this assessment suggest that the overlap ranges between 33 and 70 per cent, resulting in possible additional net contributions of the order of 0.75 to $2 \mathrm{GtCO}_{2} \mathrm{e}$ in 2020.

Even if ICls are not necessarily additional to national 2020 pledges, they can be an important component of actually implementing these and at the same time facilitate or even drive increased national ambition. Only one study extrapolates the potential reductions to 2030 , so it is not possible to present numbers here, but the study indicates that the mitigation contribution from existing ICls would be substantial.

\section{Figure ES3: National statements of intention to undertake forest-related mitigation activities}
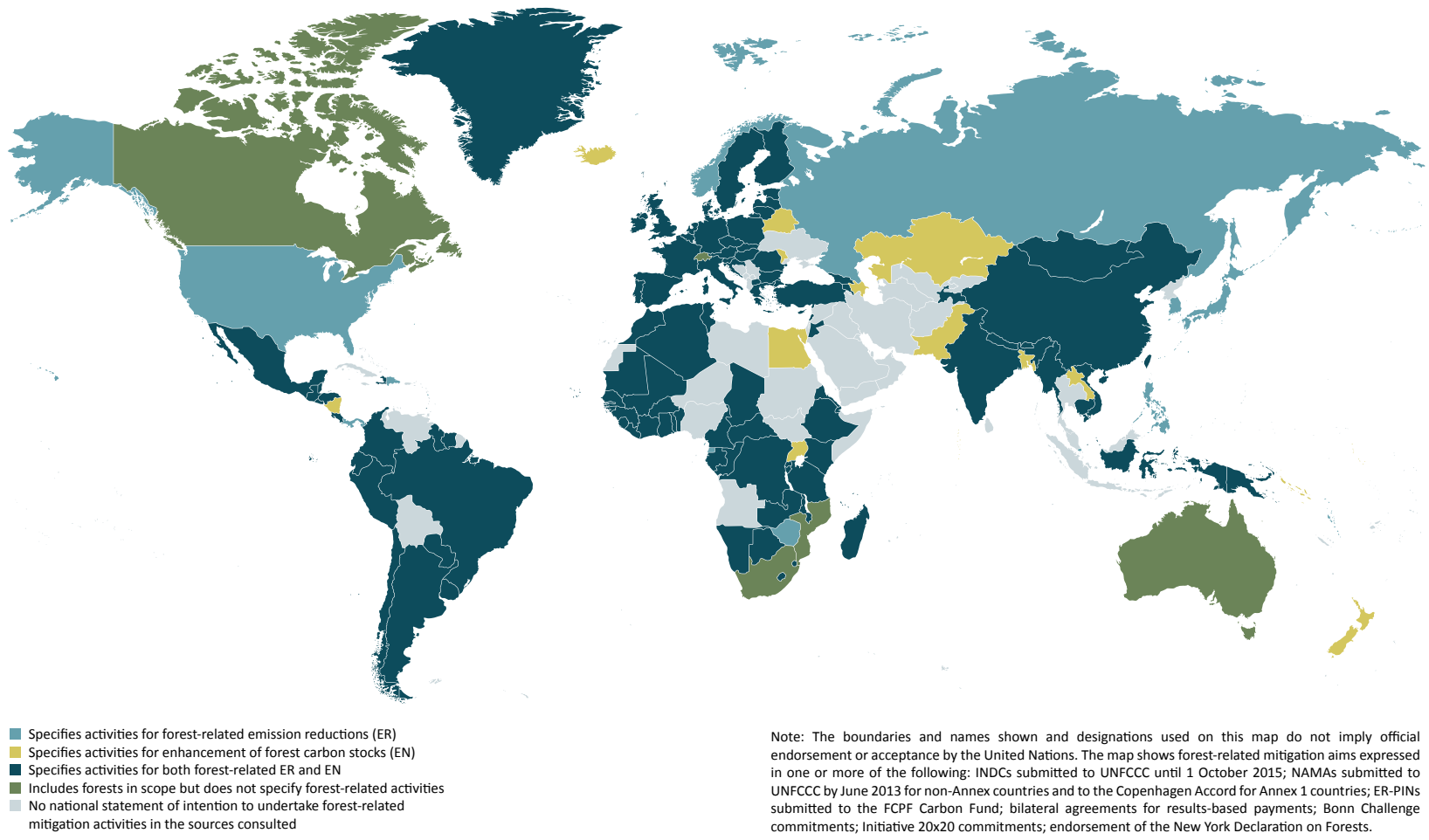

Note: The boundaries and names shown and designations used on this map do not imply official endorsement or acceptance by the United Nations. The map shows forest-related mitigation aims expressed in one or more of the following: INDCS submitted to UNFCCC until 1 October 2015; NAMAs submitted to UNFCCC by June 2013 for non-Annex countries and to the Copenhagen Accord for Annex 1 countries; ER-PINs (a) 
9. What is the potential for greater forestrelated mitigation, in particular through REDD+?

Forest-related mitigation activities in both developing and developed countries are attracting significant political attention, both in the negotiation process over the last years and in many of the submitted INDCs. Special focus is on policies and actions under REDD+ as the theoretical potential of forest-related mitigation activities in developing countries is estimated to be up to $9 \mathrm{GtCO}_{2}$ in 2030. The realization of this theoretical potential will be constrained by economic and land-use factors.

A rapid review ${ }^{6}$ has been undertaken of forestry related mitigation actions in the submitted INDCs and these are together with other types of national engagement in forestry related mitigation illustrated in the global map below. The map clearly shows that many countries see potential mitigation opportunities in the forestry sector.

A special focus in the assessment has been devoted to the set of policy approaches and actions known as REDD+ as one option for facilitating cost-effective contributions to climate change mitigation, in developing countries. REDD+ (as defined under the UNFCCC) includes - reducing greenhouse gas emissions from deforestation and forest degradation, conservation of forest carbon stocks, sustainable management of forests and enhancement of forest carbon stocks.

REDD+ has seen marked progress under the UNFCCC negotiations over the last ten years, as a policy tool to reduce forest related emissions, including on measurement, safeguards and eligibility for results-based finance. In order for developing countries to access results-based finance for REDD+ emissions reductions or enhanced removals of carbon from the atmosphere, they need to have in place:

- A national strategy or action plan

- A national forest monitoring system

- A safeguards information system and a summary of information on how the REDD+ safeguards have been addressed and respected

- A forest reference emissions level or forest reference level

- Fully measured, reported and verified results, in terms of emission reductions/enhanced removals.

These requirements place some constraints on the potential for REDD+ implementation in the short term, for example the speed at which policies can be put in place and governance improvements can be implemented. The availability of finance, whether domestic or international, to cover the upfront costs of REDD+ measures will also be a determining factor. Results-based finance, by its nature, will be released only after success has been achieved. Many developing countries have expressed their interest in largescale forest-related actions, both in their INDCs and a range of other statements.

The theoretical emissions reduction potential has been assessed for Africa, Asia-Pacific, and Latin America and the Caribbean and is broadly in the range $2.7-3.3 \mathrm{GtCO}_{2}$ in 2030 for each region. However, the realization of this theoretical potential will be significantly constrained by economic and land-use factors. 


\section{Chapter 1}

\section{Scoping the 2015 report}

Lead authors: John Christensen (UNEP DTU Partnership), Paul Burgon (independent consultant)

\subsection{Moving towards a new international climate change agreement}

The year 2015 has the potential to become a turning point in global efforts to transform the prevailing economic development paradigm into a more sustainable one.

All UN member countries reached agreement in September 2015 on a set of 17 sustainable development goals (SDGs) to be achieved by 2030 . The main political instrument to address SDG 13 - "Take urgent action to combat climate change and its impacts" - is the United Nations Framework Convention on Climate Change (UNFCCC). Countries will meet again at the UNFCCC $21^{\text {st }}$ Conference of the Parties (COP 21) in Paris with the aim of establishing a new international climate change agreement, hereafter the 'Paris Agreement', with the ambition of limiting changes in global temperatures to below $2^{\circ} \mathrm{C}$ or $1.5^{\circ} \mathrm{C}$ warming in 2100 compared to pre-industrial levels. The decision "[...] to adopt a protocol, another legal instrument or an agreed outcome with legal force under the Convention applicable to all Parties" originated at COP 17 in Durban (Decision 1/CP.17) and has been confirmed most recently at COP 20 in Lima (Decision 1/CP.20) (UNFCCC, 2014).

As the foundation for a new agreement, and reiterating decisions of COP 19 in Warsaw, the 'Lima Call for Climate Action' requested each Party "[...] to communicate to the secretariat its intended nationally determined contribution [INDC] towards achieving the objective of the Convention as set out in its Article 2" (UNFCCC, 1992) ${ }^{1}$ ensuring that these are submitted "[...] well in advance of the twenty-first session of the Conference of the Parties [...] in a manner that facilitates the clarity, transparency and understanding

1 Article 2 states "The ultimate objective of this Convention and any related legal instruments that the Conference of the Parties may adopt is to achieve, in accordance with the relevant provisions of the Convention, stabilization of greenhouse gas concentrations in the atmosphere at a level that would prevent dangerous anthropogenic interference with the climate system. Such a level should be achieved within a time frame sufficient to allow ecosystems to adapt naturally to climate change, to ensure that food production is not threatened and to enable economic development to proceed in a sustainable manner" (UNFCCC, 1992) of the intended nationally determined contributions" (UNFCCC, 2014).

The architecture of a new climate agreement has many facets relating to mitigation and adaptation, and the array of issues under negotiation has become significantly more complex since the Convention was established. The Paris Agreement will also aim to establish a framework to enhance capacity building and provide technological and financial support for developing countries to accelerate the transition towards low carbon and climate resilient development paths. A number of key decisions related to these issues will be required, while the core structure of the agreement will be based on the INDCs.

\subsection{Key questions}

Subsequent to COP 15, UNEP has produced an annual Emissions Gap Report presenting an up-to-date assessment of how actions, pledges and commitments by countries affect the global GHG emissions trend and how this compares to emissions trajectories consistent with the goal of keeping temperatures below $1.5^{\circ} \mathrm{C}$ or $2^{\circ} \mathrm{C}$ by 2100 . The difference has become known as the emissions gap, calculated for specific target years.

This year, UNEP was requested by a number of countries to undertake an independent scientific assessment of the INDC submissions to inform the political process. The UNFCCC Secretariat has undertaken the formal compilation for COP 21.

The 2015 UNEP Emissions Gap Report asks four principal questions:

i) What are the latest estimates of 2025 and 2030 total global emissions levels consistent with the goal of holding the global average temperature rise below $2^{\circ} \mathrm{C}$ or $1.5^{\circ} \mathrm{C}$ above pre-industrial levels by 2100 ?

ii) What is the progress on implementation of the Cancun pledges for the period to 2020?

iii) Will the combined INDC commitments for 2030 
(if fully implemented) be sufficient to stay within the range consistent with the $2^{\circ} \mathrm{C}$ temperature goal?

iv) What are possible contributions in selected key areas, where action can be accelerated to enhance the ambition of national pledges both in the period before and after the expected entry into force in 2020 of the Paris Agreement? This year the detailed assessment is on possible mitigation contributions from International Cooperative Initiatives (ICls) and enhanced forest-related mitigation activities with a focus on Reducing Emissions from Deforestation and Forest Degradation (REDD+).

\subsection{Aim of the report and assessment principles}

This is the sixth UNEP Emissions Gap Report and while the focus of the assessment has gradually shifted from initially examining the emissions gap in 2020 to focusing on 2030, the scientific basis has remained firmly based on the best available analysis worldwide.

The objective of the report remains the same, which is to assess the global progress towards the emissions reductions required to be on track towards the agreed target of limiting global average temperature increase to below $2^{\circ} \mathrm{C}$ by the end of the century compared to pre-industrial levels. In parallel, the report assesses the possible actions to be taken to achieve the necessary reductions and how these can be accelerated and scaled up to close the gap between the target and actual emissions trends - a constant feature of this series of reports.

\subsection{INDC Assessment process}

The INDC assessment team's approach has been to assess the impacts of the INDCs on future global GHG emissions. Global GHG emissions in 2025 and 2030 are compared under four scenarios - the baseline scenario (assuming no additional climate policies since 2010), the current policy trajectory scenario (includes currently adopted and implemented policies), the INDC scenario (how global GHG emissions might evolve with full implementation of the INDCS) and the $2^{\circ} \mathrm{C}$ scenario (representing an idealized global scenario consistent with limiting warming to below $2^{\circ} \mathrm{C}$ by 2100 , keeping the option open to strengthen the global temperature target to $1.5^{\circ} \mathrm{C}$ ). Each scenario is a composite in the sense that it draws on multiple individual scenarios from the published literature. The emissions gap is estimated as the difference between the INDC scenario and the $2^{\circ} \mathrm{C}$ scenario.

The approach to the assessment is characterized by the following principles:

i) For nationally-generated data, assessment is based on the figures directly available in the officially submitted INDCs

ii) For independently-generated data, assessment is based on peer-reviewed published analyses (or on related outputs) by independent modelling groups/ analysts based on the analysis of the information available in the INDCs

iii) Participation of a balanced team of experts in the INDC assessment (by gender, professional and sectoral background, institutional affiliation and geographical location).

In the process of preparing the Report and the INDC assessment, experts have frequently debated differences in understanding of assumptions (such as forms of mitigation contribution, conditional versus unconditional INDCs, use of international market mechanisms and treatment of the land use sector). By scrutinising assumptions (used by governments, independent modelling groups and international bodies), the team has been able to resolve many inconsistencies which, in turn, has led to increased confidence in the accuracy and validity of results.

\subsection{Organization of the report}

The report comprises six chapters - this first one scoping the outline, with subsequent ones falling under two main parts of the report.

Part I comprises Chapters 2 and 3. Chapter 2 focuses on the importance of enhanced pre-2020 mitigation action. It starts by presenting recent estimates for global emission levels and assesses pathways consistent with the $2^{\circ} \mathrm{C}$ and $1.5^{\circ} \mathrm{C}$ temperature goals, based on the latest available literature. It then explains why enhanced early action matters and outlines the implications of not enhancing action, followed by a review of progress with current 2020 pledges. Chapter 3 assesses the 119 INDCs, covering 146 countries, submitted by 1 October 2015, with a specific focus on the extent to which the INDCs in aggregate contribute to a reduction in global GHG emissions consistent with limiting average global temperature increase to below $2^{\circ} \mathrm{C}$ in 2100 with $>66$ per cent chance. The chapter quantifies an emissions gap - the gap in 2025 and 2030 between future emission levels with the INDCs fully implemented and the emission levels consistent with the temperature goals of $1.5^{\circ} \mathrm{C}$ and $2^{\circ} \mathrm{C}$ in 2100 .

PART II explores some of the opportunities for narrowing and potentially bridging the estimated emissions gap in 2030 . It starts with an overview of key issues and potentials for reducing GHG emissions by 2030, based on an assessment of a number of recent studies. This is followed by two focal chapters. Chapter 5 assesses the possible contribution to global mitigation efforts by key International Cooperative Initiatives (ICls) led by actors other than the Parties to the UNFCCC. Finally, Chapter 6 reviews a range of forest-related mitigation activities and identifies the technical potential for both $\mathrm{CO}_{2}$ emissions reductions and sequestration from these activities in developing countries, and with a special focus on REDD+.

As in previous editions, this year's Report has been put together by an international team of top scientists. This year 42 scientists from 24 scientific groups in 18 countries have contributed to the report. 


\section{Chapter 2}

\section{The importance of pre-2020 action}

Section 2.2:

Lead author: Joeri Rogelj (International Institute for Applied Systems Analysis)

Contributing authors: Kejun Jiang (Energy Research Institute), Jason Lowe (Met Office), Greet Maenhout (Joint Research Centre, European Commission), Steven Smith (Pacific Northwest National Laboratory)

Section 2.3:

Lead authors: Taryn Fransen (World Resources Institute), Michel den Elzen (PBL Netherlands Environmental Assessment Agency), Hanna Fekete (NewClimate Institute), Niklas Höhne (NewClimate Institute)

Contributing authors: Mengpin Ge (World Resources Institute), Heleen van Soest (PBL Netherlands Environmental Assessment Agency)

\subsection{Introduction}

This Chapter first discusses recent global emission levels and trends, and reviews where global emissions would be heading in the absence of additional deliberate climate policies. It then presents assessment of global emission pathways that would keep global warming to below respectively $1.5^{\circ} \mathrm{C}$ or $2^{\circ} \mathrm{C}$ in 2100 . This is followed by an elaboration of why enhanced early action matters and a discussion of the implications of not increasing short-term climate mitigation efforts.

Achievement of the Cancun 2020 pledges will be important for the transition to least-cost mitigation pathways from 2020. Section 2.3 therefore takes a closer look at progress towards achieving the 2020 pledges. The focus is on the Parties that are members of the G20, as these economies collectively generate around three quarters of global GHG emissions. However, it remains critical that all countries advance as far as possible towards achieving - and ideally exceeding - their Cancun pledges.

\subsection{Global emission pathways and the importance of enhanced action}

\subsubsection{Recent trends and baselines}

Over the past decades, global GHG emissions have increased steadily with small variations around a longer term trend. Moreover, during the first decade of the $21^{\text {st }}$ century, emissions increased at a faster rate (2.2 per cent/yr) than during the last three decades of the $20^{\text {th }}$ century (1.3 per cent/yr) (IPCC, 2014a). After the recovery from the economic crisis (with a 3.5 per cent increase in 2010-2011), the emissions growth slowed to 1.8 per cent on average over the subsequent two years ${ }^{1}$. The most recent global emission estimates ${ }^{2}$ are for the year 2014. In that year, total global Kyoto-GHG emissions ${ }^{3}$ amounted to about $52.7 \mathrm{GtCO}_{2} \mathrm{e} / \mathrm{yr}$ (range: 47.9-57.54, Figure 2.1). Global carbon dioxide $\left(\mathrm{CO}_{2}\right)$ emissions from fossil fuels and industry alone were estimated at $35.5 \mathrm{GtCO}_{2} / \mathrm{yr}^{5}$ for 2014 (range: $32.5-38.5^{6}$ ).

In the absence of any further mitigation action compared to these trends, GHG emission projections are set to increase significantly over the $21^{\text {st }}$ century. These projections are influenced by many factors. For example, economic and population growth will generally result in an increase in emissions, while energy intensity improvements in the global economy and reductions of carbon intensity in energy production will generally result in a decrease in emissions. These factors have characterized the last three decades of the $20^{\text {th }}$ century. During the first decade of the $21^{\text {st }}$ century, however, carbon intensity increased again, thus further contributing to rising global emissions.

1 Based on EC-JRC/PBL. EDGAR version 4.3. http://edgar.jrc.ec.europa.eu/, 2015 update (forthcoming).

2 Data for this year is available from EDGAR and PRIMAP.

Sources: EC-JRC/PBL. EDGAR version 4.3. http://e gar.jrc.ec.europa.eu/, 2015 update (forthcoming), PRIMAP4 baseline: PIK-Potsdam. https://www. pik-potsdam.de/research/climate-impacts-and-vulnerabilities/research/rd2flagship-projects/primap/emissions-module

3 Here aggregated with 100-year Global Warming Potentials (GWPs) of the IPCC Second Assessment Report.

490 per cent confidence interval, based on the uncertainty range assessed in IPCC AR5 Working Group III.

5 Source: BP Statistical Review of World Energy June 2015, http://www. bp.com/statisticalreview

95 per cent uncertainty range, based on Andres et al. (2014). 
Figure 2.1: Historical greenhouse gas (GHG) emissions and projections until 2050

\section{Kyoto-GHG emissions \\ $\left(\mathrm{GtCO}_{2} \mathrm{e} / \mathrm{yr}\right)$}

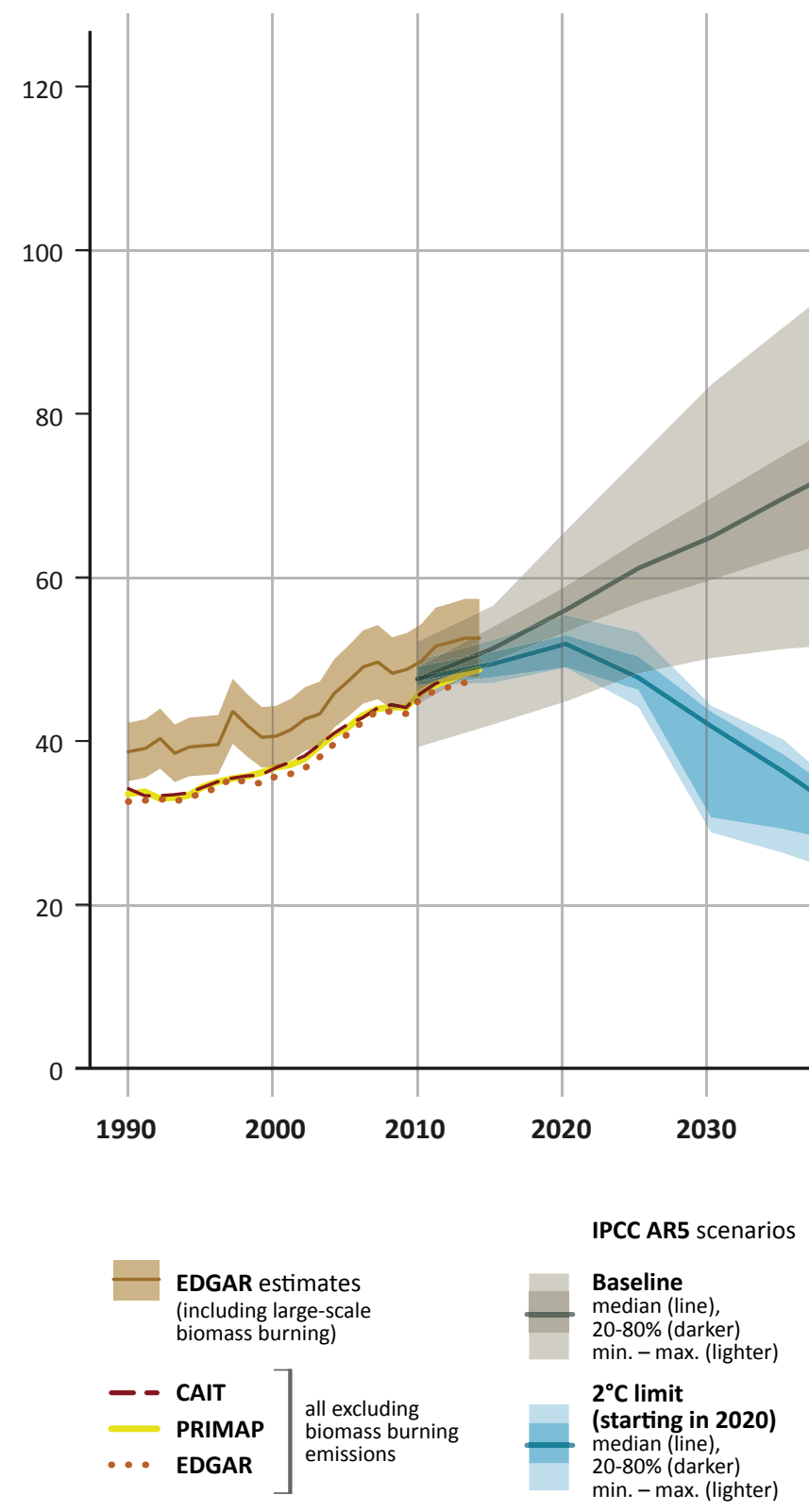

Estimated global

warming by 2100

$\left({ }^{\circ} \mathrm{C}\right.$ rel. 1850-1900)

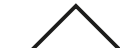

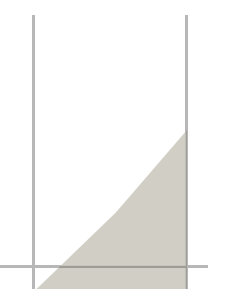

Baseline
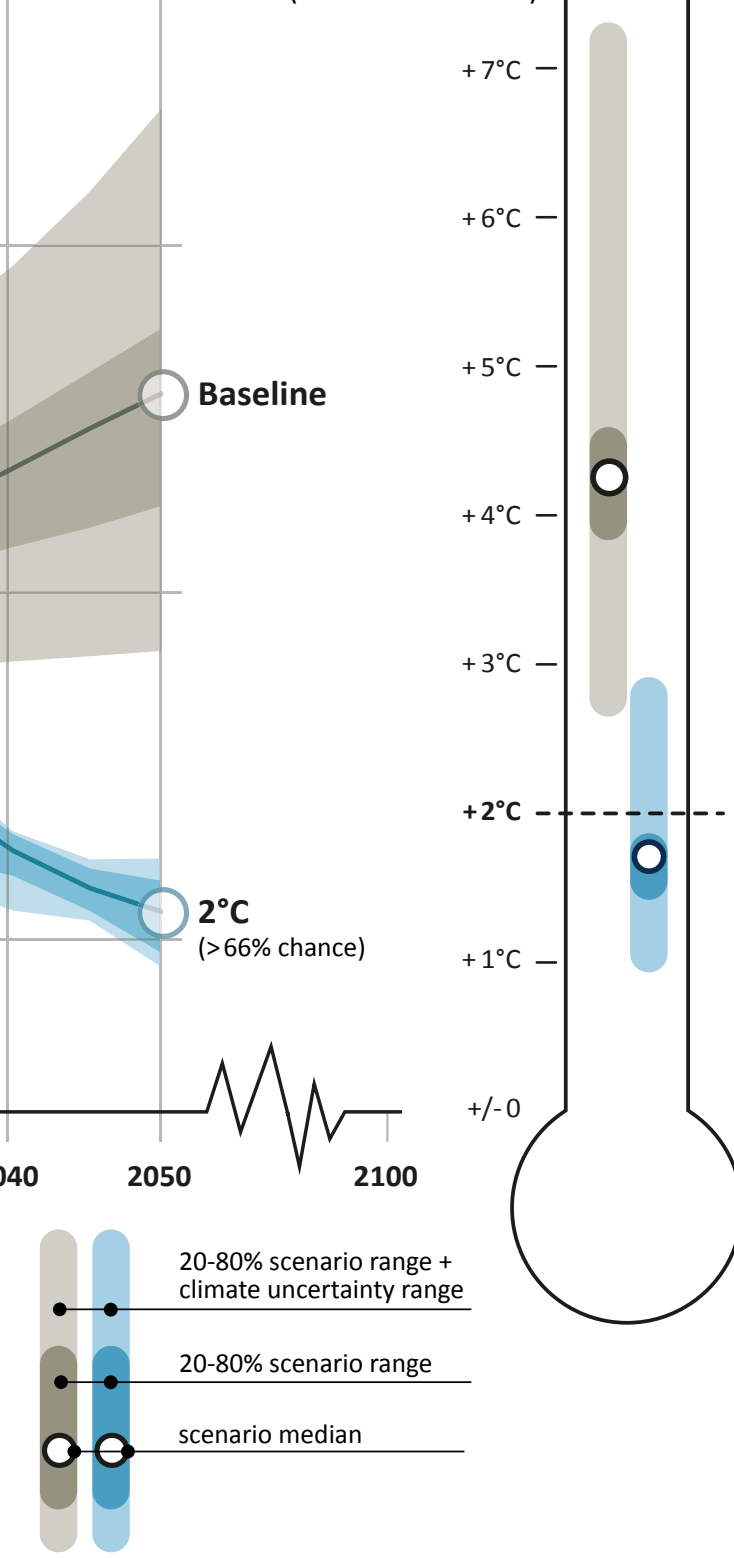

$2^{\circ} \mathrm{C}$

(>66\% chance)

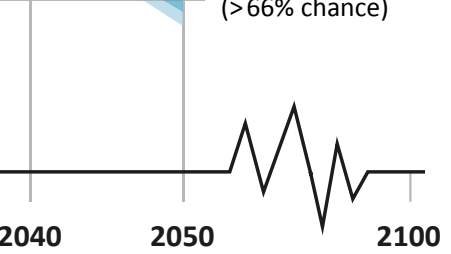

Left hand panel: Historical GHG from CAIT* (dashed line), PRIMAP** (solid line), and EDGAR*** (dotted line) - all excluding biomass-burning emissions. The solid line surrounded by the brown-shaded area shows the EDGAR estimates when including large-scale biomass burning emission estimates as in IPCC AR5 WG3****, and their overall $90 \%$ uncertainty range. Projections are drawn from the IPCC AR5 Scenario Database and show baselines (grey) and scenarios limiting warming to below $2^{\circ} \mathrm{C}$ by 2100 with at least a likely $(>66 \%)$ chance (blue). The $2^{\circ} \mathrm{C}$ scenarios start from 2020 levels and assume a global least-cost pathway afterwards. Data for these pathways can be found in Table 2.1 under label " $2{ }^{\circ} \mathrm{C}(>66 \%$ in 2100 )", along with other temperature target definitions. For each subset the median (solid line), the $20-80 \%$ range (dark) and the min-max range (lighter) of Kyoto-GHG emissions are shown.

Right hand panel: Estimated global temperature increase in 2100 of both scenario subsets. The climate uncertainty represents the $90 \%$ range of carbon-cycle and climate response uncertainty, as used in the IPCC AR5 WGIII assessment. Kyoto-GHG emissions are aggregated using 100-year Global Warming Potentials reported in the IPCC Second Assessment Report.

SOURCES:

* CAIT: World Resource Institute (WRI). http://www.wri.org/resources/data-sets/cait-historical-emissions-data-countries-us-states-unfccc

** PRIMAP4 baseline: Potsdam Institute for Climate Impact Research (PIK). https://www.pik-potsdam.de/research/climate-impacts-and-vulnerabilities/research/ rd2-flagship-projects/primap/emissions-module

*** EDGAR: European Commission, Joint Research Centre (JRC)/ Netherlands Environmental Assessment Agency (PBL). Emission Database for Global Atmospheric Research (EDGAR) version 4.3. http://edgar.jrc.ec.europa.eu/, 2015 update (forthcoming), (Olivier and Janssens-Maenhout, 2012).

$* * * *$ based on updates of van der Werf et al. (2010). 
A projection of GHG emissions and their driving factors in the absence of dedicated climate policies is often referred to as a 'baseline'. In the IPCC Fifth Assessment Report (Clarke et al., 2014), baselines are defined as "not to include climate policy after 2010"7. In such baselines, GHG emissions are expected to increase to about $70-90 \mathrm{GtCO}_{2} \mathrm{e} / \mathrm{yr}$ in $2050^{8}$, and in most cases global warming would exceed $4^{\circ} \mathrm{C}$ by the end of the century, as indicated in Figure 2.1.

\subsubsection{Pathways towards $1.5^{\circ} \mathrm{C}$ and $2^{\circ} \mathrm{C}$}

In 2014, the UNEP Emissions Gap Report described how global temperature levels are linked to so-called carbon dioxide emission budgets, and how these budgets, in line with holding warming to below $2^{\circ} \mathrm{C}$, can be spread over time (UNEP, 2014). While these budgets remain useful and valid benchmarks, this year's analysis uses emission scenario data compiled for the IPCC AR5 ${ }^{9}$ to further explore the timing of reaching global net zero emissions and the evolution of annual GHG emissions over time. Data from a recent scientific study that described pathways that limit warming to below $1.5^{\circ} \mathrm{C}$ by 2100 were also included ${ }^{10}$.

Pathway characteristics for both $1.5^{\circ} \mathrm{C}$ and $2^{\circ} \mathrm{C}$ scenarios are provided in Table 2.1. These show pathways with limited action until 2020 and global least-cost mitigation afterwards. These are in line with current policy trajectories (see Section 2.3 and Chapter 3 ), which suggest that the global community did not enhance its mitigation action from 2010 aligned with long-term least-cost $1.5^{\circ} \mathrm{C}$ or $2^{\circ} \mathrm{C}$ pathways from 2010 onward (UNEP, 2014). Therefore, the scenarios used in this year's report assume global emissions in 2020 that are roughly in line with the Cancun pledges for 2020 (that is, 49$56 \mathrm{GtCO}_{2} \mathrm{e}$ in 2020 as indicated in Table 2.1). Furthermore, the pathways shown allow temperatures to 'overshoot' - that is, to temporarily exceed the $2^{\circ} \mathrm{C}$ limit before falling below it again by $2100^{11}$. These pathways do not represent the only possibilities of limiting warming to below $1.5^{\circ} \mathrm{C}$ and $2^{\circ} \mathrm{C}$. Some level of flexibility is available for emissions falling outside the range. However, this flexibility is not infinite and enhanced pre-2020 action matters (as further discussed in Section 2.2.3).

As Table 2.1 shows all scenarios are characterized by net negative global total GHG emissions by 2100 . Looking specifically at $\mathrm{CO}_{2}$ emissions that play a dominant role in determining long-term warming as described in Box 2.1, $1.5^{\circ} \mathrm{C}$ - and $2^{\circ} \mathrm{C}$-consistent scenarios reach net zero $\mathrm{CO}_{2}$ emissions globally between 2045 and 2075 (Table 2.1). Scenarios in line with $1.5^{\circ} \mathrm{C}$ reach net zero $\mathrm{CO}_{2}$ emissions around 2050. In scenarios that keep warming to below $2^{\circ} \mathrm{C}$

7 They may or may not include Kyoto Protocol commitments until 2012.

8 Scenario-based ranges in this chapter refer to the $20^{\text {th }}$ to $80^{\text {th }}$ percentile range, unless stated otherwise.

9 In particular, the emission scenarios available in the IPCC AR5 Scenario Database were used. Temperature projections for the IPCC AR5 Scenario Database were computed with a probabilistic version of MAGICC. (Meinshausen et al., 2009; Meinshausen et al., 2011).

10 Rogelj et al. (2015a). These $1.5^{\circ} \mathrm{C}$ scenarios temporarily exceed the $1.5^{\circ} \mathrm{C}$ limit during the 21st century in order to fall below it again with $>50$ per cent chance in 2100 . This is sometimes referred to as a temperature overshoot. Insufficient data are available for assessing pathways that return warming to below $1.5^{\circ} \mathrm{C}$ by 2100 with $>66$ per cent chance.

11 Pathways for $2^{\circ} \mathrm{C}$ scenarios that do not allow overshooting (that is, where temperatures stay below $2^{\circ} \mathrm{C}$ during the 21 st century) are shown in the technical Annex A to Chapter 2, available online. with $>66$ per cent chance, the timing is of the order of one or more decades later, more specifically around 2070 (range: $2060-2075)^{12}$.

Achieving global net zero $\mathrm{CO}_{2}$ emissions is a geophysical requirement. It follows directly from the fact that to limit warming to any level, total net $\mathrm{CO}_{2}$ emissions need to be capped, and from the fact that, up to the present day, global $\mathrm{CO}_{2}$ emissions are still rising ${ }^{13}$. In theory, a small set of scenarios is able to limit warming to below $2^{\circ} \mathrm{C}^{14}$ without achieving net negative emissions by 2100 (UNEP, 2014). However, these scenarios all start stringent, global mitigation before 2020 (see also Section 2.2.3), which is no longer considered realistic. Without exception, all $1.5^{\circ} \mathrm{C}$ scenarios available in the literature reach net negative $\mathrm{CO}_{2}$ emissions by mid-century, even with stringent mitigation action having started in 2010.

In most scenarios, global net zero and negative emissions are achieved by the use of so-called negative emission technologies that offset any residual positive emissions. Such negative emissions might be achieved on a large scale, for example, by massive afforestation or by combining bioenergy with capture and storage of $\mathrm{CO}_{2}$. Bio-energy combined with capture and geological storage of $\mathrm{CO}_{2}$ has been studied increasingly over the past decade, but uncertainties about its large-scale deployment remain (see Annex A for details).

Compared to $2^{\circ} \mathrm{C}$ pathways, significantly fewer studies have explored pathways that limit warming to $1.5^{\circ} \mathrm{C}$ (Clarke et al., 2014). Findings for the very stringent $1.5^{\circ} \mathrm{C}$ limit are therefore less robust. However, one scientific review of $1.5^{\circ} \mathrm{C}$ scenarios (Rogelj et al., 2015a) found that such scenarios are in many aspects similar to $2^{\circ} \mathrm{C}$-consistent scenarios, but that they are characterized by faster emissions reductions in the near term (in 2020 and 2030). Compared to $2^{\circ} \mathrm{C}$, the rapid and profound decarbonization of the energy system in $1.5^{\circ} \mathrm{C}$ scenarios is driven by earlier reductions in the power sector, important efforts to limit energy demand in the industry, buildings, and transport sector; and no delays in global mitigation action beyond 2020. This more rapid transformation translates into significantly higher costs. For example, carbon prices are about two or three times higher in $1.5^{\circ} \mathrm{C}$ scenarios than in scenarios that keep warming to below $2^{\circ} \mathrm{C}$ with $>66$ per cent chance (Rogelj et al., 2015a).

\subsubsection{Why enhanced early action matters}

Enhanced early action facilitates the transition to the stringent, long-term emission reductions required for limiting warming to below $1.5^{\circ} \mathrm{C}$ and $2^{\circ} \mathrm{C}$. It would enable countries i) to overachieve their current pledges by 2020 ,

12 These numbers differ from the ones presented in the 2014 Emissions Gap Report (UNEP, 2014, Table 2.1), where the median year and range of annual net global $\mathrm{CO}_{2}$ emissions including LULUCF becoming zero was indicated as 2065 (range: 2055-2070). The reason is that this year the final IPCC AR5 Scenario Database data are used, whereas the estimate last year was based on a preliminary release of the IPCC AR5 scenarios database data. In addition, this year the estimate is corrected for sampling bias by removing scenarios that do not represent a variation at the global level, but only represent a variation in the regional burden sharing scheme. See Annex A, available online, for technical details.

13 See Rogelj et al. (2015b) for a detailed discussion.

14 Both with a $>66$ per cent or $>50$ per cent chance, based on the IPCC AR5 Scenario Database. 
Box 2.1: The global carbon dioxide $\left(\mathrm{CO}_{2}\right)$ budget, non- $\mathrm{CO}_{2} \mathrm{GHGs}$ and the link to global warming Limiting warming to any desired level requires a cap on total, cumulative anthropogenic $\mathrm{CO}_{2}$ emissions. Working Group I of the IPCC (IPCC, 2013) showed that global mean temperature increases are almost directly proportional to cumulative carbon dioxide emissions since the pre-industrial period. This leads to the important conclusion that there is a maximum amount of carbon dioxide emissions, or a $\mathrm{CO}_{2}$ budget, that can be discharged to the atmosphere over time if society wishes to stay within a $2^{\circ} \mathrm{C}$ or other global warming limit. The IPCC indicated that to limit warming to below $2^{\circ} \mathrm{C}$ with a 'likely chance' (that is $>66 \%$ chance) by the end of the century, about $1000 \mathrm{GtCO}_{2}$ of $\mathrm{CO}_{2}$ emissions remained 'in the budget' from 2011 onward* (IPCC, 2014b; Knutti and Rogelj, 2015). To keep $\mathrm{CO}_{2}$ emissions within such a budget allowance, annual global $\mathrm{CO}_{2}$ emissions have to become zero at some point during the $21^{\text {st }}$ century. This is a geophysical requirement that applies regardless of the budget level chosen. For non- $\mathrm{CO}_{2} \mathrm{GHGs}_{\text {with }}$ a shorter lifetime in the atmosphere, such as methane, the levels of emissions that are emitted per year are more important than the cumulative amount**. Reducing their annual emissions is also important to limit global mean temperature increase to low levels. Table 2.1 indicates the year of global annual emissions becoming net zero for each of the pathways considered.

* This number is accompanied by an uncertainty range, which depends on the concurrent mitigation of non- $\mathrm{CO}_{2} \mathrm{GHGs}_{\text {. }}$

** This is approximately true, as for non- $\mathrm{CO}_{2}$ GHGs that stay in the atmosphere for quite a while (for example, $\mathrm{N}_{2} \mathrm{O}$ has an atmospheric lifetime of 121 years) there is also a more limited cumulative effect. See, for example, Smith et al. (2012).

Table 2.1: Overview of pathway characteristics of $1.5^{\circ} \mathrm{C}$ and $2^{\circ} \mathrm{C}$ scenarios based on a re-analysis of the IPCC AR5 Scenario Database and a recent study on $1.5^{\circ} \mathrm{C}$ scenarios ${ }^{15}$.

All scenarios have prescribed 2020 emissions consistent with the GHG pledges made by Parties in Cancun in 2010, and hence do not represent least-cost emission levels until then. All available scenarios with limited action until 2020 rely on net negative $\mathrm{CO}_{2}$ emissions from energy and industry during the $21^{\text {st }}$ century. Most scenarios with such specifications were contributed to the IPCC AR5 Scenario Database by the LIMITS intercomparison project ${ }^{16}$. Note that this table provides data for limiting warming below $1.5^{\circ} \mathrm{C}$ and $2^{\circ} \mathrm{C}$ in 2100 . Further information is provided in the Tables of Annex A (available online)

\section{Limiting warming in 2100 (allowing for overshoot) \\ $1.5^{\circ} \mathrm{C}(>50 \%$ in 2100$)$

Number of available scenarios: 6 ; Number of contributing modelling frameworks: 2

Year of global annual emissions becoming net zerot for:

Kyoto-GHGs: (2060-2080); total $\mathrm{CO}_{2}$ (including LULUCF): (2045-2050); $\mathrm{CO}_{2}$ from energy and industry: (2045-2055)

\begin{tabular}{|l|l|l|l|l|l|}
\hline \multicolumn{7}{|l|}{ Annual emissions of global total greenhouse gases [GtcO } \\
\hline
\end{tabular}

\section{$2^{\circ} \mathrm{C}\left(>66 \%\right.$ in 2100) $\quad$ Pathways limiting warming to below $2^{\circ} \mathrm{C}$ by 2100 with $>66 \%$ chance}

Limited action until 2020 and least-cost mitigation afterwards

Number of available scenarios: 10; Number of contributing modelling frameworks: 4

Year of global annual emissions becoming net zerot for:

Kyoto-GHGs: 2085 (2080-2090); total $\mathrm{CO}_{2}$ (including LULUCF): 2070 (2060-2075); $\mathrm{CO}_{2}$ from energy and industry: 2070 (2060-2075)

\begin{tabular}{|c|c|c|c|c|c|}
\hline \multirow[b]{2}{*}{ Year } & \multicolumn{5}{|c|}{ Annual emissions of global total greenhouse gases [GtCO2e/yr] } \\
\hline & 2020 & 2025 & 2030 & 2050 & 2100 \\
\hline median* & 52 & 48 & 42 & 23 & -3 \\
\hline range and spread** & $49(49 / 53) 55$ & $44(46 / 50) 53$ & $29(31 / 44) 44$ & $17(18 / 27) 29$ & $-11(-9 /-1) 0$ \\
\hline $2^{\circ} \mathrm{C}(50-66 \%$ in 2100$)$ & $\begin{array}{l}\text { Pathways limiting } \mathrm{w} \\
\text { Limited action until }\end{array}$ & $\begin{array}{l}\text { to below } 2^{\circ} \mathrm{C} \mathrm{b} \\
\text { id least-cost } \mathrm{m}\end{array}$ & $\begin{array}{l}\text { with } 50-66 \% \mathrm{cl} \\
\text { n afterwards }\end{array}$ & & \\
\hline
\end{tabular}

Number of available scenarios: 4; Number of contributing modelling frameworks: 2

Year of global annual emissions becoming net zerot for:

Kyoto-GHGs: (2095-2095); total $\mathrm{CO}_{2}$ (including LULUCF): (2065-2070); $\mathrm{CO}_{2}$ emissions from energy and industry: (2070-2080)

\begin{tabular}{|l|l|l|l|l|l|}
\hline & \multicolumn{4}{|l|}{ Annual emissions of global total greenhouse gases [GtCO 2 e/yr] } \\
\hline Year & 2020 & 2025 & 2030 & 2050 & 2100 \\
\hline median* & $\mathbf{5 3}$ & $\mathbf{5 0}$ & $\mathbf{4 7}$ & $\mathbf{2 8}$ & $\mathbf{- 1}$ \\
\hline range and spread** & $50(-/-) 55$ & $49(-/-) 51$ & $46(-/-) 48$ & $27(-/-) 29$ \\
\hline
\end{tabular}

+ Rounded to nearest 5 years. Explanation of format: 'median ( $20^{\text {th }}$ percentile $-80^{\text {th }}$ percentile $)^{\prime}-$ for example, '2085 (2080-2090)'; no median is provided if fewer than 10 scenarios are available '(minimum-maximum)' - for example, '(2060-2080)'.

* Rounded to the nearest $1 \mathrm{GtCO}_{2} \mathrm{e} / \mathrm{yr}$.

** Rounded to the nearest $1 \mathrm{GtCO}_{2} \mathrm{e} / \mathrm{yr}$. Explanation of format: 'minimum value $\left(20^{\text {th }}\right.$ percentile/ $80^{\text {th }}$ percentile) maximum value' - for example, ' $44(46 / 50) 53^{\prime}$. No percentiles are provided if fewer than 10 scenarios are available - for example, '46(-/-)48'. 
and ii) to transition towards a pathway in line with a leastcost trajectory after 2020. By making the shift in emissions less abrupt, enhanced pre-2020 and pre-2030 action reduces the so-called transitional challenges (see below). Furthermore, to keep the door open for limiting warming to below $1.5^{\circ} \mathrm{C}$ by 2100 , enhanced early action seems essential. Previous reports (UNEP, 2012, 2013, 2014) provided detailed discussion of the trade-offs between early and late action. Three main areas of importance with respect to enhanced early action were highlighted in particular:

1. Economics and technology, where enhanced early action will:

- mediate the requirement for very steep emission reductions in the medium term

- facilitate mitigation in the medium to long term by reducing lock-in of carbon and energy intensive infrastructure in the energy system and society as a whole

- spur near-term learning and development of technologies that will be essential in the long term

- provide early policy signals which are needed for action in the following decades

- reduce the overall costs and economic challenges during the transitional period, for example, in terms of upscaling of energy investments

- reduce the dependence on unproven technologies such as negative emissions technologies ${ }^{17}$ and increase the options society can choose from to achieve stringent emission reductions.

2. Climate outcomes: Enhanced early action will reduce climate risks, for example, by influencing the rate of temperature increase (Schaeffer et al., 2013; Ricke and Caldeira, 2014).

3. Co-benefits: Enhanced early action will enable the realisation of near-term co-benefits of climate change mitigation, such as improved public health as a result of lower air pollution, improved energy security, and reduced crop yield losses ${ }^{18}$.

The issue of lock-in is very important in a number of ways. Even with enhanced early action, it is projected that carbon intensive infrastructure, such as unabated coal-fired power plants, will have to be shut down before the end of their lifetime in some stringent mitigation scenarios, and delay exacerbates this (Rogelj et al., 2013; Johnson et al., 2015). Furthermore, delay also locks in energy intensive practices. Limiting energy demand is critical to keep stringent mitigation targets within reach (Clarke et al., 2014). Furthermore, the transition to a low energy-demand society is also inhibited by delays of action, as more energy intensive infrastructure continues to be built up. Infrastructure lock-in makes the transition to a low-carbon path harder.

17 Enhanced early action is important in reducing dependence on negative emissions in the long term for achieving stringent climate targets like $2^{\circ} \mathrm{C}$. However, there are no scenarios available that return warming to below $1.5^{\circ} \mathrm{C}$ by 2100 , without the use of bio-energy combined with capture and geological storage of $\mathrm{CO}_{2}$

18 Note that the IPCC AR5 also identified adverse side-effects of climate change mitigation, which will have to be considered simultaneously.
Enhanced early action is thus important. As described above, overachievement of the 2020 pledges will improve the chances for the stringent emission reductions that are required post-2020 ( Rogelj et al., 2013; Clarke et al., 2014).

\subsection{Progress towards the 2020 pledges: a closer look at major economies}

Section 2.2 underlined the importance of pre-2020 mitigation action to achieving consistency with the below $2^{\circ} \mathrm{C}$ by 2100 scenarios. It is critical that all countries, and particularly the highest-emitting economies, advance as far as possible towards achieving - and ideally exceeding - their Cancun pledges. This section takes a closer look at progress towards achieving these 2020 pledges, focusing on the parties that are members of the $\mathrm{G}_{20} \mathrm{O}^{19}$. These economies collectively generate around three quarters of global GHG emissions ${ }^{20}$.

\subsubsection{Assessment of G20 countries' 2020 emissions under three cases}

The section compares current emissions trajectories of G20 members with the trajectories associated with the achievement of these Parties' 2020 pledges. It should be read with three important caveats in mind. First, not all pledges demand the same level of effort to achieve. In other words, a country currently on track to achieve its pledge has not necessarily made a greater effort to mitigate emissions than a country not yet on track ${ }^{21}$. Secondly, these projections are subject to the uncertainty associated with macroeconomic trends, such as changes in gross domestic product (GDP), as well as the impact of policies. Thirdly, the emission trajectories analysed here do not quantify the potential impact of using offsets to achieve pledges. If offsets are traded internationally, and are counted towards the pledges of both buying and selling parties, the global impact of the pledges will be weakened. Most countries have not clarified their intentions concerning use of offsets to meet their 2020 pledges. Australia, Brazil, Canada, the European Union, and the United States have explicitly not excluded the possibility; others have not formally commented (CAIT WRI, 2015).

Table 2.2 compares 2020 emissions under three cases: a pledge case, based on official data; a current policy trajectory case, based on official data; and a current policy trajectory case, based on independent analysis. These cases are described in Box 2.2.

19 The members of the G20 are Argentina, Australia, Brazil, Canada, China, France, Germany, India, Indonesia, Italy, Japan, Republic of Korea, Mexico, Russia, Saudi Arabia, South Africa, Turkey, the UK, the USA, and the EU. In our analysis, the EU including all its Member States (regardless of G20 status) is considered as a single Party, and EU Member States are not considered individually. In general, evaluating the pledges of other countries is limited by a lack of data.

20 In 2012, these parties accounted for 77 per cent of global emissions excluding LULUCF and 75 per cent of global GHG emissions including LULUCF (CAIT WRI, 2015).

21 See Appendix 2.D of the 2013 UNEP Emissions Gap Report (UNEP, 2013) for further discussion of this issue. 


\section{Box 2.2: Assumptions of analysis of progress towards pledges}

For each country or Party, Table 2.2 compares estimates for 2020 emissions under three cases:

1. Pledge case (official data): Identifies the maximum level of GHG emissions that each country or Party could emit in 2020 and still meet its pledge - without considering the use of offsets. If a pledge is presented as a range (Brazil, China and India), the less ambitious end of the range is adopted as the official pledge estimate. If a country has both a conditional and unconditional pledge (Indonesia), only the unconditional pledge is used. If a country has only a conditional pledge (Mexico, South Africa), the conditional pledge is used. For countries whose pledges are framed relative to a baseline scenario, it is assumed that baselines are not adjusted in the future. For countries whose pledges are framed as GHG intensity targets, economic growth consistent with official projections is assumed ${ }^{22}$. Where available, the 2020 emission level described by the country or Party as the pledge level is used; alternatively, these levels are calculated working from official base-year or baseline data.

2. Current policy trajectory case (official data): Identifies official estimates of 2020 emissions considering projected economic trends and current policy approaches, including policies at least through 2012.

3. Current policy trajectory case (independent analysis): Similarly identifies estimates of 2020 emissions considering the best current estimates of projected economic trends and current policy approaches, but is based on independent analysis rather than official data. Figures are drawn from the Climate Action Tracker (CAT, 2015) and den Elzen et al. (2015) for all countries, as well as other, country-specific sources where noted. Current policy trajectory (independent analysis) supplements the official sources described in point two by providing data that aim for consistency across countries and political independence.

Projections only consider a limited subset of sectors and gases, for example, $\mathrm{CO}_{2}$ emissions from fossil fuels are omitted, as they cannot be compared to projections and targets that include the full set of GHGs across the entire economy.

22 For China, GDP is assumed to reach 61.6 trillion yuan in 2020, consistent with China's National Communication (People's Republic of China, 2012). For India, GDP is assumed to reach 120.41 trillion rupees ('06-'07 rupee value) in 2020, consistent with the average of the scenarios presented in Planning Commission Government of India (2014). 
Table 2.2: Emissions in 2020 under pledge case and current policy trajectory cases for $\mathrm{G} 20$ countries $\left(\mathrm{MtCO}_{2} \mathrm{e}\right)^{23}$

\begin{tabular}{|c|c|c|c|c|}
\hline Parties & $\begin{array}{l}2020 \text { Pledge Case } \\
\text { (based on official } \\
\text { data) }\end{array}$ & $\begin{array}{l}\text { Current Policy } \\
\text { Trajectory } \\
\text { (based on official data) }\end{array}$ & $\begin{array}{l}\text { Current Policy Trajectory } \\
\text { (based on independent } \\
\text { estimates) }{ }^{24}\end{array}$ & $\begin{array}{l}\text { Mitigation pledge and current policy } \\
\text { trajectory details }\end{array}$ \\
\hline Australia & $\begin{array}{l}530^{\mathrm{a}} \\
(\mathrm{DoE}, 2015)\end{array}$ & $\begin{array}{l}655^{\mathrm{a}} \\
\text { (DoE, 2015) }\end{array}$ & $\begin{array}{l}575-580^{b} \text { (CAT, 2015) } \\
650-665^{a} \text { (den Elzen et al., } \\
2015)\end{array}$ & $\begin{array}{l}\text { Base year pledge } \\
\text { Current Policy Trajectory (official data) } \\
\text { excludes impacts of Emissions Reduction } \\
\text { Fund (ERF) (see discussion below) }\end{array}$ \\
\hline Brazil & $\begin{array}{l}2070^{\mathrm{a}} \\
\text { (Brazilian } \\
\text { Government, 2010) }\end{array}$ & N/A & $\begin{array}{l}1750-2075^{a} \text { (CAT, 2015) } \\
1470-1520^{a} \text { (den Elzen et } \\
\text { al., 2015) }\end{array}$ & Baseline scenario pledge \\
\hline Canada & $\begin{array}{l}610^{\mathrm{a}} \\
\text { (Environment Canada, } \\
\text { 2014) }\end{array}$ & $\begin{array}{l}730^{\mathrm{a}} \\
\text { (Environment Canada, } \\
\text { 2014) }\end{array}$ & $\begin{array}{l}745^{\mathrm{b}} \text { (CAT, 2015) } \\
720-760^{\mathrm{b}} \text { (den Elzen et al., } \\
2015)\end{array}$ & Base year pledge \\
\hline China* & $\begin{array}{l}14500^{\mathrm{a}} \\
\text { (People's Republic of } \\
\text { China, 2012) }\end{array}$ & N/A & $\begin{array}{l}12 \text { 200-12 600 } \\
12535-13420^{\mathrm{a}} \text { (den Elzen et } \\
\text { al., 2015) }\end{array}$ & $\begin{array}{l}\text { Intensity pledge } \\
2020 \text { Pledge Case assumes } 40 \% \text { reduction } \\
\text { in GHG intensity and } 2020 \mathrm{GDP} \text { of People's } \\
\text { Republic of China (2012), adjusted for } \\
\text { non-CO projections from CAT (2015). The } \\
\text { high end of this range is based in part on } \\
\text { China's Second National Communication } \\
\text { (People's Republic of China, 2012), which } \\
\text { considers policies only through 2010, and } \\
\text { is therefore likely to be higher than actual } \\
2020 \text { emissions }\end{array}$ \\
\hline $\begin{array}{l}\text { European } \\
\text { Union }\end{array}$ & $\begin{array}{l}4500^{b} \\
(E E A, 2014 a)\end{array}$ & $\begin{array}{l}4230^{\mathrm{b}} \\
(\mathrm{EEA}, 2015)\end{array}$ & $\begin{array}{l}4115-4375^{b} \text { (CAT, 2015) } \\
4105-4370^{b} \text { (den Elzen et } \\
\text { al., 2015) }\end{array}$ & $\begin{array}{l}\text { Base year pledge } \\
\text { Current Policy Trajectory (official data) does } \\
\text { not fully reflect all policies adopted past } \\
\text { mid-2012 }\end{array}$ \\
\hline India* & $\begin{array}{l}3815^{\mathrm{b}} \\
\text { (Planning Commission } \\
\text { Government of India } \\
2011,2014 \text { ) }\end{array}$ & N/A & $\begin{array}{l}3500-3600^{b} \text { (CAT, 2015) } \\
3535-3960^{\mathrm{a}} \text { (den Elzen et } \\
\text { al., 2015) }\end{array}$ & $\begin{array}{l}\text { Intensity pledge } \\
2020 \text { Pledge Case assumes } 20 \% \text { reduction } \\
\text { in GHG intensity per Planning Commission } \\
\text { Government of India (2011), } 2020 \text { GDP } \\
\text { per Planning Commission Government of } \\
\text { India (2014), and exclusion of the emissions } \\
\text { from agriculture and LULUCF per Planning } \\
\text { Commission Government of India (2011) }\end{array}$ \\
\hline Indonesia & $\begin{array}{l}1335^{\mathrm{a}} \\
\text { (BAPPENAS, 2015) } \\
2185^{\mathrm{a}} \\
\text { (Ministry of } \\
\text { Environment } \\
\text { Indonesia, 2010) }\end{array}$ & N/A & $\begin{array}{l}2540^{\mathrm{a}} \text { (CAT, 2015) } \\
1910-1950^{\mathrm{a}} \text { (den Elzen et } \\
\text { al., 2015) }\end{array}$ & $\begin{array}{l}\text { Baseline scenario pledge } \\
2020 \text { Pledge Case of } 1335^{\mathrm{a}} \text { is calculated } \\
\text { based on the baseline from BAPPENAS } \\
(2015)^{25} \\
2020 \text { Pledge Case of } 2185^{\mathrm{a}} \text { is calculated } \\
\text { based on the baseline from Ministry of } \\
\text { Environment Indonesia (2010) }\end{array}$ \\
\hline Japan & $\begin{array}{l}1300^{\mathrm{b}} \\
\text { (UNFCCCC, 2014) }\end{array}$ & $\begin{array}{l}1320^{\mathrm{b}} \\
\text { (UNFCCC, 2014) }\end{array}$ & $\begin{array}{l}1230-1330^{\mathrm{b}} \text { (CAT, 2015) } \\
1135-1330^{\mathrm{b}} \text { (den Elzen et } \\
\text { al., 2015) } \\
1350-1400^{\mathrm{b}} \text { (Kuramochi, } \\
\text { 2014) }\end{array}$ & Base year pledge \\
\hline Mexico & $\begin{array}{l}555^{\mathrm{a}} \\
\text { (Mexico, 2015) } \\
670^{\mathrm{a}} \\
\text { (NCCS, 2013) }\end{array}$ & $\begin{array}{l}830^{\mathrm{a}} \\
\text { (Government of Mexico, } \\
\text { 2012; SEMARNAT, 2013) }\end{array}$ & $\begin{array}{l}785-800^{\mathrm{a}} \text { (CAT, 2015) } \\
770-810^{\mathrm{a}} \text { (den Elzen et al., } \\
2015)\end{array}$ & $\begin{array}{l}\text { Baseline scenario pledge } \\
2020 \text { Pledge Case of } 555^{a} \text { is calculated from } \\
\text { INDC (Mexico, 2015) baseline }{ }^{26} \text { of } 792 \\
\text { Current Policy Trajectory (official data) is } \\
\text { based on Government of Mexico (2012), } \\
\text { adjusted per SEMARNAT (2013) }\end{array}$ \\
\hline
\end{tabular}

23 Figures do not consider the possible purchase or sale of offsets. Figures including LULUCF indicated with a , excluding LULUCF indicated with ${ }^{\mathrm{b}}$.

24 References to den Elzen et al. (2015) in this column represent PBL estimates based on the method of den Elzen et al. (2015). Some numbers presented here have been updated per latest estimates available from http://infographics.pbl.nl/indc/.

25 The INDC baseline is based on a revised national inventory that shows significantly lower 2010 emissions than those shown in the National Communication and assumed by other studies cited here. See http://ranradgrk.bappenas.go.id/rangrk/beranda/92-bahasa/informasi-sektoral/193-hasil-indc for a comparison of 2010 emissions.

26 The INDC baseline is based on a new methodology with global warming potentials (GWPs) from the IPCC 5th Assessment Report; it is therefore not comparable to any other sources cited here. All other sources use GWPs from the IPCC $2^{\text {nd }}$ Assessment Report; the NCCS (2013) also uses a previous methodology. 


\begin{tabular}{|c|c|c|c|c|}
\hline Parties & $\begin{array}{l}2020 \text { Pledge Case } \\
\text { (based on official } \\
\text { data) }\end{array}$ & $\begin{array}{l}\text { Current Policy } \\
\text { Trajectory } \\
\text { (based on official data) }\end{array}$ & $\begin{array}{l}\text { Current Policy Trajectory } \\
\text { (based on independent } \\
\text { estimates) }{ }^{24}\end{array}$ & $\begin{array}{l}\text { Mitigation pledge and current policy } \\
\text { trajectory details }\end{array}$ \\
\hline $\begin{array}{l}\text { Republic of } \\
\text { Korea }\end{array}$ & $\begin{array}{l}550^{a} \\
\text { (Republic of Korea, } \\
2015) \\
545^{a} \\
\text { (Republic of Korea, } \\
2014 \text { ) }\end{array}$ & N/A & $\begin{array}{l}745-755^{\mathrm{b}} \text { (CAT, 2015) } \\
585-620^{\mathrm{b}} \text { (den Elzen et al., } \\
2015)\end{array}$ & $\begin{array}{l}\text { Baseline scenario pledge } \\
2020 \text { Pledge Case of } 550^{\mathrm{a}} \text { is calculated from } \\
\text { INDC (Republic of Korea, 2015) baseline of } 783\end{array}$ \\
\hline $\begin{array}{l}\text { Russian } \\
\text { Federation }\end{array}$ & $\begin{array}{l}2515^{\mathrm{b}} \\
\text { (Government of } \\
\text { Russia, 2014) }\end{array}$ & $\begin{array}{l}2410^{\mathrm{b}} \\
\text { (Government of Russia, } \\
\text { 2014) }\end{array}$ & $\begin{array}{l}2600^{b} \text { (CAT, 2015) } \\
2295-2375^{b} \text { (den Elzen et } \\
\text { al., 2015) }\end{array}$ & $\begin{array}{l}\text { Base year pledge } \\
2020 \text { Pledge Case reflects } 25 \% \text { reduction } \\
\text { calculated based on national inventory data } \\
\text { (Government of Russia, 2014) }\end{array}$ \\
\hline $\begin{array}{l}\text { South } \\
\text { Africa }\end{array}$ & $\begin{array}{l}585^{a} \\
\text { (Department of } \\
\text { Environmental Affairs, } \\
\text { 2011a, 2011b) }\end{array}$ & N/A & $\begin{array}{l}730^{\mathrm{b}}(\mathrm{CAT}, 2015) \\
560-885^{\mathrm{b}}(\mathrm{PBL}, 2015)\end{array}$ & Baseline scenario pledge \\
\hline $\begin{array}{l}\text { United } \\
\text { States of } \\
\text { America }\end{array}$ & $\begin{array}{l}5145^{a} \\
\text { (Biennial Report, } \\
\text { 2013) }\end{array}$ & $\begin{array}{l}5920^{\mathrm{a}} \\
\text { (Biennial Report, 2013) }\end{array}$ & $\begin{array}{l}6360-6600^{b} \text { (CAT, 2015) } \\
5445-6170^{a} \text { (den Elzen et al., } \\
2015)^{27}\end{array}$ & $\begin{array}{l}\text { Base year pledge } \\
\text { Current Policy Trajectory (official data) is } \\
\text { from the 'with measures' scenario in the } \\
\text { Biennial Report (2013). The USA considers } \\
\text { that it has moved onto the 'with additional } \\
\text { measures' trajectory, with a range of } \\
4893-5591 \mathrm{MtCO}_{2} \text { e for } 2020\end{array}$ \\
\hline \multicolumn{5}{|c|}{ No 2020 pledge } \\
\hline Argentina & No pledge & No pledge & $380-480^{\mathrm{b}}$ (CAT, 2015) & \\
\hline $\begin{array}{l}\text { Saudi } \\
\text { Arabia }\end{array}$ & No pledge & No pledge & $645^{\mathrm{b}}$ (CAT, 2015) & \\
\hline Turkey & No pledge & No pledge & $\begin{array}{l}655^{\mathrm{b}} \text { (CAT, 2015) } \\
485-690^{\mathrm{b}} \text { (den Elzen et al., } \\
2015)\end{array}$ & \\
\hline
\end{tabular}

\section{Notes:}

aFigures including LULUCF

bFigures excluding LULUCF

"China and India have GHG intensity targets based on the ratio of GHG emissions to GDP. For consistency, we have converted these to absolute emission numbers based on the official documentation cited above, but a determination of whether each country has achieved its pledge should be based on intensity rather than absolute emissions.

Estimates are rounded to the nearest $5 \mathrm{MtCO}_{2} \mathrm{e}$. 


\subsubsection{Progress of $\mathrm{G} 20$ countries}

Based on this analysis, three of the parties considered here - China, the EU28, and India - are on track to meet their pledges without purchasing offsets according to all available analyses. Three more - Brazil, Japan, and Russia - are on track according to most estimates and are within one per cent, one per cent, and three per cent of the pledge level, respectively, according to all estimates.

China's and India's pledges are framed in terms of GHG intensity reductions from 2005 levels, and several sources indicate that both countries are currently on track to achieve them. Studies indicate that China, which pledged a reduction of 40-45 per cent in emissions intensity, is on track to achieve a reduction of at least 42 per cent (IEA, 2014a, 2014b; CAT, 2015; PBL, 2015; Sha et al., 2015). For India, Garg et al. (2014) show that by 2012 , India had already reduced intensity by 17 per cent out of a pledged reduction of 20-25 per cent by 2020, and the CAT (2015) and PBL (2015) show India on track for a 36 per cent or 28 per cent reduction by 2020 , respectively ${ }^{28}$.

Japan announced an adjustment to its pledge in November 2013 from a 25 per cent reduction on 1990 levels to a 3.8 per cent reduction on 2005 levels (similar to an increase of about 3.1 per cent on 1990 levels). While this adjustment makes it much easier for Japan to achieve its pledge, current official projections still place Japan's 2020 emissions slightly above its pledge threshold (UNFCCC, 2014). Independent projections differ slightly - CAT (2015) shows Japan on track to meet its revised pledge, whereas den Elzen et al. (2015) estimates a range in 2020 from slightly below to slightly above the pledge level. Japan's actual trajectory, however, will depend significantly on the respective roles of nuclear power and coal-fired power to meet future needs ${ }^{29}$.

Canada and Mexico are likely to require further action or purchased offsets, or both in order to meet their pledges, according to government and independent estimates. Mexico's 2020 pledge is conditional on the provision of adequate financial and technological support from developed countries as part of a global agreement (Mexico, 2015).

According to independent analysis, the Republic of Korea will also require further action to meet its pledge, but this cannot be verified based on publicly available official projections. Independent estimates of 2020 emissions range from well below to well above the pledge level (CAT, 2015; den Elzen et al., 2015).

In the cases of Australia ${ }^{30}$ and the USA, government and independent analyses reach differing conclusions regarding each country's progress towards its pledge. In the case of Australia, the government projects 2020 emissions of approximately $655 \mathrm{MtCO}_{2} \mathrm{e}$, not including the impact of the Emission Reduction Fund (ERF). The Australian government states that it is "on track" to meet its target of $533 \mathrm{MtCO}_{2} \mathrm{e}$, and that the ERF has contracted projects expected to deliver

28 Calculated for China based on an assumed GDP growth rate of 8.5 per cent (PBL, 2015) and 7.0 per cent (CAT, 2015), and for India based on an assumed GDP growth rate of 7.5 per cent (PBL, 2015) and 6.4 per cent (CAT, 2015).

29 A study commissioned by Japan's Ministry of Environment (MOE, 2015) projected that by 2030 , the share of renewable energy in the electricity sector could reach around 25-30 per cent in a 'medium deployment' case and 30-35 per cent in a 'high deployment' case.

30 See CCA (2014) for further discussion. abatement of $47 \mathrm{MtCO}_{2} \mathrm{e}$ (Commonwealth of Australia, 2015). Prior to the initial auction, CCA (2014) reviewed studies of the potential of the ERF and concluded, "In short, these studies suggest that the ERF's contribution to reducing emissions is likely to fall some way short of what is required to meet Australia's minimum 2020 target". Independent analyses (CAT, 2015; PBL 2015) project emissions above the pledge level.

The USA contends that the 'with additional measures' scenario from a 2014 addendum to its biennial report now represents its current policy trajectory. This trajectory shows the United States on track to achieve its pledge. Independent analyses, by contrast, find that further action is still necessary (see, for example, Rhodium Group, 2014; Belenky, 2015; CAT, 2015; Hausker et al., 2015; PBL, 2015).

Insufficient information is currently available to determine whether Indonesia and South Africa are on track to meet their pledges. In the case of Indonesia, independent projections span a wide range, and official projections reflecting current policies are unavailable. In the case of South Africa, official projections to 2020 do not reflect recently adopted and implemented policies, and independent estimates vary widely, from well below the pledge level to well above it. South Africa's pledge is conditional.

Finally, Argentina, Saudi Arabia and Turkey have not proposed GHG reduction pledges for 2020 (as of 1 October 2015, Argentina and Turkey had submitted post-2020 pledges to the UNFCCC as part of their Intended Nationally Determined Contributions).

Despite progress towards implementing policies in line with pledges, work remains to be done to bring all G20 countries into pledge attainment. Additionally, better data are necessary to adequately track this progress in some countries. Ensuring continued progress towards 2020 pledges will reduce the mitigation burden associated with achieving the post-2020 pledges put forward in the INDCs.

This section has examined the extent to which G20 countries are proceeding towards the minimum level of their 2020 pledges, in light of the importance of pre-2020 GHG reductions for achieving consistency with $2^{\circ} \mathrm{C}$ scenarios, with implications beyond 2020. As described earlier in this chapter, this report does not address the global emissions gap in 2020, so the cumulative impact of the progress towards 2020 pledges is not calculated. UNEP (2014) found that emissions under the global current policy trajectory - taking into account progress by the G20 countries roughly aligned with the higher-emissions end of the range associated with meeting the unconditional pledges.

It is important to recognise that these pledge levels do not align with the least-cost pathways to limit warming with stringent mitigation action starting in 2010 (UNEP, 2014). Ideally, all countries with 2020 pledges will recognise the need to exceed their undertakings while countries without 2020 pledges will strengthen their own mitigation ambition with appropriate polices and measures. This would allow a transition towards a pathway in line with a least-cost trajectory after 2020, with the associated economic, technology, societal co-benefits, and climate outcome benefits highlighted in Section 2.2. 


\section{Chapter 3}

\section{The emissions gap in 2025 and 2030}

Lead authors: Michel den Elzen (PBL Netherlands Environmental Assessment Agency), Taryn Fransen (World Resources Institute), Niklas Höhne (NewClimate Institute), Harald Winkler (University of Cape Town), Roberto Schaeffer (Universidade Federal do Rio de Janeiro), Fu Sha (National Center for Climate Strategy and International Cooperation), Amit Garg (Indian Institute of Management Ahmedabad)

Contributing authors: Guy Cunliffe (University of Cape Town), Hanna Fekete (NewClimate Institute), Mengpin Ge (World Resources Institute), Giacomo Grassi (Joint Research Centre, European Commission), Mark Roelfsema (PBL Netherlands Environmental Assessment Agency), Joeri Rogelj (International Institute for Applied Systems Analysis), Sebastian Sterl (NewClimate Institute), Eveline Vasquez (Universidade Federal do Rio de Janeiro)

\subsection{Introduction}

The Lima Call for Climate Action, adopted by Parties to the United Nations Framework Convention on Climate Change (UNFCCC) in December 2014, noted the gap between Parties' mitigation pledges for 2020 and the emission pathways consistent with limiting the increase in global average temperature to below $2^{\circ} \mathrm{C}$ or $1.5^{\circ} \mathrm{C}$ (UNFCCC, 2014). It reiterated the invitation issued by the 2013 Warsaw decision for Parties to communicate their Intended Nationally Determined Contributions (INDCS) towards achieving the objective of the Convention (UNFCCC, 2013) (see Box 3.1).
This chapter explores the INDCs submitted by 1 October 2015 (UNFCCC, 2015a), with a specific focus on the extent to which the INDCs in aggregate are in accordance with the long-term objective of the Convention, which is "[...] to achieve [...] stabilization of greenhouse gas concentrations in the atmosphere at a level that would prevent dangerous anthropogenic interference with the climate system". The chapter quantifies an 'emissions gap' - the gap between future emissions under full implementation of the INDCs and under the pathways consistent with limiting warming to below $2^{\circ} \mathrm{C}$ in 2100 - for the years 2025 and 2030. The Chapter first presents qualitative information about the

\section{Box 3.1: INDCs in the Warsaw (2013) and Lima (2014) decisions under the UNFCCC}

The Warsaw decision 1/CP19 (UNFCCC, 2013) introduced the concept of INDCs as follows:

- All Parties are invited to initiate or intensify preparations for their INDCs, without prejudice to the legal nature of the contributions

- All Parties are invited to communicate their INDCs well in advance of COP 21 "[...] (by the first quarter of 2015 by those Parties ready to do so) in a manner that facilitates the clarity, transparency and understanding of the intended contributions, without prejudice to the legal nature of the contributions".

The Lima decision 1/CP20 (UNFCCC, 2014) reiterated the points agreed in Warsaw, and also:

- Agreed that each Party's intended nationally determined contribution towards achieving the objective of the Convention as set out in its Article 2 will represent a progression beyond the current undertaking of that Party

- Invited all Parties to consider communicating their undertakings in adaptation planning or consider including an adaptation component in their INDCs

- Agreed that the information to be provided by Parties may include, as appropriate, inter alia, quantifiable information on the reference point (including, as appropriate, a base year), time frames and/or periods for implementation, scope and coverage, planning processes, assumptions and methodological approaches including those for estimating and accounting for anthropogenic greenhouse gas emissions and, as appropriate, removals, and how the Party considers that its INDC is fair and ambitious, in light of its national circumstances, and how it contributes towards achieving the objective of the Convention as set out in its Article 2 (UNFCCC, 1992). 


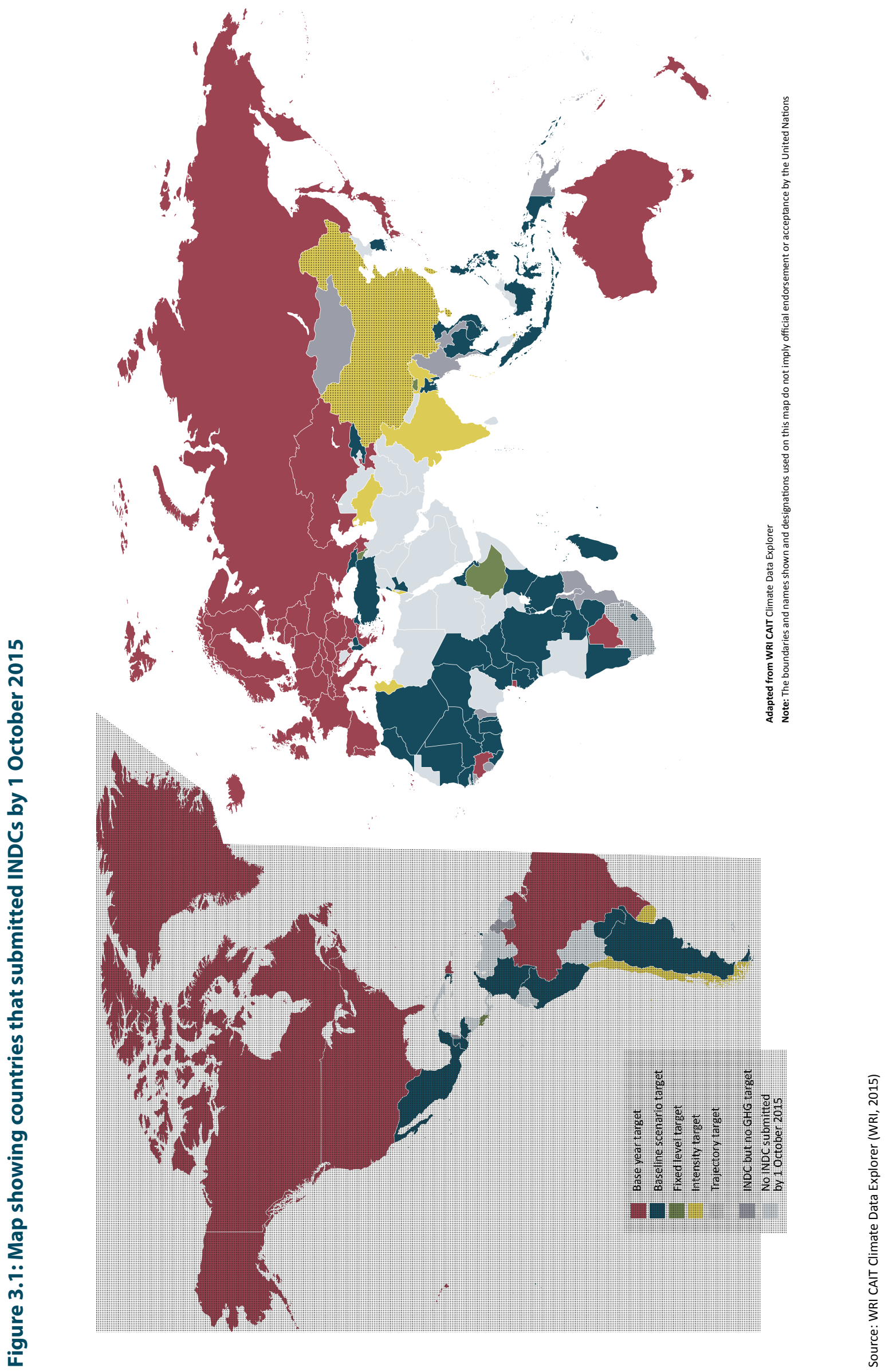


INDCs submitted, concerning - for example, the treatment of adaptation, equity, and various GHG accounting issues. It then quantifies future global GHG emission pathways with full implementation of INDCs out to 2030, and compares them to the pathways for limiting warming to below $2^{\circ} \mathrm{C}$ that were described in Chapter 2.2. INDCs that countries intend to achieve unconditionally, as well as INDCs that are subject to conditions (such as the provision of international climate finance), are evaluated separately. A final update of the assessment including later submissions will be presented on the UNEP Live website before the start of COP 21.

\subsection{Broad characteristics of submitted INDCs}

By 1 October 2015, a total of 119 INDCs, covering 146 countries and 85-88 per cent of global GHG emissions in 2012 (JRC/PBL, 2012; WRI, 2015), had been submitted to the UNFCCC ${ }^{1,2}$. Every INDC includes a mitigation component and just over 85 per cent cover both mitigation and adaptation. Fifteen INDCs cover mitigation only.

Mitigation INDCs were submitted by countries from all regions (see Figure 3.1), and the 10 largest emitters had all submitted their INDCs by 1 October. These are, in descending order of emission levels, China, the USA, EU, India, Russia, Indonesia, Brazil, Japan, Canada and Mexico. The review of the INDCs submitted by 1 October 2015 identified broad mitigation-related groupings as follows:

Coverage: 38 INDCs explicitly state that they are economywide. Many of these cover 100 per cent of national GHG emissions, while another specifies 98.5 per cent coverage.

Sectors: 50 INDCs include all major IPCC sector categories (energy, industrial processes and product use, agriculture, waste, and Land Use, Land-Use Change and Forestry (LULUCF)), while 61 INDCs are sector-specific. Eight INDCs do not explicitly state which sectors are covered.

Nitrogen trifluoride: 19 INDCs cover nitrogen trifluoride $\left(\mathrm{NF}_{3}\right.$, also a Kyoto gas from 2013 onward) in addition to all Kyoto GHGs of the first commitment period. With respect to $\mathrm{NF}_{3}$, two countries (Gabon and Republic of Congo) indicate the gas is to be included in future.

Selective GHGs: 50 INDCs cover only $\mathrm{CO}_{2}, \mathrm{~N}_{2} \mathrm{O}$ and $\mathrm{CH}_{4}$ (and another INDC includes $\mathrm{SF}_{6}$ in addition to these). Eleven INDCs include only $\mathrm{CO}_{2}$ emissions, while two (Mauritius and Mexico), besides first-commitment-period Kyoto Protocol gases, also include Short Lived Climate Forcers (SLCF) ${ }^{3}$.

100-year Global Warming Potential (GWP): The common metric of 100 -year GWP values is indicated in some, but not

1 This total of 119 recognizes that the EU submitted collectively as 1 INDC. Counting the $28 \mathrm{EU}$ member states separately, the country total covered by the INDCs is 146 .

2 Covering all sectors including land use, land-use change and forestry (LULUCF), and all six Kyoto gases of the first commitment period [carbon dioxide $\left(\mathrm{CO}_{2}\right)$, methane $\left(\mathrm{CH}_{4}\right)$, nitrous oxide $\left(\mathrm{N}_{2} \mathrm{O}\right)$, hydrofluorocarbons (HFCs), perfluorocarbons (PFCs) and sulphur hexafluoride $\left(\mathrm{SF}_{6}\right)$

3 Mexico's unconditional INDC is equivalent to a reduction of 51 per cent of black carbon (BC); with conditional reductions extending up to 70 per cent of BC emissions, both below BAU by 2030. Mauritius does not provide further information about their SLCF emissions. all, INDCs, referring to different IPCC Assessment Reports (ARs). GWP values used in INDCs are not all the same. 38 INDCs indicate the use of 100-year GWP values from the IPCC Second Assessment Report (AR2), while 29 INDCs use values from the IPCC AR4. Mexico, Brazil and Ecuador use 100-year GWP values from the IPCC AR5. Brazil further indicated 100-year Global Temperature Potential (GTP) values from the IPCC AR5.

\subsubsection{Forms of mitigation contributions}

Figure 3.1 illustrates that Parties' mitigation contributions take several forms. Below, the various forms of targets included by Parties in their INDCs are summarized.

Base year target: 32 INDCs report on an absolute reduction from historical base year emissions. The base year chosen varies, with 1990, 2005 and 2010 being the most common. Most Parties chose 2030 as the target year for their INDCs. However, 11 countries chose 2025.

Baseline scenario target: The form of emissions reduction relative to a baseline projection has been chosen in 63 INDCs, mainly for countries located in South and Central America, Africa and South Asia. Two countries using a baseline scenario target are Guyana and Mozambique. They quantify the $\mathrm{MtCO}_{2} \mathrm{e}$ they intend to reduce, but do not specify relative baseline emissions projections.

Trajectory target: South Africa has a trajectory target stating the emission range in 2025 and 2030 and adds an emission range in absolute $\mathrm{Mt}$ to its trajectory target. Specifying a peaking year is part of China's and Singapore's INDCs. In these cases, the timing of the maximum $\mathrm{CO}_{2}$ emissions has been communicated, but not the level, while adding intensity targets.

Intensity target: China also specifies the carbon intensity of GDP, indicating percentages by which $\mathrm{CO}_{2}$ emissions per unit of GDP will be reduced by 2030 , compared to the 2005 intensity. Singapore adopts the same approach, but for all GHG emissions, giving an emission intensity of GDP. A further four countries (Chile, India, Tunisia and Uruguay) indicate reductions in emission intensity of GDP as the main form of their mitigation INDC.

Fixed level target: Seven countries put forward a fixed level target; that is, they specify the $\mathrm{MtCO}_{2}$ e that they intend not to exceed in a given year (Armenia, Bhutan, Costa Rica, Eritrea, Ethiopia, Israel and Sierra Leone). Kenya's INDC, though framed as percentage emission reduction relative to a baseline projection, adds the Mt in the same sentence; the calculation of absolute emissions in 2030 is simple multiplication.

Actions and non-GHG metrics only: Six countries (Gambia, Guinea Bissau, Malawi, Myanmar, Rwanda and Swaziland) include only actions and another four countries only non-GHG metrics (Cape Verde, Papua New Guinea, Samoa and Vanuatu).

Additional non-GHG metrics: Some INDCs include additional non-GHG metrics, for example, in the form of a target for non-fossil-fuel primary energy share, in the case of China, and a reduction from baseline projections of Short Lived Climate Pollutants, in the case of Mexico. 
Renewable energy (RE) target: 42 INDCs include quantified renewable energy (RE) targets as a form of non-GHG metric or actions consistent with their GHG target, in addition to other forms. For example, Brazil targets 45 per cent of renewables in its energy mix by 2030 , including expanding the use of renewable energy sources other than hydropower to between 28-33 per cent and increasing the share of renewables (other than hydropower) in the power supply to at least 23 per cent. Furthermore, eight INDCs (Cape Verde, Gabon, Indonesia, Jordan, Lebanon, Papua New Guinea, Samoa and Vanuatu) made RE targets part of their headline mitigation contribution. As an example, Gabon's RE target is expressed as 80 per cent of electricity supply from hydropower by 2025 , and as a summary component of its mitigation INDC in addition to an emission reduction target, while Samoa's contribution is a "[...] 100\% renewable energy target for electricity generation through to the year 2025".

From the above review, it is evident that, in the absence of agreed forms of mitigation contribution and the units in which those might be expressed, countries have selected a wide variety of forms. Over 50 per cent of the mitigation INDCs have taken the form of emission reduction relative to a baseline projection. Within single forms, different units have been chosen; forms are not mutually exclusive; and several countries have chosen more than one form of mitigation contribution. This has increased the analytical challenge of comparing INDC elements and ensuring consistency when aggregating the different contributions.

\subsubsection{Treatment of Agriculture, Forestry and Other Land Use}

The vast majority of INDCs includes the land-use sector or a component of it. Only a few countries (including Albania, Andorra, Djibouti, Georgia, Marshall Islands, Republic of Macedonia and Trinidad and Tobago) explicitly exclude it. Some countries (for example, Republic of Korea) indicate that a decision on whether to include LULUCF will be made later. Few countries explicitly include a separate forest goal (for example, Benin, China and India).

Most Parties referring to LULUCF include it (or at least the forest component of it) as any other sector within the INDC. In some cases it is not clear if LULUCF is included in the base year. Among those Parties referring to LULUCF accounting rules (most developed or Annex I country Parties), in several cases there is some uncertainty on which rule will be applied. Canada, United States and Australia intend to use a net-net approach ${ }^{4}$. Japan and Switzerland declare the use of an equivalent methodology to those under the Kyoto Protocol. New Zealand will confirm details of the accounting approach prior to or upon ratification of the Paris Agreement. The EU indicates that policy on how to include LULUCF will be established as soon as technical conditions

$4 \quad$ Net-net is a term used to describe a method for LULUCF accounting under the Kyoto Protocol, where credits and debits are obtained by comparing the accounting period to the base year. However, under the Kyoto Protocol, LULUCF forestry activities were often without reference to the base year, or were with reference to a projected reference level. If an INDC explicitly includes LULUCF in the base year, then net-net is assumed to be treating LULUCF is the same way as any other GHG inventory sector. It is also possible for countries to use a net-net accounting approach where the base year does not include LULUCF, but the LULUCF contribution is added or subtracted from total national emissions in the target year. allow. In addition, Switzerland, Australia, New Zealand, United States and Canada declared also that emissions from natural disturbances may or will be excluded, consistent with available IPCC guidance.

Almost all developing countries have mitigation actions both in agriculture and LULUCF. In many cases, LULUCF represents the most relevant current source of emissions and the main area for future mitigation. Often REDD+ is mentioned, but sometimes the relationship between INDC and REDD+ is not fully clear.

Several developing countries include specific LULUCF information within the unconditional and the conditional targets (for example the expected LULUCF mitigation and the related cost of implementation).

In terms of methodology for estimating GHG emissions and removals, the IPCC 2006 Guidelines are mentioned as the primary guidance by most countries (including all developed country Parties). The 2003 Good Practice Guidance for LULUCF is mentioned by few countries (for example, Kenya, Madagascar, Peru, Jordan and Benin). Some countries also refer to the 1996 IPCC guidelines (for example, Argentina, Democratic Republic of Congo, Macedonia and Republic of Korea).

\subsubsection{Adaptation components in INDCs and undertakings in adaptation planning}

The Lima decision invited all Parties to consider including an adaptation component in their INDCs or to consider communicating their undertakings in adaptation planning. Components on adaptation have been included in just over 85 per cent of INDCs submitted by 1 October (102/119). Of these, three (Australia, Israel and Monaco) indicate in their INDCs that they are working to build their adaptation strategies during 2015, while Brazil's INDC states that it is "[...] working on the design of new public policies, through its National Adaptation Plan (NAP), in its final elaboration phase", and Macedonia's INDC states that "[...] climate change adaptation shall be the subject of more detailed analysis in the future" (UNFCCC, 2015a).

Four undertakings in adaptation planning were submitted or referred to in the INDCs submitted to the UNFCCC. Undertakings in adaptation planning were submitted by both the EU and the USA. These are available on the UNFCCC website (UNFCCC, 2015b) as distinct from the INDC portal (UNFCCC, 2015a). Furthermore, New Zealand and Norway refer in their INDCS (UNFCCC, 2015a) to undertakings in adaptation planning by referring to chapters in their national communications.

\subsubsection{Specifying support required or offered}

Several countries have stated requirements for support for their INDCs in the form of finance, technology transfer, and investment in capacity building, and through international support or the use of international market mechanisms or both.

Conditional versus unconditional INDCs: 42 INDCs have both unconditional and conditional components to their GHG emission reduction targets while 39 include only conditional contributions. 37 INDCs do not make a clear distinction between conditional and unconditional provisions in their INDCs. 
Use of international market mechanisms: 22 INDCs indicate they will mainly achieve their emission reductions domestically, although only seven of these specifically state international market mechanisms will not be used. An explicit intention to use these mechanisms is stated by 11 countries, while 20 INDCs express support for their use and a further 23 are considering their potential use. Norway and Iceland indicate in their INDCs that they will likely continue their participation in the EU Emissions Trading System (ETS). Liechtenstein's INDC indicates "[...] supplemental emission reductions abroad", while Albania, Chad, Ethiopia, Montenegro and Rwanda intend to "[...] sell carbon credits". In formulating their mitigation INDCs, four countries (Ghana, Guyana, Japan and New Zealand) have assumed that international mechanisms will be used.

Requests for international support, including finance: 91 countries have indicated requirements for international support, with 71 INDCs quantifying these requirements in monetary terms. Examples include India's INDC, which notes that "[...] a preliminary estimate suggests that at least US\$2.5 trillion will be required [...]" as a total cost, for its intended contributions, and Morocco's INDC, which communicates that meeting its target will require US\$45 billion of investment, of which US\$35 billion is conditional on international support (UNFCCC, 2015a). Ethiopia notes that "[...] full implementation of Ethiopia's INDC requires support in the form of finance, capacity building and technology transfer", and estimates that implementing its Green Economy Strategy requires expenditure which exceeds US\$150 billion (UNFCCC, 2015a). Another example comes from Kenya's INDC, which states that "Kenya will require support in form of finance, investment, technology development, and capacity building", estimating that "[...] over US\$40 billion is required for mitigation and adaptation actions across sectors up to 2030". For further detail on these examples, see UNFCCC (2015a).

Offers of international support (including finance): No Annex II country has specified finance, technology or capacity-building support that might be offered or provided in the future. China has offered support for other developing countries, "[...] including the small island developing countries, the least developed countries and African countries", and plans to establish the "Fund for SouthSouth Cooperation on Climate Change". Finally, the Republic of Belarus stated that it has supported, and will support, developing nations, mainly in the area of awareness-raising, education, capacity building, and in the area of research and development relating to climate change issues. For further detail on these examples, see UNFCCC (2015a).

\subsubsection{How countries address equity, ambition and Article 2 of the Convention}

The Lima decision invited information on fairness and ambition, and how the INDC contributes towards achieving the objective of the Convention as set out in its Article 2 (UNFCCC, 1992).

In relation to the objective of the Convention, 52 of the INDCs make reference to Article 2 (verbatim or indirectly), while 62 INDCs refer to the $2^{\circ} \mathrm{C}$ goal; 36 INDCs make no reference to either Article 2 or $2^{\circ} \mathrm{C}$.

Most INDCs have addressed equity (or fairness) and ambition in some way. However, 80 INDCs do not offer specific metrics to support their claims to relative fairness in relation to their INDCs, instead providing only general statements or reference to principles. A further 31 INDCs draw on analyses conducted by modelling teams or experts from within the country. Only eight INDCs - Andorra, Brazil, Macedonia, Monaco, Norway, Republic of Moldova, South Africa and Switzerland - refer to external, independent analyses.

On equity, a range of arguments and indicators is referred to in the INDCs. The most common indicator chosen is per capita emission levels, described in 57 INDCs. Specifically, 68 INDCs refer to their countries representing a small share of global emissions. Additionally nine INDCs (Andorra, Armenia, Bangladesh, EU, Japan, Jordan, Monaco, Norway and Switzerland) reference ranges in IPCC reports for consistency with $2^{\circ} \mathrm{C}$.

Further details are available in Annex B of this report (available online), presenting a summary of key characteristics of all INDCs submitted by 1 October 2015 in table form.

\subsection{Methodology for quantifying the effect of INDCs on global GHG emissions}

\subsubsection{Overview of scenarios}

To assess the impact of the INDCs on future global GHG emissions, global GHG emissions in 2025 and 2030 are compared under four scenarios. Each scenario is composite. It draws on multiple individual scenarios from the published literature in line with the characteristics described below.

- The baseline scenario assumes that no additional climate policies have been put in place since 2010 (see also Chapter 2). It is sourced from the scenario database that accompanied the Fifth Assessment Report (AR5) of the Intergovernmental Panel on Climate Change (IPCC) (Clarke et al., 2014).

- The current policy trajectory scenario takes into account currently adopted and implemented policies. It is based on (i) the current policies scenarios from three ${ }^{5}$ out of the eight global INDC analyses ${ }^{6}$ that provide such current policy trajectory scenarios, (ii) official country-specific data sources, and (iii) independent country-specific data sources, as detailed in Table 3.1.

5 These three groups with current policy scenarios are: (i) the Climate Action Tracker by Climate Analytics, NewClimate Institute, Ecofys and Potsdam Institute for Climate Impact Research-PIK (CAT, 2015); (ii) International Energy Agency (IEA, 2014); and iii) PBL Netherlands Environmental Assessment Agency (den Elzen et al., 2015). The groups from LSE and DEA (see footnote 6) also have current policies scenarios that are calibrated at the IEA current policies scenario.

6 These eight global groups with INDC scenarios are: (i) the Climate Action Tracker by Climate Analytics, NewClimate Institute, Ecofys and PIK (CAT, 2015); (ii) PBL Netherlands Environmental Assessment Agency (PBL, 2015) (iii) International Energy Agency (IEA, 2014, 2015); (iv) London School of Economics and Political Science (LSE) (Boyd et al., 2015); (v) Climate and Energy College / University of Melbourne dataset (Meinshausen, 2015); (vi) Danish Energy Agency (DEA, 2015); (vii) Climate Interactive (Climate Interactive, 2015); and (viii) NIES (Masui, 2015). 
- The INDC scenario portrays how global GHG emissions might evolve with full implementation of INDCs. It is sourced from (i) the official estimates included in the INDCs (UNFCCC, 2015a), (ii) calculations based on the INDCs and on other documents submitted by countries to the UNFCCC (such as national GHG inventories, national communications, biennial reports, and biennial update reports), (iii) estimates published in country-specific studies, and (iv) eight global analyses, described further below.
- The $2^{\circ} \mathrm{C}$ scenario represents an idealized global scenario consistent with limiting warming to below $2^{\circ} \mathrm{C}$, keeping the option open to strengthen the global temperature target to $1.5^{\circ} \mathrm{C}$. It comprises the subset of scenarios from the IPCC AR5 scenario database that (i) have a greater than 66 per cent chance of keeping global temperature increase to below $2^{\circ} \mathrm{C}$ in 2100 compared pre-industrial levels, (ii) are consistent with full implementation of 2020 pledges that are anchored in the Cancun Agreements, and

Table 3.1: Overview of INDC studies included in the assessment by type of source (in alphabetical order)

\begin{tabular}{|c|c|c|c|}
\hline Reference & Geographic coverage & $\begin{array}{l}\text { Sector } \\
\text { and gas } \\
\text { coverage }\end{array}$ & Scenario coverage \\
\hline \multicolumn{4}{|l|}{ Global INDC analyses } \\
\hline Climate Action Tracker (CAT, 2015; Gütschow et al., 2015) & Global & All & Current policy trajectory, INDC \\
\hline $\begin{array}{l}\text { Climate and Energy College / University of Melbourne } \\
\text { dataset (Meinshausen, 2015) }\end{array}$ & Global & All & INDC \\
\hline Climate Interactive (Climate Interactive, 2015) & Global & All & INDC \\
\hline Danish Energy Agency (DEA, 2015) & Global & All & INDC \\
\hline $\begin{array}{l}\text { London School of Economics and Political Science (LSE) } \\
\text { (Boyd et al., 2015) }\end{array}$ & Global & All & INDC \\
\hline $\begin{array}{l}\text { International Energy Agency - World Energy Outlook (IEA, } \\
\text { 2014; IEA, 2015) }\end{array}$ & Global & $\begin{array}{l}\mathrm{CO}_{2} \text { from } \\
\text { energy use }\end{array}$ & Current policy trajectory, INDC \\
\hline $\begin{array}{l}\text { National Institute for Environmental Studies (NIES) (Masui, } \\
\text { 2015) }\end{array}$ & Global & All & INDC \\
\hline $\begin{array}{l}\text { PBL Netherlands Environmental Assessment Agency (den } \\
\text { Elzen et al., 2015; PBL, 2015) }\end{array}$ & Global & All & Current policy trajectory, INDC \\
\hline \multicolumn{4}{|l|}{ Official country-specific data sources } \\
\hline Australian Government (2015) & Australia & All & Current policy trajectory \\
\hline $\begin{array}{l}\text { Biennial Report/Biennial Update Report (UNFCCC National } \\
\text { Reports, 2015) }{ }^{\text {a }}\end{array}$ & $\begin{array}{l}\text { Brazil, Japan, Norway, } \\
\text { Korea, Republic of, } \\
\text { Russia and Switzerland }\end{array}$ & Varies & Current policy trajectory \\
\hline Department of Environmental Affairs (2014) & South Africa & All & Current policy trajectory, INDC \\
\hline EEA (2014) & EU & All & Current policy trajectory \\
\hline Government of Canada (2014) & Canada & All & Current policy trajectory \\
\hline INDCs (UNFCCC, 2015a) & $\begin{array}{l}\text { Brazil, Japan, Korea, } \\
\text { Republic of, Mexico, } \\
\text { Morocco, South Africa } \\
\text { and the USA }\end{array}$ & Varies & INDC \\
\hline National Climate Change Strategy (2013) & Mexico & All & Current policy trajectory \\
\hline National Communications (UNFCCC National Reports, 2015) & Indonesia, USA & Varies & INDC \\
\hline \multicolumn{4}{|l|}{ Independent country-specific data sources } \\
\hline Centre for Policy Research (Dubash et al., 2015) & India & $\mathrm{CO}_{2}$ & Current policy trajectory \\
\hline Climate Advisers (Belenky, 2015) & United States & All & Current policy trajectory, INDC \\
\hline $\begin{array}{l}\text { Energy Research Institute Low carbon scenarios (based on } \\
\text { Jiang et al., 2013) }\end{array}$ & China & $\mathrm{CO}_{2}^{\mathrm{b}}$ & Current policy trajectory, INDC \\
\hline $\begin{array}{l}\text { Indian Institute of Management, Ahmedabad (Garg et al., } \\
\text { 2014) }\end{array}$ & India & All & Current policy trajectory \\
\hline $\begin{array}{l}\text { Institut du Développement Durables et des Relations } \\
\text { Internationales (IDDRI, 2015) }\end{array}$ & Japan & All & INDC \\
\hline $\begin{array}{l}\text { National Center for Climate Strategy and International } \\
\text { Cooperation (Sha et al., 2015) }\end{array}$ & China & $\mathrm{CO}_{2}^{\mathrm{b}}$ & INDC \\
\hline World Resources Institute (Kuramochi, 2014) & Japan & All & INDC \\
\hline World Resources Institute (Hausker et al., 2015) & United States & All & Current policy trajectory, INDC \\
\hline
\end{tabular}

${ }^{a}$ Augmented with US Environmental Protection Agency (2012), JRC/PBL (2012) and den Elzen et al. (2015) to produce economy-wide figures.

${ }^{\mathrm{b}}$ Augmented with Tavoni et al. (2015) and Government of China (2012) to produce economy-wide figures. 
(iii) distribute emission reductions across regions, gases and sectors after 2020 in such a way that that global mitigation costs of necessary reductions are minimized.

\subsubsection{Methodology for current policy trajectory and INDC scenarios}

While the baseline and $2^{\circ} \mathrm{C}$ scenarios are drawn entirely from the IPCC AR5 database and have not been adjusted, the data sources and methodologies for the current policy trajectory and INDC scenarios are more complex, as indicated above and in Table 3.1. The methodology in the assessment of these scenarios is therefore described in more detail in the following.

As mentioned, the current policy trajectory scenario draws from the current policy scenarios of three of the eight global analyses, in addition to current policy scenarios from official and independent country-specific sources. Where no data are available from official or independent country-specific sources, the assessment uses the median current policy scenario estimate from the three global studies.

Current policy trajectory scenarios assume that no additional mitigation action is taken beyond current policies - even if it results in 2020 pledges not being achieved or being overachieved. Current policy trajectories reflect all adopted and implemented policies, which for the purpose of this report are defined as legislative decisions, executive orders, or their equivalent. This implies that publicly announced plans or strategies alone would not qualify, while individual executive orders to implement such plans or strategies would qualify. Ultimately, however, these definitions may be interpreted differently in the different underlying studies. This assessment is bound by the definitions that the individual research groups use.

The INDC scenario draws on individual INDC scenarios from the same eight global analyses. It furthermore draws on official and independent country-specific sources, as indicated in Table 3.1. These are converted to two global estimates in the same manner as for the current policy trajectory scenario. Finally, it considers five additional scenarios that are created by combining emission growth rates of the non-INDC countries from five modelling groups (Tavoni et al., 2015) ${ }^{7}$ with the median emission values for INDC-countries taken from the INDC scenarios of the eight global INDC analyses, and the two additional analyses based on the aggregated official and independent country-specific data sources ${ }^{8}$. The resulting composite INDC scenario comprises the median, $10^{\text {th }}$ percentile, and $90^{\text {th }}$ percentile global estimates for 2025 and 2030 from all of these sources.

$7 \quad$ The Low climate IMpact scenarios and the Implications of required Tight emission control Strategies (LIMITS) study modelled reference scenarios consistent with achieving the Cancun pledges, assuming constant climate policies thereafter. The LIMITS modelling groups are: Energy Research Centre of the Netherlands (ECN), Fondazione Eni Enrico Mattei (FEEM), International Institute for Applied Systems Analysis (IIASA), Pacific Northwest National Laboratory (PNNL), and Potsdam Institute for Climate Impact Research (PIK).

8 These five scenarios represent the sum of the median value for 2025 and 2030 emissions for countries with INDCs from the ten INDC analyses (eight global studies, one official and one national global estimate) and estimated values for future emissions in non-INDC countries. The latter are calculated by applying the 2010-2030 emission growth rates from each of the five LIMITS studies to the median 2010 emissions of the non-INDC countries from the ten INDC analyses. This results in five additional global INDC scenarios considered in the composite INDC scenario.

\subsubsection{Unconditional and conditional INDC cases}

As discussed in Section 3.2, some countries place conditions on all or part of their INDCs. Consequently, two cases are explored in this assessment: unconditional INDCs and conditional INDCs. In the unconditional INDC case, Parties with INDCs are assumed to implement targets without conditions only. Parties that solely have a conditional target, or have not submitted an INDC, are assumed to follow a current policy trajectory. In the conditional INDC case all Parties with INDCs are assumed to implement their conditional targets. Parties that only have an unconditional target are assumed to implement that target, and Parties with no INDCs are assumed to follow a current policy trajectory, or if that is not available, a baseline scenario. In both the unconditional and the conditional INDC cases, it is assumed that for any traded international offsets, each unit is counted towards the INDC of a single country only - either the buyer or the seller.

The studies from which the current policy trajectory scenario and the INDC scenario are drawn differ in a number of respects, such as: conditional versus unconditional INDCs; assumptions regarding non-covered sectors and gases; treatment of LULUCF and surplus emission units; and different bases for calculating Global Warming Potentials (GWPs).

The methodological differences between the groups cannot be fully harmonized, which leads to some uncertainty as indicated in the results presented in Section 3.4, where the implications of the differences between studies are also further explored.

\subsection{The effect of INDCs on global GHG emissions}

This section presents the findings regarding the aggregate effect on global total GHG emissions of full implementation of the INDCs in 2025 and 2030, compared to the emissions implied by baseline, current policy trajectory and $2^{\circ} \mathrm{C}$ scenarios. The results are shown in Figure 3.2, with details on medians and ranges provided in Table 3.2. It should be noted that the baseline emission projection is about $2.5 \mathrm{GtCO}_{2}$ e lower in 2030 compared to the projection in last year's Emissions Gap Report (UNEP, 2014). The reason is that this year baseline emission projections are not harmonized to the global GHG emissions of $49.5 \mathrm{GtCO}_{2} \mathrm{e}$ in 2010.

Taken together, Figure 3.2 and Table 3.2 show that full implementation of the unconditional INDCs will reduce global GHG emissions in 2025 by $7 \mathrm{GtCO}_{2} \mathrm{e}$ (range: $3-8$ ) relative to the baseline, and by $3 \mathrm{GtCO}_{2} \mathrm{e}$ (range: $0-4$ ) relative to the current policy trajectory. This leaves a gap in 2025 of $7 \mathrm{GtCO}_{2}$ e (range: $5-10$ ) between the unconditional INDC scenario and the $2^{\circ} \mathrm{C}$ scenario.

In 2030, the reduction from the unconditional INDCs is $9 \mathrm{GtCO}_{2} \mathrm{e}$ (range: $6-11$ ) relative to the baseline and $4 \mathrm{GtCO}_{2} \mathrm{e}$ 
Figure 3.2: Global greenhouse gas emissions under different scenarios and the emissions gap in 2030

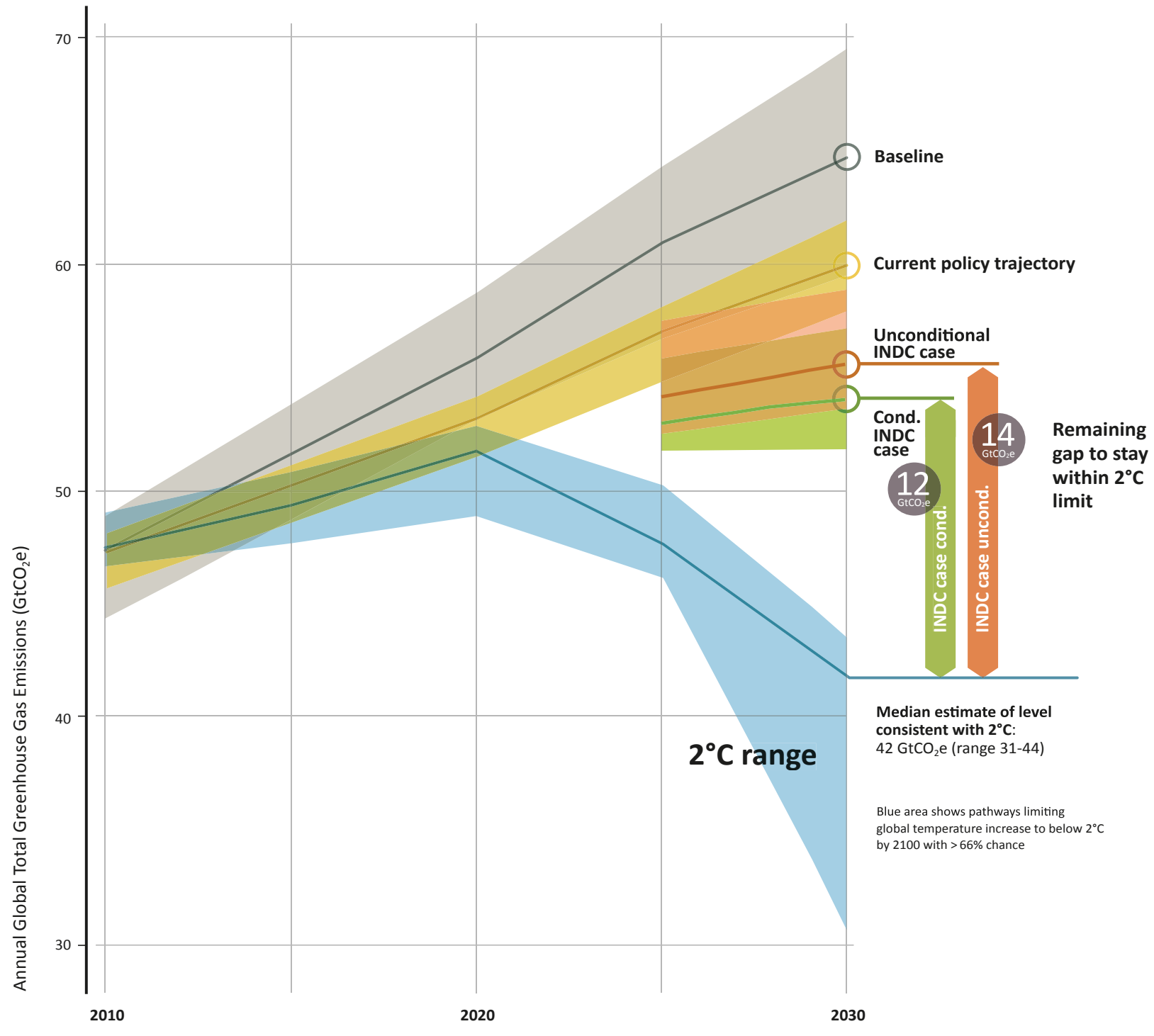

Sources:

Baseline and $2^{\circ} \mathrm{C}$ ranges: $20^{\text {th }}$ to $80^{\text {th }}$ percentile of the scenarios in IPCC database

INDC case: $10^{\text {th }}$ to $90^{\text {th }}$ percentile of the global estimates for 2025 and 2030 from all global analyses and official and independent country-specific sources 
Table 3.2: Global total GHG emissions, emission reductions and distance to the $2^{\circ} \mathrm{C}$ range in 2025 and 2030 under different scenarios (median and range)

\begin{tabular}{|l|l|l|l|l|}
\hline 2025 emissions gap assessment estimates \\
\hline Scenario & $\begin{array}{l}\text { Global total } \\
\text { emissions } \\
\text { (range) }\end{array}$ & $\begin{array}{l}\text { Emission reduction } \\
\text { compared to baseline } \\
\text { (range) }\end{array}$ & $\begin{array}{l}\text { Emission reduction } \\
\text { compared to current policy } \\
\text { trajectory (range) }\end{array}$ & $\begin{array}{l}\text { Remaining emission } \\
\text { reduction to stay within } 2^{\circ} \mathrm{C} \\
\text { limit (range) }\end{array}$ \\
\hline Baseline & $\mathrm{GtCO}_{2} e$ & $G t \mathrm{GO}_{2} e$ & GtCO $e$ & $\mathrm{GtCO}_{2} e$ \\
\hline Current policy trajectory & $61(57-64)$ & $\mathrm{n} / \mathrm{a}$ & $\mathrm{n} / \mathrm{a}$ & $13(9-17)$ \\
\hline Unconditional INDCs & $57(55-58)$ & $4(3-6)$ & $\mathrm{n} / \mathrm{a}$ & $9(7-10)$ \\
\hline Conditional INDCs ${ }^{a}$ & $54(53-58)$ & $7(3-8)$ & $3(0-4)$ & $7(5-10)$ \\
\hline $2^{\circ} \mathrm{C}$ pathways & $53(52-56)$ & $8(5-9)$ & $4(1-5)$ & $5(4-8)$ \\
\hline
\end{tabular}

\begin{tabular}{|l|l|l|l|l|}
\hline 2030 emissions gap assessment estimates & $\begin{array}{l}\text { Global total } \\
\text { emissions (range) }\end{array}$ & $\begin{array}{l}\text { Emission reduction } \\
\text { compared to baseline } \\
\text { (range) }\end{array}$ & $\begin{array}{l}\text { Emission reduction compared } \\
\text { to current policy trajectory } \\
\text { (range) }\end{array}$ & $\begin{array}{l}\text { Remaining emission reduction } \\
\text { to stay within 2 }{ }^{\circ} \mathrm{C} \text { limit (range) }\end{array}$ \\
\hline Baseline & $\mathrm{GtCO}_{2} e$ & $\mathrm{GtCO} e$ & $\mathrm{GtCO} e$ & $\mathrm{GtCO}_{2} e$ \\
\hline Current policy trajectory & $65(60-70)$ & $\mathrm{n} / \mathrm{a}$ & $\mathrm{n} / \mathrm{a}$ & $23(18-28)$ \\
\hline Unconditional INDCs & $60(58-62)$ & $5(3-7)$ & $\mathrm{n} / \mathrm{a}$ & $18(16-20)$ \\
\hline Conditional INDCs & $56(54-59)$ & $9(6-11)$ & $4(1-6)$ & $14(12-17)$ \\
\hline $2^{\circ} \mathrm{C}$ pathways & $54(52-57)$ & $11(8-13)$ & $6(3-8)$ & $12(10-15)$ \\
\hline
\end{tabular}

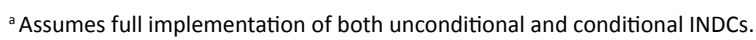

(range: 1-6) relative to the current policy scenario, leaving a gap of $14 \mathrm{GtCO}_{2}$ e (range: 12-17) between the INDC scenario and the $2^{\circ} \mathrm{C}$ scenario (See Figure 3.2 and Table 3.2) ${ }^{9}$.

In comparison, if countries were to also fully implement the conditional INDCs, global GHG emissions in 2025 would be reduced by $8 \mathrm{GtCO}_{2} \mathrm{e}$ (range: $5-9$ ) relative to the baseline, and by $4 \mathrm{GtCO}_{2}$ e (range: $1-5$ ) relative to the current policy trajectory. This leaves a gap in 2025 of $5 \mathrm{GtCO}_{2}$ e (range: 4-8) between the combined implementation of unconditional and conditional INDCs and the $2^{\circ} \mathrm{C}$ scenario.

In 2030, the emission reduction from the combined implementation of unconditional and conditional INDCs is 11 $\mathrm{GtCO}_{2} \mathrm{e}$ (range: 8-13) relative to the baseline, and $6 \mathrm{GtCO}_{2} \mathrm{e}$ (range: $3-8$ ) relative to the current policy scenario, leaving a gap of $12 \mathrm{GtCO}_{2}$ e (range: $10-15$ ) between the INDC scenario and the $2^{\circ} \mathrm{C}$ scenario in 2030 .

Excluding the potential impact of surplus emission units (for countries where achieving the INDC generates higher emissions than their current policy trajectory), would further reduce this gap by $0.5 \mathrm{GtCO}_{2} \mathrm{e}$ (range: $0-1$ ) by 2030 , to a final level of $12 \mathrm{GtCO}_{2} \mathrm{e}$ (range: 9-15).

If countries that have not yet submitted an INDC were to reduce their emissions by the same average percentage below current trajectories as those that have already

9 UNEP (2014) estimated a 2030 emissions gap of about $14-17 \mathrm{GtCO}_{2} \mathrm{e}$, based on the extrapolation of the four pledge cases in $2020\left(52-54 \mathrm{GtCO}_{2} \mathrm{e}\right)$. This study, however, estimates 2020 emissions at $54-55 \mathrm{GtCO}_{2} \mathrm{e}$. Therefore, the lower end of the previous gap estimate $\left(14 \mathrm{GtCO}_{2} \mathrm{e}\right)$ is no longer relevant, and the gap assessed in this report under the INDC scenario is more appropriately compared with the higher end of the previous gap estimate $\left(17 \mathrm{GtCO}_{2} \mathrm{e}\right)$. submitted their INDCs (as of 1 October 2015), the gap for the full implementation of both unconditional and conditional INDCs could be narrowed by an additional $0.5 \mathrm{GtCO}_{2} \mathrm{e}$ in 2025 and $1 \mathrm{GtCO}_{2} \mathrm{e}$ in 2030, to $11 \mathrm{GtCO}_{2} \mathrm{e}^{10}$.

\subsubsection{Temperature implications of the emission levels resulting from the INDCS}

The temperature implications of the emission levels implied by the INDCs are illustrated in Figure 3.3, which compares the emission levels estimated for the unconditional and conditional INDCs with emission pathways over the $21^{\text {st }}$ century $^{11,12}$.

Countries covering 85 per cent of global emissions reduce emissions for the conditional INDCs about $6 \mathrm{GtCO}_{2}$ e below the current trajectories in 2030 . The remaining 15 per cent are assumed to reduce emissions by about $1 \mathrm{GtCO}_{2} \mathrm{e}$ ((6) $/ 85 \times 15=1.05)$.

11 Based on Rogelj et al. (2011) to warrant a sufficient coverage of scenarios in the range of interest. These scenarios assume a constant level of climate mitigation from 2000 or 2005 and until 2100 .

12 Note that the scenarios underlying Figure 3.3 assume a constant level of mitigation ambition over the $21^{\text {st }}$ century, from 2000 or 2005 onward. This is different from what is assumed for the $2^{\circ} \mathrm{C}$ - consistent scenarios in Chapter 2, where scenarios achieve the Cancun pledges in 2020 and then start a global mitigation path towards $2^{\circ} \mathrm{C}$. As a result, the 2030 emission levels in line with limiting warming to below $2^{\circ} \mathrm{C}$ with greater than 66 per cent chance in Figure 3.3 are lower than the levels reported in Chapter 2. 
Figure 3.3: Greenhouse gas emissions levels in the year 2030 from long-term scenarios that assume a constant level of climate action over time starting before 2010, compared to the estimated conditional and unconditional INDC emission levels for 2030

GHG emission levels in 2030

$\left(\mathrm{GtCO}_{2} \mathrm{e} / \mathrm{yr}\right)$

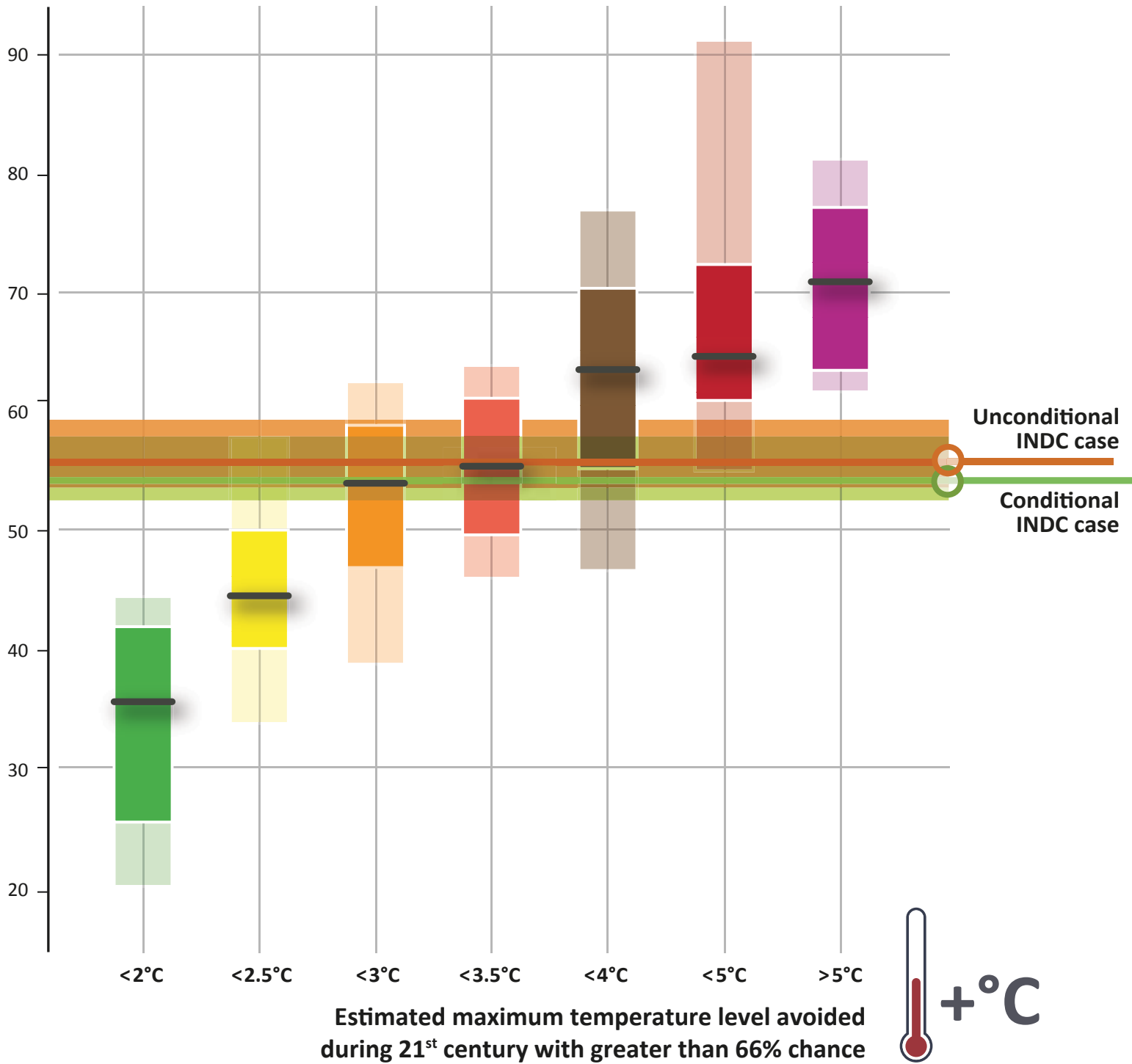

Scenarios are grouped based on the level of warming they avoid during the $21^{\text {st }}$ century with at least $66 \%$ chance, and show median (black line), $15-85^{\text {th }}$ percentile range (dark coloured boxes), and the minimum maximum range (ligher shaded boxes). The $10-90^{\text {th }}$ percentile range for the INDC cases is shown.

The Figure illustrates that compared to the levels of $4^{\circ} \mathrm{C}$ and above that would be expected under baseline projections (see also Chapter 2) current policies and full implementation of the INDCs would reduce the long-term temperature projections. More specifically, Figure 3.3 illustrates that full implementation of unconditional INDC results in estimated 2030 emission levels that are most consistent with scenarios that limit global average temperature increase to below $3.5^{\circ} \mathrm{C}$ by the end of the century 2100 with $>66$ per cent chance.

Figure 3.3 furthermore illustrates that a move from implementation of the unconditional to combined implementation of both conditional and unconditional INDCs would have an effect on long-term temperature projections. Combined implementation of unconditional and conditional INDCs, results in projections becoming more consistent with long-term scenarios that limit global average temperature increase to below $3^{\circ} \mathrm{C}$ by the end of the century with a greater than 66 per cent chance ${ }^{13}$.

There is significant overlap between the ranges of the unconditional and conditional INDC emission levels, as well as between the scenario bins. Taking uncertainty ranges into account, the $3.5^{\circ} \mathrm{C}$ value for implementation of unconditional INDCs could decrease to $3^{\circ} \mathrm{C}$ or increase towards $4^{\circ} \mathrm{C}$ for the low and high unconditional INDC estimates respectively. When including the full implementation also of conditional INDCs, the emission level estimates taking uncertainty ranges

13 Given the uncertainties in both projections and climate response, the resolution of the bins is limited and therefore the above-mentioned estimates are to be interpreted as indications of the broad order of magnitude of the expected avoided warming. 
into account become most consistent with long-term scenarios that limit global average temperature increase to below $3-3.5^{\circ} \mathrm{C}$ by the end of the century with $>66$ per cent chance.

\subsubsection{Overview of differences between studies and their implications}

A number of methodological factors can contribute to differences in findings between studies. To illustrate the range of estimates from the studies considered for this assessment, Figure 3.4 provides an overview of historical emissions (2010), current policy trajectories (2020, 2025, and 2030), Cancun pledges (2020), and unconditional and conditional INDCs (2025 and 2030) by the different studies considered.

The figure illustrates that differences can be significant. However, it is noteworthy that, amongst all the global modelling and country-specific scenarios, there is unanimity that full INDC implementation would indeed reduce global emission levels in 2025 and 2030 relative to the current policy trajectory.

\section{Figure 3.4: Global greenhouse gas emissions as implied by submitted INDCs (original data from}

different modelling groups, including LULUCF)

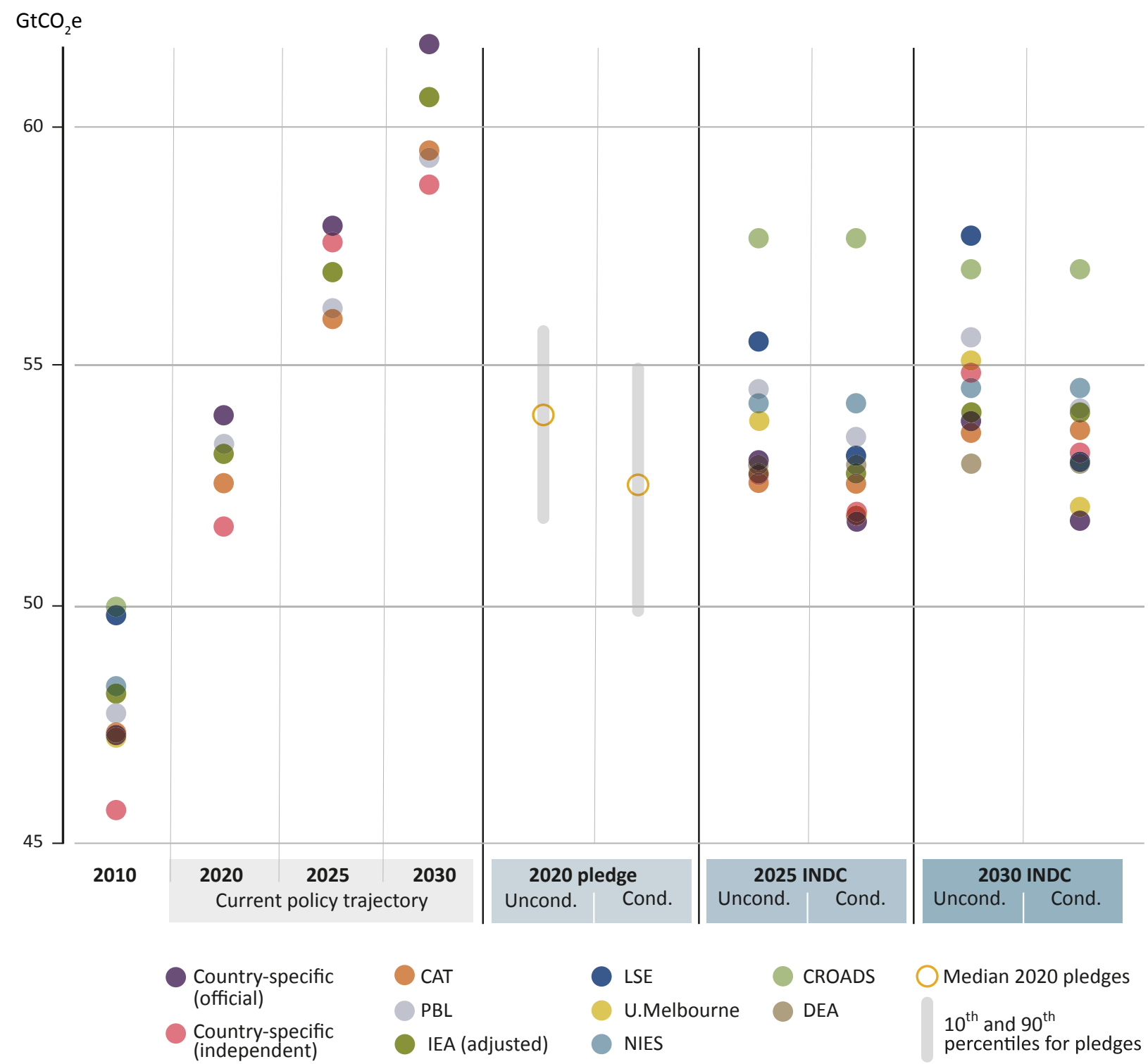

Notes:

Uncertainty ranges for baseline and $2^{\circ} \mathrm{C}$ scenarios are the $20^{\text {th }}$ and $80^{\text {th }}$ percentile of the full scenario dataset, the uncertainty range for current policy trajectories is assumed to be the same as for the baseline, the uncertainty ranges of the INDC scenario is $10^{\text {th }}$ to $90^{\text {th }}$ percentile of the data points.

Subsequent to the finalization of this gap assessment, the IEA has updated their unconditional INDC emission estimate for 2030 to 52 GtCO ${ }_{2}$. This is approximately $2 \mathrm{GtCO}_{2} \mathrm{e}$ lower than the estimate shown in the figure and based on IEA (2015). 
The main factors that contribute to the discrepancies and consequently the approximate ranges in the 2030 emission estimates are described below. Where possible, the uncertainty that each discrepancy implies for 2030 global emissions, is also indicated.

- Non-covered sectors and countries: There is often a significant range in the emission estimates for sectors not included under INDC pledges, such as emissions from international aviation and maritime transport (bunkers) and for countries which have not submitted an INDC. For example, the uncertainty range across the model groups for the emission projections from international bunker emissions are $1.7 \mathrm{GtCO}_{2} \mathrm{e}$ (range: 1.3-2.1), which is consistent with the uncertainty ranges of the projections from international shipping and aviation organisations (ICAO, 2013; IMO, 2014). The results from different studies will vary, since some have explored the impact of mitigation policies of only a subset of countries.

- Uncertainties surrounding the emission projections of the countries with INDCs: Modelling groups have used different assumptions regarding the implementation of INDCs. Many INDCs put forward absolute GHG emission goals, which can be represented easily. There are also many INDCs that referenced a business-as-usual emission projection. However, for most INDCs an estimate of target-year or target-period emissions is given. The quantification of these INDCs is not surrounded with moderate uncertainties (see Section 3.5). The few countries putting forward GDP emission intensity targets (measured as the improvement in emissions per unit of GDP), did not provide target-year GDP estimates or indicate the data source for GDP absolute level, $B A U$, or reference level if given. The quantification of these INDCs with intensity targets poses additional uncertainties.

- Land use, land-use change and forestry (LULUCF): LULUCF plays a relevant role in the mitigation target of most INDCs. Quantification of the LULUCF contribution depends on the availability of adequate official information from each country on: (i) the modality of inclusion of LULUCF in the INDC (for example, LULUCF treated as any other sector or through special accounting rules); (ii) historical data and projections (for example, from INDC, GHG inventories, National Communications, Biennial Update Reports). Using information available in 32 INDCs ${ }^{14}$ and based entirely on countries' information, the unconditional LULUCF mitigation contribution is estimated at around $1.6 \mathrm{GtCO}_{2}$ (of which $0.5 \mathrm{GtCO}_{2}$ comes from Annex I countries). In addition $0.3 \mathrm{GtCO}_{2}$ is explicitly indicated as conditional (from nonAnnex I countries). Taking into account uncertainties due to accounting rules of $\pm 0.3 \mathrm{GtCO}_{2}$ for Annex I countries, and due to countries' projections, the total range of LULUCF contribution ranges from negative

1411 Annex I Parties and 21 non-Annex I Parties accounting for about 41 per cent of global GHG emissions in 2012 contributions of $0.1 \mathrm{GtCO}_{2}$ to positive contributions of $4.3 \mathrm{GtCO}_{2}$. This range does not consider possible future natural disturbances in Annex I countries explicitly, the impact of which is assumed to be excluded according to UNFCCC Kyoto Protocol provisions. Another source of uncertainty for Annex I countries is the modality of inclusion of LULUCF in the base year, whose impact on GHG allowances is estimated as $\pm 0.2 \mathrm{GtCO}_{2}{ }^{15}$. For non-Annex I countries, uncertainty stems from the range of country projections available and from the availability of adequate support to achieve the conditional targets.

- Impact of harmonization of global 2010 emissions (no impact on emissions gap): The median estimate of all model teams shows global emissions of $47.5 \mathrm{GtCO}_{2} \mathrm{e}$ in 2010, which is lower than the independent global emission estimates of the IPCC AR5 of about $49.5 \mathrm{GtCO}_{2} \mathrm{e}$ (range: 45-54). In Chapter 2, the global emission pathways consistent with meeting the below $2^{\circ} \mathrm{C}$ target also have global emissions with a median estimate of $47.5 \mathrm{GtCO}_{2}$ e by 2010 , so the discrepancy between the historical emissions and the emission projections resulting from the INDCs of the model teams has not been corrected. If we were to resolve the discrepancy in historical emissions (that is, harmonization), this would also increase the emission projections resulting from the INDCs by about $2 \mathrm{GtCO}_{2}$ e (under a constant harmonization) or about $1 \mathrm{GtCO}_{2}$ e (under a decreasing harmonization, towards zero by 2050 , for example). However, as the global emission pathways consistent with meeting the $2^{\circ} \mathrm{C}$ target also need to be harmonized, and thus would increase by the same amount, harmonization has no impact on the global emissions gap.

- Conditional versus unconditional INDCs: Some studies report separate figures for conditional and unconditional INDCs, while others combine this aspect with other uncertainties in a maximum/minimum range or leave out the conditional targets completely.

- Surplus emission units: For countries where the emission level resulting from the INDC is higher than the current policy trajectory, some studies use the current policies trajectory as the value for the INDC emission level, implying that they do not allow the use of surplus emissions, whereas the other studies assume INDC emission levels.

- Global Warming Potential: About 25 per cent of all countries have submitted their INDC based on GWP from the Fourth Assessment Report of the IPCC. Many of the models, however, still work based on GWP from the Second IPCC Assessment Report. It is not always possible to convert from one GWP to another in the context of a particular study without making assumptions that may differ by modelling group.

- Differences between data sources for historic data and projections: Assumptions differ on baselines and reference years.

15 Here, natural disturbances are taken into account, if they are explicitly mentioned in the INDC, because if LULUCF is included in the base year natural disturbances are expected to be excluded in the base year. 


\subsection{INDCs of $\mathrm{G} 20$ countries}

This section presents additional findings concerning the emissions of some of the highest-emitting countries namely 13 of the G20 countries (counting the EU as one) that had submitted their INDCs by 1 October 2015. Their emission levels and INDCs have the largest impact on the aggregate, global findings of this assessment.
Cross-cutting information regarding national emissions, emissions per GDP and emissions per capita for these countries is summarized in Figure 3.5, Figure 3.6, and Figure 3.7 respectively. The figures present this crosscutting information for historic emissions (for 1990 and 2010), current policy trajectories (for 2020, 2025, and

Figure 3.5: Greenhouse gas emissions for G20 countries with INDCs submitted by 1 October for historic emissions $(1990,2010)$, current policy trajectory emissions $(2020,2025,2030)$, and INDC emissions $(2025,2030)$

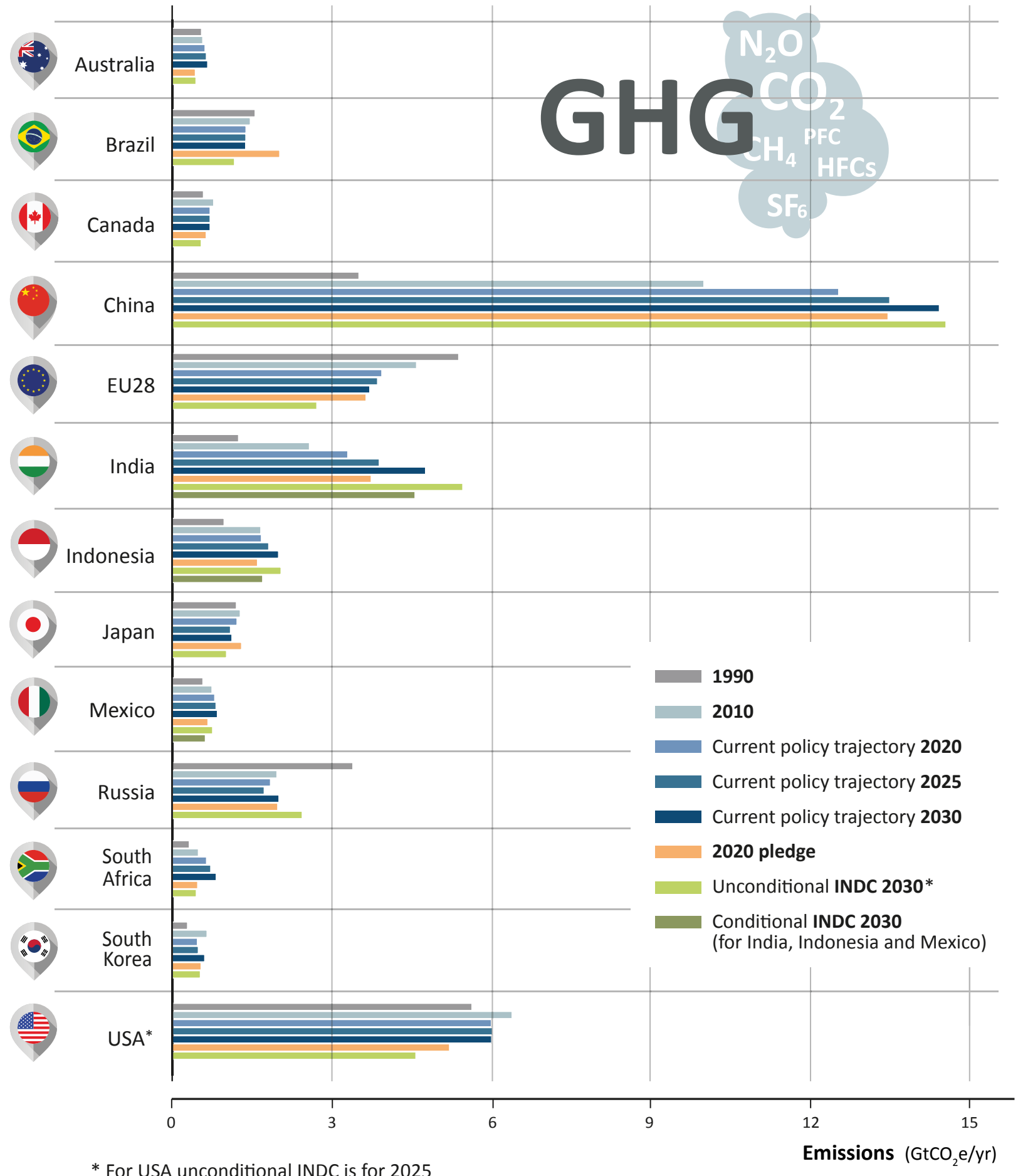


Figure 3.6: Greenhouse gas emissions per unit of real GDP (US\$2005) G20 countries with INDCs submitted by 1 October for historic emissions $(1990,2010)$, current policy trajectory emissions (2020, 2025, 2030), and INDC emissions $(2025,2030)$

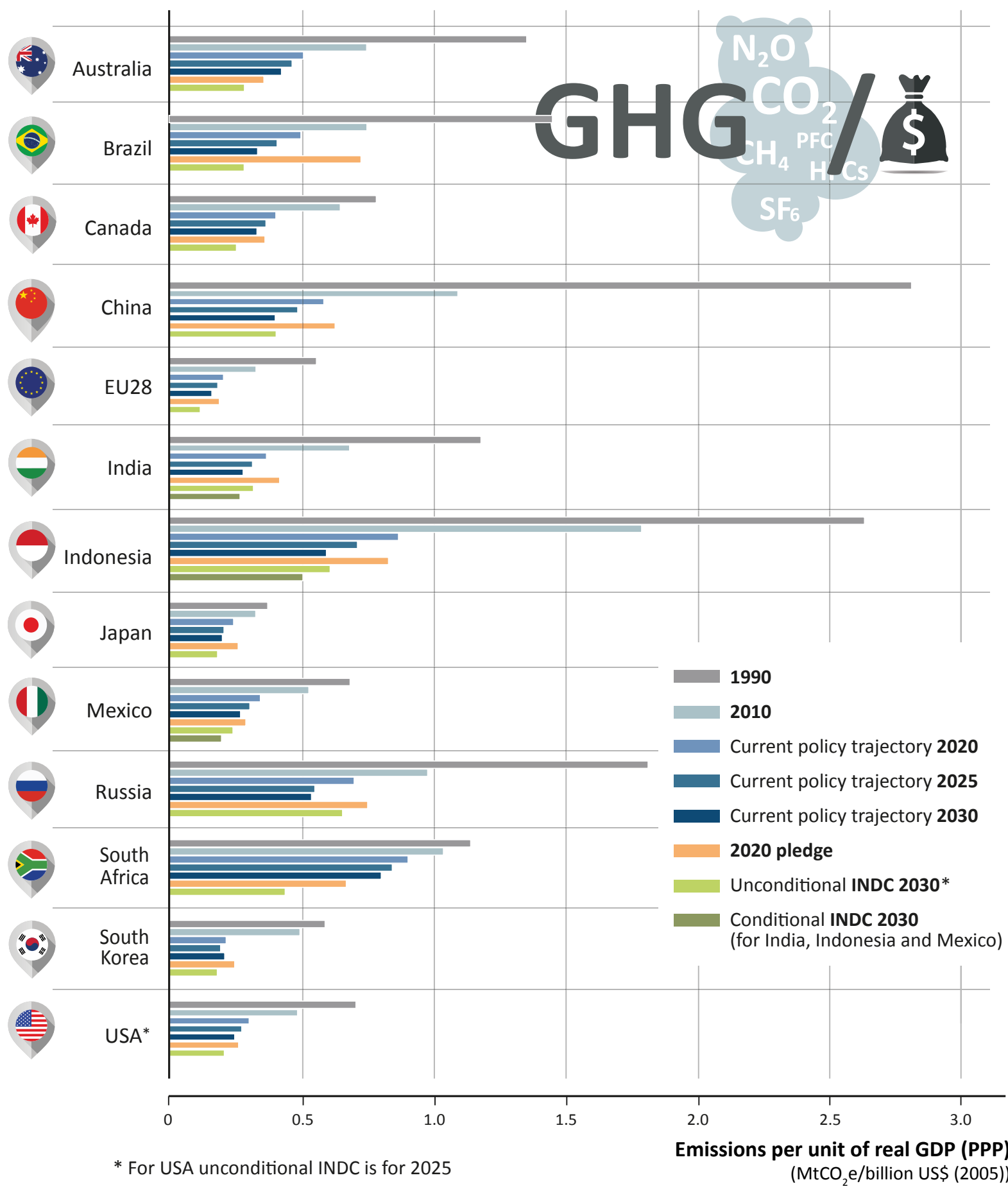

2030) ${ }^{16}$, Cancun pledges (for 2020) ${ }^{17}$, and unconditional and conditional (in the case of India, Indonesia and Mexico) INDC cases (for 2030, noting that for USA, the 2025 unconditional INDC is shown).

By comparing the current policy trajectory scenarios and the INDC scenarios, the figures indicate whether or not a

16 The current trajectories draw only from those studies that explicitly account for currently adopted and implemented policies. These include Climate Action Tracker, IEA adjusted, and PBL and relevant country-specific studies where available.

17 The estimates for 2020 pledges are based on the UNEP 2014 report (UNEP, 2014) and as these estimates are based on a different set of model studies from current year, only the median emission level are shown in the country graphs. country is on track to meet its 2020 pledge (as discussed in Chapter 2.3) and its INDC target. The figures do not attempt to comment on the ambition of either the 2020 pledges or the INDC targets. It is also important to note that the current policy trajectory scenarios, which attempt to reflect the most recent mitigation policies, differ from the baseline or "business as usual" scenarios employed by some countries, which typically assume that no new policies are adopted or implemented after a given cut-off year.

Figure 3.5 shows that the emissions from middle-income countries such as Mexico, Indonesia (only for conditional INDC), Brazil and South Korea are expected to peak before 2025. Emissions of China and India are expected to peak by 
Figure 3.7: Greenhouse gas emissions per capita of G20 countries with INDCs submitted by 1 October for historic emissions (1990, 2010), current policy trajectory emissions (2020, 2025, 2030), and INDC emissions $(2025,2030)$

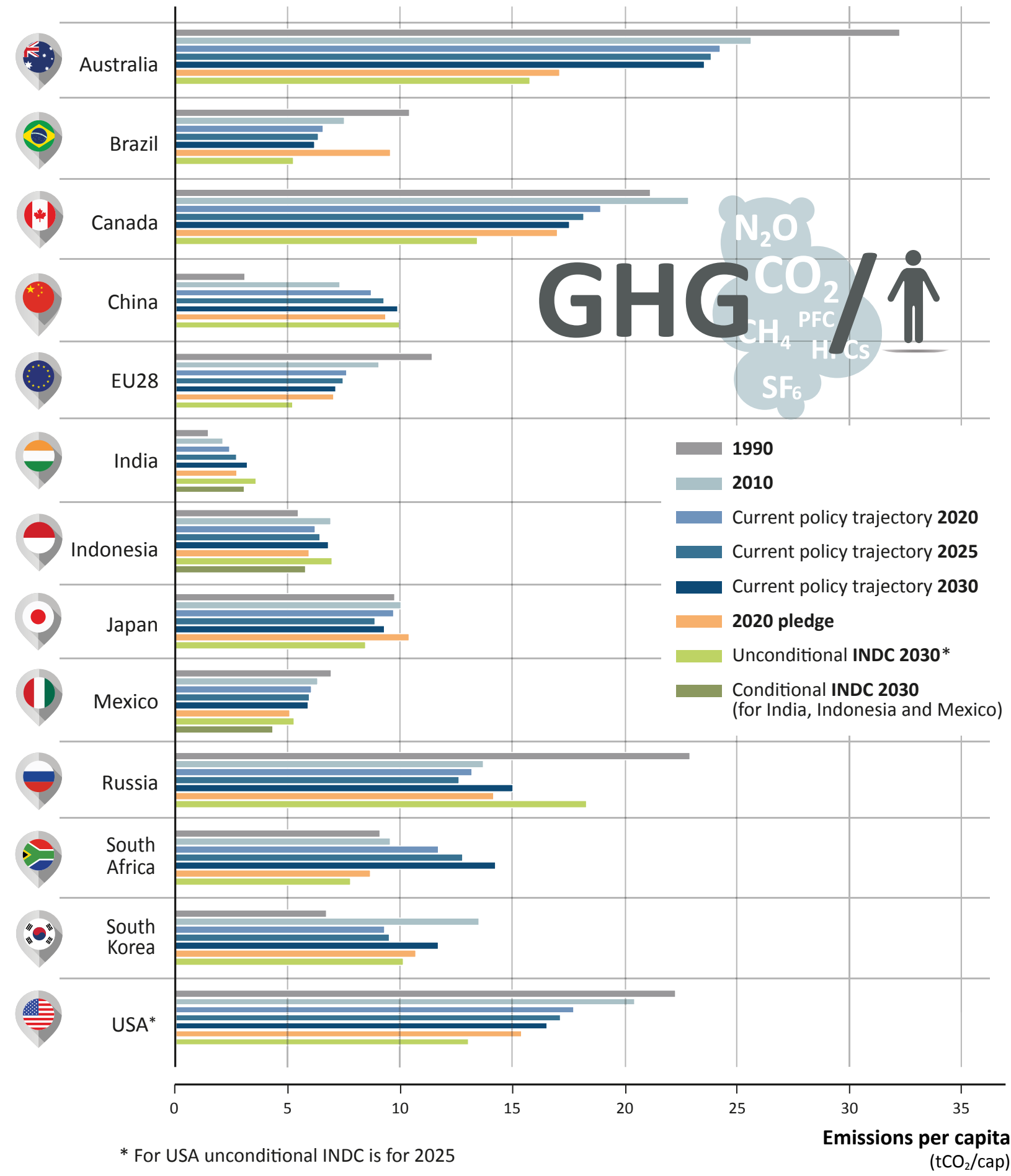

2030 or later. These countries have relatively high emission intensities due to carbon intensive economies. Emissions from most high-income countries have already peaked. The EU28 peaked around 1980, the Russian Federation around 1990, and in Canada, Japan, and the USA around 2005.

The emission levels as a result of INDCs show a decline in per capita emissions between 2010 and 2030, except for China, India and the Russian Federation (Figure 3.6)

All countries show a substantive reduction and convergence in emission intensity (emissions per GDP) by 2030 as a result of their INDCs (Figure 3.7). The largest reductions take place in countries with the highest emission intensities in 2010, such as Indonesia and China.

In addition, detailed findings for each of the above-mentioned countries are provided in Annex 1 to this report. For each of these countries, Annex 1 includes a brief description of the elements of the INDC that have been considered by the modelling groups. A discussion of the reasons for discrepancies between different data sources is included. Data is sourced from the global studies, the national studies and official government sources. 


\subsection{Concluding remarks}

A number of important policy implications can be drawn based on the assessment presented above. First, due to the steep rate at which global emissions must decline after 2020 to be consistent with the $2^{\circ} \mathrm{C}$ scenario, the emissions gap grows rapidly over time. This underscores the importance of enhanced early action to reduce emissions. Secondly, bearing in mind the emissions gap that remains even under the most optimistic assumptions about the INDCs, countries should not assume that these proposed contributions will be sufficient to meet agreed global objectives. While an appropriate level of additional ambition would depend on equity considerations, in general, countries should expect that additional ambition will be necessary. Failure to anticipate this could result in technological lock-in and stranded assets. Third, the INDC process has proven to elicit greater ambition from countries relative to a current policy trajectory. Future calls for INDCs may therefore be successful in eliciting even greater ambition. Early calls to enhance ambition for the 2020 to 2030 timeframe can best address the need for enhanced early action.

In this context the IPCC AR5 (IPCC, 2014) highlighted that if GHG emissions are above $55 \mathrm{GtCO}_{2} \mathrm{e}$ in 2030 , challenges of transitioning to low emission levels in line with $2^{\circ} \mathrm{C}$ in the longer term will become particularly daunting (Figure 6.32 in Clarke et al., 2014). The challenges are much reduced if 2030 Kyoto-GHG emissions are kept below $50 \mathrm{GtCO}_{2}$ e (Clarke et al., 2014), or even more so, to $42 \mathrm{GtCO}_{2} \mathrm{e}$ in line with a leastcost $2^{\circ} \mathrm{C}$ pathway after 2020 .

To sum up, this assessment of the aggregate effect of the INDCs on global total GHG emissions in 2025 and 2030 essentially tells two stories. First, the INDCs do present a real increase in the levels of ambition compared to a projection of current policies; all global modelling analyses and scenarios based on country-specific data sources assessed, reached this conclusion. Secondly, however, the ambitions are far from sufficient, and the emissions gap in 2030 is very significant. Unless ambition is raised rapidly, the projected emission levels resulting from the INDCs are likely to lead to a path that at best will be consistent with an increase in global average temperature of below $3^{\circ} \mathrm{C}$ in 2100 . If considering unconditional INDC levels only, the projected temperature increase is closer to below $3.5^{\circ} \mathrm{C}$. Taking uncertainty ranges into account, the emission level estimates under full implementation of both unconditional and conditional INDCs become most consistent with long-term scenarios that limit global average temperature increase to below $3-3.5^{\circ} \mathrm{C}$ by the end of the century with $>66$ per cent chance. 


\section{Chapter 4}

\section{Opportunities for bridging the gap}

Lead author: Anne Olhoff (UNEP DTU Partnership)

Contributing author: John Christensen (UNEP DTU Partnership)

\subsection{Introduction}

The INDCs represent a real increase in the level of mitigation ambition compared to a continuation of current policies. However, as Chapter 3 illustrates, even with combined implementation of unconditional and conditional INDCs, the emissions gap in 2030 is estimated to be in the order of $12 \mathrm{GtCO}_{2} \mathrm{e}$.

The central question is then if and how this emissions gap can be narrowed and potentially bridged?

This second part of the Emissions Gap Report explores some of the answers to this question. Assessing the most recent literature, it sets off by providing an overview of key issues and opportunities for narrowing and potentially bridging the emissions gap in 2030 in this chapter. These opportunities include:

- Establishing a dynamic framework under the Paris Agreement to drive continuous strengthening of mitigation ambition and ensure efficient implementation of the agreement

- Boosting pre-2020 mitigation action to reduce mitigation costs, avoid lock-in and maintain a possibility of staying below $1.5^{\circ} \mathrm{C}$ by 2100

- Introducing, replicating and scaling up good practice mitigation action, enabling countries to overachieve on their INDCs and bring about a transition to a low carbon economy

- Full integration of development and climate cobenefits in policies, planning and action.

This is followed by 2 chapters providing in-depth assessment of opportunities to further tap into emission reduction potentials in one cross-cutting area, International Cooperative Initiatives (Chapter 5), and for one sector, forestry (Chapter 6).

\subsection{Ensuring coherence, synergy and complementarity between climate change, economic growth and sustainable development}

A deeper understanding and recognition of the interdependency between climate change, economic growth and sustainable development has emerged over the past decade. The Sustainable Development Goals (SDGs) recently adopted in New York by Heads of State of all member states of the United Nations (UN, 2015a) (see also Chapter 1) are an exemplification of this recognition. The SDG process explicitly recommends prioritizing coherence, co-benefits, and complementarity between a climate change agreement under the UNFCCC and the SDGs.

The interrelationships between climate and development are demonstrated in the SDGs and the Fifth Assessment Report by the Intergovernmental Panel on Climate Change (IPCC, 2014a, 2014b). Similarly linkages between economic growth, sustainable development and climate change are echoed across the recent literature (GGBP, 2014; Ansuategi et al., 2015; GCEC 2015a, 2015b; IEA, 2015a, 2015b). A briefing paper prepared for the United Nations Sustainable Development Summit in New York earlier this year states that "Progress towards many SDGs will be affected, overwhelmingly negatively, by climate change (for example food security, water scarcity and water related disasters, poverty and livelihoods, health, and the well-being of ocean and terrestrial ecosystems)" (UN, 2015a, p.2). At the same time, "[...] significant progress on many SDGs can contribute to tackling climate change (including sustainable energy, infrastructure and industrialization, sustainable consumption and production, sustainable agriculture and sustainable cities)" (UN, 2015a, p.2). 


\section{Box 4.1: Preparation of the INDC in Chile}

The preparation of the INDC has involved high level political responsibility starting with a political mandate from the President implemented by the Council of Ministers for Sustainability and Climate Change. In order to get both political engagement and input for consideration, the draft INDC was submitted for public consultation over a period of 4 months with public briefings throughout the country. Proposals received went into a revision process for the draft INDC and final decision rested with the Council. Mitigation discussion was focused around two possible emission intensity targets for the country with different implications but neither of them was seen as damaging to the economy. So climate change policies were treated, in effect, as an integral part of overall national development.

\section{Box 4.2: Preparation of the INDC in the Gambia}

The INDC of the Gambia comprehensively addresses mitigation and adaptation and relevant means for implementation like finance, technology and capacity building. The INDC process has been founded in the context of the regular national development planning process. The national INDC preparation process has a strong focus on stakeholder engagement with sensitization workshops in each of the eight districts of the country and broad cross ministerial and institutional engagement in the actual preparation of the national submission. As a small LDC the Gambia has limited mitigation potential but has identified a number of areas like renewable energy, forestry and agriculture where actions can be implemented - some domestically, others requiring international financial and technological support.

Similarly, the recent IPCC AR5 Synthesis Report states with high confidence that climate change poses a threat to equitable and sustainable development (IPCC, 2014a). However, the report also finds that it is possible to pursue strategies and actions that will move towards climateresilient pathways for sustainable development, while simultaneously facilitating improved livelihoods, social and economic well-being and effective environmental management (IPCC, 2014a).

The SDG Goal 13 "Take urgent action to combat climate change and its impacts" specifically acknowledges that the United Nations Framework Convention on Climate Change is the primary international, intergovernmental forum for negotiating the global response to climate change (UN, 2015b), and the targets associated with the Goal are clearly aligned with the ambitions in the INDCs. From the assessment of the submitted INDCs it is evident that many countries have established national processes that are explicitly anchored in an understanding of climate change mitigation and adaptation in the broader context of sustainable development planning at the national level (see Box 4.1 and 4.2).

\subsection{A robust, effective and transparent follow-up and review framework under the Paris Agreement is vital to narrow the emissions gap}

A robust, effective and transparent follow-up and review framework is critical to ensure the implementation of an ambitious global agreement on climate change. The SDG process has emphasized the importance of establishing a framework for periodic follow-up and review of progress towards implementation of the SDGs and mobilization of further action to accelerate implementation with a four-year interval (UN, 2015c).
A similar approach seems likely to feature in the Paris Agreement. As of 23 October 2015, the UNFCCC draft negotiating text includes mention of periodical global stocktakes of the implementation of the Paris Agreement guided by modalities to be adopted by a body under the new agreement at its first session ${ }^{1}$.

A dynamic approach of the Paris Agreement that enables countries to regularly review and strengthen their INDCs is consistently highlighted as essential to enhance mitigation ambition and narrow the emissions gap (GCEC, 2015a; IDDRI, 2015; IEA, 2015a; INDC Forum, 2015; Spencer et al., 2015). In this way it has been stressed that the first round of INDCs should be seen as the basis for a 'virtuous circle' of rising ambition (IEA, 2015a), and as representing 'floors rather than ceilings' to national ambition over the coming years (GCEC, 2015a).

In this context it is important to note that the social and political effects of the INDCs and the processes undertaken at national level transcend the aggregate effect they are estimated to have on total global GHG emission levels in 2025 and 2030. The preparation of the INDCs, has in many countries incentivized exploration of linkages between development and climate outcomes, and can be seen as a step towards a transition to a low carbon economy. As Figures 3.6 and 3.7 in Chapter 3 illustrate, in many cases the INDCs support a decoupling of economic growth and emissions growth, and reduce per capita emissions.

The Paris Agreement can support these national transitions and provide the framework for mobilization of the enhanced mitigation effort that is required to align national efforts with the global mitigation ambition indicated by the $2^{\circ} \mathrm{C}$ pathways.

1 Draft text available at http://unfccc.int/files/meetings/bonn_oct_2015/application/pdf/ws_1_and_2.pdf [Accessed 6 November 2015]. 
Establishing a robust, effective and transparent follow-up and review framework as part of the Paris Agreement will be critical in this context.

The following sections look into the opportunities for further enhancing mitigation action to narrow and potentially bridge the emissions gap, which would support the transition towards a low carbon economy and facilitate overachievement of the emission reductions put forward in the INDCs.

\subsection{Bridging the gap - realizing emission reduction potentials by 2020 and 2030}

\subsubsection{The critical role of boosting pre-2020 mitigation action}

The importance of increasing pre-2020 mitigation action was underscored in Chapter 2. Reducing emissions compared to the current policy trajectories before 2020 will not only improve the chances for achieving the stringent emission reductions that are required after 2020 to limit warming to below $2^{\circ} \mathrm{C}$ by 2100 . It will also reduce the costs of emission reductions, avoid lock-in of carbon and energy intensive infrastructure, and lower the risk associated with substantial dependence on negative emissions beyond 2050 to limit global warming to $2^{\circ} \mathrm{C}$. In addition, as shown in Chapter 2 , enhanced early action that goes beyond current policies would facilitate maintaining the option of limiting warming to below $1.5^{\circ} \mathrm{C}$ in 2100 (with a greater than 50 per cent chance).

Previous Emissions Gap Reports (UNEP, 2011, 2012, 2013) showed estimates of the aggregate emission reduction potential by sector by $2020^{2}$. This potential was based on studies that assumed earlier and more stringent mitigation action than indicated by the current policy trajectory. As we get closer to 2020, it is no longer possible to realize the full 2020 emission reduction potential referred to in previous Emissions Gap Reports. One reason is that often there is a considerable time lag between the adoption of emission reducing policies and options, their implementation and the reaping of the associated emission reductions. In addition, failure to invest in best available technologies and options as early as possible constrains our ability, in the near-future, to reduce emissions in some sectors and cross-cutting areas, because of lock-in of higher-energy use and emission investments with long timeframes.

The size of the remaining emission reduction potential by 2020 is difficult to assess, as few comprehensive updated studies are available. However, three recent technical reports by the UNFCCC (2014a, 2014b, 2015) highlight that significant emission reduction potential by 2020 remains. These reports focus on the thematic areas of renewable energy; energy efficiency; land use; urban environments; carbon dioxide capture, use and storage; and non-carbon dioxide GHG emissions. Another recent study finds that scaling up and replicating current good practices could, reduce global emissions by around

2 Assessed in previous Emissions Gap Reports to be in the order of $17 \pm 3$ $\mathrm{GtCO}_{2} \mathrm{e}$, adopting a sectoral bottom-up approach, with marginal costs of up to US\$50-100/ $\mathrm{tCO}_{2} \mathrm{e}$.
4.6 $\mathrm{GtCO}_{2}$ ein 2020, if wide-spread and urgentaction is undertaken (Fekete et al., 2015).

\subsubsection{Reaping emission reduction potentials by 2030 to narrow and potentially bridge the gap}

\section{Extensive emission reduction potential by 2030}

Looking beyond 2020, a number of recent studies and reports, including by the IPCC and leading international institutions, identify a significant emissions reduction potential by 2030 (IPCC, 2014b; IRENA, 2014; Fekete et al., 2015; GCEC, 2015a; IDDRI, 2015; IEA, 2015a; JRC, 2015; OECD/IEA/ NEA/ITF, 2015). Acknowledging that the methodologies, assumptions, scope and coverage of measures vary across these studies, they all document that tapping into unused emission reduction potential could narrow the emissions gap in 2030 considerably.

Specific examples are presented in Table 4.1 showing emission reduction opportunities by 2030 estimated by different studies, and how this potential relates to the gap assessment findings presented in Chapter 3. Only studies that allow comparison of emission reductions relative to the INDC case levels are included in the table. Several other recent studies show sizeable emission reduction potential in specific sectors or thematic areas, but cannot be directly compared to the 2030 baseline, current policy trajectory and INDC emission levels from Chapter 3 and are therefore not included in the table.

Taken together, the studies shown in Table 4.1 indicate that global GHG emissions could be further reduced in 2030 by between $5-12 \mathrm{GtCO}_{2} \mathrm{e}$ (range: $3-13$ ) relative to the emissions level resulting from implementation of the unconditional INDCs, and between 5-10 $\mathrm{GtCO}_{2}$ e (range: 1 -11) relative to the emissions level associated with implementation of the conditional INDCs. Such reductions would significantly narrow the emissions gap in 2030, which as previously stated is estimated at $14 \mathrm{GtCO}_{2} \mathrm{e}$ (range: 12-17) for the unconditional INDC case, and at $12 \mathrm{GtCO}_{2} \mathrm{e}$ (range: 10-15), if both unconditional and conditional INDCs are implemented. Furthermore, the studies rely exclusively on implementation of proven technologies and policies.

There is considerable uncertainty associated with the emission reduction potential estimated in the studies included in Table 4.1. On the other hand, the studies do not cover all possible measures, thematic areas or sectors. The study by NCI, PBL and IIASA (Fekete et al., 2015), for example, excludes potential emission reductions in agriculture, parts of the transport and industrial sector, waste, and bunkers. Similarly, the IEA study only considers options for reducing energy-related $\mathrm{CO}_{2}$ emissions.

In other words the total technical and economic emission reduction potential in 2030 could very well be larger than indicated in the table. Other sources like the Fourth Assessment Report, AR4, of the IPCC (2007) provided an estimate of total emission reduction potential in 2030 of 
Table 4.1: Illustration of estimated emission reduction potentials by 2030 from various studies

\begin{tabular}{|c|c|c|c|}
\hline Study & $\begin{array}{l}\text { Emission reduction } \\
\text { compared to baseline }\end{array}$ & $\begin{array}{l}\text { Emission reduction } \\
\text { compared to current policy } \\
\text { trajectory }\end{array}$ & $\begin{array}{l}\text { Emission reduction compared } \\
\text { to INDCs unconditional / } \\
\text { conditional }\end{array}$ \\
\hline & \multicolumn{3}{|l|}{$\begin{array}{l}\text { GtCO } \\
\text { Median by } 2030 \\
\text { (range) }\end{array}$} \\
\hline $\begin{array}{l}\text { Emission reduction required to transition to } \\
2^{\circ} \mathrm{C} \text { pathways }\end{array}$ & $23(18-28)$ & $18(16-20)$ & $14(12-17) / 12(10-15)$ \\
\hline “Global mitigation scenario” (JRC, 2015) & 19.5 & 14.5 & $11 / 8.5$ \\
\hline \multicolumn{4}{|c|}{$\begin{array}{l}\text { Assumes a rapid intensification of policies across several world countries from } 2015 \text {, leading to a peak in emissions as early as } 2020 \text {. A } \\
\text { progressive convergence of underlying carbon prices after } 2030 \text {, depending on their per capita income, leads to an emissions profile by } 2050 \\
\text { that is compatible with the below } 2^{\circ} \mathrm{C} \text { target. }\end{array}$} \\
\hline $\begin{array}{l}\text { NewClimate Institute (NCI), PBL } \\
\text { Netherlands, and International Institute } \\
\text { for Applied Systems Analysis (IIASA) } \\
\text { (Fekete et al., 2015) }\end{array}$ & $18-20$ & $13-15$ & $9-12 / 7-10$ \\
\hline \multicolumn{4}{|c|}{$\begin{array}{l}\text { Considers the global implications of scaling up and replicating current good practice across nine policy areas and actions: 1) Increase } \\
\text { renewable share in electricity through country dependent policy mix; 2) Emission reductions from production of fossil fuels; 3) Promotion } \\
\text { of industrial energy efficiency through country specific policy instruments; 4) HFC and other F-gas emission reductions; 5) Standards for } \\
\text { efficiency of appliances and lighting; } 6 \text { ) Energy efficiency of the building envelope (heating/cooling); 7) Fuel efficiency/emission standards } \\
\text { light duty vehicles; 8) Support Electric cars driven by renewable electricity; and 9) Emission reduction from deforestation. } \\
\text { The following sectors are not included: agriculture, parts of the transport and industrial sector, waste, and bunkers. }\end{array}$} \\
\hline New Climate Economy (GCEC, 2015a) & $17(12-22)^{b}$ & $12(7-17)$ & $8(3-13) / 6(1-11)$ \\
\hline \multicolumn{4}{|c|}{$\begin{array}{l}\text { Identifies } 10 \text { key areas of opportunity for stronger climate action: 1) Accelerate low-carbon development in the world's cities; } 2 \text { ) Restore } \\
\text { and protect agricultural and forest landscapes and increase agricultural productivity; } 3 \text { ) Invest at least US\$1 trillion a year in clean energy by } \\
\text { 2030; 4) Raise energy efficiency standards to the global best; 5) Implement effective carbon pricing; } 6 \text { ) Ensure new infrastructure is climate- } \\
\text { smart; 7) Galvanize low-carbon innovation; 8) Drive low-carbon action through business and investor action; 9) Raise ambition to reduce } \\
\text { international aviation and maritime emissions; and 10) Phase down the use of hydrofluorocarbons. }\end{array}$} \\
\hline “Bridge Scenario" (IEA, 2015a, 2015b)c & 16 & 11 & 5 \\
\hline \multicolumn{4}{|c|}{$\begin{array}{l}\text { Medium coverage. } \\
\text { Includes five energy-related measures: } 1 \text { ) Increasing energy efficiency in the industry, buildings and transport sectors; } 2 \text { ) Progressively } \\
\text { reducing the use of the least-efficient coal-fired power plants and banning their construction; 3) Increasing investment in renewable energy } \\
\text { technologies in the power sector from US\$270 billion in } 2014 \text { to US\$400 billion in } 2030 ; 4) \text { Gradual phasing out of fossil-fuel subsidies to end- } \\
\text { users by 2030; and 5)Reducing methane emissions in oil and gas production. }\end{array}$} \\
\hline
\end{tabular}

Notes: It is not possible to indicate technical and economic potential for specific levels of marginal cost based on the information provided in the studies.

${ }^{a}$ Median and range is indicated where possible. JRC (2015) and IEA (2015a, 2015b) do not provide uncertainty ranges. NCl, PBL, and IIASA (Fekete et al., 2015) provide a range indicating medians of two analyses, but no uncertainty ranges.

${ }^{b}$ The New Climate Economy study (GCEC, 2015a) has baseline emissions in 2030 of 69 GtCO e and indicate a total emission reduction potential of 21 (range: 16-26) $\mathrm{GtCO}_{2} \mathrm{e}$ compared to this baseline level. In the Table, the 2030 baseline emissions of $65 \mathrm{GtCO}_{2}$ e estimated in Chapter 3 are used. Therefore, the total emission reduction potential of the New Climate Economy study has been adjusted by $-4 \mathrm{GtCO}_{2}$ e to be comparable to the Emissions Gap Assessment.

CIEA (2015a, 2015b) only considers CO emissions. As the studies do not indicate the projected energy-related CO emission share of global GHG emissions in 2030, the emission reduction calculations in the table are approximate, based on the assumption that global energy-related $\mathrm{CO}_{2}$ emissions will also account for roughly two-thirds of global GHG emissions in 2030. This study does not distinguish between unconditional and conditional INDCs. Therefore, only one estimate for the emission reduction compared to INDC is included in the Table.

$23 \mathrm{GtCO}_{2} \mathrm{e}$ (range: $\left.16-31\right)^{3}$, which is in the order of magnitude required to bridge the gap in 2030 . An update of the total emission reduction potential in 2030 is not available in the Fifth Assessment Report, AR5, of the IPCC (2014a, 2014b). However, updates for key sectors in AR5 indicate that emission reduction potentials in 2030 remain in the same order of magnitude as in the AR4 (IPCC, 2007).

For the industry sector overall, global mitigation potentials in 2030 of up to $8 \mathrm{GtCO}_{2}$ e are referenced in AR5 (IPCC, 2014b). For the transport sector, the emission reduction potential is assessed to be higher than reported in the AR4, with projected energy efficiency and vehicle performance improvements ranging from $30-50$ per cent in 2030 relative to 2010 (IPCC, 2014a). Similarly, for the building sector, the AR5 reports that mitigation or energy saving potentials often go beyond 30 per cent up to even 60 per cent of the baseline

3 The IPCC (2007) estimated sectoral emission reduction potentials in $\mathrm{GtCO}_{2} \mathrm{e}$ by 2030 with marginal costs in the range of US\$50-100/tCO e as follows: Power sector [2.4-4.7]; Manufacturing industry [2.5-5.5]; Transportation [1.6-2.5]; Buildings [5.4-6.7]; Forestry [1.3-4.2]; Agriculture [2.3-6.4]; and Waste [0.4-1.0]
(IPCC, 2014b) 4 . Analyses have furthermore shown that "[...] technological improvement keeps replenishing the potential for efficiency improvement, so that the potential for costeffective energy efficiency improvement has not been diminishing in spite of continuously improving standards" (IPCC, 2014b).

Finally, for Agriculture, Forestry and Other Land Use (AFOLU), emission reduction potential of supply-side measures is estimated to be 7.2-11 $\mathrm{GtCO}_{2}$ e in 2030 (IPCC, 2014b) ${ }^{5}$.

The studies assessed all emphasize the key importance of enhanced energy efficiency, with a particular emphasis on industry, buildings and transport. Expanded use of renewable energy technologies for power production combined with increased efficiency of fossil fuel-based power production is also considered key. Other key areas and sectors for enhanced mitigation action emphasized in the studies include forestry, agriculture and waste. These are all areas that have been

4 Base years for the studies considered are generally between 2000 and 2010. For mitigation efforts consistent with carbon prices up to US\$100/tCO $2 \mathrm{e}$, of which about a third can be achieved at below US\$20/ $\mathrm{tCO}_{2} \mathrm{e}$. 
assessed in earlier UNEP Emissions Gap Reports and where significant opportunities for bridging the gap have been highlighted through possibilities for replication, acceleration and scaling up proven good practices and policies.

\section{The importance of scaling up good practices and policies}

There is immense potential for reducing emissions through world-wide replication and scaling up of good practices and policies as illustrated above. However, the emission reduction potentials shown in the previous sections can only be realized if strong, long-term and sector-specific policies are put in place at the global and national levels without delay.

Previous editions of the Emissions Gap Report (UNEP 2012, 2013, 2014) have demonstrated how proven policies can be scaled up (both in ambition and geographical reach) across countries and regions taking national differences and circumstances into account. Box 4.3 summarizes key proven policies in different areas considered in earlier Emissions Gap Reports.

\section{Box 4.3: Summary of proven policies for reducing GHG emissions and achieving development goals highlighted in previous UNEP emissions gap reports (source: UNEP 2012, 2013, 2014)}

The 2012, 2013 and 2014 UNEP Emission Gap Reports identify policies in key areas that have proven successful in reducing greenhouse gas emissions in many different countries, while contributing to national development goals. Such policies have the potential to make a significant contribution to bridging the gap, if scaled up in terms of ambition and geographical coverage.

\section{Energy}

These policies are related to improvements in energy efficiency in various sectors:

- Building sector - Regulations for building energy performance or codes for new construction: especially with regards to energy efficiency in heating, cooling appliances and lighting. Most developed countries also need to pay attention to renovating existing buildings in an energy efficient manner

- Industry sector - Country- and subsector-specific approaches rather than standardized policies: due to the diverse nature of the industry sector target policies have proven most effective

- Transport sector - Mandatory fuel economy standards for road vehicles: principal means for slowing down the growing fossil fuel consumption. Often supplemented with measure such as labelling, taxes and incentives, while promoting more efficient transportation modes

- Appliance standards - Regulations that prescribe the energy performance of manufactured products

- Appliance labels - Energy-efficiency labels that are fixed to manufactured products to describe the products' energy performance.

\section{Agriculture}

- Promotion of no-tillage practices

- Improved nutrient and water management in rice production

- Agroforestry: different agricultural management practices that all deliberately include woody perennials on farms and the landscape, and which promote a greater uptake of carbon dioxide from the atmosphere by biomass and soils.

\section{Buildings}

Policies that lower energy use and therefore reduce carbon-dioxide and other emissions (see also under Energy):

- Building codes: regulatory instruments that set standards for specific technologies or energy performance levels and that can be applied to both new buildings and retrofits of existing buildings.

\section{Transport}

These policies reduce energy use and therefore reduce carbon dioxide and other emissions (see also under Energy):

- Transit-oriented development: the practice of mixing residential, commercial and recreational land uses to promote high-density neighbourhoods around public transit stations

- Bus Rapid Transit (BRT): key elements of bus rapid transit include frequent, high-capacity service; higher operating speeds than conventional buses; separated lanes; distinct stations with level boarding; and fare prepayment and unique branding

- Vehicle performance standards: establish minimum requirements based on fuel consumption or greenhouse gas emissions per unit of distance travelled by certain vehicle classes.

The policies included above do not represent a comprehensive list. Moreover, some policies will be more appropriate and successful in reducing emissions in some countries than in others. Their success also depends on how stringently they are implemented. 


\section{Consideration of multiple benefits essential}

Previous editions of the Emissions Gap Report have emphasized that in many, if not most, cases climate change mitigation is not the primary driver for action, but rather a significant co-benefit of sound sectoral and national development planning and policies. The previous Emissions Gap Reports offer examples of how ambitious policy instruments that lead to significant emission reductions can foster innovation and economic growth, bolster national energy security, improve public health and address other key developmental priorities.

The feasibility of introducing, replicating or expanding ambitious regulatory measures, market- and price-based instruments, and command-and-control measures varies across thematic areas, sectors and countries (UNEP, 2012; IPCC, 2014b). In order to build a strong case for enhanced action by policy makers and other stakeholders, it will be important to provide clear and convincing documentation of the wide range of benefits associated with the implementation of the policies and actions that can bring about the needed reductions of GHG emissions (UNEP, 2012).

Numerous studies confirm that many actions that reduce GHG emissions are associated with considerable co-benefits (IPCC, 2014a; Parry, et al., 2014; WB, 2014; Fekete et al., 2015; GCEC, 2015b; Höhne et al., 2015; UNFCCC, 2014a, 2014b, 2015). Accounting for co-benefits reduces the average cost of emission reduction options and increases the total emission reduction potential associated with a net benefit. For energy efficiency options, inclusion of multiple benefits in some cases triples the overall benefit of these options, notably where they heavily reduce coal use (GCEC, 2015b). Options associated with net costs, may also swing to net benefits when co-benefits are taken into account. This is, for example, the case for reduced deforestation, recycling of new waste, and offshore wind (GCEC, 2015b).

Full integration of co-benefits in planning and decisionmaking can thus have profound implications for climate and development action. 


\section{Chapter 5}

\section{International Cooperative Initiatives}

Lead authors: Walter Vergara (UNEP DTU Partnership / World Resources Institute), Michiel Schaeffer (Climate Analytics), Kornelis Blok (Ecofys)

Contributing authors: Andrzej Ancygier (Climate Analytics), Skylar Bee (UNEP DTU Partnership), Philip Drost (United Nations Environment Programme), Lara Esser (Ecofys), Mark Roelfsema (PBL Netherlands Environmental Assessment Agency)

\subsection{Introduction}

The objective of this chapter is to provide an assessment based on published or readily available information of the possible contribution to global mitigation efforts especially by key International Cooperative Initiatives (ICls). In addition, the chapter looks into the role of other groups of non-state actors. In the context of climate mitigation, $\mathrm{ICls}$ are considered to be cooperative efforts led by actors other than Parties to the UNFCCC, but many are undertaken in partnership with national governments whose agencies are very often critical to the realization of the ICIs' emission reduction potential. Many ICls have strong international partners - catalyzing both national and international actions and often providing opportunity for enhancing national ambition.

Across this spectrum, ICls cover a wide range of activities, and although it is a challenge to cover them comprehensively, an effort has been made to assess available information and prioritize initiatives according to their potential mitigation significance. The chapter starts by presenting the results of a number of recent studies regarding the potential emission reduction contribution of ICls together with an assessment as to what extent $\mathrm{ICl}$ contributions can be considered as additional to those anticipated from the Cancun pledges. This is followed by an examination of the links between national level cooperative initiatives and the UNFCCC process, with examples from selected INDCs submitted during 2015. The chapter then presents a detailed overview of ICls grouped into three categories, cities and regions, companies and sectors, which helps illustrate the innovative approaches adopted by many non-state actors and facilitate opportunities for identifying new types of partnerships that could contribute to addressing the mitigation challenge.

A particular effort has been made to examine south-south initiatives that may have been under-represented in past reviews. The chapter focuses on actions on the ground rather than enabling measures, as the former are more quantifiable. Particular attention is given to private sector activities which, under favourable policy and legislative frameworks, strengthen technological innovation.

\subsection{Quantitative impact of ICls on emission reductions}

An earlier estimate of the possible emissions reduction impact of ICls was reported in the Emissions Gap Report 2013 (UNEP, 2013). This report stated a total expected impact of about $10 \mathrm{GtCO}_{2} \mathrm{e}$ in 2020 , based on a number of underlying studies (Blok et al., 2012; IEA, 2013; UNFCCC, 2013).

A number of recent studies have estimated both the gross emission reduction potential of ICls for 2020 and 2030, and, for 2020, attempted to calculate net impacts additional to what will be included in the 2020 pledge achievement. These include a study carried out for UNEP by Ecofys (UNEP, 2015), a study by Yale University (Hsu et al., 2015) and a study by the Netherlands' Environmental Assessment Agency (Roelfsema et al., 2015). An overview of the results, broken down by sector is given in Table 5.4.

Although all studies have comparable methodologies (Mosteller and Hsu, 2015) and consider similar categories, there are marked differences in scope between the studies. UNEP (2015) started from all initiatives gathered on the Climate Initiatives Platform (CIP, 2015), and then selected the most significant ones for quantitative analysis. Commitments made at the New York Climate Summit in 2014 were not included because of their early stage of development. This summit sparked significant new engagement on climate action and a number of new $\mathrm{ICl}$ type commitments were presented (Climate Change Summary, 2014). Hsu et al. (2015) explicitly focus on these new commitments from the Climate Summit. Roelfsema et al. (2015) took a similar approach as the UNEP report, but the authors used a different baseline scenario. They also included major initiatives outside the UNFCCC framework (for example, those of national governments 
under the Montreal Protocol). This is also the only study to project possible emission reduction contributions to 2030, partly through extrapolation. Findings from a further study (CISL/Ecofys, 2015) have been also been included in the assessment, even if the coverage was more restricted. These differences in scope and coverage indicate that the total impact of non-state climate action could be larger than reported by each individual study, as they do not fully overlap.

An overall conclusion of the assessment is that the impact of non-state climate commitments can be very significant, most likely in the range of $2.5-4 \mathrm{GtCO}_{2} \mathrm{e}$ in 2020 (taking into account that not all initiatives are included in all assessments). This already accounts for an estimate of overlap between the various initiatives, in terms of actual actions, sectors, greenhouse gases and regions.

It is difficult to estimate the overlap between these nonstate initiatives and national government pledges for 2020 .
Overlap between these varies from full overlap, for example for the Global Fuel Efficiency Initiative, to virtually no overlap, for example for the international marine and aviation sector (Roelfsema et al., 2015). For countries with economy-wide reduction pledges the overlap is hard to estimate, but likely to be larger, compared to the overlap for countries with very narrowly defined pledges limited to one or two particular sectors. Roelfsema et al. (2015) estimated the overlap for individual initiatives and country pledges and, by aggregating this to the global level, found a total of 70 per cent overlap between initiatives included and government pledges for the year 2020. In contrast, UNEP (2015) found a lower overlap of just 33 per cent at the maximum for the initiatives and country pledges included in their study. As shown in Table 5.1 below, these two key studies would suggest that the estimated range of emission reductions from ICls net of the 2020 pledges is currently in the order of $0.75-2.2 \mathrm{GtCO}_{2} \mathrm{e}$ in 2020.

Table 5.1: Quantitative emission reduction impact of initiatives in 2020, according to different studies (in $\mathrm{MtCO}_{2} \mathrm{e}$ ). All emission reductions are compared to a business-as-usual or current policies scenario

\begin{tabular}{|c|c|c|c|c|c|c|}
\hline \multirow{2}{*}{\multicolumn{2}{|c|}{$\begin{array}{l}\text { Actors or sectors } \\
\text { Target year }\end{array}$}} & \multirow{3}{*}{$\begin{array}{l}\text { UNEP, } 2015 \\
2020 \\
1080\end{array}$} & \multirow{3}{*}{$\begin{array}{l}\begin{array}{c}\text { University of } \\
\text { Yale (Hsu et al., } \\
\text { 2015) }\end{array} \\
2020 \\
454^{1} \\
\end{array}$} & \multirow{2}{*}{$\begin{array}{c}\begin{array}{c}\text { University of } \\
\text { Cambridge (CISL/ } \\
\text { Ecofys, 2015) }\end{array} \\
2020\end{array}$} & \multicolumn{2}{|c|}{$\begin{array}{c}\text { PBL (Roelfsema et al., } \\
\text { 2015) }\end{array}$} \\
\hline & & & & & \multirow{2}{*}{$\begin{array}{l}2020 \\
600^{2}\end{array}$} & \multirow{2}{*}{$\begin{array}{l}2030 \\
700 \\
\end{array}$} \\
\hline Sub-national & Cities and municipalities & & & & & \\
\hline & Regions & 760 & & & & \\
\hline \multicolumn{2}{|l|}{ Companies } & 630 & & $\begin{array}{l}51-100^{3} \\
10-30^{4}\end{array}$ & $800^{5}$ & 1400 \\
\hline \multirow[t]{9}{*}{ Sectors } & Energy efficiency & $60^{6}$ & $1750^{7}$ & 60 & & \\
\hline & Efficient cook stoves & 120 & & & & \\
\hline & Renewable energy & & $0.2^{8}$ & & & \\
\hline & Transport & & & & $200^{9}$ & 500 \\
\hline & Methane and other SLCP & 90 & & & $500^{10}$ & 1300 \\
\hline & Fluorinated GHG & & & $0.0-0.7^{11}$ & 0 & $700^{12}$ \\
\hline & Reduce deforestation & $100^{13}$ & $331^{14}$ & $20-200$ & $300^{15}$ & 700 \\
\hline & Agriculture & 300 & & & & \\
\hline & Shipping and aviation & & & & $200^{16}$ & 500 \\
\hline \multicolumn{2}{|c|}{ Overlap between initiatives } & 200 & & & 200 & 300 \\
\hline \multirow{2}{*}{$\begin{array}{l}\text { Total expected } \\
\text { impact }\end{array}$} & Midpoint & 2900 & 2540 & No total ${ }^{17}$ & 2500 & 5500 \\
\hline & Range & $2500-3300$ & & & & \\
\hline $\begin{array}{l}\% \text { overlap with } \\
\text { national pledges }\end{array}$ & & 33 & & & 70 & \\
\hline $\begin{array}{l}\text { Impact of ICls net } \\
\text { of national pledges }\end{array}$ & & $1700-2200$ & & & 750 & \\
\hline
\end{tabular}

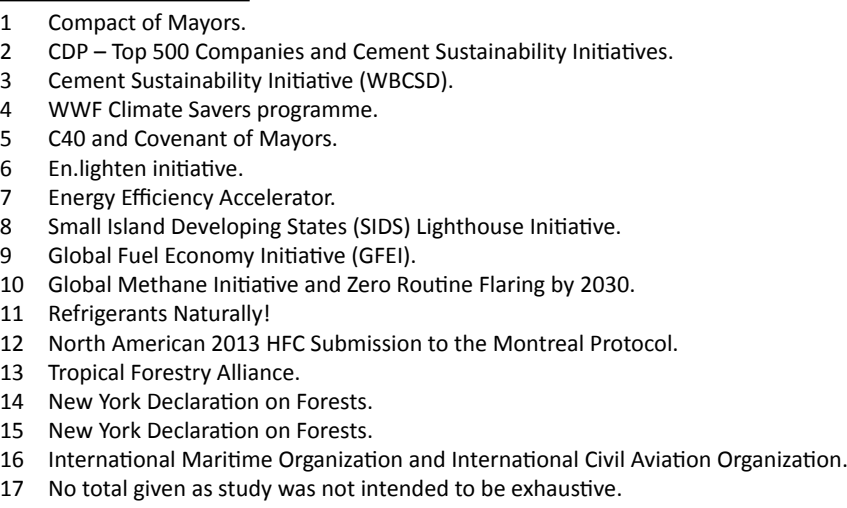


It is important to recognize that the emission reduction impact of the initiatives assessed here assumes that the actors live up to their commitments. It is currently difficult to assess whether international initiatives actually deliver. Most initiatives put forward voluntary commitments which makes it difficult to enforce accountability and compliance. For some initiatives this leads to a lack of robust Monitoring, Reporting and Verification (MRV) (IVM, 2015). In practice, actors may over- or under-deliver compared to their commitments (see section 5.4.2 on delivery by companies). Although the 2013 Emissions Gap Report (UNEP, 2013) quoted a non-state contribution of just under $10 \mathrm{GtCO}_{2} \mathrm{e} / \mathrm{yr}$ by 2020 , this represented an acknowledged overlap with national pledges that was not quantified.

Beyond the possible direct mitigation contribution either as part of fulfilling government pledges or providing additional reductions, it is important to stress the possibilities for growth and acceleration of initiatives. A recent study (CISL/Ecofys, 2015) illustrates in several areas that there is significant potential for scaling up initiatives. The development and engagement of $\mathrm{ICls}$ are rapidly evolving within all the different categories, therefore the results presented in this section must be seen as a snapshot of where ICls stand today.

It would have been very interesting to assess the possible contribution from ICls for 2030 and similarly, as with pledges, to examine how much of this contribution would be additional to the new INDCs. However, although PBL (Roelfsema et al., 2015) does offer an extrapolation of the total expected impact of $\mathrm{ICls}$ in 2030 (midpoint estimate $5.5 \mathrm{GtCO}_{2} \mathrm{e}$ ), it is not feasible at this point to consider questions of 2030 additionality in any meaningful way.

\subsection{Non-state actors and the UNFCCC process}

In view of the importance of cooperative initiatives (often led by non-state actors) in low carbon development, some UNFCCC Parties and observers have called for better representation of their role in the UNFCCC process (Chan and Paux, 2014).

In December 2014 at the COP 20 in Lima, a new platform was launched to showcase climate mitigation initiatives as distinct from national pledges (NAZCA, 2015). The Non-State Actor Zone for Climate Action (NAZCA) signifies a "[...] symbolic step towards considering subnational and non-state actors within the political sphere of the UNFCCC" (Hsu et al., 2015). The platform mainly promotes voluntary action and does not apply a standardised set of compliance, monitoring, reporting and verification rules. Although administered by the UNFCCC, data are primarily contributed by partner organisations and not collected by the UNFCCC itself.

The role of non-state actors has recently expanded due to the need to assist with INDC submissions of the UNFCCC Parties prior to COP 21 in Paris in December 2015. As pointed out by Edwards et al. (2015) "[...] the INDC design process offers an unprecedented opportunity to improve civil society and business participation in climate change policymaking".
Where some developing countries have lacked capacity, non-state actors have been able to assist. Both national and international NGOs have provided know how in connection with preparation of INDCs for different countries (for example, climateanalytics.org, energies2050.org).

Domestic non-state actors have also contributed to the national debate on INDCs. In Brazil, Observatório do Clima, a Brazilian coalition comprising more than 30 NGOs, has estimated annual GHG emissions estimates for Brazil since 2013. Even before the INDC process, the organization had already participated in domestic consultations led by the Ministry of Foreign Affairs. In Senegal, a non-governmental organization, Enda Energie, participated in the sectoral and national reports validation workshops and contributed to the preparation of scenarios used as the basis for the INDC ${ }^{18}$.

The contribution of non-state actors to climate mitigation actions will continue following the submission of INDCs. They can be instrumental not only in facilitating the achievement of the emission reduction targets, but also in monitoring, reporting and verification of actions at national level (Dodwell et al., 2015).

Some INDCs acknowledge the contribution of non-state actors. Mexico states that multiple stakeholders have been consulted during the INDC preparation, including NGOs specializing in adaptation. Interestingly, few INDCs have highlighted the role of non-state initiatives in mitigation. An exception is China, which plans to "[...] conduct lowcarbon cities (towns) pilots as well as low-carbon industrial parks, low-carbon communities, low-carbon business and low-carbon transport pilots" (UNFCCC, 2015). Indonesia mentions "[...] active participation of the private sector, small and medium enterprises, civil society organizations, local communities and the most vulnerable groups [...]" in sustainable forest management (UNFCCC, 2015).

\subsection{Summary of Initiatives}

This section presents a review of the recent literature on ICls with a main focus on initiatives that have substantial mitigation potential. Various reports (Hale and Roger, 2014; Hsu et al., 2015; Roelfsema et al., 2015; Roger et al., 2015; UNEP, 2015) provide an overview of what has been announced or implemented by subnational governments, such as cities, municipalities and regions, company initiatives and initiatives with a specific sectoral focus. Descriptions of initiatives can be found on the Climate Initiatives Platform (CIP, 2015) and the NAZCA portal (NAZCA, 2015). Monitoring, reporting and verification (MRV) arrangements for the various initiatives is also assessed, as this is a key element in providing transparency and ensuring credibility. The ICls considered are grouped into three categories, cities and regions, companies and sectors.

\subsubsection{Cities and regions initiatives}

Subnational governments can act on climate change mitigation in many ways. Sub-national jurisdictions, such as state or regional governments, have even attempted to 
compensate for the lack of political will at the national level (Somanathan et al., 2014).

There are many $\mathrm{ICls}$ in which several cities and regions cooperate; for example, UNEP's recent report on subnational actors lists twenty one initiatives of this type (UNEP, 2015). A few started in the $1990 \mathrm{~s}^{19}$, while the majority started in the period $2005-2012^{20}$ and some were announced during the UN Secretary-General's Climate Summit in September $2014^{21}$. Initiatives focus on the following roles:

- Encouraging or facilitating emission reductions at the city and regional level, via knowledge sharing, capacity building and technical support for project planning and implementation

- Identifying partnerships and supporting local communities to become climate resilient

- Representing common city-level interests to influence policymakers at other levels

- Helping implement climate plans and low-carbon and climate-resilient economic development projects

- Achieving transparency and accountability by encouraging best practice in GHG emission reporting

- Helping overcome financial barriers and attract investors and accelerate additional capital flows into cities for low carbon projects.

The overview identifies those cities and regions initiatives with members who have committed to GHG emission reductions. In most cases they have (or plan to have) inventories or registries to report both their goals and their past and current GHG emissions, with the aim of promoting transparency and accountability. The following initiatives fall into this category: C40, carbonn (including Mexico City Pact and WWF Earth Hour City Challenge), Covenant of Mayors, Climate Group's States and Regions, Compact of Mayors and Compact of States and Regions (see Table 5.2). There is an overlap in membership between some of these various initiatives.

\section{Monitoring, reporting and verification}

The Covenant of Mayors provides European local governments with guidance on how to develop a Sustainable Energy Action Plan (SEAP). Once this is adopted, implementation towards the goal is monitored. As of July 2015, about 460 monitoring reports were available from 2882 adopted SEAPs. C40 cities reporting via the CDP22 are asked to report using the primary protocol standard or methodology to calculate GHG emissions (for example, 2006 IPCC Guidelines for National Greenhouse Gas Inventories, Global Protocol for Community-Scale Greenhouse Gas Emissions Inventories (GPC) (WRI, C40 and ICLEI, 2014)).

19 Including Climate Alliance, Energy Cities, ICLEI - Local Governments for Sustainability.

20 Including C40 Cities Climate Leadership Group (C40), U.S. Conference of Mayors' Climate Protection Agreement (MCPA), World Mayors Council on Climate Change (WMCCC), Connected Urban Development, Transition Network, The Climate Registry, Covenant of Mayors, EUROCITIES Declaration on Climate Change, carbonn Climate Registry (cCR), Mexico City Pact, R20, WWF Earth Hour City Challenge (EHCC), The Clean Revolution.

21 Including City Creditworthiness Partnership, Compact of Mayors, Compact of States and Regions, District Energy Accelerator, The Cities Climate Finance Leadership Alliance.

22 CDP (formerly Carbon Disclosure Project) is an organization focussed on monitoring GHG emission performance and climate action engagement for companies and other actors.
Cities participating in the Compact of Mayors are requested to use the Global Protocol for Community-scale GHG emissions (GPC) and they are also required within 3 years to submit a climate action plan which includes an implementation and monitoring plan.

The cities and regions initiatives generally have designated registries (see Table 5.2). In the case of the newer initiatives such as the Compact of Cities and Compact of States and Regions, signatories have the choice of reporting to the carbonn Climate Registry or CDP. In addition to reporting on GHG emissions, signatories are requested to advise which GHG protocol and emissions factors were applied. The Compact of Mayors requires a complete updated inventory every three years ${ }^{23}$. Annual reports or summaries are published by the initiatives or the reporting platform. These include the total planned emission reductions and often the base year of emissions, without specifying the current progress towards the emission reduction targets. Such information is currently only publicly available for a limited number of cities such as those under the Covenant of Mayors.

The cities that disclose their information to CDP also provide information on whether or not their GHG emissions inventory has been verified by a third party. While the SEAPS that are submitted to the Covenant of Mayor are subject to verification by the European Commission's Joint Research Centre, the monitoring progress reports available for certain cities on the website do not indicate that they are third party verified. Participating authorities to the CDP States and Regions platform will be asked to report whether data sources have been verified.

It is evident from the assessment of cities and regions initiatives that there are a number of different approaches to especially monitoring and reporting and generally limited independent verification. Recent development indicates that the initiatives are gradually building the necessary processes and moving towards more uniform approaches.

23 The year of the inventory should not be more than three years prior to the reporting year - that is, in 2017 inventories must be dated between 2014 and 2016. Over time, the Compact would like cities to update their inventories on a more frequent / annual basis. 


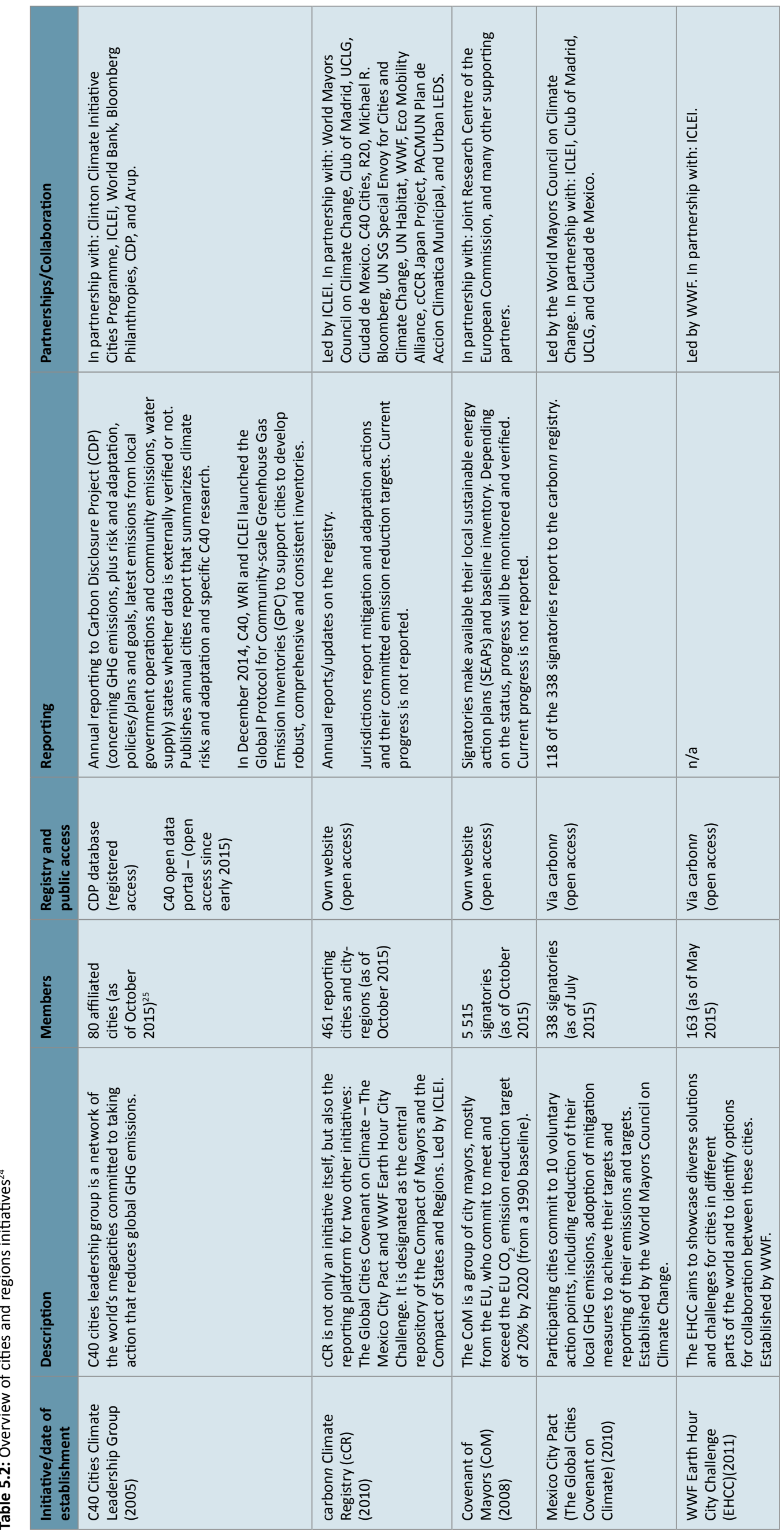




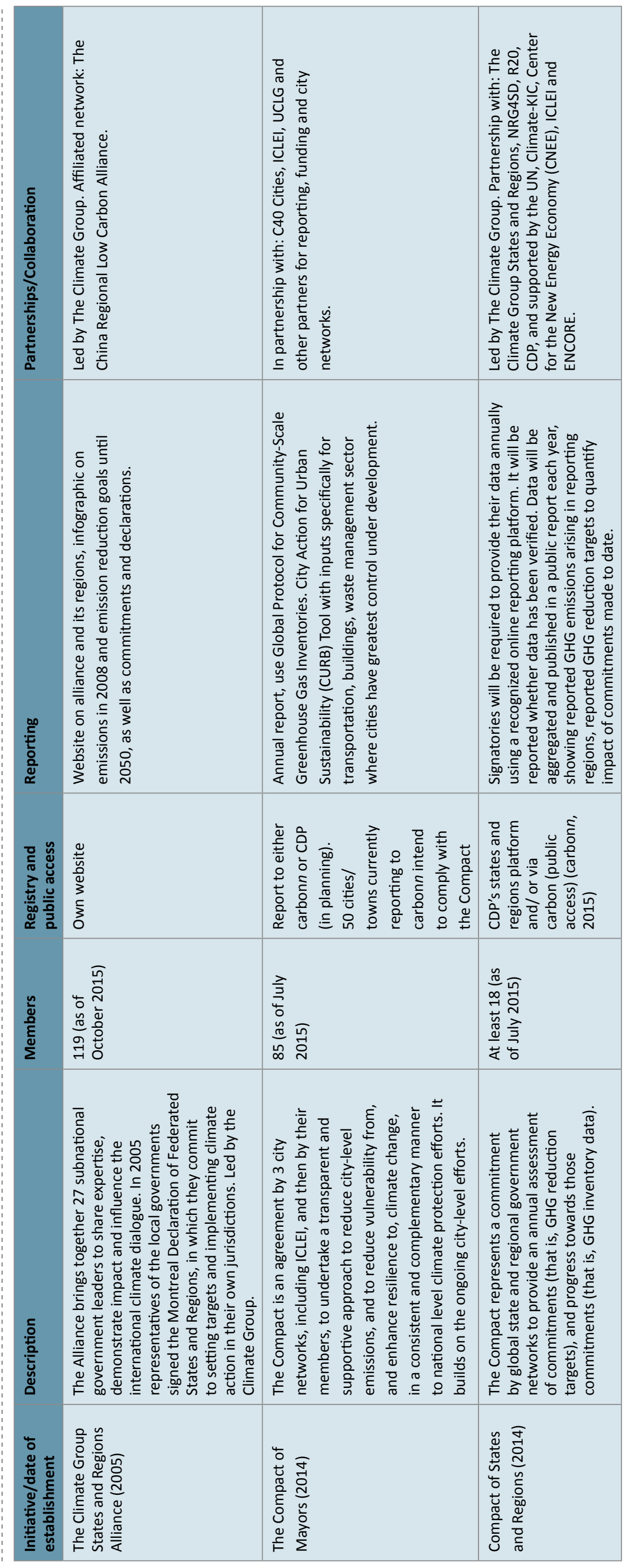




\subsubsection{Companies initiatives}

Another set of ICls engage private sector companies in mitigation activities. A total of 30 such initiatives are currently listed on the Climate Initiatives Platform (CIP, 2015). Many of these initiatives act more as convening platforms for exchange of best practice and advocacy than engaging in direct commitments. But some have objectives that indirectly lead to emission reduction, for example, those aiming to re-direct investment to clean energy.

An overview of companies' initiatives that focus on direct GHG emission reduction is provided in Table 5.3. One common characteristic, of the initiatives with considerable potential for emission reductions (UNEP, 2015), is the requirement for participating companies to set their own emission reduction commitments. The most recent climate initiative assessed in this chapter, the Science Based Target Initiative which was launched in 2014, requests participating companies to set targets that are compatible with a global $2^{\circ} \mathrm{C}$ goal (CDP, WRI and WWF, 2014).

There is a trend towards more collaboration between different kinds of partners. Most private sector companies' initiatives have up to 50 member companies, while others like the Caring for Climate Initiative has over 380 signatories.

\section{Monitoring, reporting and verification}

Among companies initiatives, members of the Cement Sustainability Initiative (CSI) use the Cement $\mathrm{CO}_{2}$ and Energy Protocol, while others reporting via CDP routinely use The Greenhouse Gas Protocol: A Corporate Accounting and Reporting Standard. The Caring for Climate companies are recommended to use CDP's reporting process on an annual basis. Other alternatives are the Global Reporting Initiative (GRI) guidelines and the Global Compact Advanced Communication on Progress (COP).

Almost all companies of the Business Environmental Leadership Council (BELC), the majority of WWF Climate Savers and $\mathrm{CSI}^{26}$ companies, and half of the participating companies of Ultra-Low $\mathrm{CO}_{2}$ Steelmaking (ULCOS) initiative self-report to $\mathrm{CDP}$ by means of a questionnaire. The information related to supply chain or climate change reported to CDP as part of their corporate disclosure can be viewed by registered users. The company can choose via the CDP Platform, whether their disclosure is available to registered users and whether their submission is scored. The Caring for Climate companies should annually report by means of a Communication on Progress-Climate (COPClimate), which is available via the initiative's website ${ }^{27}$.
Annual reports or summaries are published by the various initiatives or reporting platforms, covering total planned emission reductions and often the base year of emissions, without specifying the current progress towards the emission reduction targets.

The companies that disclose their information to the CDP, report whether their information on GHG emissions has been verified, whether assurance is still underway or whether no third party verification took place. The annual reports of Caring for Climate are self-assessed. The overall picture on MRV for company initiatives is, therefore, quite similar to that for cities and regions though with variation in approach and limited evidence of verification at present.

\section{Progress towards goals}

An important question is to what extent companies are on track to reach their goals. According to their Progress Report (Caring for Climate, 2014), which lists both large companies and SMEs, a subsample of 33 large companies with high quality data for 2012 and 2013 demonstrated a decrease in GHG emission levels of around 13 per cent against 2007 levels. However, the CDP Carbon Action Report 2014 (CDP, 2014) suggests that more than half of the companies in its sample did not set absolute targets and a quarter of absolute targets ended in the reporting year. The report notes that 70 per cent of the correctly set absolute targets by companies "[...] will not be achieved in a business-as-usual scenario and further action will be required" (CDP, 2014, p.12).

26 CSI companies can also report their information to a voluntary and independently-managed database of $\mathrm{CO}_{2}$ and energy performance information of the global cement industry called Getting the Numbers Right (GNR). Annual summary information is published. The database covers over 930 individual facilities including non-CSI.

27 Failure to prepare a publicly available COP-Climate report will result in a change of status (to "non-communicating") and eventually in the delisting of a signatory from Caring for Climate. 


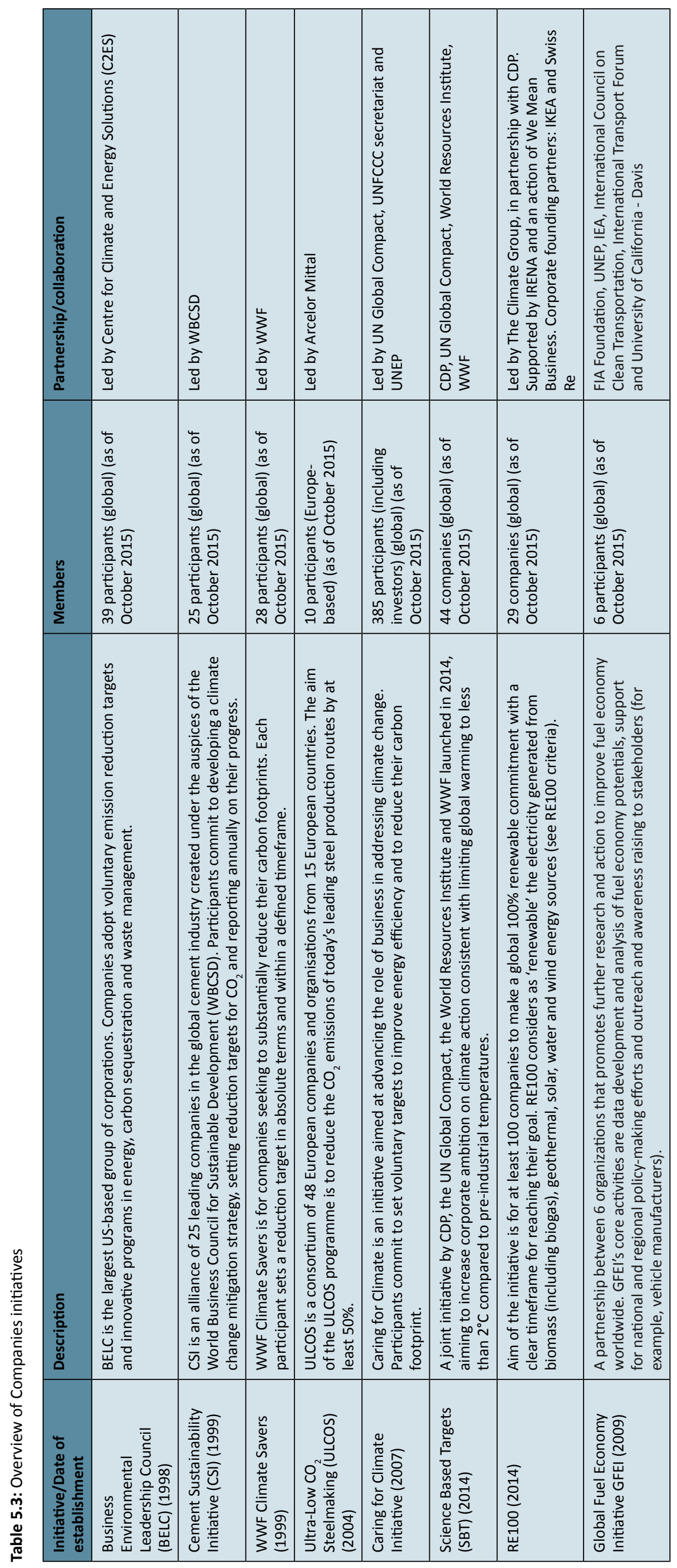




\subsubsection{Sector initiatives}

Sector initiatives are grouped around renewable energy, energy efficiency, industrial processes, low carbon transport, land restoration and reforestation, and marine energy. There is a clear likelihood of overlap between the sector initiatives and the other categories (cities and regions, and companies), but recent estimates indicate this overlap to be relatively small - less than 10 per cent - in the region of $0.21 \mathrm{GtCO}_{2} \mathrm{e} / \mathrm{yr}$ by 2020 on a total impact range of 2.5-3.3 $\mathrm{GtCO}_{2} \mathrm{e} / \mathrm{yr}$ by 2020 (UNEP, 2015). Table 5.4 identifies principal sector-led initiatives.

\subsection{The private sector and innovation in mitigation}

Looking beyond ICls, the private sector is engaged in a wide range of climate activities that have the potential to reduce carbon intensity in many economies (Vergara et al., 2015). Acknowledging the critical role of favourable policy and regulatory frameworks, the private sector is instrumental for innovation, as innovation stems from technology advances, often through new economic and financial opportunities, and market-based risk-taking undertaken by the private sector. Selected examples include:

- Renewable energy, which has seen annual investments grow between 2004-2014 by 500 per cent from US\$45 billion to US\$270 billion (FS UNEP Centre, 2015) partially as a result of significant reductions in capital and operation and maintenance costs. For example, PV utility-size costs have been consistently falling at 22 per cent per year since 1976 (Seba, 2014). Capital costs for wind energy have also seen substantial decreases (IRENA, 2015). This pace of change is already affecting how new capacity is being planned and has the potential to bring substantive additional changes in the power generation market in the near future

- Deployment of distributed power, which has the ability to shift modes of generation and transmission from

Table 5.4: Overview of sector initiatives

\begin{tabular}{|c|c|c|}
\hline Sector & Sector initiative & Objectives and targets \\
\hline \multirow{4}{*}{$\begin{array}{l}\text { Renewable } \\
\text { energy }\end{array}$} & RE 100 & Ambition to attain $100 \%$ renewable energy by 100 leading businesses. \\
\hline & $\begin{array}{l}\text { European Industrial } \\
\text { Renewable Energy Initiative }\end{array}$ & $\begin{array}{l}\text { Initiative for European businesses - PV to supply } 12 \% \text { of EU power by } 2020 \text {; wind to } \\
\text { provide } 34 \% \text { of EU power by } 2030 \text {. }\end{array}$ \\
\hline & Africa Clean Energy Initiative & $\begin{array}{l}\text { Investment in renewable energy through Overseas Private Investment Corporation } \\
\text { (OPIC) - US\$250 million in loans and guarantees in Africa by } 2020 .\end{array}$ \\
\hline & CSP Alliance: USA & $\begin{array}{l}\text { The CSP Alliance comprises solar thermal electric power developers and suppliers who } \\
\text { advocate for the increasing acceptance, adoption and implementation of solar thermal } \\
\text { electric technology and thermal energy storage. }\end{array}$ \\
\hline \multirow[t]{4}{*}{$\begin{array}{l}\text { Energy } \\
\text { efficiency }\end{array}$} & $\begin{array}{l}\text { Sustainable Energy for All } \\
\text { - Global Energy Efficiency } \\
\text { Accelerator }\end{array}$ & $\begin{array}{l}\text { By } 2030 \text {, aiming to contribute to the target of doubling the global rate of improvement } \\
\text { in energy efficiency - driving action by public and private leaders at all levels. }\end{array}$ \\
\hline & Zero Routine Flaring by 2030 & $\begin{array}{l}\text { Major oil companies and governments of oil-producing countries have committed to } \\
\text { end routine gas flaring at oil production sites by } 2030 \text {. }\end{array}$ \\
\hline & $\begin{array}{l}\text { Climate and Clean Air } \\
\text { Coalition }\end{array}$ & $\begin{array}{l}\text { Partnership engaging both countries and non-state actors to reduce short-lived climate } \\
\text { pollutants including methane, black carbon and hydrofluorocarbons (HFCs). }\end{array}$ \\
\hline & Coalition for Energy Savings & $\begin{array}{l}\text { Coalition representing } 400 \text { associations, } 150 \text { companies in } 30 \text { countries in Europe } \\
\text { (aiming for } 40 \% \text { energy savings in } 2030 \text { compared to } 1990 \text { levels). }\end{array}$ \\
\hline \multirow[t]{4}{*}{$\begin{array}{l}\text { Industrial } \\
\text { processes }\end{array}$} & Carbon Disclosure Project & $\begin{array}{l}\text { Improving the management of environmental risk by putting information on climate } \\
\text { change, water and forest-risk at the core of business, investment and policy decision } \\
\text { making. }\end{array}$ \\
\hline & $\begin{array}{l}\text { Cement Sustainability } \\
\text { Initiative }\end{array}$ & $\begin{array}{l}\text { Global effort by } 25 \text { leading cement producers (accounting for over } 30 \% \text { of global } \\
\text { production) to pursue sustainable operations in over } 100 \text { countries. }\end{array}$ \\
\hline & Global Methane Initiative & $\begin{array}{l}\text { A multilateral partnership ( } 14 \text { countries) aiming to reduce global methane emissions } \\
\text { and to advance the abatement, recovery and use of methane as a valuable clean } \\
\text { energy source. }\end{array}$ \\
\hline & $\begin{array}{l}\text { Industrial Energy Efficiency } \\
\text { Coalition }\end{array}$ & $\begin{array}{l}\text { Alliance of private sector companies seeking to promote continuous energy efficiency } \\
\text { improvements in industrial processes in the USA. }\end{array}$ \\
\hline \multirow[t]{2}{*}{$\begin{array}{l}\text { Low carbon } \\
\text { transport }\end{array}$} & $\begin{array}{l}\text { International Civil Aviation } \\
\text { Organisation }\end{array}$ & Targeting $1.5 \%$ fuel use efficiency per year until 2020 and $2 \%$ thereafter. \\
\hline & $\begin{array}{l}\text { Bus Rapid Transit systems } \\
\text { (BRTs) }\end{array}$ & Informal coalition of 64 BRTs in over 40 countries. \\
\hline \multirow{2}{*}{$\begin{array}{l}\text { Land } \\
\text { restoration and } \\
\text { reforestation }\end{array}$} & Bonn Challenge & Targeting restoration of 150 million ha of forests by 2020 . \\
\hline & $20 \times 20$ Initiative & $\begin{array}{l}\text { Targeting restoration of over } 20 \text { million ha of degraded land in Latin America by } 2020 . \\
\text { Eight private impact investors have pledged US\$670 million. }\end{array}$ \\
\hline Marine energy & Marine Energy Council & $\begin{array}{l}\text { Unites technology developers, academia, consultants, suppliers and service providers } \\
\text { representing the wave, tidal, ocean current and riverine sectors focussing attention on } \\
\text { opportunities in marine energy. }\end{array}$ \\
\hline
\end{tabular}


centralized solutions with large grids to local systems with only distribution grids, resulting in lower overall costs in many developing countries, in particular for rural and isolated communities

- Electric power storage, which has seen an average reduction in production costs of 14 per cent per year during the period 2007-2014 and may be at a tipping point for mass production (Nykvist and Nilsson, 2015)

- Electric vehicle technologies, which are projected to potentially disrupt the use of fossil fuels in transport and may represent one of the largest available energy efficiency measures (Vergara et al., 2015), and

- The application of land restoration practices, which can significantly impact accumulation of carbon sinks.
Most, if not all, of these measures are also associated with significant co-benefits, for example through improvements in energy security, reductions in emissions of harmful airborne pollutants, increased food security, and recovery of soil and water quality (IPCC, 2014; Vergara et al., 2015).

Together these developments improve the outlook for substantial reductions in global carbon emissions, in some cases at an unexpected pace, bringing new market solutions into play - working hand in hand with enabling policy from government and behaviour change initiatives in civil society. In the broader picture of raising ambition and closing the gap, these recent developments indicate that acceleration is possible with the right incentives, and action on the ground may eventually surpass formal commitments. 


\section{Chapter 6}

\section{Mitigation potential from forest- related activities and incentives for enhanced action in developing countries}

Lead authors: Lera Miles (UNEP World Conservation Monitoring Centre), Denis Jean Sonwa (Center for International Forestry Research)

Contributing authors: Riyong Kim Bakkegaard (UNEP DTU Partnership), Blaise Bodin (UNEP World Conservation Monitoring Centre), Rebecca Mant (UNEP World Conservation Monitoring Centre), Lisen Runsten (UNEP World Conservation Monitoring Centre), Maria Sanz Sanchez (Food and Agriculture Organization of the United Nations), Kimberly Todd (United Nations Development Programme), Francesco Tubiello (Food and Agriculture Organization of the United Nations), Arief Wijaya (Centre for International Forestry Research / Thuenen Institute Hamburg)

\subsection{Introduction}

Forest-related mitigation activities in both developing and developed countries represent important opportunities for climate change mitigation, and enhanced action on these activities could contribute significantly to narrowing the emissions gap. The IPCC AR5 (Smith et al., 2014) highlights that 12 per cent of global greenhouse gas (GHG) emissions (in the period 2000-2009) come from forests and other land use change. Forests hold large carbon stores within their living biomass (above and below ground), in dead organic matter (litter/dead wood) and in soil. Enhanced mitigation action could involve enhancing carbon stocks in new or existing forests, changes to forest management, and increased reforestation and afforestation.

This chapter starts by providing a global overview of existing statements regarding intended forest-related mitigation actions by countries, including in their INDCs. This is followed by a review of the range of available forest-related mitigation options. International multi-stakeholder partnerships such as the New York Declaration on Forests and the Bonn Challenge on forest landscape restoration have focused on ambitious global objectives for the sector. Over the last ten years, there has also been considerable effort and progress under the UNFCCC in negotiating the set of policy approaches and interventions known as REDD+ (reducing GHG emissions from deforestation and forest degradation, 'plus' conservation of forest carbon stocks, sustainable management of forests and enhancement of forest carbon stocks), which is considered a key option under the UNFCCC for facilitating specific cost-effective contribution to climate change mitigation in developing countries (Eliasch, 2008; UNFCCC, 2009).

Reflecting the political interest in REDD+, the chapter has a special focus on assessing the potential contribution of carbon dioxide emissions reductions and sequestration from forest-related activities in developing countries to bridging the emissions gap in 2030; and the role REDD+ can play as a key instrument to realize these reductions.

\subsection{Global overview of forest-related mitigation engagement}

Countries are already committing to substantial efforts towards forest-related mitigation. To date a total of 109 countries (counting the EU as one), including 94 developing countries ${ }^{1}$, have made statements regarding their willingness to reduce emissions from deforestation and forest degradation, or to enhance forest carbon stocks. Figure 6.1 provides a global overview of these national statements ${ }^{2}$ that are made in a range of different texts and fora including:

- Contributions under UNFCCC:

- Intended Nationally Determined Contributions (INDCS), conditional or unconditional (see Box 6.1): Several countries include quantitative information on anticipated forest-related activities and LULUCF. Of the 82 developing countries that submitted their INDC by 1 October 2015 and included forest-related contributions, the majority aim to undertake actions to reduce forest-related emissions and to enhance forest carbon stocks. Fifteen Annex I countries included forest-related contributions in their INDC of which eight specify these activities, which include reducing forest-related emissions, enhancing forest carbon stock or both

1 For analytical purposes, this chapter requires a list of developing countries. There is no standard UN list, but the UNFCCC states that most of the Convention's 'non-Annex I' Parties are developing, so this set is here used as an approximation (as in the former REDD+ Partnership's Voluntary REDD+ Database). In contrast, Annex I Parties are all industrialized or have economies in transition. http://unfccc.int/parties and observers/items/2704.php, see also http://unfccc.int/parties_and_observers/parties/negotiating_groups/ items/1031.php

2 Underlying data can be found in Annex $\mathrm{C}$, which is available online. 
- Nationally Appropriate Mitigation Actions (NAMAs): Several countries include quantitative information on anticipated forest-related mitigation activities, in hectares or in carbon terms (UNFCCC, 2014a, 2014b, 2014c)

- Bilateral arrangements: Donors (including Germany and Norway) have agreements with Brazil, Ecuador, Ethiopia, Guyana, Indonesia, Liberia and Peru to provide funding conditional upon demonstrated success in contributing to mitigation through REDD+ ('results-based payments'). Other donors have made or are negotiating similar bilateral agreements

- Carbon Fund: Proposals for reductions as documented in ER-PINs (FCPF, 2015)

- International multi-stakeholder partnerships: The New York Declaration on Forests and Bonn Challenge commitments on forest landscape restoration (Bonn Challenge, 2015).

Of the 79 developing country Parties and five Annex I countries that have declared their intention to enhance forest carbon stocks in any of the sources listed above, 36 have quantified the area intended for restoration/ afforestation/reforestation, amounting to a total of over 141 million hectares (ha).

As indicated in Chapter 3, analysis of the emission reduction contribution of LULUCF in INDCs estimates an approximate contribution of $1.6 \mathrm{GtCO}_{2}$ (of which $0.5 \mathrm{GtCO}_{2}$ comes from Annex I countries) from full implementation of unconditional INDCs, increasing to $1.9 \mathrm{GtCO}_{2}$ (range: -0.1-4.3) under full implementation of both unconditional and conditional

Figure 6.1: National statements of intention to undertake forest-related mitigation activities

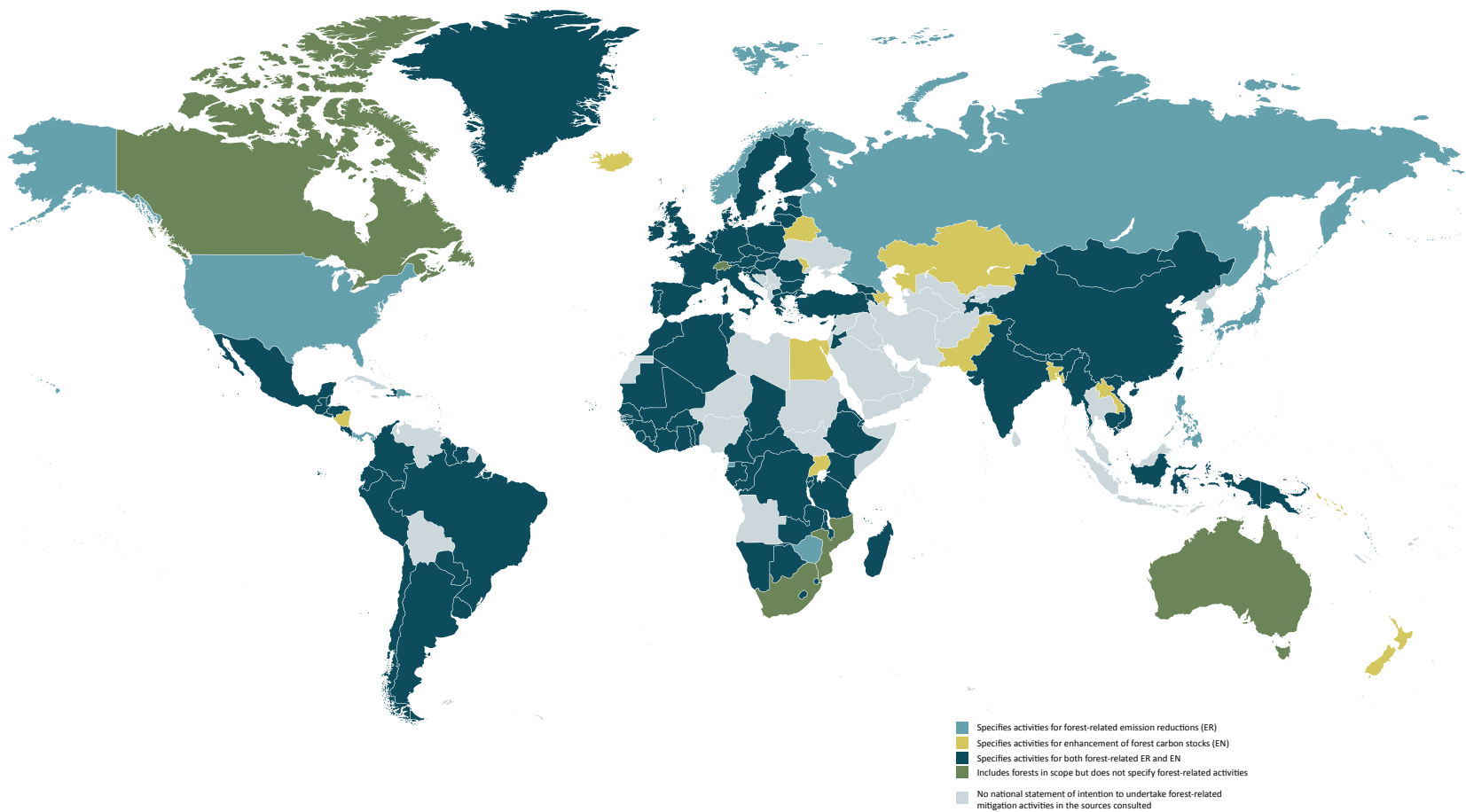

\section{Box 6.1: Forest-related mitigation in INDCs}

Countries that have submitted INDCs describe their forest-related activities in a variety of different ways (see also Chapter 3). Some countries mention that the forest sector is relevant, but do not provide any quantification. Some specify conditional and unconditional contributions without indicating how these are attributed to forests. Some examples of the types of statements in the INDCs are:

- Democratic Republic of Congo: the INDC presents a 17 per cent emissions reduction contribution entirely conditional on finance, and achieved through agriculture, forestry and energy sectors. Forestry activities will focus mainly on afforestation and reforestation

- Ethiopia: the INDC presents a quantified target for mitigation in the forestry sector of $130 \mathrm{MtCO}_{2}$ through protecting and re-establishing forests and increasing carbon stocks, fully conditional on international support

- Brazil: the INDC presents an unconditional economy-wide emissions reduction for 2025. Specifically in the forest sector, implementation and permanence of REDD+ activities require the provision, on a continuous basis, of adequate and predictable results-based payments in accordance with the relevant COP decisions. 
INDCs. The forest-related mitigation potential under the INDCs will be less than this, as forestry comprises a subset of LULUCF activities described in the INDCs. The following sections put these numbers into a broader context of forestrelated mitigation opportunities and potentials.

\subsection{Forest-related mitigation opportunities}

Forest-related mitigation opportunities include maintaining or increasing forest areas and carbon density through reducing deforestation and degradation, afforestation or reforestation, or forest management to increase stand- and landscape-level carbon density (Nabuurs et al., 2007).

Best practice policies to curb deforestation were reviewed in the 2012 Emissions Gap Report (UNEP, 2012). This report highlighted four distinct policy categories, including:

- Establishing new protected areas

- Using command-and-control measures (enacting, enforcing and monitoring of regulations on conversion of forest, may include investment in existing protected areas to prevent incursion (Scharlemann et al., 2010))

- Using economic instruments (taxes, subsidies, payments for ecosystem services), and

- Creating policies affecting drivers and contexts that currently promote deforestation (sectoral policies, institutional frameworks, governance structures and agricultural subsidy reform).

Addressing the drivers of deforestation is critical. On-the-ground measures to reduce pressure on forests include sustainable intensification of agriculture to improve yields on existing land, and alternative livelihoods development for communities dependent on deforestation. Designating new protected areas, indigenous lands and community-managed forests can be effective in preventing deforestation in situ ${ }^{3}$ and avoiding its displacement to other areas. However, forestrelated mitigation approaches are generally found to be more effective if they also address the direct and indirect drivers of land-use change (Ewers and Rodrigues, 2008). Combinations of policies and measures that work at the landscape scale to reduce the drivers of deforestation, whilst identifying and protecting the most valued forests, are most likely to yield multiple benefits (New Climate Economy, 2015).

Reducing degradation and promoting enhancement of forest carbon stocks can also benefit from policies ranging from incentives for best practice to actions to address drivers (for example, fire and unsustainable harvesting). Sustainable forest management can reduce emissions from forest degradation through specific policies and measures, including adoption of reduced-impact logging in areas designated as production forest; prevention of illegal logging; planting of woodlots for poles or charcoal; promotion of more sustainable extraction and efficient use of fuelwood and charcoal; and support to community forestry and development of systems to limit the spread of anthropogenic fires such as those used in agriculture.

3 Though around nine per cent of all deforestation emissions in the humid tropics between 2000 and 2005 resulted from forest cleared from within protected areas (Scharlemann et al., 2010).
Enhancing carbon stocks may involve afforestation or reforestation, with approaches ranging from assisted natural regeneration to tree planting. In areas of disturbed forest, carbon stocks may be enhanced by controlling the degradation drivers covered above and by direct interventions, for example, through enrichment planting (Paquette et al., 2009) or rewetting of drained peatland forest (Jaenicke et al., 2010). Enhancing carbon stocks is one goal among many in the process known as forest landscape restoration, which aims to regain ecological integrity and enhance human well-being in deforested or degraded forest landscapes to meet present and future needs, whilst accommodating multiple uses over time (Maginnis et al., 2012). Forest landscape restoration may involve planting trees on farms, woodlots or agroforestry systems, or establishing new areas of forests to restore and recreate the structure, function and composition of an original forest ecosystem, or both (Lamb and Gilmour, 2003).

Conserving, restoring and sustainably managing forests offers numerous benefits other than carbon storage, strengthening the case for prioritizing forest-related mitigation options. Forests provide essential ecosystem goods and services, such as water quality and regulation (providing more consistent flows of clean water for drinking and agriculture), erosion control (preventing sedimentation of hydropower dams, and protecting other lands downstream), forest products (directly supporting livelihoods, for example through timber, fuelwood, foods, medicine and fibre) and cultural services (supporting cultural traditions and tourism) (Shvidenko et al., 2005). Hence, well-chosen and implemented forestrelated mitigation activities can contribute to many other domestic and international policy objectives, including those defined in the Convention on Biological Diversity's Strategic Plan for Biodiversity 2011-2020 and the Aichi Targets (CBD, 2010), the Sustainable Development Goals (Goal 13 on urgent climate action and Goal 15 including to halt deforestation by 2020) (UNGA, 2015), the UN Declaration on the Rights of Indigenous Peoples (UN, 2008), the UNCCD 10-year strategic plan and framework (UNCCD, 2007) and the Non-Legally Binding Instrument on All Types of Forests (UNGA, 2007). Synergies between adaptation and mitigation also exist in many cases and can, for example, be achieved through ecosystem-based adaptation (Rizvi et al., 2015). Furthermore, forest-related mitigation opportunities are integral to landscape-level mitigation approaches, and complement actions to reduce emissions from agricultural land ${ }^{4}$ and from non-forested peatlands (Smith et al., 2014).

The variety of forest-related mitigation opportunities presented here demonstrates the potential for broad participation by countries in forest-related mitigation according to their national circumstances. Drivers of landuse change, potential for restoration, and climate impacts on forest ecology among many other factors will differ between countries and regions, and determine the appropriate forestrelated mitigation activities.

4 Responsible for a similar quantity of annual GHG emissions, based on $\mathrm{CO}_{2}$ only from deforestation and forest degradation (Table 6.1) compared to all greenhouse gases from agricultural land in 2005 (Smith et al., 2014, Figure 11.4). 


\subsection{Emission reduction potential of forest- related mitigation activities}

The previous sections provided a global overview of countries' intentions regarding forest-related mitigation activities and illustrated the wide range of areas in which such activities can be undertaken. In addition, the estimated LULUCF mitigation contribution in the INDCs was highlighted. While acknowledging the importance of reducing forest-related emissions in all countries, the political interest and emphasis given to REDD+ as a key instrument to realizing forest-based emission reductions reflects the critical role of developing countries in reducing emissions from deforestation.

This section assesses the total potential contribution to bridging the emissions gap in 2030 that could be brought about by forest-related emission reductions in developing countries. More specifically, the section assesses the technical potential for reducing emissions through forestrelated activities in developing countries based on a review of the published literature. The technical potential represents the full biophysical potential of a mitigation option without accounting for economic or other constraints (as defined in Smith et al., 2014, p. 847). It represents a halt of emissions from deforestation and forest degradation including on peatland, and universal 'wide-scale' forest restoration on available and suitable areas. This represents an upper technical maximum and is estimated to be around $9 \mathrm{GtCO}_{2}$ in 2030 (range: 6.7-11.9) (Table 6.1).

Achieving the technical mitigation potential of the forest sector is limited by operational and socio-economic factors. Factors that can place increased demands on forest land include limited capacity to increase production in agriculture, national objectives for food self-sufficiency, infrastructure development, and wood product requirements. Demands can be reduced by factors such as restoring degraded lands to agricultural production, changing dietary preferences or reducing waste. Hence, country goals for forest-related emission reductions and enhancement of carbon stocks need to take into account potential competition with other land uses.

\subsubsection{Technical mitigation potential of reducing carbon dioxide emissions}

A wide range of estimates of global $\mathrm{CO}_{2}$ emissions from deforestation and forest degradation exist (Ciais et al., 2013; Smith et al., 2014). The range reflects uncertainty in data sources, use of different methodologies to estimate emissions, and differences in the land use change processes included, the range of emission sources included and the land-cover definitions adopted (Houghton et al., 2012). For example, the forest definitions used in international analyses are frequently based on those used by FAO's Global Forest Resources Assessment (forest area $>0.5$ ha, tree height $>5 \mathrm{~m}$ and canopy cover $>10$ per cent, or trees able to reach these thresholds in situ, not predominantly under agricultural or urban use) (IPCC, 2006; FAO, 2010a). However, national forest definitions vary widely in terms of thresholds for canopy cover and tree height, and land uses included (Sasaki and Putz, 2009), meaning that vegetation types such as savannas, agroforestry systems, and mangroves may or may not be addressed by forest policies, depending on the country. Differences in definition, not only of land cover types but also land-use change processes, influence both the overall estimated mitigation potential and whether certain emissions result from deforestation or from forest degradation (Romijn et al., 2013).

To estimate the technical mitigation potential of reducing deforestation and degradation and enhancing forest management in 2030 (second and third columns of Table 6.1), recent emissions given by published studies (referenced below the table) are used to approximate future emissions, assuming no further forest-related mitigation action. The business-as-usual scenarios in Clarke et al. (2014) suggest that total emissions from AFOLU (agriculture, forestry and other land use) may remain stable or decline, as they assume a slowing of population growth and increased efficiencies of food production that will contribute to reducing deforestation. Emissions from forest degradation in non-Annex I countries have declined marginally from $1.1 \mathrm{GtCO}_{2} / \mathrm{yr}$ in 2001-2010 to $1 \mathrm{GtCO}_{2} / \mathrm{yr}$ in 2011-2015, but the relative emissions from degradation compared to deforestation have increased from a quarter to a third (Federici et al., 2015). Indeed, in scenarios that consider increased reliance on biofuels for energy generation and climate mitigation, demand for agricultural land continues to grow. Bottom-up assessments of drivers also suggest that pressures will increase (Kissinger et al., 2012). For example, emissions from deforestation in the Congo basin are expected to increase in the future, with average annual deforested area between 2020 and 2030 varying amongst policy scenarios from 0.4 to 1.3 million ha (Megevand, 2013). Hence, the technical mitigation potential from reduced deforestation and forest degradation and enhanced forest management are estimated at 5.2 $\mathrm{GtCO}_{2} / \mathrm{yr}$ (range: 2.1-6.3), and may be a relatively conservative approximation of total potential, assuming that emissions from these sources are likely to continue at present levels or increase.

In the two decades up to 2010, tropical deforestation emissions have been found to represent around 98 per cent of reported deforestation emissions from non-Annex I countries $^{5}$. Therefore tropical deforestation derived from published studies (Harris et al., 2012; Achard et al., 2014) has been used to approximate the technical potential for reduced deforestation in developing countries, which amounts to between 1.7-4.7 $\mathrm{GtCO}_{2} / \mathrm{yr}$, with a mean of $3.4 \mathrm{GtCO}_{2} / \mathrm{yr}$ (Table 6.1).

Forest degradation in non-Annex I countries, including the effects of selective logging, fire or drought, and fuelwood harvest, accounts for around $1 \mathrm{GtCO}_{2} / \mathrm{yr}$ (between 2011-2015 (Federici et al., 2015)), which is very similar to the results found by Grace et al. (2014) for 2000-2012 of a mean of $1 \mathrm{GtCO}_{2} / \mathrm{yr}$ (range: $0.3-1.7)$. In addition, emissions from drainage and fire in forested or deforested peatlands in Southeast Asia were estimated at a mean of $0.8 \mathrm{GtCO}_{2} / \mathrm{yr}$ (drainage in 2006, fire 1998-2009 (Smith et al., 2014, Box 11.1)). Therefore the total

Percentage calculated from FAO (2010b) Global Forest Resources Assessment 2010. Global Tables: Table 11 Trends in carbon stock in living forest biomass 1990-2010. Available at: http://www.fao.org/forestry/fra/fra2010/en/ 
technical potential of reducing degradation and enhancing forest management would equal $1.8 \mathrm{GtCO}_{2} / \mathrm{yr}$.

\subsubsection{Technical mitigation potential of enhanced carbon sequestration}

As noted, increased sequestration, or enhanced removals, of carbon can result from increasing forest area, or through enhancing sequestration in existing forest (for example, rehabilitating degraded forest). When tree density increases, carbon is removed from the atmosphere by the increasing plant biomass, and soil carbon stocks are protected from erosion and may also increase.

Reforestation can take place at a variety of scales, from increasing tree cover in small areas within a mosaic of other land uses (so called 'mosaic restoration') to restoring larger areas ('wide-scale' restoration, see Glossary). The estimated global potential for 'wide-scale' restoration of closed-canopy forest is up to half a billion ha, excluding areas in intensive use (WRI, 2011) $)^{6}$. An additional 1.5 billion ha globally may have the potential for mosaic restoration (WRI, 2011). Mosaic restoration may be easier to undertake as it allows a greater range of land uses, whilst restoring areas to closedcanopy forest is likely to remove more $\mathrm{CO}_{2}$ per unit of area. Depending on ecosystem type, and whether the result is a natural forest or a plantation, areas converted to forest are estimated to remove between about 1 and $35 \mathrm{tCO}_{2}$ per ha per year in above- and below-ground biomass (from default data in IPCC $\left.(2006)^{7}\right)$. If natural forest were simultaneously restored over the 351 million ha with potential for wide-scale restoration in non-Annex I countries in Africa, Asia-Pacific and Latin America and the Caribbean regions, calculated from WRI (2011), this could equate to $3.8 \mathrm{GtCO}_{2} / \mathrm{yr}$ while the forest was re-growing.

Standing, secondary and planted forests also contribute to the global 'terrestrial carbon sink', absorbing $\mathrm{CO}_{2}$ from the atmosphere. The forest carbon sink is estimated to be large and vary widely, from a global value of $3.4 \pm 1 \mathrm{GtCO}_{2} / \mathrm{yr}$ (for the period 2001-2010 (Federici et al., 2015)), to estimates for tropical sinks alone of $6.8 \mathrm{GtCO}_{2} / \mathrm{yr}$ (for the period 2005-2010 (Grace et al., 2014)). The IPCC states with high confidence that increased atmospheric $\mathrm{CO}_{2}$ will lead to increased terrestrial carbon uptake (Ciais et al., 2013), and a recent review suggests that the largest increase has been in woody biomass within savanna (included in some national forest definitions) and non-forest ecosystems (Liu et al., 2015). Carbon sink figures for existing forests are not included in the technical potential for reduced deforestation given here, as a result of the uncertainty surrounding how carbon sinks and their capacity to absorb $\mathrm{CO}_{2}$ will change in the changing climate (Bellassen and Luyssaert, 2014).

\subsubsection{Economic mitigation potential of forest- related mitigation}

A number of recent studies estimate the global economic mitigation potential in 2030 of various forest-related activities given economic and land-use constraints, at different levels of costs and for different regions of the world.

Table 6.1: Technical potential for forest related mitigation activities for developing countries (GtCO in 2030, median (range)).

\begin{tabular}{|l|l|l|l|l|}
\hline & Reduced deforestation & $\begin{array}{l}\text { Reduced degradation } \\
\text { and forest management }\end{array}$ & $\begin{array}{l}\text { Afforestation and } \\
\text { reforestation }\end{array}$ & Totals \\
\hline Regions & Technical (tropics) ${ }^{\text {a,b }}$ & $\begin{array}{l}\text { Technical (degradation, } \\
\text { tropics) }\end{array}$ & $\begin{array}{l}\text { Technical (non-Annex I } \\
\text { countries) }\end{array}$ & Technical \\
\hline Africa & $0.6(0.2-0.8)$ & $0.5(0.2-0.9)$ & 1.6 & $2.7(1.9-3.3)$ \\
\hline $\begin{array}{l}\text { Latin America and } \\
\text { Caribbean }\end{array}$ & $1.9(1.2-2.5)$ & $0.1(0-0.2)$ & 1 & $3(2.3-3.7)$ \\
\hline Asia-Pacific & $1(0.4-1.4)$ & $0.3(0.1-0.6)$ & 1.2 & 2.5 (1.7-3.1) \\
\hline Peatland degradation & - & 0.8 & - & $\mathbf{3}$ \\
\hline Totals & $\mathbf{3 . 5 ( 1 . 8 - 4 . 7 )}$ & $\mathbf{1 . 7}(\mathbf{0 . 3}-1.7)$ & $\mathbf{3 . 8}$ & $\mathbf{9 ( 6 . 7 - 1 1 . 9 )}$ \\
\hline
\end{tabular}

Notes to Table 6.1:

${ }^{a}$ Achard et al. (2014), Table 2: annual carbon losses from gross loss of tropical forest cover ( $>30 \%$ cover) and other wooded land (<30\% cover) for $2000-2010$. Three estimates from Achard study (Ecozone/IPCC, max and min Saatchi). Tropical regions: Central and South America, Africa, Southeast Asia.

${ }^{\mathrm{b}}$ Harris et al. (2012), Table 1: WHRC and Winrock team's estimates of gross carbon emissions from tropical deforestation, 2000-2005. Tropical regions: Sub-saharan Africa, Latin America, South and Southeast Asia. Only forest biomass carbon stocks.

' Grace et al. (2014), Table 5: estimated annual degradation flux from tropical degradation, 2000-2012. Tropical regions: Africa, America, Asia.

${ }^{\mathrm{d}}$ Total technical potential for degradation includes peatland degradation. Emissions from drainage (in 2006 according to Hooijer et al., 2010 in Smith et al., 2014 ) and fire in forested or deforested peatlands in Southeast Asia (lower estimate for 1998-2009, Box 11.1 in Smith et al., 2014).

eAfforestation and reforestation, including any expansion of forest area (see section 6.3).

${ }^{\mathrm{f}}$ Calculated for this chapter as: area of wide-scale restoration potential WRI (2011) in different FAO ecological zones (FAO, 2012) for non-Annex I countries in UNEP region codes (excluding Europe and West Asia), multiplied by net annual $\mathrm{CO}_{2}$ uptake based on IPCC (2006) [annual net above + below-ground biomass growth, for natural forest in each ecological zone]/ [biomass to carbon conversion factor $=0.47$ ] ${ }^{*}$ [carbon to $\mathrm{CO}_{2}$ conversion factor $=3.67$ ]. This figure is greater than the maximum estimate of $3.4 \mathrm{GtCO}_{2}$ for the similar area of 350 million hectares at 2030 by Wolosin (2014); however that analysis was not restricted to non-Annex I countries and averages over restoration scenarios that include a large proportion of mosaic restoration and improved secondary and naturally regenerated forest, of which will result in a lower average biomass growth per hectare. Use of the IPCC biomass growth figures for plantation forest would yield a still higher estimate. Single source, no range.

6 In (WRI, 2011) closed-canopy forest has a canopy density greater than 45 per cent.

7 In (IPCC, 2006, Tables 4.4 and 4.12) ecosystems from boreal tundra woodland to tropical plantation 
They offer a very large range of estimates of global mitigation potential at different cost levels, ranging from 0-1.5 $\mathrm{GtCO}_{2} \mathrm{e}$ for costs $<\mathrm{US} \$ 20 / \mathrm{tCO}_{2} \mathrm{e}$, to mitigation potentials of 0.1-9.5 $\mathrm{GtCO}_{2} \mathrm{e}$ for costs <US\$50/ $\mathrm{tCO}_{2} \mathrm{e}$, and ranging from $0-13.8 \mathrm{GtCO}_{2}$ e for costs $<U S \$ 100 / \mathrm{tCO}_{2}$ e (Smith et al., 2014). Differences among models reviewed include the cost levels used, the economic assumptions, model approach (bottomup or top-down), and the mitigation options considered. The economic mitigation potential for developing countries is not provided separately. However, it is highlighted that for developing countries the most cost-effective mitigation options in forestry are reducing deforestation, sustainable forest management and afforestation (Nabuurs et al., 2007). Regional breakdowns show that reduced deforestation dominates as the most cost-effective forestry option for Latin America and Middle East and Africa regions, whereas forest management dominates the Asia region (Smith et al., 2014).

In general, the economic mitigation potential will be smaller than the technical potential. Furthermore, estimates of economic mitigation potential do not consider policy incentives and socio-cultural and institutional barriers to implementation of forest-related mitigation activities (Smith et al., 2014), which further affect in either direction the extent to which emission reduction potentials are realized.

Real-world examples of how the results of full-scale realisation of forest mitigation policies might compare to these economic mitigation potentials are limited. Nevertheless, Brazil's success in reducing deforestation by 82 per cent in the Brazilian Amazon between 2004-2014 (INPE, 2015) results from a mix of policies that included expansion of protected areas, supply chain interventions, and positive incentives for landholders (Nepstad et al., 2014) as well as exogenous economic factors such as falling commodity prices (Assunção et al., 2015). This emphasizes the role of socio-cultural, institutional and policy-related contexts for realising forest-related emission reductions.
Nonetheless, the previous sections have indicated that there is significant potential to further reduce forest-related emissions, both compared to current practices and to the contributions indicated in the submitted INDCs. The last section of this chapter focuses on REDD+ as a key option under the UNFCCC for further enhancing forest-related mitigation in developing countries.

\subsection{REDD+ as a key instrument to realize forest-related emission reductions in developing countries}

The immediate and relatively large impact of preserving carbon through reducing deforestation and degradation, as well as the cost-effectiveness of this land use option compared to other mitigation measures (Golub et al., 2010; Smith et al., 2014) has driven the momentum behind development of the REDD+ mechanism. Originally recognizing the contribution of "reducing emissions from deforestation in developing countries" ('RED') (UNFCCC, 2005), the scope was expanded in 2007 to include emissions from degradation and became a component of enhanced action on mitigation ('REDD') (UNFCCC, 2007). In 2009 REDD+ was further expanded to include "conservation of forest carbon stocks, sustainable management of forests and enhancement of forest carbon stocks" ('REDD+') (UNFCCC, 2009) and now represents a specific suite of forest-related mitigation activities in the developing world (see Box 6.2) that countries can implement voluntarily to contribute to the global mitigation effort. Since 2005, the REDD+ framework has evolved under the UNFCCC, adapting to improved understanding of issues regarding potential impacts, methodological accounting, safeguards, and financing (Smith et al., 2014).

At COP 16 in Cancun in 2010, a phased approach to REDD+ was decided "[...] beginning with the development of national strategies or action plans, policies and measures, and capacity-building, followed by the implementation of

\section{Box 6.2: The REDD+ activities}

While the five REDD+ activities are listed in UNFCCC decision text, it is useful to further define these to understand how REDD+ can contribute to forest-related mitigation. Noting that countries will have their own definitions, this chapter adopts:

a) Reducing emissions from deforestation - reducing emissions resulting from conversion of forest to other land uses

b) Reducing emissions from forest degradation - reducing emissions resulting from activities in forest areas that do not result in conversion of forest

c) Conservation of forest carbon stocks - the retention of existing forest carbon stocks. This activity can only make a contribution to mitigation if the carbon stock would otherwise be lost, so it is difficult to estimate mitigation potential separately from (a) or (b). The rationale for inclusion of this activity was to provide conservation incentives for those countries with limited deforestation or stable forest cover

d) Sustainable management of forest - though this could include the whole set of REDD+ forest activities, it is defined more narrowly here as the sustainable management of forest including for timber or fuelwood production (maintaining constant or increasing levels of carbon stocks over multiple harvest cycles) (Miles and Dickson, 2010). This contributes to reduced emissions from forest degradation, and rehabilitation of carbon stocks in degraded forest

e) Enhancement of forest carbon stocks - both the restoration of carbon stocks in degraded forest, and through expansion of forest cover. 
national policies and measures and national strategies or action plans that could involve further capacity-building, technology development and transfer and results-based demonstration activities, and evolving into results-based actions that should be fully measured, reported and verified" (UNFCCC, $2010^{8}$ ). This was to provide a progressive pathway to full-scale REDD+ implementation, taking into account the differing capacities of countries.

Moreover, interventions at the national level are needed to overcome internal displacement of pressures from one area to the next. For this to happen, nationally coordinated cross-sectoral strategies are required, and should be based on an analysis of the drivers of deforestation and forest degradation, and barriers to the sustainable management of forest and enhancement of forest carbon stocks. National, and often, subnational institutions need to be mandated, resourced and have the capacity to implement these strategies. Safeguards need to be promoted and supported - to protect or enhance the many social and environmental values of forest, to respect the knowledge and rights of indigenous peoples and member of local communities, and to enable the full and effective participation of relevant stakeholders, in particular indigenous peoples and local communities. A robust and transparent national forest monitoring system is also required, enabling consistency in data and information to support the implementation of REDD+ activities (UN-REDD Programme, 2013).

Each of these pre-requisites to successful implementation is reflected in a series of decisions made under the 2013 Warsaw Framework on REDD+ (UNFCCC, 2013), which made significant progress on deciding on the coordination of financing, transparency and safeguards, development of national forest monitoring systems, verification at the international level, institutional arrangements to receive results-based finance, and action on drivers of deforestation (UNFCCC, 2013 ${ }^{9}$ ). To access results-based payments for REDD+ activities, actions need to be fully measured, reported and verified. To this end, countries need to have in place:

- A national strategy or action plan,

- A national forest monitoring system (or interim subnational system),

- A safeguards information system and a summary of information on how the REDD+ safeguards have been addressed and respected, and

- A forest reference emission level or forest reference level (or interim subnational reference level).

The contribution of REDD+ to meeting the potential for forest-related mitigation is partly contingent on available resources, first to put these requirements in place and to develop enabling policy frameworks and institutional capacity to implement them (sometimes referred to as 'REDD+ readiness'), and later to supply the financing that

8 Decision 1/CP.16 (UNFCCC, 2010).

9 Decision 9-15/ CP. 19 (UNFCCC, 2013). creates positive incentives for enhanced results-based action on mitigation by developing countries ${ }^{10}$.

The series of decisions made under the 2013 Warsaw Framework on REDD+ (UNFCCC, 2013) has been accompanied by an ongoing and diverse set of early action REDD+ activities and other multilateral, bilateral or country driven initiatives being implemented that contribute to REDD+ readiness or complement the goals of REDD+ (for example, conservation and sustainable forest management).

Despite the complexities that have slowed REDD+ implementation on the ground (Sills et al., 2014), REDD+ is seen as a unique approach to better integrate the forest sector in the broader climate change and sustainable development plans of developing countries. Indeed, support to REDD+ readiness actions offers national benefits to many countries, including the development of national forest monitoring systems, understanding of drivers of deforestation, the strengthening of policies, laws and regulations relevant to the UNFCCC'S REDD+ safeguards, the adoption of wider stakeholder engagement in decisionmaking, and development of better data and information on the distribution of forest carbon stocks, biodiversity and ecosystem services (Lee and Pistorius, 2015). It involves implementing policies and measures that contribute substantially to climate change mitigation, are based on positive incentives for action, and can deliver additional co-benefits. Hence, REDD+ continues to receive political support from many developed and developing countries.

Some major constraints on the potential for REDD+ implementation include the speed at which policies can be put in place and governance improvements can be implemented, as well as competition with other land uses (food security with a growing global population). In principle, national strategies and action plans should take account of these constraints when determining the scale of ambition for REDD+. The availability of finance to cover the readiness and upfront costs of REDD+, whether domestic or international, will also be a determining factor (Streck, 2012).

Many countries have included forest-related mitigation contributions within their INDCs, which can contribute to setting the stage for large-scale implementation of REDD+ in the coming years. Together with an awareness of the challenges facing implementation and building on the existing momentum in this sector, forest-related mitigation activities represent significant opportunities to narrow the emissions gap and facilitate the transition to a low-emission pathway consistent with limiting global average temperature increase to below $2^{\circ} \mathrm{C}$ in 2100 with $>66$ per cent chance.

10 "Results-based finance may come from a wide variety of sources, public and private, bilateral and multilateral, including alternative sources" (UNFCCC, 2013). 


\section{Annex 1}

\section{Country-specific findings}

This Annex presents detailed country-level findings for 13 of the G20 countries that had submitted their INDCs by 1 October 2015. The EU is considered as one (EU28). Accounting for around three quarters of global GHG emissions, the $\mathrm{G} 20$ has the largest effect on the aggregate, global findings of this assessment.

For each country, a brief description of the INDC elements discrepancies between different data sources are discussed. Data are sourced from global studies (if available), national studies, and official government sources. It should be noted that the current policy trajectory emissions are based only on the CAT (2015) and PBL (2015), as well as official and national studies. Other studies do not provide current policy trajectory emission projections. 


\section{Australia}

Australia intends to reduce GHG emissions by 26-28 per cent from 2005 levels including land use, land use change and forestry (LULUCF) by 2030. Australia's target covers all sectors (energy, industrial processes and product use, agriculture, LULUCF, and waste) and gases $\left(\mathrm{CO}_{2}, \mathrm{CH}_{4}\right.$ $\mathrm{N}_{2} \mathrm{O}, \mathrm{HFCs}, \mathrm{PFCs}, \mathrm{SF}_{6}$ and $\mathrm{NF}_{3}$ ).
The four modelling groups which estimated the INDC scenario in 2030 all agree on the impact of Australia's INDC on its emissions in 2030. As an official estimate is not available in Australia's INDC itself, an alternative official country-specific data source was used (Australian Government, 2015). This source provided the 'official estimate' in the Figure below. All models demonstrate a significant difference between current policy trajectories and the INDC trajectory in 2030.

\section{Figure A1.1: GHG emissions of Australia under the 2020 pledge, INDC and current policy}

\section{trajectory case}

The official study is: Australian Government (2015). Noted, CROADS, IEA (adjusted) and NIES are excluded as the results of these studies are presented at a regional level, only cover limited countries

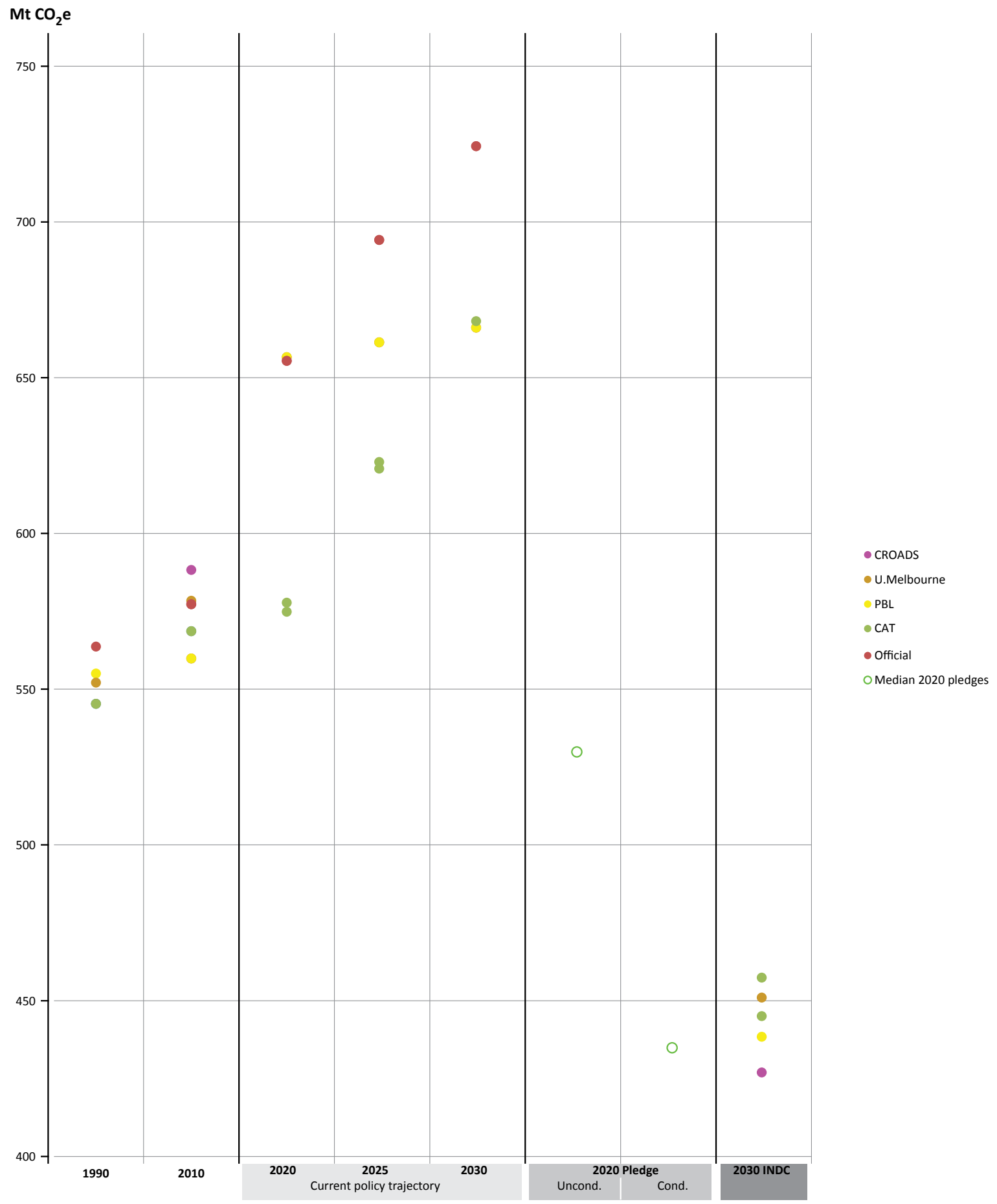


Brazil

The Brazilian INDC establishes an absolute target relative to 2005, reducing GHG emissions by 37 per cent in 2025 and indicating further reductions by 43 per cent in 2030 . These percentage reductions are relative to reported emissions of $2.1 \mathrm{GtCO}_{2} \mathrm{e}$ in 2005 , corresponding respectively to emission levels of $1.3 \mathrm{GtCO}_{2} \mathrm{e}$ in 2025 and $1.2 \mathrm{GtCO}_{2} \mathrm{e}$ in 2030, using IPCC AR5 GWP-100. Brazil's INDC is economy-wide, covers all IPCC sectors and six gases $\left(\mathrm{CO}_{2}, \mathrm{CH}_{4}, \mathrm{~N}_{2} \mathrm{O}, \mathrm{HFCs}, \mathrm{PFCs}\right.$ and
$\mathrm{SF}_{6}$ ), and is unconditional. Actions to achieve the targets focus mainly on the forest sector and on increasing the share of biofuels and renewable electricity in the Brazilian energy mix.

Modelling groups estimate higher historical emission levels than official estimates, but do roughly agree with the projection of the current policy trajectory for 2020. Modelling group estimates for emission levels in 2025 and 2030 are similar to national estimates as they also used official INDC projections.

Figure A1.2: GHG emissions of Brazil under the 2020 pledge, INDC and current policy trajectory case The official study is: INDC Brazil (UNFCCC, 2015)

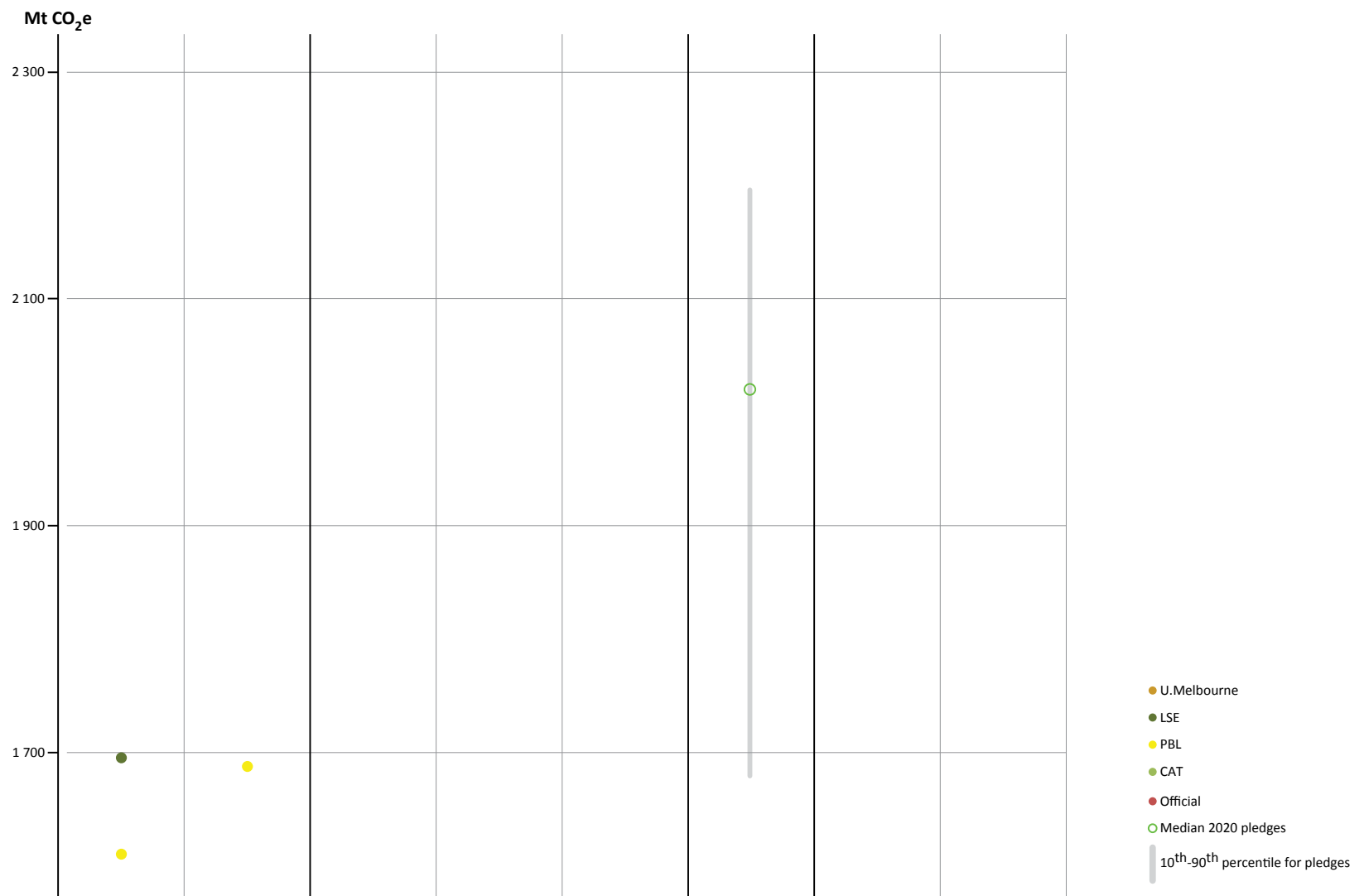




\section{Canada}

Canada proposes an economy-wide target to reduce GHG emissions by 30 per cent below 2005 levels in 2030. Canada's INDC is said to include all sectors and GHG gases. However, there are some uncertainties on the treatment of LULUCF. Although the country declares its target to include all IPCC sectors (excluding emissions from natural disturbances), the
LULUCF sector does not appear to be included in the base year (based on the information presented in the INDC). For that reason, it is possible that the LULUCF sector will be treated separately from the other sectors.

The modelling groups largely agree on the impact of Canada's INDC on its emissions. Projections of Canada's future emissions under current policies, however, vary widely.

Figure A1.3: GHG emissions of Canada under the 2020 pledge, INDC and current trajectory policy case The official and national studies are: UNFCCC inventories for historic data/6th National Communication for projections and the first Biennial Report of Canada (Government of Canada 2014a) and Government of Canada (2014b)

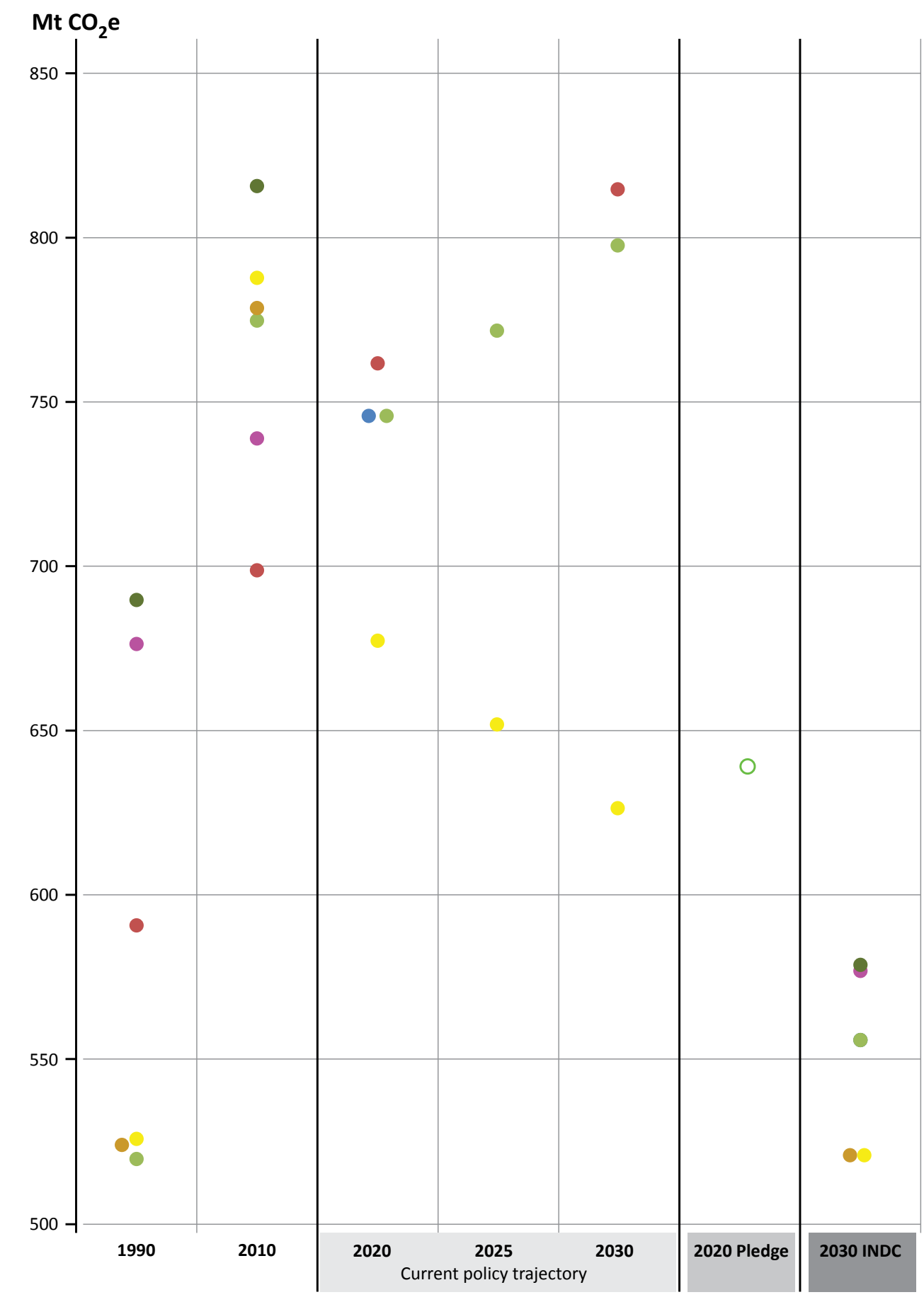

- CROADS

- U.Melbourne

- LSE

PBL

- CAT

- National

- Official

O Median 2020 pledges 


\section{China}

China's INDC includes an intention to peak $\mathrm{CO}_{2}$ emissions around 2030, making best efforts to peak earlier, to reduce the carbon intensity of GDP by 60-65 per cent from 2005 levels by 2030 , to increase the share of non-fossil fuels in primary energy consumption to around 20 per cent by 2030, and to increase the forest stock volume by around 4.5 billion cubic metres from 2005 levels by 2030. Although China's INDC is framed in terms of $\mathrm{CO}_{2}$, the discussion text also implies action on other gases. China's INDC also includes a comprehensive list of actions. The GHG targets cover $\mathrm{CO}_{2}$ but the sectors to which the targets apply are not specified.

The studies assessed show a wide range of potential impacts of China's INDC on national emissions (varying from 12.8-14 $\mathrm{GtCO}_{2} \mathrm{e}$ by 2030), with higher estimates (LSE, CROADS, Climate Advisers), arising, inter alia, from different assumptions on GDP growth rate, different base year data (varying from 9.1-11.3 $\mathrm{GtCO}_{2} \mathrm{e}$ ) and different estimates on emissions other than $\mathrm{CO}_{2}$ emissions from the energy sector (and cement), etc. The higher estimates of LSE, CROADS and Climate Advisers are confined to the INDC intensity target calculations only.

An official estimate is not available, but two national estimates for $\mathrm{CO}_{2}$ emissions from the energy sector (and cement) are available from NCSC (Sha et al., 2015) and updated calculations from Energy Reserarch Institute (ERI) (Jiang et al., 2013). Three studies (CAT, 2015; IEA, 2014, 2015; PBL, 2015) that estimated both China's current policy trajectory and the INDC scenario, demonstrate a further reduction from current policy trajectories to the INDC in 2030.

Only NCSC's estimate adjusts for the possible effect of including energy statistics from the 2014 economic census, which leads to a much higher estimate for China's $\mathrm{CO}_{2}$ emission in 2030 (around $1 \mathrm{GtCO}_{2} \mathrm{e}$ higher than the preadjustment estimate) (Sha et al., 2015).

\section{Figure A1.4: GHG emissions of China under the 2020 pledge, INDC and current policy trajectory case}

The national studies are: NCSC (Sha, et al., 2015) and ERI (updated calculations based on Jiang et al. (2013)). Noted that the higher estimates of LSE, CROADS and Climate Advisers for China on INDC 2030 did not provide current policy trajectory estimates. Three studies (CAT, 2015; IEA, 2014, 2015; PBL, 2015) that estimated both China's current policy trajectory and the INDC scenario, demonstrate a further reduction from current policy trajectories to the INDC in 2030.

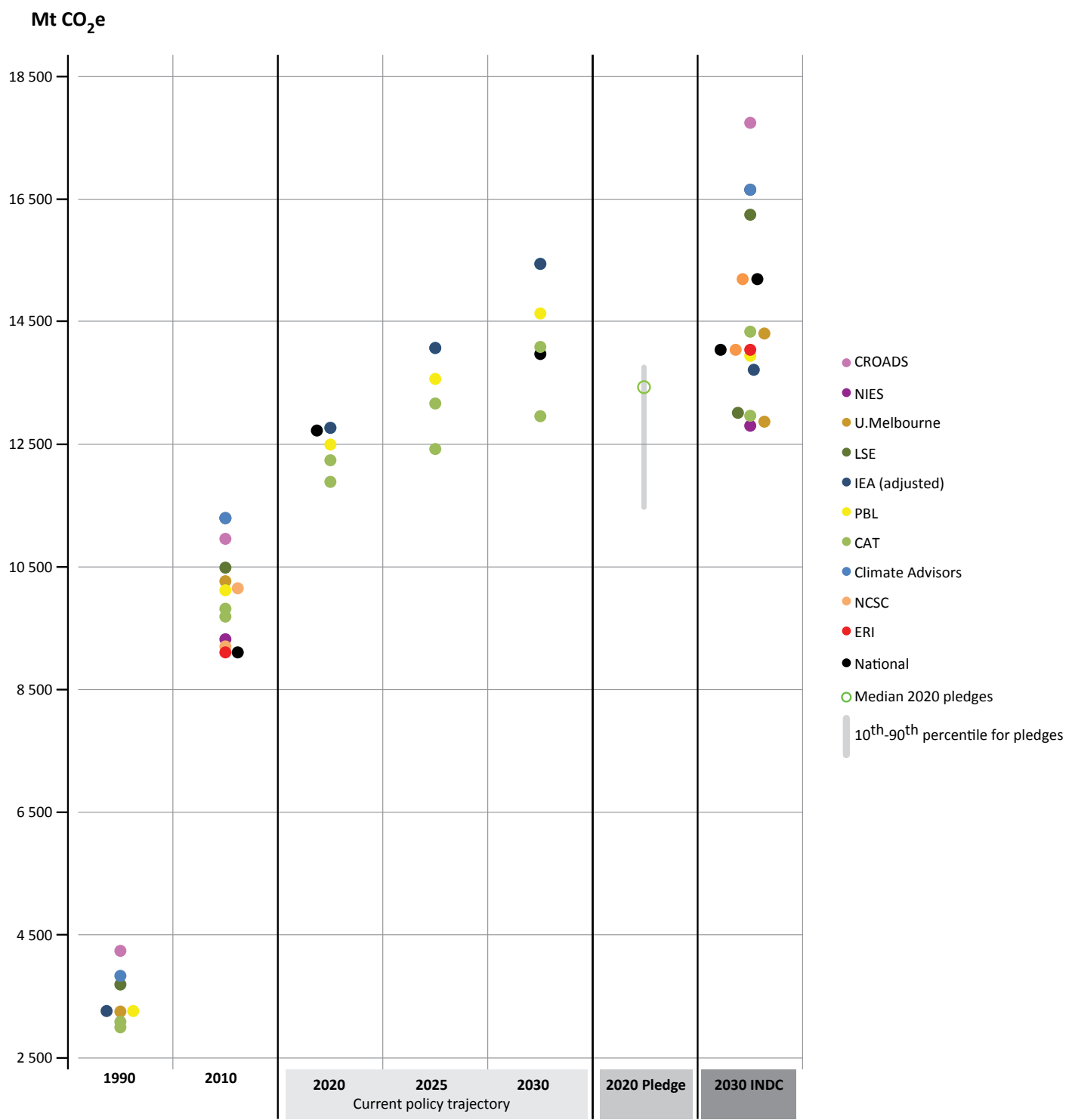




\section{European Union}

The EU proposes a binding target of at least 40 per cent domestic reduction in GHG emissions by 2030 compared to 1990. It includes all sectors and gases. The INDC also states a policy on including LULUCF in the 2030 GHG mitigation framework - to be established as soon as technical conditions allow and in any case before 2020 .
While the modelling groups largely agree on the impact of the EU's INDC on its emissions, the Climate Action Tracker estimates a higher level of emissions in 2030 due to its accounting assumptions regarding LULUCF. CAT (2015) assumes that LULUCF accounting rules may lead to credits for 2030 of the order of 1-4 per cent of 1990 emissions. All other studies assume a net-net approach.

\section{Figure A1.5: GHG emissions of the European Union under the 2020 pledge, INDC and current policy}

trajectory case

The official and national studies are: UNFCCC inventories for historic data/6th National Communication for projections (UNFCCC National Reports, 2015) and EEA (2015)

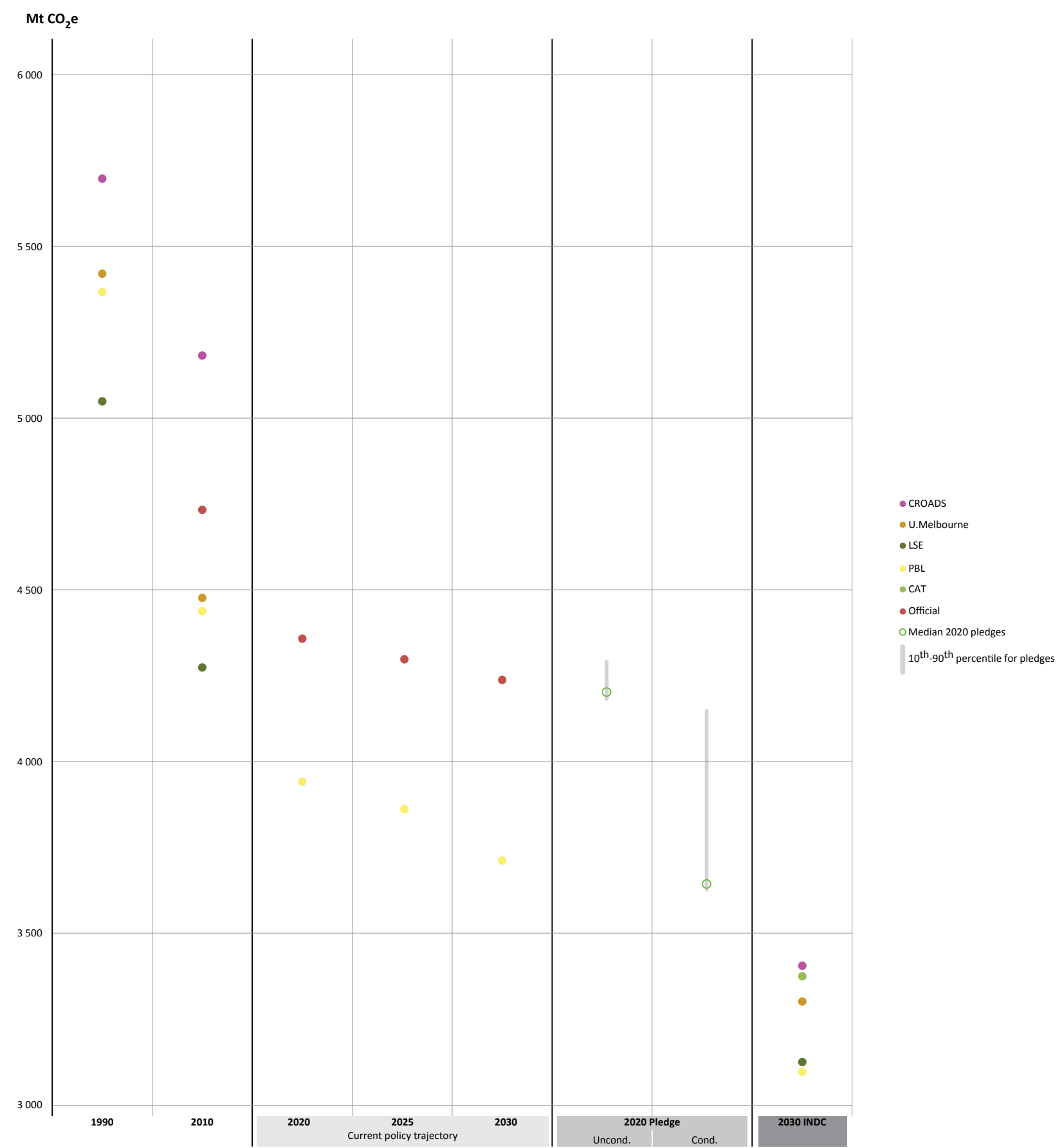


India

India's INDC for the period 2021 to 2030 included the following intentions: "[...] to put forward and further propagate a healthy and sustainable way of living based on traditions and values of conservation and moderation; to adopt a climate friendly and a cleaner path than the one followed hitherto by others at corresponding level of economic development; to reduce the emissions intensity of its GDP by 33 to 35 per cent by 2030 from 2005 level; to achieve about 40 per cent cumulative electric power installed capacity from non-fossil fuel based energy resources by 2030 with the help of transfer of technology and low cost international finance including from Green Climate Fund (GCF); to create an additional carbon sink of 2.5 to 3 billion tonnes of $\mathrm{CO}_{2}$ equivalent through additional forest and tree cover by 2030" (UNFCCC, 2015). The sectors and gases covered by the intensity target are not specified.

The studies assessed show a wide range of potential mitigation impacts of India's INDC on national emissions, varying from 3.7-4.8 $\mathrm{GtCO}_{2}$ e by 2030 for the conditional INDCs (assuming a full implementation of the INDC, including the non-fossil fuel target), and varying from 3.7-6.5 $\mathrm{GtCO}_{2}$ e by 2030 for the unconditional INDCs (assuming current policies, or only accounting for the intensity target). The wide ranges are caused mainly by different assumptions regarding GDP growth rate, different base year data, and interpretation of the conditionality of the INDCs. The higher estimates of LSE and the national study stem from a focus on the INDC intensity target calculations only, and do not consider other INDC elements, such as the non-fossil energy target.

An official estimate of emissions under the INDC is not available. National estimates for $\mathrm{CO}_{2}$ emissions from the energy sector (and cement) are available from Dubash et al. (2015), which are not included here. From Damassa et al. (2015, forthcoming), there are national 'all GHG' projections including land-use for India based on a relatively large range of GDP assumptions (6.3-7.4 per cent average GDP growth for the period 2005-2030), resulting in emissions of 5.7-7.5 $\mathrm{GtCO}_{2}$ e in 2030 .

Figure A1.6: GHG emissions of India under the 2020 pledge, INDC and current policy trajectory case The official and national studies are: INDC India (UNFCCC, 2015) and Damassa et al. (2015, forthcoming)

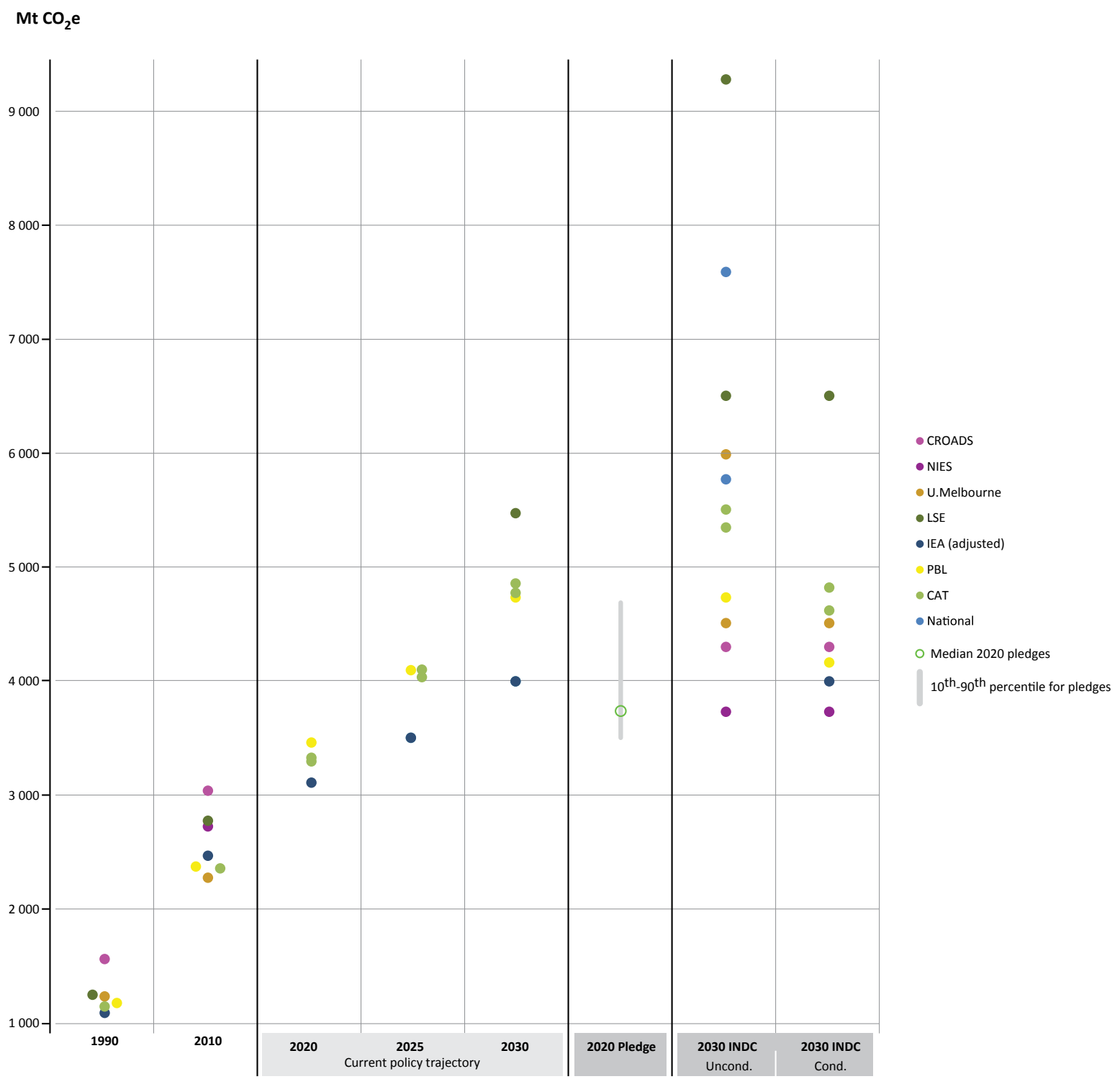




\section{Indonesia}

Indonesia's INDC states that the country “[...] has committed to reduce unconditionally 26 per cent of its greenhouse gases against the business as usual scenario by the year 2020 . Indonesia is committed to reducing emissions by 29 per cent compared to the business as usual (BAU) scenario by 2030". Furthermore, "Indonesia's target should encourage support from international cooperation, which is expected to help
Indonesia to increase its contribution up to 41 per cent reduction in emissions by 2030" (UNFCCC, 2015). Indonesia defines its baseline emissions as $2881 \mathrm{GtCO}_{2} \mathrm{e}$ in 2030. The INDC covers all sectors and $\mathrm{CO}_{2}, \mathrm{CH}_{4}$, and $\mathrm{N}_{2} \mathrm{O}$.

Studies diverge on Indonesia's emissions in all cases, due in part to different assumptions regarding land use emissions, for which data are highly uncertain (for example, den Elzen et al., 2015).

Figure A1.7: GHG emission of Indonesia under the 2020 pledge, INDC and current policy trajectory case

Official sources include: INDC Indonesia (UNFCCC, 2015)

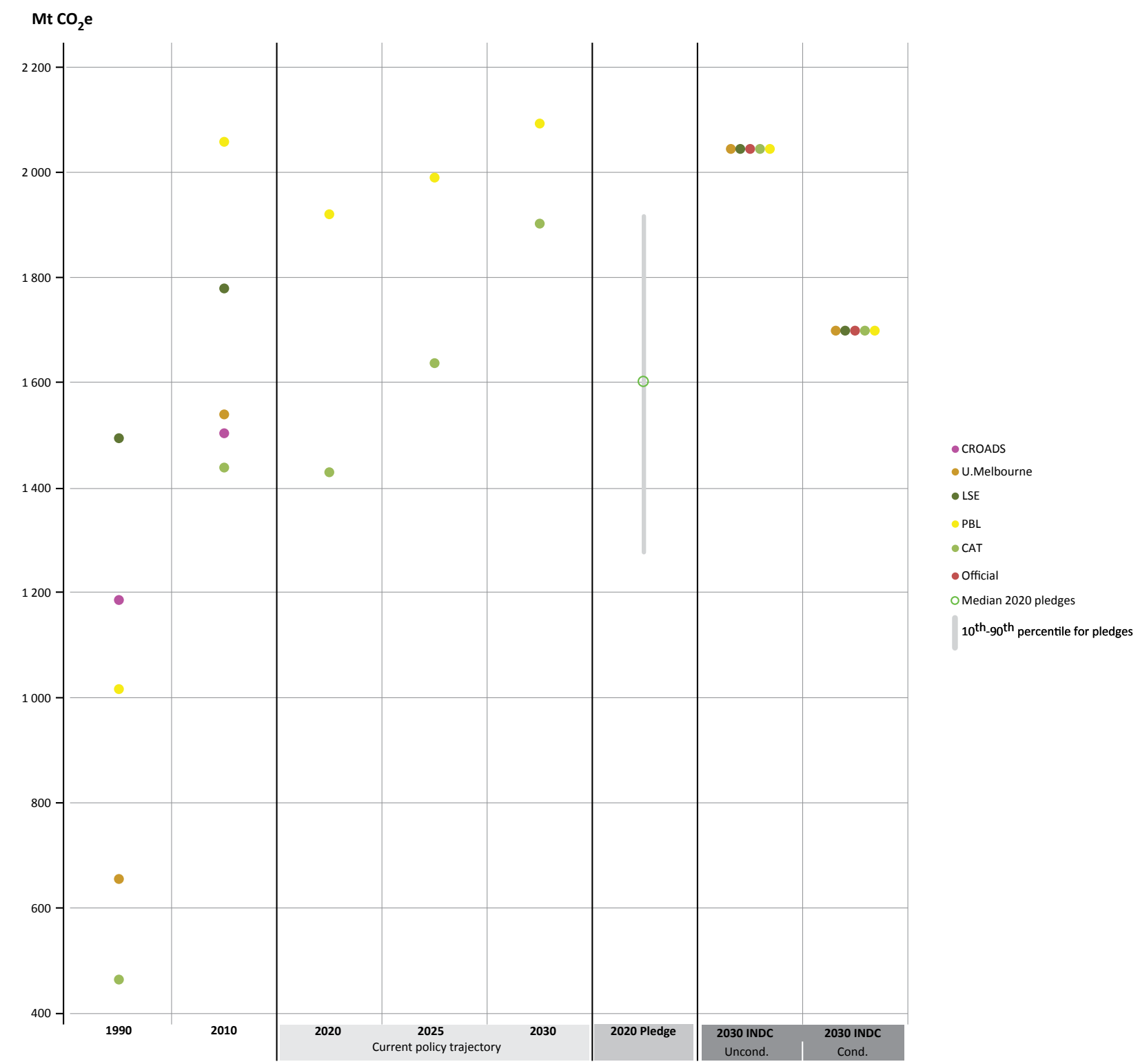




\section{Japan}

Japan's INDC proposes to reduce GHG emissions by 26 per cent by 2030 compared to 2013 levels, equivalent to a 25.4 per cent reduction against 2005 levels. All sectors and all GHGs $\left(\mathrm{CO}_{2}, \mathrm{CH}_{4}, \mathrm{~N}_{2} \mathrm{O}, \mathrm{HFCs}, \mathrm{PFCs}, \mathrm{SF}_{6}\right.$ and $\left.\mathrm{NF}_{3}\right)$ are covered (UNFCCC, 2015).

Figure A1.8: GHG emissions of Japan under the 2020 pledge, INDC and current policy trajectory case The official and national studies are: INDC Japan (UNFCCC, 2015), IDDRI (2015), Damassa et al. (2015, forthcoming) and Kuramochi (2014)

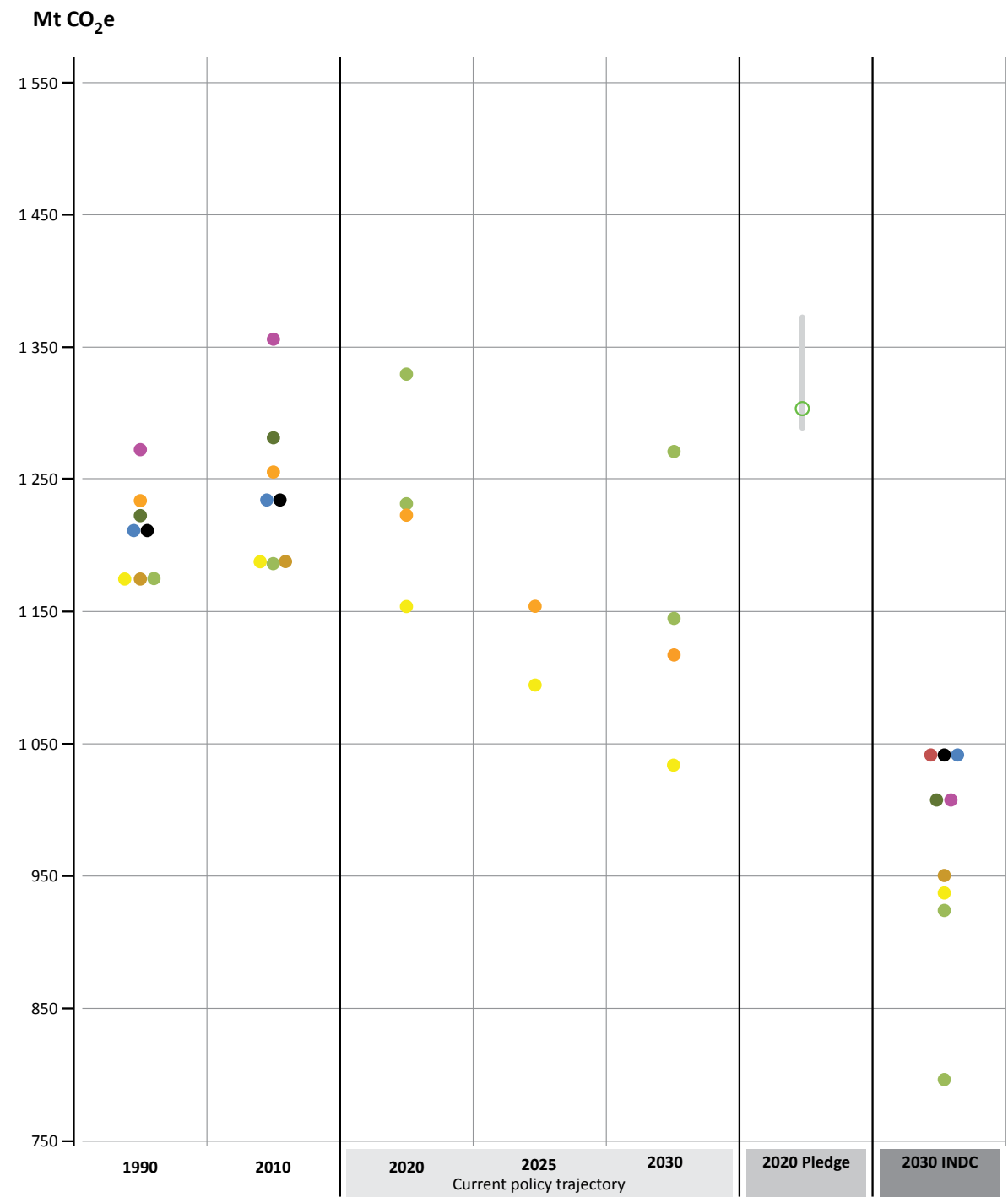

- CROADS

- U.Melbourne

- LSE

PBL

- CAT

- Open Climate Network

- Official

- IDDR

- National

O Median 2020 pledges

$10^{\text {th }}-90^{\text {th }}$ percentile for pledges 


\section{Mexico}

Mexico aims to reduce its GHG emissions by 22 per cent (unconditional) and by 36 per cent (conditional) from BAU by 2030. Mexico's INDC provides the resulting 2030 emission levels in MtCO2e. The target covers all sectors (energy, industrial processes and product use, agriculture, LULUCF, and waste) and six greenhouse gases $\left(\mathrm{CO}_{2}, \mathrm{CH}_{4}, \mathrm{~N}_{2} \mathrm{O}, \mathrm{HFCs}\right.$, PFCs and $\mathrm{SF}_{6}$ ).

Figure A1.9: GHG emissions of Mexico under the 2020 pledge, INDC and current policy trajectory case The official study is: INDC of Mexico (UNFCCC, 2015), and national studies are: Government of Mexico (2012) and SEMARNAT (2013)

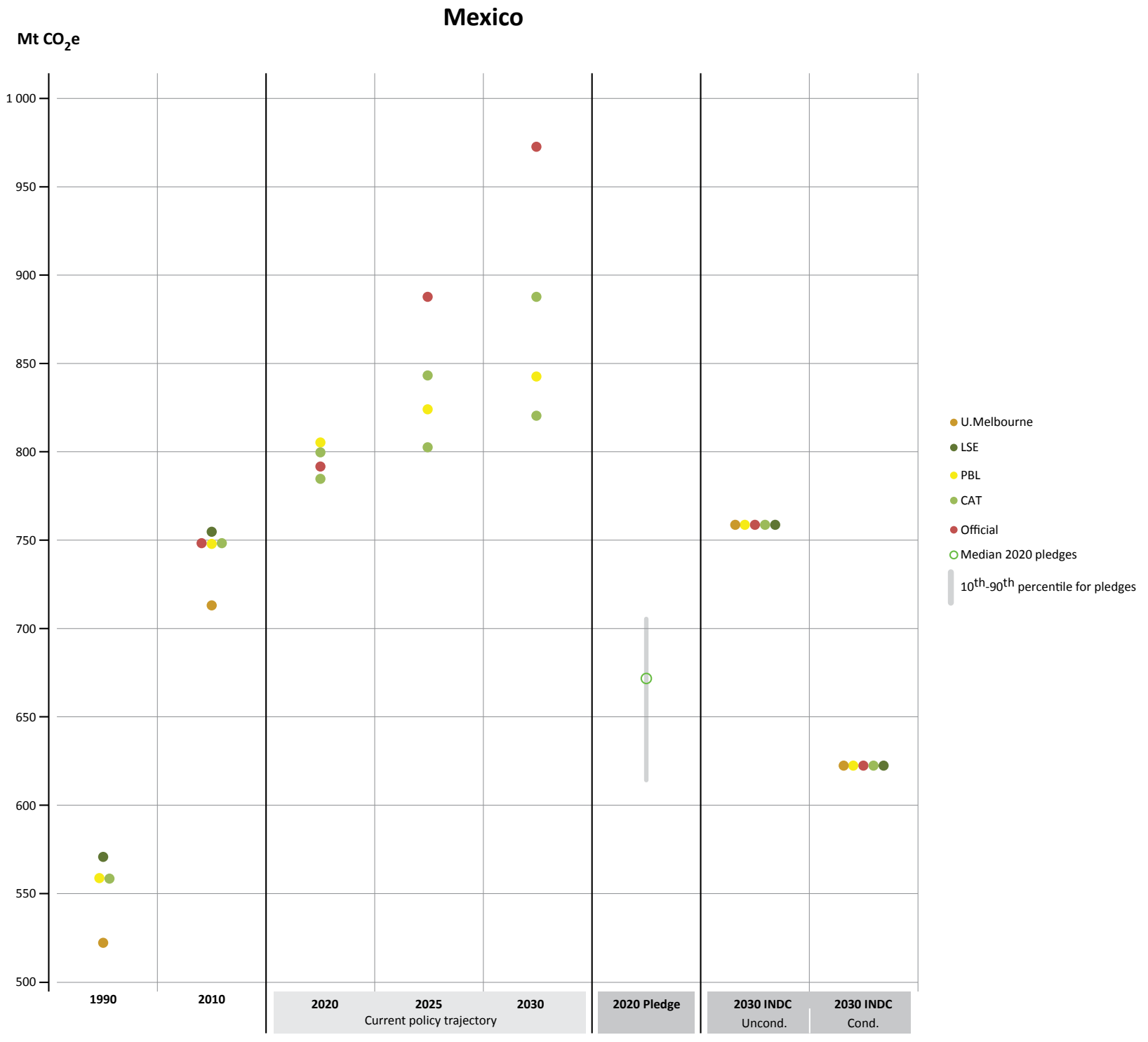

The studies assessed adopted the official estimate of 2030 emissions from the INDC, and therefore agree on this figure. The 2020 pledge presented here is measured from a different baseline than that presented in the INDC (Fransen et al., 2015).
- U.Melbourne

- LSE

Officia

Median 2020 pledges

$10^{\text {th }}-90^{\text {th }}$ percentile for pledges 


\section{Republic of Korea}

The Republic of Korea put forward an economy-wide target to reduce its GHG emissions by 37 per cent from businessas-usual (BAU) by 2030. The Republic of Korea intends to achieve a 25.7 per cent emissions reduction from BAU domestically. The INDC covers energy, industrial processes and product use, agriculture and waste, and states that "[...] a decision will be made at a later stage on whether to include greenhouse gas emissions and sinks of the land sector as well as the method for doing so" (UNFCCC, 2015). The target applies to five sectors (energy, industrial processes and product use, agriculture, LULUCF and waste) and six gases $\left(\mathrm{CO}_{2}, \mathrm{CH}_{4}, \mathrm{~N}_{2} \mathrm{O}, \mathrm{HFCS}, \mathrm{PFCs}\right.$ and $\left.\mathrm{SF}_{6}\right)$.

The Republic of Korea provides an official estimate in its INDC document, which would equate to emission levels of about 535.9 $\mathrm{MtCO}_{2} \mathrm{e}$ in 2030. Modelling groups agree on the emission levels in 2030 since they use the emission level taken from the INDC document. The Climate Action Tracker (CAT, 2015) provides a higher estimate indicating the levels of intended domestic reductions.

\section{Figure A1.10: GHG emissions of the Republic of Korea under the 2020 pledge, INDC and current}

policy trajectory case

The official and national study is: UNFCCC National Reports (2015)

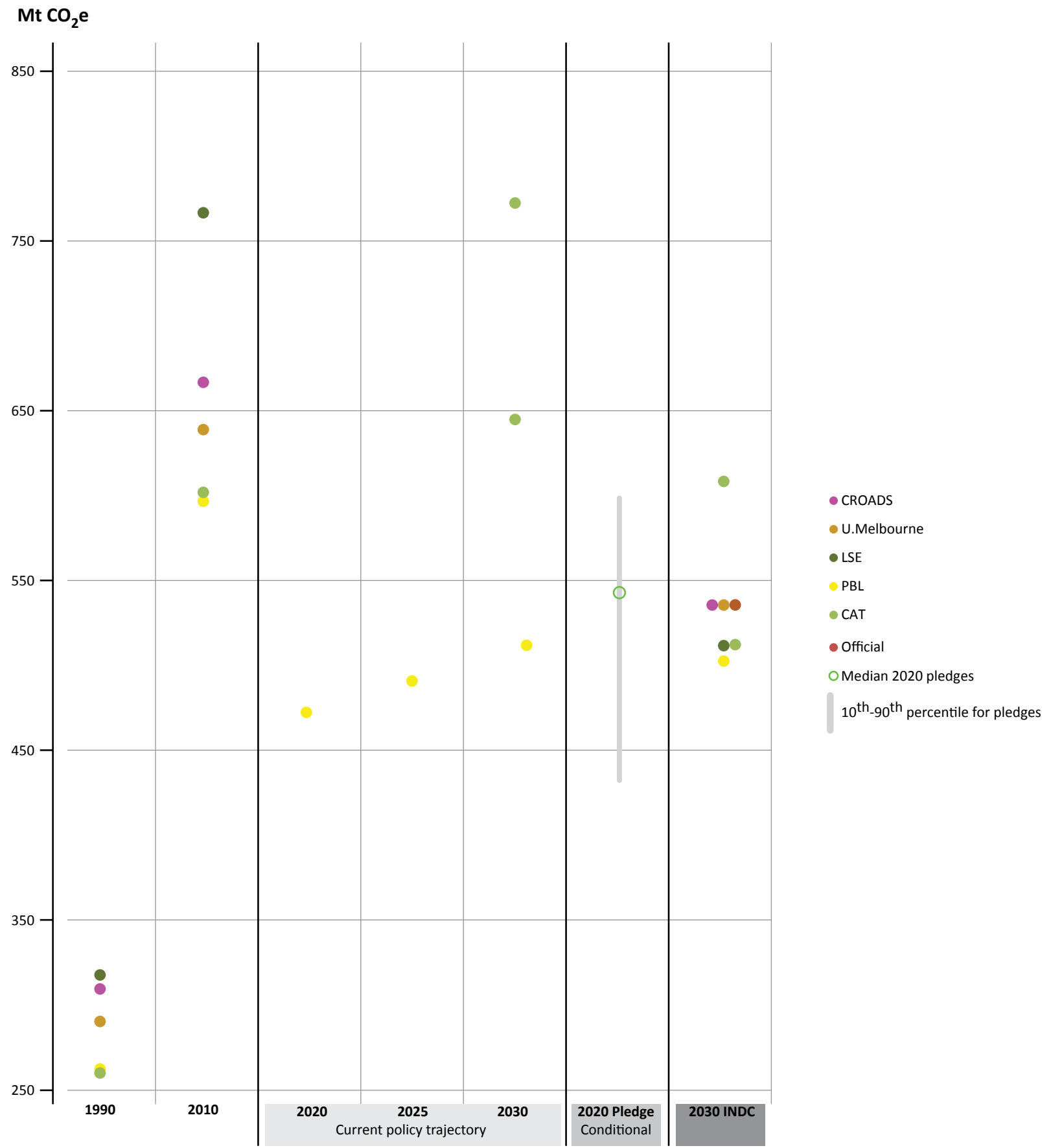




\section{Russian Federation}

The INDC of the Russian Federation states that "Limiting anthropogenic greenhouse gases in Russia to $70-75 \%$ of 1990 levels by the year 2030 might be a long-term indicator, subject to the maximum possible account of absorbing capacity of forests". This implies reducing emissions by 25-
30 per cent below the 1990 level (UNFCCC, 2015). It is an economy-wide target and includes all greenhouse gases.

Study estimates diverge significantly on future emission trends under the current policy trajectory and under the INDC. This is due primarily to different assumptions on accounting of LULUCF emissions.

\section{Figure A1.11: GHG emissions of the Russian Federation under the 2020 pledge, INDC and current policy trajectory case}

The official studies are: UNFCCC inventories for historic data/6th National Communication for current policy projections (UNFCCC National Reports, 2015). For INDC: reductions from INDC submission applied to base year 1990 (UNFCCC, 2015)

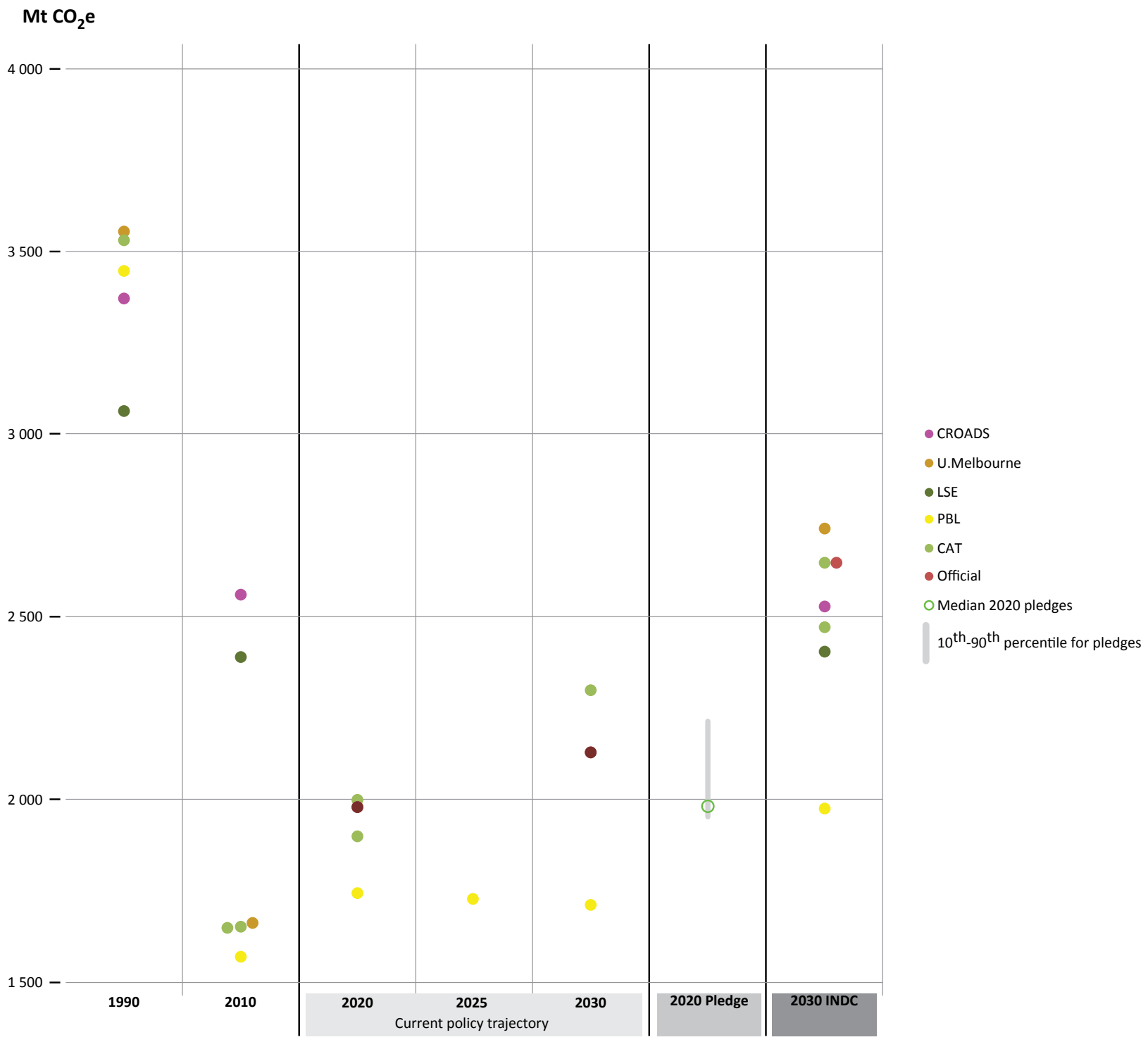




\section{South Africa}

South Africa proposes that the form of its mitigation INDC is a peak, plateau and decline GHG emissions trajectory range. South Africa's emissions by 2025 and 2030 will be in a range between 398 and $614 \mathrm{MtCO}_{2} \mathrm{e}$. It includes all sectors and gases. No quantification of any unconditional share of mitigation is offered. Uncertainties are noted in relation to AFOLU emissions and trace gases, with the intention of reducing uncertainty over time and moving to a comprehensive accounting approach for land-based emissions and removals. South Africa proposes innovative methodologies for adaptation, both impacts and investments required, also noting that methodologies can be improved.

Given that the INDC states emission ranges in absolute units $\left(\mathrm{MtCO}_{2} \mathrm{e}\right)$, modelling groups have greater certainty on the impact of South Africa's INDC. There is reference to more than one mitigation potential analysis, which has provided estimates of what mitigation can be implemented, the most recent being in 2014.

\section{Figure A1.12: GHG emissions of the South Africa under the 2020 pledge, INDC and current policy}

trajectory case

The official and national studies are INDC of South Africa (UNFCCC, 2015) and the Mitigation Report (Department of Environmental Affairs, 2014)

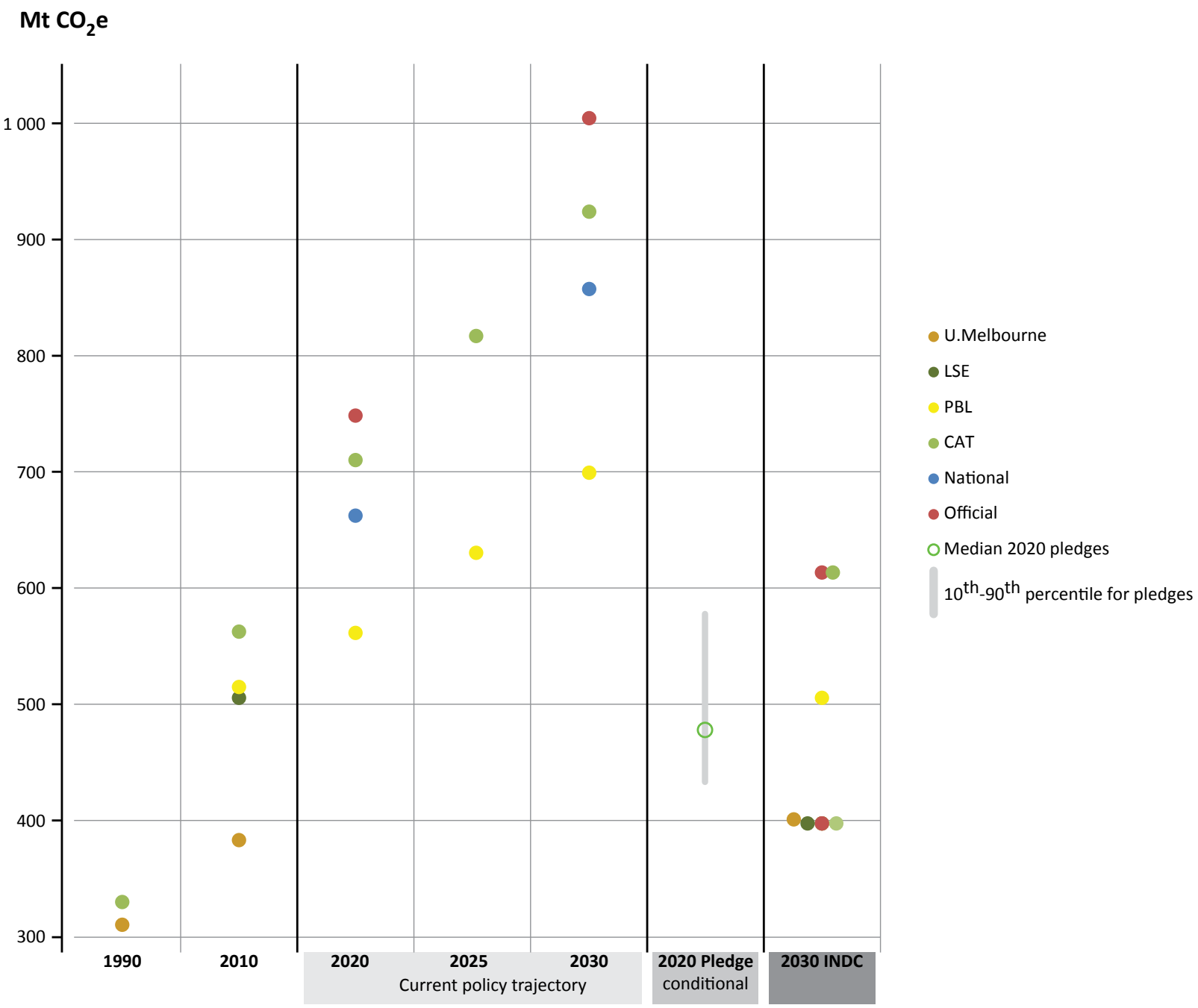




\section{United States of America}

The USA intends to reduce net GHG emissions by $26-28$ per cent from 2005 by 2025, including LULUCF. The target covers all IPCC sectors and seven greenhouse gases.
The modelling groups largely agree on the impact of the USA's INDC on its emissions.

\section{Figure A1.13: GHG emissions of the United States of America under the 2020 pledge, INDC and current policy trajectory case}

The official studies are: UNFCCC inventories for historic data, 6th National Communication for current policy projections (UNFCCC National Reports, 2015). For INDC: INDC submission (UNFCCC, 2015). The analysis in this report uses the 'with measures' scenario from the 6th National Communication. The US indicates that its current trajectory is better represented by the 'with additional measures' scenario. The national studies are: Belenky (2015) and Hausker et al. (2015). Current policies only from Belenky (2015). 2030 INDC estimate only from Hausker et al. (2015)

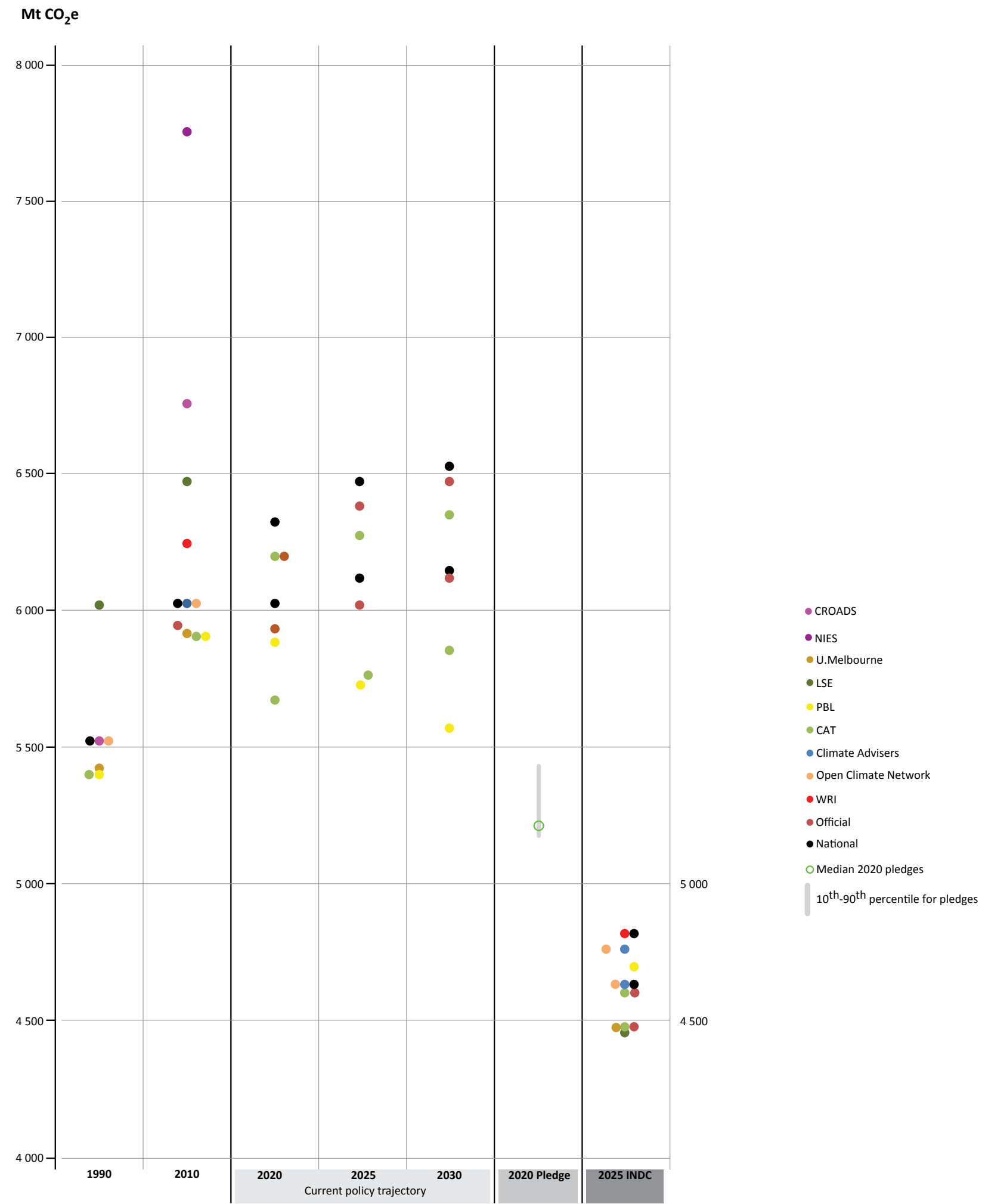




\section{References}

\section{Chapter 1}

UNFCCC (1992) 'United Nations Framework Convention on Climate Change', United Nations. Available at: https://unfccc.int/ resource/docs/convkp/conveng.pdf [Accessed 10 November 2015].

UNFCCC (2014) 'Lima call for climate action', The Conference of the Parties. Available at: https://unfccc.int/files/meetings/lima_ dec_2014/application/pdf/auv_cop20_lima_call_for_climate_action.pdf [Accessed 10 November 2015].

\section{Chapter 2}

Andres, R. J., Boden, T. A., and Higdon, D. (2014) 'A new evaluation of the uncertainty associated with CDIAC estimates of fossil fuel carbon dioxide emission'. Tellus B. Available at: http://www.tellusb.net/index.php/tellusb/article/view/23616 [Accessed 10 November 2015].

BAPPENAS (2015) 'Sekretariat RAN-GRK'. Available at: http://ranradgrk.bappenas.go.id/rangrk/component/content/article/92bahasa/informasi-sektoral/193-hasil-indc [Accessed 10 November 2015].

Belenky, M. (2015) 'Achieving the U.S. 2025 Emissions Mitigation Target. Climate Advisers'. Available at: http://www.climateadvisers. com/wp-content/uploads/2013/12/US-Achieving-2025-Target_May-2015.pdf [Accessed 10 November 2015].

Biennial Report (2013) '2014 First Biennial Report of The United States of America Under the United Nations Framework Convention on Climate Change'. Available at: http://unfccc.int/files/national_reports/biennial_reports_and_iar/submitted_biennial_ reports/application/pdf/first_u.s._biennial_report_rev.pdf [Accessed 10 November 2015].

Brazilian Government (2010) 'Decreto No. 7390, de 9 de Dezembro de 2010'. Presidência da República, Casa Civil Available at: http://www.planalto.gov.br/ccivil_03/_Ato2007-2010/2010/Decreto/D7390.htm [Accessed 10 November 2015].

CAIT WRI (2015) 'CAIT Climate Analysis Indicators Tool. Data Explorer - Pre-2020 Pledges Map'. Available at: http://cait.wri.org/ pledges/ [Accessed on 10 November 2015].

CAT (2013) 'India - Climate Action Tracker'. Available at: http://climateactiontracker.org/countries/india/2013.html [Accessed 10 November 2015].

CAT (2015) 'Climate Action Tracker'. Available at: http://climateactiontracker.org/ [Accessed 10 November 2015].

CCA (2014) 'Carbon Farming Initiative Review Report. Government of Australia - Climate Change Authority'. Available at: http:// climatechangeauthority.gov.au/sites/prod.climatechangeauthority.gov.au/files/files/CCA-CFI-Review-published.pdf [Accessed 10 November 2015].

Clarke, L., Jiang, K., Akimoto, K., Babiker, M., Blanford, G., Fisher-Vanden, K., Hourcade, J-C., Krey, V., Kriegler, E., Löschel, A., McCollum, D., Paltsev, S., Rose, S., Shukla, P. R., Tavoni, M., van der Zwaan, B. and van Vuuren, D.P. (2014) 'Assessing Transformation Pathways' in Edenhofer, O., Pichs-Madruga, R., Sokona, Y., Farahani, E., Kadner, S., Seyboth, K., Adler, A., Baum, I., Brunner, S., Eickemeier, P., Kriemann, B., Savolainen, J., Schlömer, S., Stechow, C. v., Zwickel, T. and Minx, J. C., eds., Climate Change 2014: Mitigation of Climate Change. Contribution of Working Group III to the Fifth Assessment Report of the Intergovernmental Panel on Climate Change, Cambridge, United Kingdom and New York, NY, USA: Cambridge University Press, 413-510. Available at: http://www.ipcc.ch/pdf/assessment-report/ar5/wg3/ipcc_wg3_ar5_chapter6.pdf [Accessed 10 November 2015].

Commonwealth of Australia (2015) 'Setting Australia's post-2020 target for reducing greenhouse gas emissions'. Final report of the UNFCCC Taskforce. Canberra: Commonwealth of Australia. Available at: https://www.dpmc.gov.au/sites/default/files/ publications/Setting\%20Australias\%20post-2020\%20target\%20for\%20reducing\%20greenhouse\%20gas\%20emissions_0.pdf [Accessed 10 November 2015].

den Elzen, M.G.J., Fekete, H., Admiraal, A., Forsell, N., Höhne, N., Korosuo, A., Roelfsema, M., van Soest, H., Wouters, K., Day, T., Hagemann, M., Hof, A.F. (2015). 'Enhanced policy scenarios for major emitting countries. Analysis of current and planned climate policies, and selected enhanced mitigation measure'. Bilthoven, the Netherlands: PBL Netherlands Environmental Assessment Agency. Available at: http://www.pbl.nl/sites/default/files/cms/publicaties/pbl-2015-enhanced-policy-scenarios-for-majoremitting-countries_1631.pdf [Accessed 10 November 2015].

Department of Environmental Affairs (2011a) 'South Africa's Second National Communication under the UNFCCC'. Available at: http://unfccc.int/resource/docs/natc/zafnc02.pdf [Accessed 10 November 2015].

Department of Environmental Affairs (2011b) 'South African Government's position on Climate Change'. SA Government Position on Climate Change. Available at: http://www.climateaction.org.za/cop17-cmp7/sa-government-position-on-climate-change [Accessed 10 November 2015]. 
DoE (2015) 'Australia's emissions projections 2014-15'. Department of the Environment, Australian Government. Available at: http://www.environment.gov.au/climate-change/publications/emissions-projections-2014-15 [Accessed 10 November 2015].

EEA (2014a) 'Annual European Union greenhouse gas inventory 1990-2012 and inventory report 2014'. European Environment Agency. Available at: http://www.eea.europa.eu/publications/european-union-greenhouse-gas-inventory-2014 [Accessed 10 November 2015].

EEA (2014b) 'Trends and projections in Europe 2014 - Tracking progress towards Europe's climate and energy targets until 2020'. European Environment Agency. Available at: http://www.eea.europa.eu/publications/trends-and-projections-in-europe-2014 [Accessed 31 October 2015].

EEA (2015) 'Trends and projections in Europe 2015 - Tracking progress towards Europe's climate and energy targets for 2020'. European Environment Agency. Available at: http://www.eea.europa.eu/publications/trends-and-projections-in-europe-2015 [Accessed 10 November 2015].

Environment Canada (2014) 'Canada's Emissions Trends' Available at: http://ec.gc.ca/Publications/default. asp?lang=En\&xml=E998D465-B89F-4EOF-8327-01D5B0D66885 [Accessed 10 November 2015].

Garg, A., Shukla, P.R., and Bhushan K. (2014) 'India Report - Alternate Development Pathways for India: Aligning Copenhagen Climate Change Commitments with National Energy Security and Economic Development. Low Climate Impact Scenarios and the Implications of Required Tight Emission Control Strategies [LIMITS]'. Ahmedabad, India: Indian Institute of Management, Ahmedabad. Available at: http://www.feem-project.net/limits/docs/limits_india\%20report_iim.pdf [Accessed 10 November 2015].

Government of Mexico (2012) 'Programas para mitigar el cambio climático'. Available at: http://www2.inecc.gob.mx/publicaciones/ libros/685/programas2.pdf [Accessed 10 November 2015].

Government of Russia (2014) 'First Biennial Report of the Russian Federation'. Available at: http://unfccc.int/files/national_reports/ biennial_reports_and_iar/submitted_biennial_reports/application/pdf/1br_rus_unoffical_translation_eng.pdf [Accessed 10 November 2015].

Hausker, K., Meek, K., Gasper, R., Aden, N. and Obeiter, M. (2015) 'Delivering on the U.S. Climate Commitment: A 10-Point Plan Toward a Low-Carbon Future'. Working Paper Executive Summary. Washington, DC: World Resources Institute. Available at: http://www.wri.org/sites/default/files/Delivering_on_the_US_Climate_Commitment_ES.pdf [Accessed 10 November 2015].

IEA (2014a) 'World Energy Outlook 2014'. Paris: International Energy Agency. Available at: http://www.worldenergyoutlook.org/ publications/weo-2014/ [Accessed 10 November 2015].

IEA (2014b) 'CO emissions from fuel combustion - Highlights'. Available at: https://www.iea.org/publications/freepublications/ publication/CO2EmissionsFromFuelCombustionHighlights2014.pdf [Accessed 10 November 2015].

IPCC (2013) 'Summary for Policymakers' in Stocker, T.F., Qin, D., Plattner, G.-K., Tignor, M., Allen, S.K., Boschung, J., Nauels, A., Xia, Y., Bex V. and Midgley P.M. (Eds.), Climate Change 2013: The Physical Science Basis. Contribution of Working Group I to the Fifth Assessment Report of the Intergovernmental Panel on Climate Change. Cambridge, UK and New York, USA: Cambridge University Press, pp. 1-29. Available at: https://www.ipcc.ch/pdf/assessment-report/ar5/wg1/WGIAR5_SPM_brochure_en.pdf [Accessed 10 November 2015].

IPCC (2014a) 'Climate Change 2014: Mitigation of Climate Change'. Contribution of Working Group III to the Fifth Assessment Report of the Intergovernmental Panel on Climate Change, Cambridge, United Kingdom and New York, NY, USA: Cambridge University Press. Available at: http://www.ipcc.ch/report/ar5/wg3/ [Accessed 10 November 2015].

IPCC (2014b) 'Climate Change 2014: Synthesis Report'. Contribution of Working Groups I, II and III to the Fifth Assessment Report of the Intergovernmental Panel on Climate Change, Geneva, Switzerland: IPCC. Available at: https://www.ipcc.ch/pdf/assessmentreport/ar5/syr/AR5_SYR_FINAL_SPM.pdf [Accessed 10 November 2015].

Johnson, N., Krey, V., McCollum, D. L., Rao, S., Riahi, K., and Rogelj, J. (2015) 'Stranded on a low-carbon planet: Implications of climate policy for the phase-out of coal-based power plants'. Technological Forecasting and Social Change, 90, Part A(0):89-102. Available at: http://www.sciencedirect.com/science/article/pii/S0040162514000924 [Accessed 10 November 2015].

Knutti, R. and Rogelj, J. (2015) 'The legacy of our $\mathrm{CO}_{2}$ emissions: a clash of scientific facts, politics and ethics'. Climatic Change: 1-13. Available at: http://link.springer.com/article/10.1007\%2Fs10584-015-1340-3 [Accessed 10 November 2015].

Kriegler, E., Tavoni, M., Aboumahboub, T., Luderer, G., Calvin, K., Demaere, G., Krey, V., Riahi, K., Rösler, H., Schaeffer, M., and Van Vuuren, D. P. (2013) 'What does the $2^{\circ} \mathrm{C}$ target imply for a global climate agreement in 2020? The LIMITS study on Durban Platform Scenarios'. Clim. Change Econ., 04(04):1340008. Available at: http://www.iiasa.ac.at/publication/more_XO-13-041.php [Accessed 10 November 2015].

Kuramochi, T. (2014) 'GHG Mitigation in Japan: An Overview of the Current Policy Landscape'. Working Paper. Washington, DC: World Resources Institute. Available at: http://www.wri.org/sites/default/files/wri_workingpaper_japan_final_ck_6_11_14.pdf [Accessed 10 November 2015].

Meinshausen, M., Meinshausen, N., Hare, W., Raper, S. C. B., Frieler, K., Knutti, R., Frame, D. J., and Allen, M. R. (2009) 'Greenhousegas emission targets for limiting global warming to $2^{\circ} \mathrm{C}$. Nature, 458(7242):1158-62. Available at: https://www1.ethz.ch/iac/ people/knuttir/papers/meinshausen09nat.pdf [Accessed 10 November 2015].

Meinshausen, M., Raper, S. C. B., and Wigley, T. M. L. (2011) 'Emulating coupled atmosphere-ocean and carbon cycle models with a simpler model, MAGICC6 - Part 1: Model description and calibration'. Atmos. Chem. Phys., 11(4):1417-56. Available at: http:// www.atmos-chem-phys.net/11/1417/2011/acp-11-1417-2011.html [Accessed 10 November 2015].

Mexico (2015) 'Mexico Intended Nationally Determined Contribution'. Available at: http://www4.unfccc.int/submissions/INDC/ Published\%20Documents/Mexico/1/MEXICO\%20INDC\%2003.30.2015.pdf [Accessed 10 November 2015].

Ministry of Environment Indonesia (2010) 'Indonesia Second National Communication under the UNFCCC'. Jakarta: Ministry of Environment, Republic of Indonesia. Available at: http://unfccc.int/files/national_reports/non-annex_i_natcom/submitted_ natcom/application/pdf/indonesia_snc.pdf [Accessed 10 November 2015].

MOE (2015) 'Chapter 4: Renewable Energy Deployment Potential'. In: 'Heisei 26nendo 2050nen saiseikanou enerugii nado bunsangata enerugii fukyuukanousei kenshoukentou houkokusho' (FY2013 report on the assessment of deployment potential for renewable energy and other distributed energy technologies). In Japanese. Tokyo: Ministry of the Environment. Available at: http://www.env.go.jp/policy/ [Accessed 10 November 2015].

NCCS (2013) 'National Climate Change Strategy. 10-20-40 Vision'. Mexico: Federal Government of Mexico. Available at: http:// mitigationpartnership.net/sites/default/files/encc_englishversion.pdf [Accessed 10 November 2015]. 
Olivier, J. G. J. and Janssens-Maenhout, G. (2012) 'CO Emissions from Fuel Combustion -- 2012 Edition' in 'IEA CO report 2012, Part III, Greenhouse-Gas Emissions', Paris, France: IEA, 554. Available at: http://edgar.jrc.ec.europa.eu/docs/IEA_PARTIII.pdf [Accessed 10 November 2015].

PBL (2015) 'PBL Climate Pledge INDC tool'. Bilthoven: PBL Netherlands Environmental Assessment Agency. Available at: http:// infographics.pbl.nl/indc/ [Accessed 10 November 2015].

Planning Commission Government of India (2011) 'Low Carbon Strategies for Inclusive Growth: An Interim Report'. Interim Report of the Expert Group on Low Carbon Strategies for Inclusive Growth. New Delhi: Planning commission. Available at: http://www.moef.nic.in/ downloads/public-information/Interim\%20Report\%20of\%20the\%20Expert\%20Group.pdf [Accessed 10 November 2015].

Planning Commission Government of India (2014) 'The Final Report of the Expert Group on Low Carbon Strategies for Inclusive Growth'. New Delhi: Planning Commission. Available at:

http://planningcommission.nic.in/reports/genrep/rep_carbon2005.pdf [Accessed 10 November 2015].

People's Republic of China (2012) 'Second National Communication on Climate Change of the People's Republic of China'. Beijing: National Development and Reform Commission Available at: http://unfccc.int/resource/docs/natc/chnnc2e.pdf [Accessed 10 November 2015].

Republic of Korea (2014) 'First Biennial Update Report of the Republic of Korea'. Seoul, South Korea: Greenhouse Gas Inventory \& Research Center of Korea. Available at: http://unfccc.int/resource/docs/natc/rkorbur1.pdf [Accessed 10 November 2015].

Republic of Korea (2015) 'Submission by the Republic of Korea - Intended Nationally Determined Contribution'. Available at: http:// www4.unfccc.int/submissions/INDC/Published\%20Documents/Republic\%20of\%20Korea/1/INDC\%20Submission\%20by\%20 the\%20Republic\%20of\%20Korea\%20on\%20June\%2030.pdf [Accessed 10 November 2015].

Rhodium Group (2014) 'Is the US on Track? EPA's Clean Power Plan and the US 2020 Climate Goal'. Available at: http://rhg.com/ notes/is-the-us-on-track-epas-clean-power-plan-and-the-us-2020-climate-goal [Accessed 10 November 2015].

Ricke, K. L. and Caldeira, K. (2014) 'Maximum warming occurs about one decade after a carbon dioxide emission'. Environmental Research Letters, 9(12):124002. Available at: http://iopscience.iop.org/article/10.1088/1748-9326/9/12/124002/meta [Accessed 10 November 2015].

Rogelj, J., McCollum, D. L., O'Neill, B. C., and Riahi, K. (2013) '2020 emissions levels required to limit warming to below $2^{\circ} \mathrm{C}$ '. Nature Clim. Change, 3(4):405-412. Available at: http://www.nature.com/nclimate/journal/v3/n4/abs/nclimate1758.html [Accessed 10 November 2015].

Rogelj, J., Luderer, G., Pietzcker, R. C., Kriegler, E., Schaeffer, M., Krey, V., and Riahi, K. (2015a) 'Energy system transformations for limiting end-of-century warming to below $1.5^{\circ} \mathrm{C}$. Nature Clim. Change, 5(6):519-527. Available at: http://www.nature.com/ nclimate/journal/v5/n6/full/nclimate2572.html [Accessed 10 November 2015].

Rogelj, J., Schaeffer, M., Meinshausen, M., Knutti, R., Alcamo, J., Riahi, K., and Hare, W. (2015b) 'Zero emission targets as longterm global goals for climate protection'. Environmental Research Letters, 10(10):105007. Available at: http://iopscience.iop. org/article/10.1088/1748-9326/10/10/105007 [Accessed 10 November 2015].

Schaeffer, M., Gohar, L. K., Kriegler, E., Lowe, J. A., Riahi, K., and Van Vuuren, D. P. (2013) 'Mid-and long-term climate projections for fragmented and delayed-action scenarios'. Technological Forecasting \& Social Change, 90 (Part A): 257-68. Available at: http:// www.iiasa.ac.at/publication/more_XJ-15-018.php [Accessed 10 November 2015].

SEEG (2014) 'Sistema de Estimativa de Emissão de Gases de Efeito Estufa'. Brasil. Available at: http://seeg.observatoriodoclima.eco. br [Accessed 10 November 2015].

SEMARNAT (2013) 'Estrategia Nacional de Cambio Climático: visión 10-20-40’. Secretaría de Medio Ambiente y Recursos Naturales, México. Available at: http://www.inmujeres.gob.mx/inmujeres/images/stories/medioambiente/2014/09_SEPTIEMBRE/ estrategia_nacional_cambio_climatico.pdf [Accessed 10 November 2015].

Sha, F., Ji, Z., and Linwei, L. (2015) 'An Analysis of China's INDC'. Beijing: China National Center for Climate Change Strategy and International Cooperation. Available at: http://www.chinacarbon.info/wp-content/uploads/2010/12/Comments-on-ChinasINDC.pdf [Accessed 10 November 2015].

Smith, S. M., Lowe, J. A., Bowerman, N. H. A., Gohar, L. K., Huntingford, C., and Allen, M. R. (2012) 'Equivalence of greenhousegas emissions for peak temperature limits'. Nature Clim. Change, 2(7):535-538. Available at: http://www.nature.com/nclimate/ journal/v2/n7/full/nclimate1496.html [Accessed 10 November 2015].

UNEP (2012) 'The Emissions Gap Report 2012', Nairobi: United Nations Environment Programme. Available at: http://www.unep. org/pdf/2012gapreport.pdf [Accessed 10 November 2015].

UNEP(2013) 'The Emissions Gap Report 2013', Nairobi:UNEP. Availableat: http://www.unep.org/pdf/UNEPEmissionsGapReport2013. pdf [Accessed 10 November 2015].

UNEP (2014) 'The Emissions Gap Report 2014', Nairobi: UNEP. Available at: http://www.unep.org/publications/ebooks/ emissionsgapreport2014/portals/50268/pdf/EGR2014_LOWRES.pdf [Accessed 10 November 2015].

UNFCCC (2014) 'Submitted Biennial Reports'. Available at: http://unfccc.int/national_reports/biennial_reports_and_iar/submitted_ biennial_reports/items/7550.php [Accessed 10 November 2015].

van der Werf, G.R., Randerson, J.T., Giglio, L., Collatz, G J., Mu, M., Kasibhatla, P S., Morton, D.C., DeFries, R.S., Jin, Y. and van Leeuwen, T.T. (2010) 'Global fire emissions and the contribution of deforestation, savanna, forest, agricultural, and peat fires (1997-2009)'. Atmos. Chem. Phys., 10(23):11707-11735. Available at: http://www.atmos-chem-phys.net/10/11707/2010/acp10-11707-2010.html [Accessed 10 November 2015]. 


\section{Chapter 3}

Australian Government (2015) 'Australia's emissions projections 2014-15'. Department of the Environment. Available at: http:// www.environment.gov.au/climate-change/publications/emissions-projections-2014-15 [Accessed 10 November 2015].

Belenky, M. (2015) 'Achieving the U.S. 2025 Emissions Mitigation Target'. Available at: http://www.climateadvisers.com/wpcontent/uploads/2013/12/US-Achieving-2025-Target_May-20151.pdf [Accessed 10 November 2015].

Boyd, R., Cranston-Turner, J., Ward, B. (2015) 'Intended nationally determined contributions: what are the implications for greenhouse gas emissions in 2030?' Policy Paper, London: ESRC Centre for Climate Change Economics and Policy and Grantham Research Institute on Climate Change and the Environment. Available at: http://www.Ise.ac.uk/Granthamlnstitute/wp-content/ uploads/2015/10/Boyd_Turner_and_Ward_policy_paper_October_2015.pdf [Accessed 10 November 2015].

Clarke, L., Jiang, K., Akimoto, K., Babiker, M., Blanford, G., Fisher-Vanden, K., Hourcade, J-C., Krey, V., Kriegler, E., Löschel, A., McCollum, D., Paltsev, S., Rose, S., Shukla, P. R., Tavoni, M., van der Zwaan, B. and van Vuuren, D.P. (2014) 'Assessing Transformation Pathways' in Edenhofer, O., Pichs-Madruga, R., Sokona, Y., Farahani, E., Kadner, S., Seyboth, K., Adler, A., Baum, I., Brunner, S., Eickemeier, P., Kriemann, B., Savolainen, J., Schlömer, S., Stechow, C. v., Zwickel, T. and Minx, J. C., eds., Climate Change 2014: Mitigation of Climate Change. Contribution of Working Group III to the Fifth Assessment Report of the Intergovernmental Panel on Climate Change, Cambridge, United Kingdom and New York, NY, USA: Cambridge University Press, 413-510. Available at: http://www.ipcc.ch/pdf/assessment-report/ar5/wg3/ipcc_wg3_ar5_chapter6.pdf [Accessed 10 November 2015].

CAT (2015) 'Climate Action Tracker'. Available at: http://climateactiontracker.org. [Accessed 10 November 2015].

Climate Interactive (2015) 'Scoreboard Science and Data'. Climate Interactive. Available at: https://www.climateinteractive.org/ tools/scoreboard/scoreboard-science-and-data/ [Accessed 10 November 2015].

DEA (2015) 'Analyzing the 2030 emissions gap'. Energistyrelsen. Available at: http://www.ens.dk/en/info/facts-figures/scenariosanalyses-models/models/compare/analyzing-2030-emissions-gap [Accessed 10 November 2015].

den Elzen, M.G.J., Fekete, H., Admiraal, A., Forsell, N., Höhne, N., Korosuo, A., Roelfsema, M., van Soest, H., Wouters, K., Day, T., Hagemann, M., Hof, A.F. (2015). 'Enhanced policy scenarios for major emitting countries. Analysis of current and planned climate policies, and selected enhanced mitigation measure'. Bilthoven, the Netherlands: PBL Netherlands Environmental Assessment Agency. Available at: http://www.pbl.nl/sites/default/files/cms/publicaties/pbl-2015-enhanced-policy-scenarios-for-majoremitting-countries_1631.pdf [Accessed 10 November 2015].

Department of Environmental Affairs (2014) 'South Africa's Greenhouse Gas (GHG) Mitigation Potential Analysis'. Pretoria: Department of Environmental Affairs. Available at: https://www.environment.gov.za/sites/default/files/docs/mitigationreport. pdf [Accessed 10 November 2015]

Dubash, N.K., Khosla, R., Rao, N.D., Sharma, K.R. (2014) 'Informing India's Energy and Climate Debate: Policy Lessons from Modelling Studies'. New Delhi: Centre for Policy Research, Climate Initiative, Research Report. Available at: http://www.iiasa.ac.at/ publication/more_XO-15-012.php [Accessed 10 November 2015]

EEA (2014) 'Trends and projections in Europe 2014'. Brussels: European Environment Agency. Available at: http://www.eea.europa. eu/publications/trends-and-projections-in-europe-2014 [Accessed 10 November 2015]

Garg, A., Shukla, P.R. and Bhushan K. (2014) 'India Report on Alternate Development Pathways for India: Aligning Copenhagen Climate Change Commitments with National Energy Security and Economic Development'. Low Climate Impact Scenarios and the Implications of Required Tight Emission Control Strategies [LIMITS]. Ahmedabad, India: Indian Institute of Management, Ahmedabad Available at: http://www.feem-project.net/limits/docs/limits_india\%20report_iim.pdf [Accessed 10 November 2015]

Government of Canada (2014) 'Canada's Emission Trends 2014'. Environment Canada. Available at: https://www.ec.gc.ca/ges-ghg/ default.asp?lang=En\&n=E0533893-1 [Accessed 10 November 2015].

Government of China (2012) 'Second national communication on climate change of the People's Republic of China'. Beijing: National Development and Reform Commission. Available at: http://unfccc.int/resource/docs/natc/chnnc2e.pdf [Accessed 10 November 2015].

Gütschow, J., Jeffery, L., Alexander, R., Hare, B., Schaeffer, M., Rocha, M., Höhne, N., Fekete, H., van Breevoort, P., and Blok, K. (2015) 'INDCs lower projected warming to $2.7^{\circ} \mathrm{C}$ : significant progress but still above $2^{\circ} \mathrm{C}$ '. Potsdam Institute for Climate Impact Research (PIK), Climate Analytics, NewClimate Institute and Ecofys. Available at: http://climateanalytics.org/publications/2015/indcs-lowerprojected-warming-to-2-7-c-significant-progress-but-still-above-2oc [Accessed 10 November 2015].

Hausker, K., Meek, K., Gasper, R., Aden, N. and Obeiter, M. (2015) 'Delivering on the U.S. Climate Commitment: A 10-Point Plan Toward a Low-Carbon Future'. Working Paper. Executive Summary. Washington, DC: World Resources Institute. Available at: http://www.wri.org/sites/default/files/Delivering_on_the_US_Climate_Commitment_ES.pdf [Accessed 10 November 2015].

ICAO (2013) 'Environmental Report 2013 - Destination Green'. Available at: http://cfapp.icao.int/Environmental-Report-2013/files/ assets/common/downloads/ICAO_2013_Environmental_Report.pdf [Accessed 10 November 2015].

IDDRI (2015) 'Beyond the Numbers: Understanding the Transformation Induced by INDCs'. Available at: http://www.iddri.org/ Publications/Collections/Analyses/MILES\%20report.pdf [Accessed 10 November 2015].

IEA (2014) 'World Energy Outlook 2014'. Paris: International Energy Agency. Available at: http://www.worldenergyoutlook.org/ publications/weo-2014/ [Accessed 10 November 2015].

IEA (2015) 'World Energy Outlook Special Report 2015: Energy and Climate Change'. Paris: International Energy Agency. Available at: $\quad$ https://www.iea.org/publications/freepublications/publication/weo-2015-special-report-energy-climate-change.html [Accessed 10 November 2015].

IMO (2014) 'Third IMO Greenhouse Gas study 2014'. London: International Maritime Organization. Available at: http://www.imo. org/en/OurWork/Environment/PollutionPrevention/AirPollution/Documents/MEPC\%2067-INF.3\%20-\%20Third\%20IMO\%20 GHG\%20Study\%202014\%20-\%20Final\%20Report\%20(Secretariat).pdf [Accessed 10 November 2015].

IPCC (2014) 'Climate Change 2014: Mitigation of Climate Change'. Contribution of Working Group III to the Fifth Assessment Report of the Intergovernmental Panel on Climate Change, Cambridge, United Kingdom and New York, NY, USA: Cambridge University Press. Available at: http://www.ipcc.ch/report/ar5/wg3/ [Accessed 10 November 2015].

Jiang, K., Zhuang, X., Miao, R., and He, C. (2013). 'China's role in attaining the global $2^{\circ} \mathrm{C}$ target'. Climate Policy, 13(supp01), 5569. doi: 10.1080/14693062.2012.746070. Available at: http://www.tandfonline.com/doi/full/10.1080/14693062.2012.746070 [Accessed 10 November 2015] 
JRC/PBL (2012) 'EDGAR version 4.2 FT 2010'. Belgium and Netherlands: Joint Research Centre of the European Commission/ PBL Netherlands Environmental Assessment Agency. EUROPA - EDGAR Overview. Available at: http://edgar.jrc.ec.europa.eu/ overview.php?v=GHGts1990-2010 [Accessed 10 November 2015].

Kuramochi, T. (2014) 'GHG Mitigation in Japan: An Overview of the Current Policy Landscape'. Working Paper. Washington, DC: World Resources Institute. Available at: http://www.wri.org/sites/default/files/wri_workingpaper_japan_final_ck_6_11_14.pdf. [Accessed 10 November 2015].

Masui, T. (2015) 'Assessment of INDCs toward 2 degree target based on AIM (Asia-Pacific Integrated Model)'. Tokyo: National Institute For Environmental Studies. Available at: http://www.env.go.jp/earth/ondanka/attach_8/1_4_ToshihikoMasui.pdf [Accessed 10 November 2015]

Meinshausen, M. (2015) 'Australian-German Climate and Energy College'. Available at: http://www.climate-energy-college.net/ search/content/INDC\%20factsheets [Accessed 10 November 2015].

National Climate Change Strategy (2013) 'National Climate Change Strategy. 10-20-40 Vision'. Mexico: Federal Government of Mexico. Available at: http://mitigationpartnership.net/mexico-2013-national-climate-change-strategy-10-20-40-vision [Accessed 10 November 2015].

PBL (2015) 'The Climate Pledge INDC tool'. Bilthoven: PBL Netherlands Environmental Assessment Agency. Available at: http:// infographics.pbl.nl/indc/ [Accessed 10 November 2015].

Rogelj, J., Hare, W., Lowe, J., van Vuuren, D. P., Riahi, K., Matthews, B., Hanaoka, T., Jiang, K. and Meinshausen, M. (2011) 'Emission pathways consistent with a $2^{\circ} \mathrm{C}$ global temperature limit', Nature Clim. Change, 1(8):413-418. Available at: http://www.nature. com/nclimate/journal/v1/n8/abs/nclimate1258.html [Accessed 10 November 2015].

Sha, F., Ji, Z. and Linwei, L. (2015) 'An Analysis of China's INDC'. Beijing: China National Center for Climate Change Strategy and International Cooperation. Available at: http://www.chinacarbon.info/wp-content/uploads/2010/12/Comments-on-ChinasINDC.pdf [Accessed 10 November 2015].

Tavoni,M., Kriegler,E., Riahi,K., van Vuuren,D.P., Aboumahboub,T., Bowen,A., Calvin,K., Campiglio,E., Kober,T., Jewell,J., Luderer,G., Marangoni,G., McCollum,D., van Sluisveld,M., Zimmer, A., and van der Zwaan, B. (2015) 'Post-2020 climate agreements in the major economies assessed in the light of global models'. Nature Climate Change, 5:119-126. Available at: http://www.nature. com/nclimate/journal/v5/n2/full/nclimate2475.html [Accessed 10 November 2015].

UNEP (2014) 'The Emissions Gap Report 2014'. A UNEP Synthesis Report. Nairobi: UNEP. Available at: http://www.unep.org/ publications/ebooks/emissionsgapreport2014/portals/50268/pdf/EGR2014_LOWRES.pdf [Accessed 10 November 2015].

UNFCCC (1992) 'United Nations Framework Convention on Climate Change'. Available at: https://unfccc.int/resource/docs/convkp/ conveng.pdf [Accessed 10 November 2015].

UNFCCC (2013) 'Report of the Conference of the Parties on its nineteenth session, held in Warsaw from 11 to 23 November 2013 '. Available at: http://unfccc.int/resource/docs/2013/cop19/eng/10a01.pdf [Accessed 10 November 2015].

UNFCCC (2014) 'Lima Call for Climate Action'. Available at: https://unfccc.int/files/meetings/lima_dec_2014/application/pdf/auv_ cop20_lima_call_for_climate_action.pdf [Accessed 10 November 2015].

UNFCCC (2015a) 'INDC - Submissions'. Available at: http://www4.unfccc.int/submissions/INDC/Submission\%20Pages/submissions. aspx [Accessed 10 November 2015].

UNFCCC (2015b) 'Undertakings in adaptation planning communicated by Parties in line with paragraph 12 of decision $1 /$ CP.20'. Available at: https://unfccc.int/focus/adaptation/undertakings_in_adaptation_planning/items/8932.php [Accessed 10 November 2015].

UNFCCC National Reports (2015) 'National Reports'. Available at: http://unfccc.int/national_reports/items/1408.php [Accessed 10 November 2015].

US Environmental Protection Agency (2012) 'Global Anthropogenic Non-CO, Greenhouse Gas Emissions: 1990-2030: Revised Version 2012'. Available: http://www3.epa.gov/climatechange/Downloads/EPAactivities/EPA_Global_NonCO2_Projections_Dec2012. pdf [Accessed 10 November 2015]

WRI (2015) 'CAIT Paris Contributions Map - Explore Intended Nationally Determined Contributions (INDCs)'. Available at: http://cait. wri.org/indc/ [Accessed 10 November 2015].

\section{Chapter 4}

Ansuategi, A, Greño, P., Houlden, V., Markandya, A, Onofri, L., Picot, H., Tsarouchi, G-M., and Walmsley, N. (2015): 'The impact of climate change on the achievement of the post-2015 sustainable development goals'. London: CDKN, HR Wallingford and Metroeconomica. Available at: http://cdkn.org/wp-content/uploads/2015/05/Impact-of-climate-on-SDGs-technical-reportCDKN.pdf [Accessed 10 November 2015].

Fekete, H., Roelfsema, M., Höhne, N., den Elzen, M., Forsell, N. and Becerra, S. (2015): 'Impacts of good practice policies on regional and global greenhouse gas emissions'. NewClimate Institute, PBL Netherlands Environmental Assessment Agency and International Institute for Applied Systems Analysis 2015 by order of DG CLIMA. Available at: https://newclimateinstitute.files. wordpress.com/2015/07/task2c_goodpracticeanalysis_july_2015.pdf [Accessed 10 November 2015].

GCEC (2015a) 'Seizing the global opportunity partnerships for better growth and a better climate'. The 2015 New Climate Economy Report. London: Global Commission on the Economy and Climate. Available at: http://2015.newclimateeconomy.report/ [Accessed 10 November 2015].

GCEC (2015b) 'New Climate Economy Technical Note: Abatement Reduction Potential'. London: Global Commission on the Economy and Climate. Available at: http://2014.newclimateeconomy.report/wp-content/uploads/2015/01/NCE-technical-note-emissionreduction-potential_final.pdf [Accessed 10 November 2015].

GGBP (2014) 'Green Growth in Practice: Lessons from Country Experiences'. Green Growth Best Practice. Seoul: Global Green Growth Institute. Available at: http://www.ggbp.org/sites/all/themes/ggbp/uploads/Green-Growth-in-Practice-062014-Full.pdf [Accessed 10 November 2015].

Höhne, N., Day, T., Fekete, H., and Gonzales, S. (2015): 'Assessing the missed benefits of countries' national contributions'. Quantifying potential co-benefits. Berlin: NewClimate Institute. Available at: https://newclimateinstitute.files.wordpress.com/2015/06/ cobenefits-of-indcs-june-2015.pdf [Accessed 10 November 2015]. 
IDDRI (2015) 'Beyond the Numbers: Understanding the Transformation Induced by INDCs'. IDDRI Study No.5. Paris: Institut du développement durable et des relations internationals. Available at: http://www.iddri.org/Publications/Collections/Analyses/ MILES\%20report.pdf [Accessed 10 November 2015].

IEA (2015a) 'Energy and Climate Change'. World Energy Outlook Special Report. Paris: International Energy Agency. Available at: https://www.iea.org/publications/freepublications/publication/WEO2015SpecialReportonEnergyandClimateChange.pdf [Accessed 10 November 2015].

IEA (2015b) 'Energy and Climate Change'. World Energy Outlook Special Briefing for COP21. Paris: International Energy Agency. Available at: https://www.iea.org/media/news/WEO_INDC_Paper_Final_WEB.PDF [Accessed 10 November 2015].

INDC Forum (2015): 'Meeting Documents and Presentations'. Available at: http://www.indcforum.org/2015/10/08/forumpresentations/ [Accessed 10 November 2015].

IPCC (2007) 'Climate Change 2007: Synthesis Report'. Contribution of Working Groups I, II and III to the Fourth Assessment Report of the Intergovernmental Panel on Climate Change [Core Writing Team, Pachauri, R.K and Reisinger, A. (eds.)]. IPCC, Geneva, Switzerland, 104 pp. Available at: https://www.ipcc.ch/pdf/assessment-report/ar4/syr/ar4_syr_frontmatter.pdf [Accessed 10 November 2015].

IPCC (2014a) 'Climate Change 2014: Synthesis Report'. Contribution of Working Groups I, II and III to the Fifth Assessment Report of the Intergovernmental Panel on Climate Change [Core Writing Team, Pachauri, R.K., and Meyer, L.A., eds]. Geneva: IPCC. Available at: http://www.ipcc.ch/pdf/assessment-report/ar5/syr/SYR_AR5_FINAL_full.pdf [Accessed 10 November 2015].

IPCC (2014b) 'Climate Change 2014: Mitigation of Climate Change'. Contribution of Working Group III to the Fifth Assessment Report of the Intergovernmental Panel on Climate Change [Edenhofer, O., Pichs-Madruga, R., Sokona,Y., Farahani, E., Kadner, S., Seyboth, K., Adler, A., Baum, I., Brunner, S., Eickemeier, P., Kriemann, B., Savolainen, J., Schlömer, S., von Stechow, C., Zwickel, T. and Minx, J.C., eds]. Cambridge and New York: Cambridge University Press. Available at: http://mitigation2014.org/report/ publication/ [Accessed 10 November 2015].

IRENA (2014) 'REmap 2030: A Renewable Energy Roadmap', Summary of Findings, June 2014. IRENA, Abu Dhabi: International Renewable Energy Agency. Available at: www.irena.org/remap [Accessed 10 November 2015].

JRC (2015) 'Analysis of scenarios integrating the INDCs. JRC Policy Brief'. EC JRC IPTS/J1. October 2015. Brussels: Joint Research Centre. Available at: https://ec.europa.eu/jrc/en/publication/eur-scientific-and-technical-research-reports/analysis-scenariosintegrating-indcs [Accessed 10 November 2015]

OECD/IEA/NEA/ITF (2015) 'Aligning Policies for a Low-Carbon Economy'. Paris: OECD Publishing. Available at: http://dx.doi. org/10.1787/9789264233294-en [Accessed 10 November 2015].

Parry, I., Chandara, V., and Dirk, H. (2014) 'How Much Carbon Pricing is in Countries' Own Interests? The Critical Role of Co-Benefits'. IMF Working Paper WP/14/174. Washington: International Monetary Fund. Available at: https://www.imf.org/external/pubs/ft/ wp/2014/wp14174.pdf [Accessed 10 November 2015].

Spencer, T., Pierfederici, R. et al. (2015): 'Beyond the Numbers: Understanding the Transformation Induced by INDCS - Executive Summary, October 2015, IDDRI - MILES Project Consortium'. Paris: Institut du développement durable et des relations internationales. Available at: http://www.iddri.org/Publications/Collections/Analyses/Exe-summary_miles.pdf [Accessed 10 November 2015].

UN (2015a) 'Protecting Our Planet and Combatting Climate Change', UN Sustainable Development Summit. Interactive Dialogue 4, New York: United Nations. Available at: https://sustainabledevelopment.un.org/content/documents/8156Interactive\%20 Dialogue\%20\%204\%20-Climate\%20Change\%20Environment.pdf [Accessed 10 November 2015].

UN (2015b) 'Goal 13: Take urgent action to combat climate change and its impacts'. Climate Change - United Nations Sustainable Development. New York: United Nations. Available at: http://www.un.org/sustainabledevelopment/climate-change-2/ [Accessed 10 November 2015].

UN (2015c) 'Discussion Paper on Follow-up and Review of the Post-2015 Development Agenda - 12 May 2015'. Available at: https://sustainabledevelopment.un.org/content/documents/7132Discussion\%20paper\%20on\%20Follow\%20up\%20and\%20 Review\%2012\%20May\%202015.pdf [Accessed 10 November 2015].

UNEP (2011) 'The Emissions Gap Report 2011: A UNEP Synthesis Report'. Nairobi: UNEP: Available at: http://www.unep.org/ publications/ebooks/bridgingemissionsgap/ [Accessed 10 November 2015].

UNEP (2012) 'The Emissions Gap Report 2012. A UNEP Synthesis Report'. Nairobi: UNEP. Available at: http://www.unep.org/ pdf/2012gapreport.pdf [Accessed 10 November 2015].

UNEP (2013) The Emissions Gap Report 2013. A UNEP Synthesis Report. Nairobi: UNEP. Available at: http://www.unep.org/pdf/ UNEPEmissionsGapReport2013.pdf [Accessed 10 November 2015].

UNFCCC (2014a) 'Updated compilation of information on the mitigation benefits of actions, initiatives and options to enhance mitigation ambition'. UNFCCC Technical Paper. FCCC/TP/2014/13. 26 November 2014. Available at: http://unfccc.int/resource/ docs/2014/tp/13.pdf [Accessed 10 November 2015].

UNFCCC (2014b) 'Updated compilation of information on mitigation benefits of actions, initiatives and options to enhance mitigation ambition'. UNFCCC Technical Paper. FCCC/TP/2014/3. 2 June 2014. Available at: http://unfccc.int/resource/docs/2014/tp/03.pdf [Accessed 10 November 2015].

UNFCCC (2015) 'Updated compilation of information on mitigation benefits of actions, initiatives and options to enhance mitigation ambition'. UNFCCC Technical Paper. FCCC/TP/2015/4. 16 October 2015. Available at: http://unfccc.int/resource/docs/2015/ tp/04.pdf [Accessed 10 November 2015].

WB (2014) 'Climate-Smart Development: Adding Up the Benefits of Actions That Help Build Prosperity, End Poverty and Combat Climate Change'. Report 88908. Washington, DC: World Bank. Available at http://www-wds.worldbank.org/external/default/ WDSContentServer/WDSP/IB/2014/06/20/000456286_20140620100846/Rendered/PDF/889080WPOv10REOSmartODevelopm entOMa.pdf [Accessed 10 November 2015]. 
Chapter 5

Blok, K., Höhne, N., van der Leun, K., and Harrison, N. (2012) 'Bridging the greenhouse-gas emissions gap'. Nature Climate Change, 2: 471-74. Available at: http://www.nature.com/nclimate/journal/v2/n7/full/nclimate1602.html?WT.mc_id=FBK_[Accessed 10 November 2015].

carbonn (2015) carbonn Climate Registry. Available at: http://carbonn.org [Accessed 17 November 2015].

Caring for Climate (2014) 'Progress Report 2014'. Available at: https://www.unglobalcompact.org/library/1121 [Accessed 10 November 2015].

CDP (2014) 'Carbon action report 2014. Why companies need emissions reduction targets'. Available at: https://www.cdp.net/ CDPResults/Carbon-action-report-2014.pdf [Accessed 10 November 2015].

CDP, WRI, WWF (2014) 'Mind the Science, Mind the Gap Frequently Asked Questions (FAQ's)'. Available at: http://www.wri.org/ sites/default/files/uploads/mind_the_gap_faqs.pdf [Accessed 10 November 2015].

Chan, S., and Paux, P. (2014) 'A global framework for climate action (GFCA). Orchestrating non-state and subnational initiatives for more effective global climate governance'. Available at: https://www.die-gdi.de/uploads/media/DP_34.2014.pdf [Accessed 10 November 2015].

CISL/Ecofys (2015) 'Better Partnerships: Understanding and increasing the impact of private sector cooperative initiatives', University of Cambridge and Ecofys report highlights emissions reduction opportunities - Cambridge Institute for Sustainability Leadership. Available at: http://www.cisl.cam.ac.uk/publications/publication-pdfs/better-partnerships-understanding-and-increasing-theimpact-of-private-sector-cooperative-initiatives [Accessed 10 November 2015].

CIP (2015) 'Climate Initiatives Platform'. Available at: http://www.climateinitiativesplatform.org/index.php/Welcome [Accessed 10 November 2015].

Climate Change Summary (2014) 'Chair's Summary - UN Climate Summit 2014'. Available at: http://www.un.org/climatechange/ summit/2014/09/2014-climate-change-summary-chairs-summary/ [Accessed 10 November 2015].

Dodwell, C., Holdaway, E., Sura, K., and Picot H. (2015) 'Supporting ambitious Intended Nationally Determined Contributions: Lessons learned from developing countries', Working paper. Ricardo-AEA and the Climate and Development Knowledge Network. Available at: http://r4d.dfid.gov.uk/Output/201361/ [Accessed 10 November 2015].

Edwards, G., Timmons Roberts, J., Araya, M. and Retamal, C. (2015) 'A New Global Agreement Can Catalyze Climate Action in Latin America', Santiago, Chile. Available at: http://www.brookings.edu/research/papers/2015/05/global-agreement-climate-actionlatin-america [Accessed 10 November 2015].

FS UNEP Centre (2015) 'Global Trends in Renewable Energy Investment 2015'. UNEP Centre. Available [Accessed 10 November 2015].

Hale, T. and Roger C. (2014) 'Orchestration and Transnational Climate Governance'. Review of International Organizations, 9 (1): 59-82 Available at: http://econpapers.repec.org/article/sprrevint/v_3a9_3ay_3a2014_3ai_3a1_3ap_3a59-82.htm [Accessed 10 November 2015].

Hsu A., Moffat, A.S., Weinfurter, A.J., and Schwartz, J.D. (2015) 'Five of the 29 commitments made at the NY Climate Summit could result in a 2.54 GtCO e reduction in annual global total GHG emissions in 2020'. Towards a new climate diplomacy: Nature Climate Change: Nature Publishing Group. Available at: http://www.nature.com/nclimate/journal/v5/n6/fig_tab/nclimate2594_F1.html [Accessed 10 November 2015].

IEA (2013) 'Redrawing the Energy-climate map'. World Energy Outlook Special Report. Paris: International Energy Agency Available at: http://www.iea.org/publications/freepublications/publication/weo_special_report_2013_redrawing_the_energy_climate_ map.pdf [Accessed 10 November 2015].

IPCC (2014) 'Climate Change 2014: Synthesis Report'. Contribution of Working Groups I, II and III to the Fifth Assessment Report of the Intergovernmental Panel on Climate Change [Core Writing Team, Pachauri, R.K., and Meyer, L.A., eds]. Geneva: IPCC. Available at: http://www.ipcc.ch/pdf/assessment-report/ar5/syr/SYR_AR5_FINAL_full.pdf [Accessed 10 November 2015].

IRENA (2015) 'Renewable Energy in Latin America 2015: An Overview of Policies'. Abu Dhabi. Available at: http://www.irena.org/ Publications/index.aspx?mnu=cat\&PriMenuID=36\&CatID=141 [Accessed 10 November 2015].

IVM (2015) 'Non-state actors in a Paris Agreement - are cities and companies bridging the ambition gap?' Policy Brief, Amsterdam: Institute for Environmental Studies, Free University. Available at: http://fores.se/wp-content/uploads/2015/05/NSA_Policy brief_Bonn2.pdf [Accessed 10 November 2015].

Mosteller, D. and Hsu, A. (2015) 'Getting to Two Degrees: Measuring What Cities, Companies, and Others Have Promised', The Metric Yale University. Available at: http://epi.yale.edu/the-metric/getting-two-degrees-measuring-what-cities-companies-andothers-have-promised [Accessed 10 November 2015].

NAZCA (2015) 'Non-State Actor Zone for Climate Action'. Available at: http://climateaction.unfccc.int [Accessed 10 November 2015].

Nykvist, B. and Nilsson, M. (2015) 'Rapidly falling costs of battery packs for electric vehicles'. Nature Climate Change 5(4): 32932. Available at: http://www.nature.com/nclimate/journal/v5/n4/full/nclimate2564.html?WT.ec_id\%3DNCLIMATE-201504 [Accessed 10 November 2015].

Roelfsema M., Harmsen, M., and Olivier, I. (2015) 'Climate action outside the UNFCCC'. Policy Brief, PBL Netherlands Environmental Assessment Agency, Bilthoven, the Netherlands. Available at: http://www.pbl.nl/sites/default/files/cms/pbl-2015-climateaction-outside-the-unfccc_01188.pdf [Accessed 11 November 2015].

Roger, C., Hale T., and Andonova L. (2015) 'How do Domestic Politics shape participation in Transnational Climate Governance?' Blavatnik School Working Paper 001. Available at: http://www.bsg.ox.ac.uk/sites/www.bsg.ox.ac.uk/files/documents/BSGWP-2015-001.pdf [Accessed 10 November 2015].

Seba, T. (2014) 'Clean Disruption of Energy and Transportation: How Silicon Valley Will Make Oil, Nuclear, Natural Gas, Coal, Electric Utilities and Conventional Cars Obsolete by 2030'. Available at: http://tonyseba.com/portfolio-item/clean-disruption-of-energytransportation/ [Accessed 10 November 2015].

Somanathan, E., Sterner, T., Sugiyama, T., Chimanikire, D., Dubash, N.K., Essandoh-Yeddu, J., Fifita, S., Goulder, L., Jaffe, A., Labandeira, X., Managi, S., Mitchell, C., Montero, J.P., Teng, F., and Zylicz, T., (2014) 'National and Sub-national Policies and Institutions'. In: 'Climate Change 2014: Mitigation of Climate Change'. Contribution of Working Group III to the Fifth Assessment. Report of the Intergovernmental Panel on Climate Change [Edenhofer, O., Pichs-Madruga, R., Sokona, Y., Farahani, E., Kadner, S., Seyboth, K., 
Adler, A., Baum, I., Brunner, S., Eickemeier, P., Kriemann, B., Savolainen, J., Schlömer, S., von Stechow, C., Zwickel, T. and Minx, J. C.(eds.)]. Cambridge University Press, Cambridge, United Kingdom and New York, NY, USA. Available at: http://www.ipcc.ch/pdf/ assessment-report/ar5/wg3/ipcc_wg3_ar5_chapter15.pdf [Accessed 10 November 2015].

UNEP (2013) 'The Emissions Gap Report 2013: A UNEP Synthesis Report'. Nairobi: UNEP. Available at: http://www.unep.org/ publications/ebooks/emissionsgapreport2013/ [Accessed 10 November 2015].

UNEP (2015) 'Climate commitments of subnational actors and business: A quantitative assessment of their emission reduction impact' [p. 28, Table 8.1]. United Nations Environment Programme (UNEP), Nairobi. Available at: http://apps.unep.org/ publications/pmtdocuments/-Climate_Commitments_of_Subnational_Actors_and_Business-2015CCSA_2015.pdf.pdf [Accessed 10 November 2015].

UNFCCC (2013) 'Compilation of information on mitigation benefits of actions, initiatives and options to enhance mitigation ambition'. UNFCCC document FCCC/TP/2013/4. Geneva: United Nations Office. Available at: http://unfccc.int/resource/docs/2013/tp/08. pdf [Accessed 10 November 2015].

UNFCCC (2015) 'INDC - Submissions'. Available at: http://www4.unfccc.int/submissions/INDC/Submission\%20Pages/submissions. aspx [Accessed 10 November 2015].

Vergara, W., Fenhann, J. \& Schletz, M. (2015, forthcoming) ,Zero Carbon Latin America. A pathway to net decarbonisation by midcentury'. Copenhagen: UNEP DTU Partnership. Available at: http://www.unepdtu.org/PUBLICATIONS [Accessed 11 November 2015].

WRI, C40 and ICLEI (2014): 'Global Protocol for Community-Scale Greenhouse Gas Emission Inventories - An Accounting and Reporting Standard for Cities', Greenhouse Gas Protocol. Available at: http://www.ghgprotocol.org [Accessed 10 November 2015].

\section{Chapter 6}

Achard, F., Beuchle, R., Mayaux, P., Stibig, H-J., Bodart, C., Brink, A., Carboni, S., Desclée, B., Donnay, F., Eva, H.D., Lupi, A., Raši, R., Seliger, R., and Simonetti, D. (2014) 'Determination of tropical deforestation rates and related carbon losses from 1990 to 2010 '. Global Change Biology, 20: 2540-2554. Available at: http://onlinelibrary.wiley.com.globalproxy.cvt.dk/doi/10.1111/gcb.12605/ pdf [Accessed 11 November 2015].

Assunção, J., Gandour, C., and Rocha, R.(2015) 'Deforestation slowdown in the Brazilian Amazon: prices or policies?' Environment and Development Economics, 20(6): 697-722. Available at: http://climatepolicyinitiative.org/publication/deforestationslowdown-in-the-legal-amazon-prices-or-policie/ [Accessed 11 November 2015].

Bellassen, V. and Luyssaert, S. (2014) 'Managing forests in uncertain times'. Nature, 506: 153-155. Available at: http://www.nature. com/news/carbon-sequestration-managing-forests-in-uncertain-times-1.14687 [Accessed 11 November 2015].

Bonn Challenge (2015) 'The Bonn Challenge is a global aspiration to restore 150 million hectares of the world's deforested and degraded lands by 2020'. Available at: http://www.bonnchallenge.org/ [Accessed 11 November 2015].

CBD (2010) 'COP 10 Decision X/2 - X/2. Strategic Plan for Biodiversity 2011-2020'. Nagoya, Japan: Convention on Biological Diversity Conference of Parties. 18 - 29 October 2010. Available at: https://www.cbd.int/decision/cop/?id=12268 [Accessed 11 November 2015].

Ciais, P., Sabine, C., Bala, G., Bopp, L., Brovkin,V., Canadell, J., Chhabra, A., DeFries, R., Galloway, J., Heimann M., C. Jones, Le Quéré, C., Myneni, R.B., Piao, S., and Thornton, P. (2013) 'Carbon and Other Biogeochemical Cycles'. In: 'Climate Change 2013: The Physical Science Basis'. Contribution of Working Group I to the Fifth Assessment Report of the Intergovernmental Panel on Climate Change [Stocker, T.F., Qin, D., Plattner, G-K.,Tignor, M.,Allen, S.K., Boschung, A., Nauels, J., Xia, Y., Bex, V. and Midgley, P.M., eds. Cambridge and New York: Cambridge University Press. Available at: https://www.ipcc.ch/pdf/assessment-report/ar5/ wg1/WG1AR5_Chapter06_FINAL.pdf [Accessed 11 November 2015].

Clarke L. Jiang, K., Akimoto, K., Babiker, M., Blanford, G., Fisher, K., Vanden, J., Hourcade, J.C., \& Krey, V. (2014) 'Assessing Transformation Pathways'. In: Edenhofer, O. et al. eds. 'Climate Change 2014: Mitigation of Climate Change'. Contribution of Working Group III to the Fifth Assessment Report of the Intergovernmental Panel on Climate Change. Cambridge and New York: Cambridge University Press. Available at: http://www.ipcc.ch/report/ar5/wg3/ [Accessed 11 November 2015].

Eliasch, J. (2008) 'Climate Change: Financing Global Forests'. The Eliasch Review. London: Office of Climate Change / Her Majesty's Stationery Office. Available at: https://www.gov.uk/government/uploads/system/uploads/attachment_data/ file/228833/9780108507632.pdf [Accessed 11 November 2015].

Ewers, R. and Rodrigues, A.S.L. (2008) 'Estimates of reserve effectiveness are confounded by leakage'. Trends in Ecology and Evolution, 23 (3): 113-116. Available at: http://www.cell.com/trends/ecology-evolution/abstract/S0169-5347(08)00040-2? ret urnURL=http\%3A\%2F\%2Flinkinghub.elsevier.com\%2Fretrieve\%2Fpii\%2FS0169534708000402\%3Fshowall\%3Dtrue [Accessed 11 November 2015].

FAO (2010a) 'Global Forest Resources Assessment 2010. Main report'. FAO Forestry Paper 163. Rome: Food and Agriculture Organization of the United Nations. Available at: http://www.fao.org/forest-resources-assessment/past-assessments/fra-2010/ en/ [Accessed 11 November 2015].

FAO (2010b) 'Global Forest Resources Assessment 2010'. Global Tables: Table 11 Trends in carbon stock in living forest biomass 1990-2010. Available at: http://www.fao.org/forestry/fra/fra2010/en/ [Accessed 11 November 2015]

FAO (2012) 'Global ecological zones for FAO forest reporting: 2010 update'. Forest Resources Assessment Working Paper 179. Rome: Food and Agriculture Organization of the United Nations. Available at: http://www.fao.org/docrep/017/ap861e/ap861e00.pdf [Accessed 11 November 2015].

FCPF (2015) 'ER-PINs in FCPF Pipeline'. Washington: Forest Carbon Partnership Facility. Available at: https://www. forestcarbonpartnership.org/er-pins-fcpf-pipeline [Accessed 11 November 2015].

Federici, S., Tubiello, F.N., Salvatore, M., Jacobs, H., and Schmidhuber, J. (2015) 'New estimates of CO2 forest emissions and removals: 1990-2015'. Forest Ecology and Management, 352: 89-98. Available at: http://www.sciencedirect.com/science/ article/pii/S0378112715002443 [Accessed 11 November 2015].

Golub, A., Henderson, B., Hertel, T., Rose, S., Avetisyan, M. and Sohngen, B. (2010) 'Effects of GHG mitigation policies on livestock sectors', 13th Annual Conference on Global Economic Analysis, Penang, Malaysia, 2010. Available at: https://www.gtap.agecon. purdue.edu/resources/res_display.asp?RecordID=3393 [Accessed 11 November 2015].

Grace, J., Mitchard, E., and Gloor, E. (2014) 'Perturbations in the carbon budget of the tropics'. Global Change Biology, 20: 32383255. Available at: http://dx.doi.org/10.1111/gcb.12600 [Accessed 11 November 2015]. 
Harris, N.L. et al. (2012) 'Baseline Map of Carbon Emissions from Deforestation in Tropical Regions'. Science, 336: $1573-1576$. Available at: http://dx.doi.org/10.1126/science.1217962 [Accessed 11 November 2015].

Hooijer A., S. Page, J. G. Canadell, M. Silvius, J. Kwadijk, H. Wösten, and J. Jauhiainen (2010) 'Current and future CO2 emissions from drained peatlands in Southeast Asia'. Biogeosciences, 7: 1505-1514. Available at: http://www.biogeosciences.net/7/1505/2010/ bg-7-1505-2010.html [Accessed 11 November 2015].

Houghton, R. A., House, J. I., Pongratz, J., van der Werf, G. R., DeFries, R. S., Hansen, M. C., Le Quéré, C., and Ramankutty, N. (2012) 'Carbon emissions from land use and land-cover change'. Biogeosciences, 9(12): 5125-5142. Available at: http://www. biogeosciences.net/9/5125/2012/bg-9-5125-2012.html [Accessed 11 November 2015].

INPE (2015) ‘Projeto Prodes: Monitoramento da Floresta Amazônica Brasileira por Satélite'. http://www.obt.inpe.br/prodes/index. php [Accessed 11 November 2015].

IPCC (2006) 'IPCC Guidelines for National Greenhouse Gas Inventories'. Volume 4: Agriculture, Forestry and Other Land Use. Prepared by the National Greenhouse Gas Inventories Programme, Eggleston, H. S., Buendia, L., Miwa, Ki., Ngara, T. and Tanabe, K. eds. Japan: IGES. Available at: http://www.ipcc-nggip.iges.or.jp/public/2006gl/vol4.html [Accessed 11 November 2015].

Jaenicke, J., Wösten, H., Budiman, A., and Siegert, F. (2010) 'Planning hydrological restoration of peatlands in Indonesia to mitigate carbon dioxide emissions'. Mitigation and Adaptation Strategies for Global Change, 15(3): 223-239. Available at: https://www. wageningenur.nl/en/Publication-details.htm?publicationld=publication-way-343031313233 [Accessed 11 November 2015].

Kissinger, G., Herold, M., and de Sy, V. (2012) 'Drivers of Deforestation and Forest Degradation: A Synthesis Report for REDD+ Policymakers'. Vancouver: Lexeme Consulting. Available at: https://www.gov. uk/government/publications/deforestation-andforest-degradation-drivers-synthesis-report-for-redd-policymakers [Accessed 11 November 2015].

Lamb, D. and Gilmour, D. (2003) 'Rehabilitation and Restoration of Degraded Forests'. Gland and Cambridge: IUCN and WWF. Available at: http://cmsdata.iucn.org/downloads/rehabilitation_and_restoration_of_degraded_forests.pdf [Accessed 11 November 2015].

Lee, D. and Pistorius, T. (2015) 'The Impacts of International REDD+ Finance'. Climate and Land Use Alliance. Available at: http:// www.climateandlandusealliance.org/en/Impacts_of_International_REDD_Finance/ [Accessed 11 November 2015].

Liu, Y.Y., van Dijk, A.I.J.M., de Jeu, R.A.M., Canadell, J.G., McCabe, M.F., Evans, J.P., and Wang, G. (2015) 'Recent reversal in loss of global terrestrial biomass'. Nature Climate Change, 5:470-474. Available at: http://www.researchgate.net/publication/281887147_ Recent_reversal_in_loss_of_global_terrestrial_biomass [Accessed 11 November 2015].

Maginnis, S., Rietbergen-McCracken, J., and Sarre, A. eds. (2012) 'The Forest Landscape Restoration Handbook'. Trove, National Library of Australia. Available at: http://trove.nla.gov.au/work/25061115?q\&versionld=208466756 [Accessed 11 November 2015].

Megevand, C. (2013) 'Deforestation Trends in the Congo Basin: Reconciling Economic Growth and Forest Protection'. Washington: World Bank. Available at: http://www.profor.info/knowledge/economic-growth-and-drivers-deforestation-congo-basin [Accessed 11 November 2015].

Miles, L. and Dickson, B. (2010) `REDD-plus and biodiversity: opportunities and challenges'. Unasy/va 236(61):56-63. Available at: http://www.fao.org/docrep/013/i1758e/i1758e14.pdf [Accessed 11 November 2015].

Nabuurs, G.J., Masera, O., Andrasko, K., Benitez-Ponce, P., Boer, Dutschke, M., Elsiddig, E., Ford-Robertson, J., Frumhoff, P., Karjalainen, T., Krankina, O., Kurz, W.A., Matsumoto, M., Oyhantcabal, W., Ravindranath, N.H., Sanz Sanchez, M.J., and Zhang X. (2007) 'Forestry'. In 'Climate Change 2007: Mitigation'. Contribution of Working Group III to the Fourth Assessment Report of the Intergovernmental Panel on Climate Change. In: Metz, B., Davidson, O.R., Bosch, P.R., Dave, R. and Meyer, L.A. eds. Cambridge and New York: Cambridge University Press. Available at: https://www.ipcc.ch/pdf/assessment-report/ar4/wg3/ar4wg3-chapter9.pdf [Accessed 11 November 2015].

Nepstad, D., McGrath, D., Stickler, C., Alencar, A., Azevedo, A., Swette, B., Bezerra, B., DiGiano, M., Shimada, J., da Motta, R.S., Armijo, E., Castello, L., Brando, P., Hansen, M.C., McGrath-Horn, M., Carvalho, O., and Hess, L. (2014) 'Slowing Amazon deforestation through public policy and interventions in beef and soy supply chains'. Science, 344(6188), 1118-1123. Available at: https://www. sciencemag.org/content/344/6188/1118.figures-only [Accessed 11 November 2015].

New Climate Economy (2015) 'Seizing the Global Opportunity. Partnerships for better growth and a better climate'. The 2015 New Climate Economy Report. London: Global Commission on the Economy and Climate. Available at: http://2015.newclimateeconomy. report/ [Accessed 11 November 2015].

Paquette, A., Hawryshyn, J., Vyta Senikas, A. and Potvin, C. (2009) 'Enrichment planting in secondary forests: a promising clean development mechanism to increase terrestrial carbon sinks'. Ecology and Society, 14(1):31. Available at: http://www. ecologyandsociety.org/vol14/iss1/art31/ [Accessed 11 November 2015].

Rizvi, A.R., Baig, S., Barrow, E., and Kumar, C. (2015) 'Synergies between Climate Mitigation and Adaptation in Forest Landscape Restoration'. Gland: IUCN. Available at: https://portals.iucn.org/library/sites/library/files/documents/2015-013.pdf [Accessed 11 November 2015].

Romijn, E., Ainembabazi, J.H., Wijaya, A., Herold, M., Angelsen, A., Verchot, L., and Murdiyarso, D. (2013) 'Exploring different forest definitions and their impact on developing REDD+ reference emission levels: a case study for Indonesia'. Environmental Science and Policy, 33:246-259. Available at: http://www.researchgate.net/publication/253239946_Exploring_different_forest_ definitions_and_their_impact_on_developing_REDD_reference_emission_levels_A_case_study_for_Indonesia [Accessed $1 \overline{1}$ November 2015].

Sasaki, N. and Putz, F.E. (2009) 'Critical need for new definitions of "forest" and "forest degradation" in global climate change agreements'. Conservation Letters, 2(5): 226-232. Available at: http://dx.doi.org/10.1111/j.1755-263X.2009.00067.x [Accessed 11 November 2015].

Scharlemann, J. P. W., Kapos, V., Campbell, A., Lysenko, I., Burgess, N.D., Hansen, M.C., Gibbs, H.K., Dickson, B., and Miles, L. (2010) 'Securing tropical forest carbon: the contribution of protected areas to REDD'. Oryx, 44 (3):352-357. Available at: http:// macroecointern.dk/pdf-reprints/Scharlemann_O_2010.pdf [Accessed 11 November 2015].

Shvidenko, A., Barber, C.V., and Persson, R. (2005) 'Chapter 21. Forest and Woodland Systems'. In: Hassan, R., Scholes, R., Ash, A. eds. 'Ecosystems and Human Well-being: Current State and Trends, Volume 1. Findings of the Condition and Trends Working Group of the Millennium Ecosystem Assessment'. Washington: Island Press. Available at: http://www.millenniumassessment. org/documents/document.290.aspx.pdf [Accessed 11 November 2015]. 
Sills, E.O., Atmadja, S.S., de Sassi, C., Duchelle, A.E., Kweka, D.L., Resosudarmo, I.A.P., and Sunderlin, W.D. (2014) 'REDD+ on the ground. A case book of subnational initiatives across the globe'. Bogota: CIFOR. Available at: http://www.cifor.org/publications/ pdf_files/books/BCIFOR1403.pdf [Accessed 11 November 2015].

Smith P., Bustamante, M., Ahammad, H., Clark, H., Dong, H., Elsiddig, E.A., Haberl, H., Harper, R., House, J., Jafari,M., Masera, O., Mbow, C., Ravindranath, N.H., Rice, C.W., Robledo Abad, C., Romanovskaya, A., Sperling, F. and Tubiello, (2014): 'Agriculture, Forestry and Other Land Use (AFOLU)'. In: 'Climate Change 2014: Mitigation of Climate Change'. Contribution of Working Group III to the Fifth Assessment Report of the Intergovernmental Panel on Climate Change [Edenhofer, O., Pichs-Madruga, R., Sokona, Y., Farahani, E., Kadner, S., Seyboth, K., Adler, A., Baum, I., Brunner, S., Eickemeier, P., Kriemann, B., Savolainen, J., Schlömer, S., von Stechow, C., Zwickel, T. and Minx, J.C. eds. Cambridge and New York: Cambridge University Press. Available at: https://www. ipcc.ch/pdf/assessment-report/ar5/wg3/ipcc_wg3_ar5_full.pdf [Accessed 11 November 2015].

Streck C. (2012) 'Financing REDD+: matching needs and ends'. Current Opinion in Environmental Sustainability, 4(6):628-637. doi:10.1016/j.cosust.2012.10.001. Available at: http://www.sciencedirect.com/science/article/pii/S1877343512001376 [Accessed 11 November 2015].

UN (2008) 'United Nations Declaration on the Rights of Indigenous Peoples'. Available at: http://www.un.org/esa/socdev/unpfii/ documents/DRIPS_en.pdf [Accessed 11 November 2015].

UNCCD (2007) 'The 10-year strategic plan and framework to enhance the implementation of the Convention (2008-2018)'. United Nations Convention to Combat Desertification Conference of the Parties: ICCD/CoP(8)/16/Add.1, at 8 (Oct. 23, 2007). Madrid: 3 -14 September, 2007. Available at: http://www.unccd.int/Lists/OfficialDocuments/cop8/16add1eng.pdf [Accessed 11 November 2015].

UNEP (2012) 'The Emissions Gap Report 2012: A UNEP Synthesis Report'. Nairobi: UNEP. Available at: http://www.unep.org/ pdf/2012gapreport.pdf [Accessed 11 November 2015].

UNFCCC (2005) 'Report of the Conference of the Parties on its eleventh session, held at Montreal from 28 November to 10 December 2005'. Available at: http://unfccc.int/resource/docs/2005/cop11/eng/05.pdf [Accessed 11 November 2015].

UNFCCC (2007) 'Report of the Conference of the Parties on Its Thirteenth Session, Decision 2/CP.13. FCCC/CP/2007/6/Add.1, at 8 (Mar. 14, 2008)'. United Nations Framework Convention on Climate Change Conference of the Parties. Bali: 3 - 15 December, 2007. Available at: http://unfccc.int/resource/docs/2007/cop13/eng/06a01.pdf [Accessed 11 November 2015].

UNFCCC (2009) 'Report on the Conference of the Parties on Its Fifteenth Session, Decision 4/CP.15. FCCC/CP/2009/11/Add.1, at 11 (Mar. 30, 2010)'. United Nations Framework Convention on Climate Change Conference of the Parties. Copenhagen: 7 - 19 December, 2009. Available at: http://unfccc.int/resource/docs/2009/cop15/eng/11a01.pdf [Accessed 11 November 2015].

UNFCCC (2010) 'Report of the Conference of the Parties on its sixteenth session, held in Cancun from 29 November to 10 December 2010. Addendum. Part two: Action taken by the Conference of Parties at its sixteenth session'. United Nations Framework Convention on Climate Change Conference of the Parties: FCCC/CP/2010/7/Add.1at (March 15, 2011). Cancun: 9th Plenary Meeting 10-11 December 2010. Available at: http://unfccc.int/resource/docs/2010/cop16/eng/07a01.pdf [Accessed 11 November 2015].

UNFCCC (2013) 'Report on the Conference of the Parties on Its Nineteenth Session. Decisions 9-15/CP.19, FCCC/CP/2013/10/Add.1, at 24 (Jan. 31, 2014)'. United Nations Framework Convention on Climate Change Conference of the Parties. Warsaw: $11-22$ November, 2013. Available at: http://unfccc.int/resource/docs/2013/cop19/eng/10a01.pdf [Accessed 11 November 2015].

UNFCCC (2014a) 'Appendix II - Nationally appropriate mitigation actions of developing country Parties'. Available at: http://unfccc. int/meetings/cop_15/copenhagen_accord/items/5265.php [Accessed 11 November 2015].

UNFCCC (2014b) 'Appendix I - Quantified economy-wide emissions targets for 2020'. Available at: http://unfccc.int/meetings/ copenhagen_dec_2009/items/5264.php [Accessed 11 November 2015].

UNFCCC (2014c) 'Communications received from Parties in relation to the listing in the chapeau of the Copenhagen Accord'. Available at: http://unfccc.int/meetings/copenhagen_dec_2009/items/5276.php [Accessed 11 November 2015].

UNGA (2007) 'Non-Legally Binding Instrument on All Types of Forests. Agenda item 54. A/RES/62/98'. United Nations General Assembly sixty-second session. 17 December, 2007. Available at: http://www.un.org/ga/search/view_doc.asp?symbol=A/ res/62/98 [Accessed 11 November 2015].

UNGA (2015) 'Resolution adopted by the General Assembly on 1 September 2015. 69/315. Draft outcome document of the United Nations summit for the adoption of the post-2015 development agenda'. Agenda items 13 (a) and 115. A/RES/69/315'. United Nations General Assembly sixty-ninth session. 15 September, 2015. Available at: http://www.un.org/en/ga/search/view_doc. asp?symbol=A/RES/69/315 [Accessed 11 November 2015].

UN-REDD Programme (2013) 'National Forest Monitoring Systems: Monitoring and Measurement, Reporting and Verification (M \& $M R V)$ in the context of REDD+ Activities'. Geneva: UN-REDD Programme Secretariat Available at: http://www.unredd.net/index. php?option=com_docman\&view=document\&alias=12345-national-forest-monitoring-systems-monitoring-and-measurementreporting-and-verification-m-mrv-in-the-context-of-redd-activities-12345\&category_slug=other-useful-presentations-andmaterials-3439\&Itemid=134 [Accessed 11 November 2015].

Wolosin, M. (2014) 'Quantifying Benefits of the New York Declaration on Forests'. Washington: Climate Advisers. Available at: http://www.climateadvisers.com/wp-content/uploads/2014/09/Quantifying-Benefits-of-the-New-York-Declaration-onForests-09232014.pdf [Accessed 11 November 2015].

WRI (2011) 'Global Assessment of Opportunities for Restoration of Forests and Landscapes'. Final report to UNEP-WCMC. Cambridge: United Nations Environment Programme World Conservation Monitoring Centre. Available at: http://www.unep-wcmc.org/resourcesand-data/global-assessment-of-opportunities-for-restoration-of-forests-and-landscapes [Accessed 11 November 2015]. 
Annex 1

Australian Government (2015) 'Australia's emissions projections 2014-15'. Department of the Environment. Available at: http:// www.environment.gov.au/climate-change/publications/emissions-projections-2014-15 [Accessed 11 November 2015].

Belenky, M. (2015) 'Achieving the U.S. 2025 Emissions Mitigation Target'. Climate Advisers. Available at: http://www.climateadvisers. com/wp-content/uploads/2013/12/US-Achieving-2025-Target_May-20151.pdf [Accessed 11 November 2015].

CAT (2015) 'Climate Action Tracker'. Available at: http://climateactiontracker.org [Accessed 11 November 2015].

Damassa, T., Fransen, T., Ge, M., Haya, B., Pjeczka, K., and Ross, K. (2015, forthcoming) 'Interpreting INDCs: Assessment of the Transparency of Post-2020 Greenhouse Gas Mitigation Targets of Brazil, China, the EU, India, Indonesia, Japan, Mexico, and the United States'. Working Paper: Open Climate Network. Washington, DC: World Resources Institute. Available at: http://www.wri. org/our-work/project/open-climate-network/publications [Accessed 11 November 2015].

den Elzen, M.G.J., Fekete, H., Admiraal, A., Forsell, N., Höhne, N., Korosuo, A., Roelfsema, M., van Soest, H., Wouters, K., Day, T., Hagemann, M., and Hof, A.F. (2015). 'Enhanced policy scenarios for major emitting countries. Analysis of current and planned climate policies, and selected enhanced mitigation measure'. Bilthoven, the Netherlands: PBL Netherlands Environmental Assessment Agency. Available at: http://www.pbl.nl/sites/default/files/cms/publicaties/pbl-2015-enhanced-policy-scenariosfor-major-emitting-countries_1631.pdf [Accessed 11 November 2015].

Department of Environmental Affairs (2014) 'South Africa's Greenhouse Gas (GHG) Mitigation Potential Analysis'. Pretoria: Department of Environmental Affairs. Available at: https://www.environment.gov.za/sites/default/files/docs/mitigationreport. pdf [Accessed 11 November 2015].

Dubash, N.K., Khosla, R., Rao, N.D., and Sharma, K.R. (2015) 'Informing India's Energy and Climate Debate: Policy Lessons from Modelling Studies'. Centre for Policy Research, Climate Initiative, Research Report. New Delhi: Centre for Policy Research. Available at: http://www.iiasa.ac.at/publication/more_XO-15-012.php [Accessed 11 November 2015].

EEA (2015) 'Trends and projections in Europe 2015 - Tracking progress towards Europe's climate and energy targets for 2020'. European Environment Agency. Available at: http://www.eea.europa.eu/publications/trends-and-projections-in-europe-2015 [Accessed 10 November 2015].

Fransen, T., Francke, E., Damassa, T., Altamirano, J., Ge, M., Martinez, J., and Ramos L. (2015) 'Climate Change Mitigation in Mexico's Intended Nationally Determined Contribution (INDC): Preliminary Analysis and Recommendations'. Working Paper. Washington, DC: Open Climate Network. Available at: http://www.wri.org/sites/default/files/uploads/WRI15_OCN_Mexico_INDC_English2. pdf [Accessed 11 November 2015].

Government of Canada (2014a) 'Canada's Sixth National Report on Climate Change'. Available at: http://unfccc.int/files/national_ reports/annex_i_natcom/submitted_natcom/application/pdf/nc6_can_resubmission_english.pdf [Accessed 11 November 2015].

Government of Canada (2014b) 'Canada's Emission Trends 2014', Environment Canada. Available at: https://www.ec.gc.ca/gesghg/default.asp?lang=En\&n=E0533893-1 [Accessed 11 November 2015].

Government of Mexico (2012) 'Programas para mitigar el cambio climático'. Available at: http://www2.inecc.gob.mx/publicaciones/ libros/685/programas2.pdf [Accessed 11 November 2015].

Hausker, K., Meek, K., Gasper, R., Aden, N., and Obeiter, M. (2015) 'Delivering on the U.S. Climate Commitment: A 10-Point Plan Toward a Low-Carbon Future'. Working Paper Executive Summary. Washington, DC: World Resources Institute. Available at: http://www.wri.org/sites/default/files/Delivering_on_the_US_Climate_Commitment_ES.pdf [Accessed 11 November 2015].

IDDRI (2015) 'Beyond the Numbers: Understanding the Transformation Induced by INDCs'. Paris: Institut du developpement durable et des relations internationales. Available at: http://www.iddri.org/Publications/Collections/Analyses/MILES\%20report.pdf [Accessed 11 November 2015].

IEA (2014) 'World Energy Outlook 2014'. Paris: International Energy Agency. Available at: http://www.worldenergyoutlook.org/ publications/weo-2014/ [Accessed 11 November 2015].

IEA (2015) 'World Energy Outlook Special Report 2015: Energy and Climate Change'. Paris: International Energy Agency. Available at: $\quad$ https://www.iea.org/publications/freepublications/publication/weo-2015-special-report-energy-climate-change.html [Accessed 11 November 2015].

Jiang, K., Zhuang, X., Miao, R., and He, C. (2013) 'China's role in attaining the global $2^{\circ} \mathrm{C}$ target'. Climate Policy, 13(supp01), 5569. doi: 10.1080/14693062.2012.746070 Available at: http://www.tandfonline.com/doi/full/10.1080/14693062.2012.746070 [Accessed 11 November 2015].

Kuramochi, T. (2014) 'GHG Mitigation in Japan: An Overview of the Current Policy Landscape'. Working Paper. Washington, DC: World Resources Institute. Available at: http://www.wri.org/sites/default/files/wri_workingpaper_japan_final_ck_6_11_14.pdf [Accessed 11 November 2015].

PBL (2015) 'The Climate Pledge INDC tool'. Bilthoven: PBL Netherlands Environmental Assessment Agency. Available at: http:// infographics.pbl.nl/indc/ [Accessed 11 November 2015].

SEMARNAT (2013) 'Estrategia Nacional de Cambio Climático: visión 10-20-40'. Secretaría de Medio Ambiente y Recursos Naturales, México. Available at: http://www.inmujeres.gob.mx/inmujeres/images/stories/medioambiente/2014/09_SEPTIEMBRE/ estrategia_nacional_cambio_climatico.pdf [Accessed 11 November 2015].

Sha, F., Ji, Z. and Linwei, L. (2015) 'An Analysis of China's INDC'. Beijing: China National Center for Climate Change Strategy and International Cooperation. Available at: http://www.chinacarbon.info/wp-content/uploads/2010/12/Comments-on-ChinasINDC.pdf [Accessed 11 November 2015].

UNFCCC (2015) 'INDCs as communicated by Parties'. Available at: http://www4.unfccc.int/submissions/INDC/Submission\%20 Pages/submissions.aspx [Accessed 11 November 2015].

UNFCCC National Reports (2015) 'National Reports'. Available at: http://unfccc.int/national_reports/items/1408.php [Accessed 11 November 2015]. 


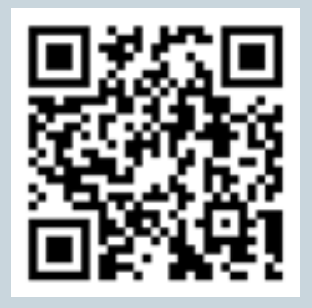

www.unep.org United Nations Environment Programme P.O. Box 30552 - 00100 Nairobi, Kenya Tel.: +254 207621234 Fax: +254207623927 e-mail: uneppub@unep.org www.unep.org
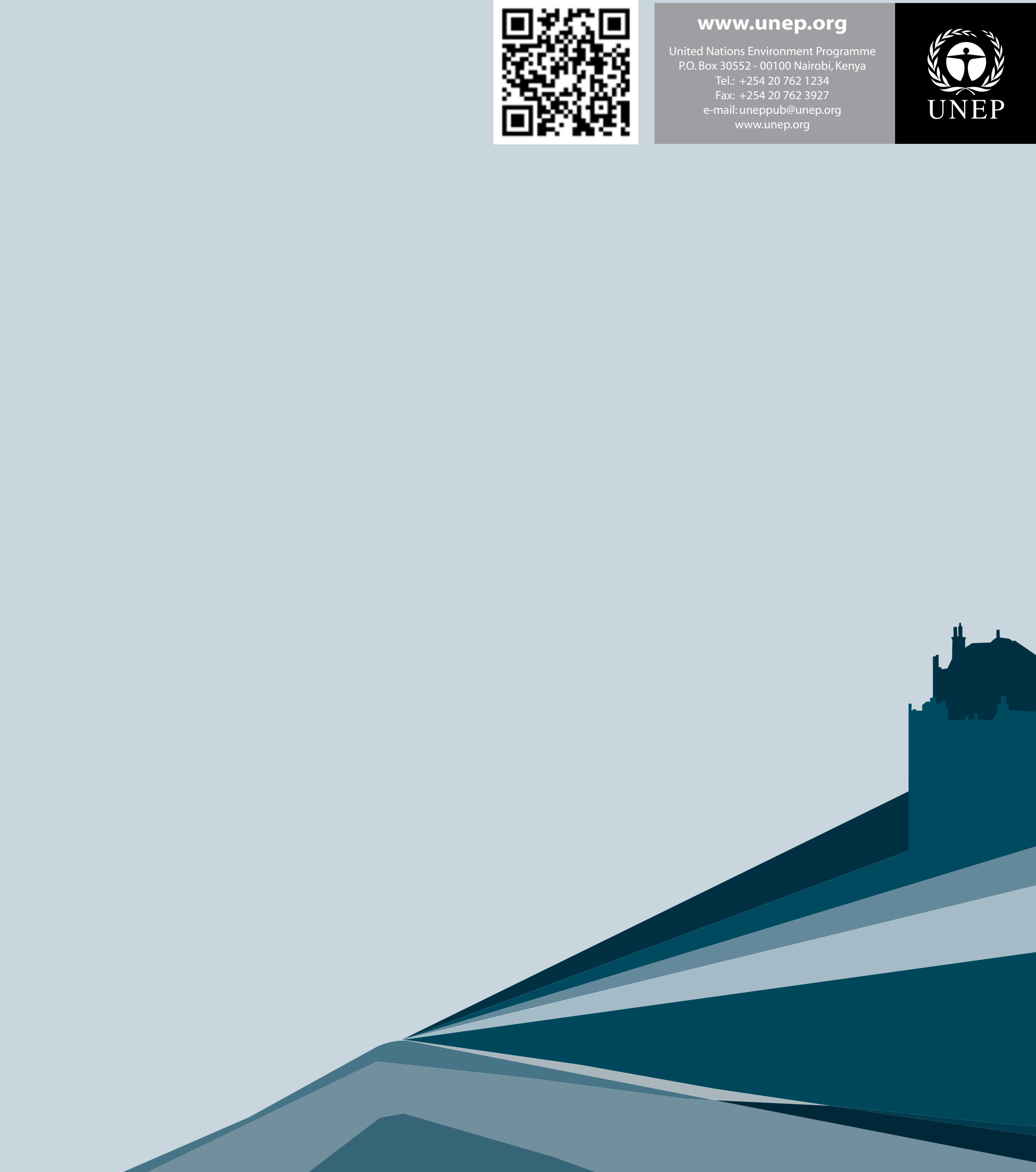